



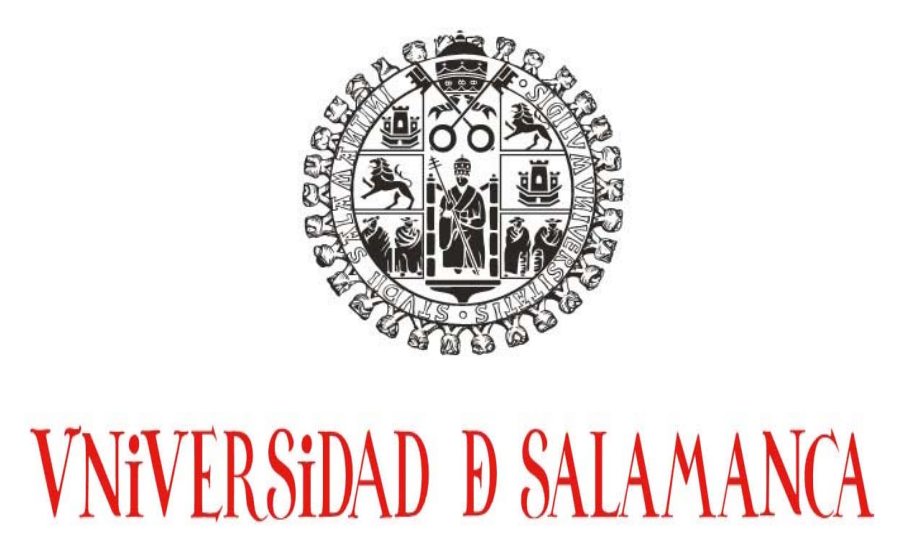

FACUlTAD DE MEDiCinA

\section{PROCEDIMIENTO TECNOLÓGICO DE VISUALIZACIÓN ANATÓMICA Y ECOGRÁFICA PARA LA FORMACIÓN EN ANESTESIA REGIONAL}

TESIS DOCTORAL

\section{ANTONIO RODRÍGUEZ CALVO}

Salamanca 2013 
Procedimiento tecnológico de visualización anatómica y ecográfica para la formación en anestesia regional

\section{Antonio Rodríguez Calvo}

Tesis doctoral, 2013

\section{Dirección y tutoría:}

\section{Juan Antonio Juanes Méndez}

Doctor en Medicina y Cirugía, Profesor Titular del Departamento de Anatomía e Histología Humanas de la Universidad de Salamanca.

\section{Doctores D. Pablo Alonso Hernández y D. Felipe Hernández Zaballos}

Adjuntos del Servicio de Anestesiología, Reanimación y Terapia del Dolor del Hospital Universitario de Salamanca

Facultad de Medicina

Universidad de Salamanca 


\section{VNiVERSiDAD \\ BSALAMANCA \\ CAMPUS DE EXCELENCIA INTERNACIONAL}

D. Juan Antonio Juanes Méndez, Doctor en Medicina y Cirugía, Profesor Titular del Departamento de Anatomía e Histología Humanas, de la Universidad de Salamanca y los Doctores D. Pablo Alonso Hernández y D. Felipe Hernández Zaballos, adjuntos del Servicio de Anestesiología, Reanimación y Terapia del Dolor del Hospital Universitario de Salamanca

\section{CERTIFICAN:}

Que el trabajo titulado "Procedimiento tecnológico de visualización anatómica y ecográfica para la formación en anestesia regional" ha sido realizado por D. Antonio Rodríguez Calvo, bajo nuestra dirección, reuniendo, a nuestro juicio, los requisitos y méritos suficientes para que el autor del mismo pueda optar al Título de Doctor por la Universidad de Salamanca.

Y para que así conste, firmo la presente certificación en Salamanca a 10 de septiembre de 2013.

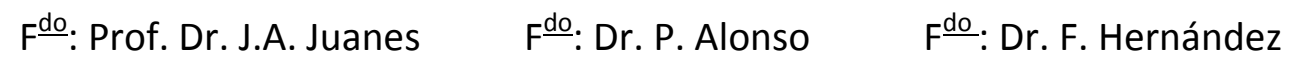



A mi tío. Conmigo hoy y siempre. 



\section{AGRADECIMIENTOS}



Quisiera expresar mi agradecimiento al Profesor Dr. D. Juan Antonio Juanes, por contagiarme ya desde la carrera de medicina su ilusión por la anatomía, por enseñarme la importancia de un trabajo bien hecho desde el principio hasta el final, por ser un gran profesor y un mejor mentor, por permitirme trabajar como un igual con uno de los mejores y, sobre todo, por creer en mí incondicionalmente, por apoyarme y estar siempre a mi lado. Gracias una vez más.

A Pablo Alonso y Felipe Hernández, por darme la oportunidad de iniciarme en el mundo de los bloqueos regionales guiados con ecografía, por transmitirme su ilusión en el trabajo del día a día, por enseñarme la importancia de la constancia y el rigor, por la oportunidad de aprender cada día un poco más en cada una de las conversaciones que mantuvimos y por ser mis amigos. Gracias por todo, compañeros.

Al Profesor Dr. D. Clemente Muriel, por ser tan cercano con nosotros desde el primer día, por tener siempre abierta la puerta de su despacho y por enseñarnos que debemos trabajar y hacer las cosas bien para que nuestro rendimiento sea siempre el mejor.

A Abbott laboratorios, que como empresa farmacéutica ha apoyado este proyecto desde el principio y sin cuya aportación no hubiera sido posible.

A la empresa informática Abadía, quien con su soporte tecnológico ha hecho que este proyecto vea la luz.

A los adjuntos del Servicio de Anestesiología que me han intentado transmitir todos sus conocimientos teóricos, prácticos y vivencias del día a día, para intentar que ahora y en nuestro futuro profesional, siempre vayamos por el camino correcto, y que además han defendido los derechos de los residentes en todo momento. A todos ellos, gracias.

Al resto de compañeros del Servicio de Anestesiología (enfermeras, auxiliares, celadores, personal de limpieza) por su compresión y paciencia, que me han enseñado diariamente cosas nuevas y sin los cuales este trabajo no hubiera sido posible. Y gracias especialmente a mis coerres, María Ramiro, Javier Cordobés e Ignacio Portalo por su apoyo personal e incondicional en todo momento. 
Reconocer asimismo, la ayuda desinteresada de la dirección del Hospital Universitario de Salamanca y del Servicio de Radiodiagnóstico (y en especial al Dr. D. José Ángel Santos), que han facilitado el que este proyecto se convierta en realidad. Gracias también a nuestros pacientes modelos, por las múltiples sesiones que tuvieron que soportar.

A mi madre que me hizo mejor persona con su actitud ante la vida, que siempre cuidó de mi y veló por mi bienestar en todo momento, que ha estado siempre a mi lado y me enseñó que de lo más importante en esta vida es el amor a la familia. También agradecerle su apoyo en todas mis decisiones académicas y que en los momentos difíciles me ha impulsado siempre a seguir hacia delante, enseñándome la importancia de la perseverancia y la entrega total en el trabajo y en la vida y que, me enseña cada día, lo importante que es un hijo para una madre.

A mi abuela que me ha enseñado lo importante que es no aferrarse al pasado, que siempre ha estado conmigo cuando la he necesitado y que me enseña día a día que es posible vivir la vejez como si se tuvieran veinte años.

Y por último, y no por ello menos importante, a Aurora, mi compañera inseparable, mi amiga, mi pareja, mi gran apoyo en todas las grandes decisiones de mi vida, la persona que mejor me conoce, no sólo mis virtudes sino también mis defectos, que me ha "aguantado" estoicamente cada día de estudio y que, a pesar de ello, ha estado conmigo apoyándome en todo momento, que con sólo una mirada sabe mi estado de ánimo y cuando debe callar y cuando necesito un abrazo. Hemos aprendido a respetarnos y conocernos en estos años y eso nos ha hecho convertirnos en mejores personas y mejor pareja. Gracias por estos últimos meses dedicados, casi exclusivamente, a este proyecto. Gracias por estar siempre a mi lado y apoyarme, incluso cuando no creía en mí mismo. Gracias por darme ese último empujón cuando era necesario. Gracias por tu cariño y estar siempre presente.

A mi hijo Álvaro, el niño más bonito del mundo, que espero siga mis pasos con menos dificultades que las que yo he tenido, pero que no por ello no valore lo que consiga. 


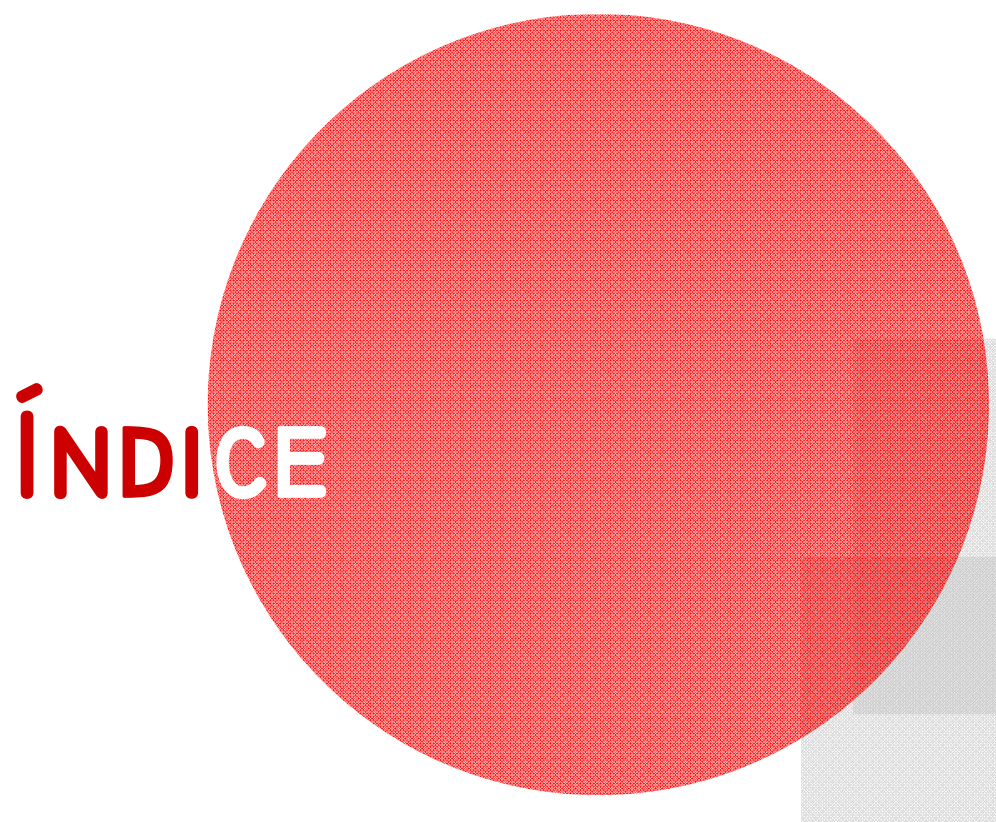





\section{ÍNDICE}

Página

AGRADECIMIENTOS

ÍNDICE 13

PRÓLOGO

ABREVIATURAS

1. INTRODUCCIÓN 25

1.1. TÉCNICAS ANESTÉSICAS

1.1.1. Historia de la Anestesia Regional 30

1.1.2. Ecografía y Anestesia Regional 35

1.2. IMPORTANCIA DEL CONOCIMIENTO ANATÓMICO PARA LA ANESTESIA REGIONAL

1.3. NUEVAS TECNOLOGÍAS EN LA FORMACIÓN MÉDICA

1.4. IMPORTANCIA DE LA IMAGEN MÉDICA TRIDIMENSIONAL

1.4.1. Los simuladores tecnológicos como herramientas de entrenamiento para la formación médica

\section{PLANTEAMIENTO DEL TRABAJO}

\section{MATERIAL Y MÉTODOS}

3.1. MATERIAL

3.1.1. Participantes y Aparatos

3.1.2. Software

3.1.3. Clasificación de los bloqueos y referencias bibliográficas

3.2.1. Instalación de la aplicación

3.2.2. Desarrollo informático 86

3.2.3. Adquisición de imágenes 88

3.2.4. Segmentación y delimitación de las áreas de interés (ROIs)

3.2.5. Generación de modelos tridimensionales 90

3.2.6. Encuesta de satisfacción del procedimiento tecnológico para la formación en anestesia regional

4.1. DESCRIPCIÓN DEL PROCEDIMIENTO TECNOLÓGICO PARA LA FORMACIÓN EN ANESTESIA REGIONAL

4.2. DESCRIPCIÓN DEL BLOQUEO SUPRACLAVICULAR Y TIBIAL MEDIANTE LA 
APLICACIÓN INFORMATICA

125

4.2.1. Bloqueo Supraclavicular 125

4.2.2. Bloqueo Tibial

4.3. DESCRIPCIÓN ICONOGRÁFICA DEL SISTEMA NEUROMUSCULAR DEL NERVIO RADIAL

4.4. ENCUESTA DE VALIDACIÓN DE LA APLICACIÓN INFORMÁTICA

5. DISCUSIÓN

153

6. CONCLUSIONES

165

7. BIBLIOGRAFÍA 169

8. ANEXOS

8.1. ENCUESTA DE VALIDACIÓN DEL VISOR ECOGRÁFICO PARA EL APRENDIZAJE DE LOS BLOQUEOS REGIONALES

196

8.2. CONCEPTOS BÁSICOS DE ECOGRAFÍA APLICADA A LA ANESTESIA REGIONAL

199

8.3. TERMINOLOGÍA ANATÓMICA

8.4. SISTEMAS NEUROMUSCULARES DE LA EXTREMIDAD SUPERIOR

8.5. SISTEMAS NEUROMUSCULARES DE LA EXTREMIDAD INFERIOR 231

8.6. DESCRIPCIONES 235

8.6.1. Cuello 235

8.6.2. Extremidad superior 239

8.6.3. Extremidad inferior 253

8.7. NERVIOS 269 


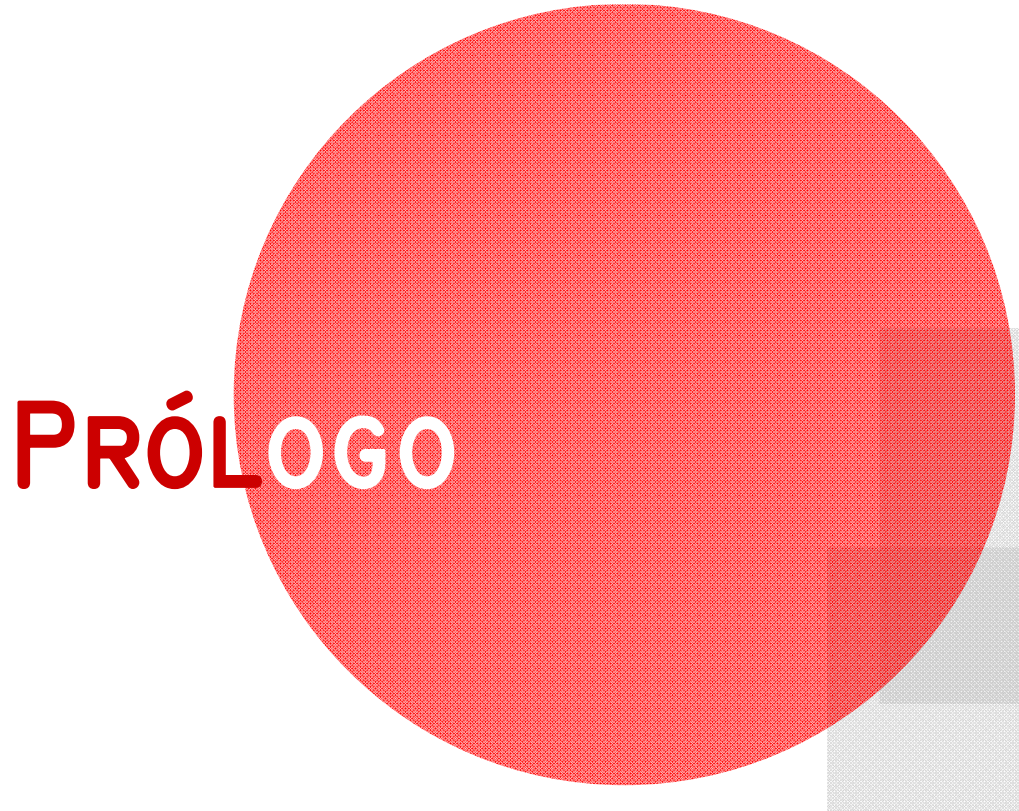



La especialidad de anestesiología se inició como la simple analgesia en pequeños actos quirúrgicos. Se ha convertido hoy en el conocimiento fisiopatológico, farmacológico y clínico necesario para tratar todas las reacciones neurohormonales derivadas del estrés quirúrgico. Su campo va desde la preparación preoperatoria de los pacientes, hasta el tratamiento postoperatorio de pacientes críticos, pasando por el tratamiento del dolor.

Para el médico anestesiólogo la docencia constituye, junto con la actividad asistencial y la investigación, uno de los pilares básicos de su actividad. La docencia para la formación de especialistas es de suma importancia, puesto que supone el método de perpetuar la especialidad, intenta aumentar el nivel de formación de los especialistas y fomenta la investigación y el progreso científico. Con estas premisas, es necesario que la formación de especialistas sea uno de los objetivos principales en los servicios de anestesiología y reanimación.

La presente tesis está redactada con el objetivo de ser un método de aprendizaje para el médico residente que se incorpora a la realización de su período docente en anestesiología, o al adjunto ya en situación activa y que se interesa por la realización de los bloqueos regionales guiados por ecografía.

Este proyecto, nace en un momento histórico, en el que las medidas de recorte sanitario han influido en la gran disminución de la inversión por parte de la industria farmacéutica (que es la que más invierte en España en I+D) y que han tenido un impacto directo sobre el sector sanitario, afectando especialmente a la investigación e innovación. Innovar en medicina se ha convertido en algo muy difícil, que requiere en la mayoría de los casos, ya no sólo de una gran inversión económica, si no de una gran dedicación del tiempo libre de cada uno y, por tanto, de mucho esfuerzo personal. Sirva como ejemplo, que el coste medio que conlleva sacar un nuevo medicamento al mercado es de unos 1.000 millones de euros. Esto supone entre 10 y 12 años de investigación arriesgada hasta que se recibe el permiso de la agencia reguladora. A pesar de esta situación, este proyecto surge gracias al apoyo de laboratorios Abbott, es una tesis hecha con mucha ilusión, donde confluyen técnicas pedagógicas, tecnología e innovación. Además está realizada en nuestro entorno, por lo que su contenido se puede adaptar a cualquier centro hospitalario del país. 
Nuestra ambición ha sido crear una herramienta que facilite el aprendizaje de la anestesia regional, en la cual el usuario tenga un paciente simulado para explorar la zona donde se realizan los bloqueos regionales y cuya visión de las estructuras ecográficas se identifique perfectamente, tanto en la anatomía tridimensional, como en un corte de Resonancia Magnética (RM). Nace de la necesidad transmitida por los múltiples profesionales que comienzan a realizar bloqueos regionales guiados con ecografía y que lo que más les cuesta es la identificación de las estructuras anatómicas. Esta tesis está realizada por un equipo multidisciplinar (anatomistas, anestesiólogos, radiólogos, informáticos...) y con muchas horas de trabajo, pero se espera que sirva de ayuda para una mejor formación y en último término, en una mejor atención a nuestros pacientes. 


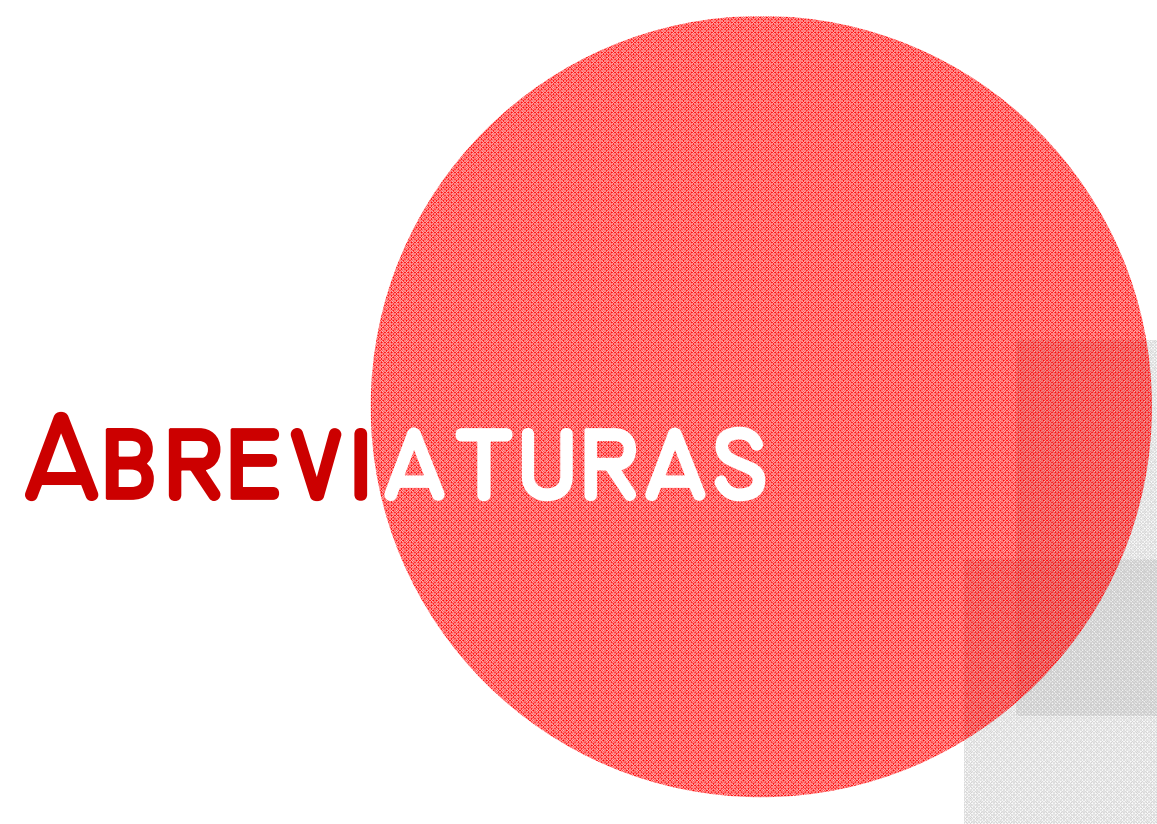



- 2D Y 3D: 2 y 3 Dimensiones.

- AL: Anestésicos Locales.

- API: Application Programming Interface.

- AR: Anestesia Regional.

- BNP: Bloqueo Nervioso Periférico.

- CMA: Cirugía Mayor Ambulatoria.

- DICOM: Digital Imaging and Communication in Medicine.

- DLL: Dynamic-Link Library.

- DP: Densidad Protónica.

- FSE: Fast Spin-Echo o Secuencia Turbo Espín- Eco (TSE).

- HTML: HyperText Markup Language («lenguaje de marcado de hipertexto»).

- I+D: Investigación y Desarrollo.

- IV: Intravenoso.

- MFC: Microsoft Foundation Classes.

- NGC: National Guideline Clearinghouse.

- NYSORA: The New York School of Regional Anaesthesia.

- PDF: Portable Document Format.

- RAE: Real Academia Española.

- RCP: Reanimación Cardiopulmonar. 
- RM: Resonancia Magnética.

- ROIs: Regions Of Interest («regiones de interés»).

- SEDAR: Sociedad Española de Anestesiología, Reanimación y Terapia del Dolor.

- SNC: Sistema Nervioso Central.

- SNM: Sistema Neuromuscular.

- STIR: Short Time Inversión Recovery. El método STIR es un método para anular la grasa muy utilizado en musculoesquelético.

- T1: Tiempo de relajación longitudinal.

- T2: Tiempo de relajación transversal.

- TAP: Transversus Abdominis Plane.

- TC: Tomografía Computarizada.

- ORL: Otorrinolaringología.

- URL: Uniform Resource Locutor («localizador uniforme de recursos»).

- VHP: Visible Human Project. 


\section{Capitulo 1}

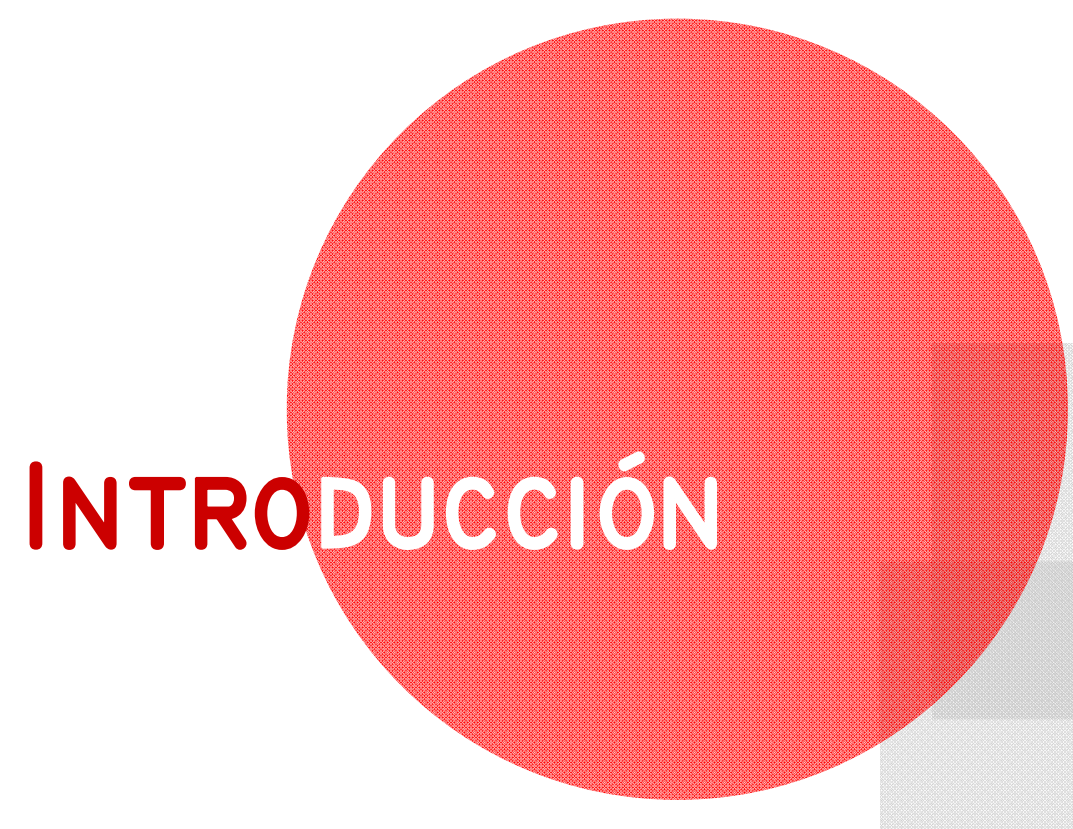





\section{I.I. TÉCNICAS ANESTÉSICAS}

El término anestesia deriva de la palabra griega "an aisthesis", que significa "privación completa o reducción de la sensibilidad de un organismo". Este término, se refiere a la supresión de todos los tipos de sensibilidad periférica, es decir, la sensibilidad al tacto, al dolor y a la temperatura (Roewer N. et al, 2007).

Desde sus orígenes, el objetivo fundamental de la anestesiología ha sido permitir la realización de intervenciones sobre la integridad del cuerpo, sin producir dolor y manteniendo la homeostasis del organismo. La especialidad, tiene como uno de sus pilares fundamentales la terapéutica de cualquier tipo de dolor, tanto agudo como crónico y de cualquier etiología. En el ámbito quirúrgico, esta abolición de la sensibilidad al dolor puede a grandes rasgos, alcanzarse por dos vías: por un lado, mediante la anestesia general y por otro mediante la anestesia regional. La anestesia general incluye la anestesia de todo el cuerpo y se asocia siempre a una pérdida o, al menos, a una gran disminución del nivel de consciencia. Para proceder a la realización de la anestesia general se precisará por tanto de dos tipos de fármacos, aquellos que afectan al estado de consciencia y aquellos que eliminan el dolor. Dentro de los primeros se dispone de fármacos inhalatorios que difunden hasta la sangre a través del pulmón y de fármacos de administración vía intravenosa (IV). Estos actúan principalmente en el sistema nervioso central (SNC) disminuyendo su actividad. Como analgésicos, se utilizan diferentes tipos de fármacos opiodes administrados por vía IV (Morgan E. et al, 2007).

A diferencia de la anestesia general, la anestesia locorregional, permite limitar la anestesia a determinadas áreas o regiones del cuerpo por interrupción de la conducción nerviosa sensitiva. Esta inducción de insensibilidad en una zona del cuerpo, se produce de forma controlada y es reversible (Miller R. et al, 1998 y 2005).

Las técnicas regionales, comprenden un amplio abanico de posibilidades, tanto en las vías de administración (epidural, perineural, infiltración de campo quirúrgico, parietal), como en la posología (bolus único, infusión continua o analgesia controlada por el paciente). Se distinguen dos grandes tipos: la anestesia regional cercana a la médula espinal (denominados bloqueos nerviosos centrales: anestesia medular o raquídea y epidural o 
caudal) y los bloqueos nerviosos periféricos (p. ej. la anestesia del plexo braquial). En estos últimos, y a través de la punción percutánea en zonas anatómicas concretas, se administran anestésicos locales en las proximidades de las estructuras nerviosas para conseguir el bloqueo selectivo de la generación y la conducción del estímulo nervioso (Miller R. et al 1998 y 2005; Morgan E. et al, 2007).

Los bloqueos nerviosos periféricos, pueden ser una alternativa a la anestesia general para muchos procedimientos quirúrgicos. Proporcionan unas condiciones quirúrgicas óptimas y analgesia postoperatoria prolongada, siendo a veces la única fuente anestésica para la cirugía de las extremidades superior e inferior. No producen una interrupción significativa de la función vegetativa, con lo que el nivel de consciencia y la respiración espontánea están preservados, sin necesidad de medidas de ventilación artificial (Roewer N. et al, 2007).

Aunque para la realización de la anestesia regional no se precisa de una disminución del estado de consciencia, se emplean con frecuencia fármacos sedantes del tipo de las benzodiacepinas con el fin de mejorar la confortabilidad del paciente. Por otra parte, este tipo de técnicas también se pueden emplear asociadas a la anestesia general con el fin de controlar el dolor postoperatorio (Miller R. et al, 2005; Morgan E. et al, 2007).

La seguridad, la satisfacción del paciente y la rápida recuperación del mismo son algunas de las ventajas que ofrecen estas técnicas (Mayfield JB, 2005).

Sin embargo, cabe preguntarse por qué la popularización de la anestesia regional ha sido limitada. Entre otros, los factores que se han argumentado han sido; el índice de fracasos, la presión sobre los tiempos de quirófano (el bloqueo requiere tiempo para que haga efecto el anestésico local) o los conocimientos requeridos para su práctica. Corroborando este hecho, en algunas series publicadas, los resultados satisfactorios de las técnicas regionales muestran porcentajes exitosos tan dispares como del 50 al 95\%. Por tanto, la realización de estas técnicas, permanece aún en nuestros días en algunos centros más como un recurso alternativo, que como una opción anestésica de primera línea (Muñoz M. et al, 2007; Griffin J. et al, 2010). 
Los adelantos vistos en el campo de la anestesia regional (AR) en los últimos años han sido importantes. La neuroestimulación es en parte responsable del gran avance experimentado en la aproximación nerviosa. Desde el punto de vista práctico, el uso de la neuroestimulación es muy simple. Consiste en enviar impulsos eléctricos desde un neuroestimulador tras puncionar en una localización anatómica concreta con una agujaelectrodo. Al aproximarse con la aguja a un nervio o plexo nervioso, se producen contracciones de la región musculotendinosa dependiente de dicho nervio o plexo. Esta respuesta puede ser aprovechada para confirmar la proximidad de la aguja al nervio. Dependiendo de la intensidad de los impulsos que provoquen la contracción muscular, podremos saber si estamos más o menos cerca del nervio. Incluso podremos saber si la aguja está colocada en el interior del nervio cuando se produzca contracción muscular con una intensidad muy pequeña. Una vez identificada una respuesta motora a una intensidad adecuada que nos indique que estamos cerca del nervio, pero no dentro del mismo, se procede a la infiltración del anestésico local. De esta forma se proporcionan unas mayores condiciones de precisión y seguridad para el paciente y se asocia a un índice de éxitos superior al de otras técnicas de acercamiento a los nervios periféricos, como la búsqueda de parestesias (esta técnica consiste en buscar la molestia que le produce al paciente la punción del nervio con una aguja). En la actualidad, en muchos centros hospitalarios, la neuroestimulación sigue siendo la técnica más habitual para la localización nerviosa. Aunque la neuroestimulación ha supuesto un gran avance en la localización y aproximación a los nervios, es una técnica "ciega", que se realiza según referencias anatómicas externas (Koscielniak-Nielsen Z. et al, 1998; Diéguez P. et al, 2007; Del Olmo C. et al, 2010).

Recientemente la utilización de técnicas de imagen, y en concreto de la ecografía para la realización de técnicas de anestesia regional, ha supuesto un cambio conceptual como método de acercamiento a los troncos nerviosos y a los nervios, lo cual se pondrá de manifiesto a lo largo del trabajo de esta tesis.

Se plantea así un nuevo reto para el anestesiólogo que deberá familiarizarse con esta técnica, la anestesia regional guiada por ecografía, que poco a poco y en parte debido al gran número de trabajos que se publican sobre la misma, se está imponiendo frente a otros métodos más tradicionales (Domingo V. et al, 2004; Alonso P. et al, 2009). 


\section{I.I.I. Historia dE LA ANEstesia Regional}

Delimitar el punto de partida histórico en la anestesia locorregional es complicado, pues desde su propio nacimiento, la humanidad ha intentado mitigar el dolor cuando se producía. Por otro lado, hablar de la historia de la AR y más concretamente de la historia de los bloqueos locorregionales es, en definitiva, hablar de la historia de la anestesia. Se indicarán, por tanto, de forma puntual los momentos históricos más importantes de la anestesia regional, considerando que fue a mediados del siglo XIX cuando se realizó por primera vez un acto anestésico entendido como tal. Desde entonces, y especialmente en los últimos años, la anestesiología ha experimentado una gran evolución (Del Olmo C. et al, 2010).

Desde muy antiguo los médicos y los cirujanos intentaron lograr la insensibilidad de una parte del cuerpo humano. Las drogas de acción general eran muy peligrosas y a veces provocaban accidentes mortales. De ahí que se procurara aliviar selectivamente la parte afectada valiéndose de múltiples remedios (Del Olmo C. et al, 2010). Así por ejemplo, los egipcios comprimían los nervios periféricos para conseguir anestesiar una determinada zona anatómica. Esta técnica aún fue usada por James Moore en el siglo XVIII, quien actuando sobre el nervio ciático y el crural anterior realizaba las amputaciones de las extremidades inferiores (Morgan E. et al, 2007).

Los incas peruanos (400-700 a. C.) empaquetaban las hojas de la cocaína en forma de bola llamada "cocada" que posteriormente vertían sobre las heridas quirúrgicas, mezcladas con cal o ceniza y saliva del cirujano (Stolberg VB, 2011).

También, en culturas ancestrales se practicaba la denominada crioanalgesia, que consistía en la aplicación de frío extremo a un nervio para conseguir un bloqueo nervioso, encontrándose referencias de la misma en textos médicos del árabe Avicena (año 1000). Esta forma de anestesia se ha mantenido hasta épocas más actuales, siendo empleada por Ambrosio Paré (1564) quien aplicaba enfriamiento o congelación en la zona operatoria como anestésico o Tomás Bartholin, que describe en 1661 la técnica quirúrgica de frotar nieve y hielo sobre el campo quirúrgico durante quince minutos. Otros autores que utilizaron la crioanalgesia fueron en 1807, Dominique-Jean Larrey cirujano mayor de Napoleón que 
realizaba amputaciones a soldados en el campo de batalla a 19 grados bajo cero durante la campaña rusa y José de Letamendi (1875); que propone en España una técnica de anestesia local aplicando objetos fríos directamente sobre el área a operar (De Andrés J. et al, 2005; Pérez-Caraville JD. et al, 2005; Del Olmo C. et al, 2010).

Ya en épocas más actuales, Descartes (1664), aportó el concepto de que el dolor viaja por finas hebras o "tubos" que transmitían las sensaciones directamente al cerebro y de ahí a la glándula pineal. Anteriormente, el genial Leonardo da Vinci hizo una descripción anatómica de los nervios y los relacionó directamente con el dolor, confirmando así la teoría galénica sobre el cerebro como motor central del dolor. Todo esto ha facilitado el desarrollo científico posterior de la anestesia regional (Pérez-Caraville JD. et al, 2005; Del Olmo C. et al, 2010).

Con la investigación sobre los efectos de la cocaína en la segunda mitad del siglo XIX, en Viena en 1884, Koller realizó la primera intervención oftalmológica (glaucoma) con anestesia local. Tras el éxito de esta primera intervención, la cocaína se comenzó a utilizar con frecuencia, convirtiéndose en un anestésico local ( $A L)$ de uso común entre oftalmólogos, odontólogos y otorrinolaringólogos (Morgan E. et al, 2007).

La realización de la primera anestesia regional troncular humana fue comunicada por Richard J. Hall, el 6 de diciembre de 1884, al referir los bloqueos de los nervios supraorbitario, infraorbitario y alveolar inferior, en sus respectivos orificios de salida. William S. Halsted en 1885, realizó la primera anestesia del plexo braquial exponiendo quirúrgicamente e inyectando intraneuralmente bajo visión directa AL (Calatayud J. et al, 2003).

Tras el primer bloqueo de un plexo nervioso y casi 30 años después, son descritas diversas técnicas de abordaje mediante agujas a diferentes plexos basándose en la anatomía. Así tenemos que Hirschel en 1911 describe la primera técnica percutánea de abordaje del plexo braquial "a ciegas" en la axila, posteriormente Kulenkampff en 1912 publica su conocida técnica supraclavicular y Alón P. Winnie en 1970, describe la vía interescalénica al identificar las relaciones anatómicas entre el plexo braquial y los músculos escalenos (Winnie AP, 1970; Miller R. et al, 1998) 
Con el empleo de las técnicas regionales, en el campo de la farmacología, surgió la necesidad de encontrar alternativas a la cocaína como anestésico local debido a sus graves efectos secundarios. La cocaína se aplicaba a concentraciones de hasta el $30 \%$, lo cual facilitaba las intoxicaciones, puesto que se superaban con facilidad los límites tóxicos. Entre 1884 y 1891 se registraron 200 casos de intoxicación, y se contabilizaron 13 muertes. Todo ello contribuyó a que se investigara en el desarrollo de nuevos anestésicos locales (Calatayud J. et al, 2003; Morgan E. et al, 2007). De hecho, James Leonard Corning recomendaba ya en 1885 el uso de una venda de Esmarch para detener la circulación local, con lo que se prolongaba el bloqueo inducido por cocaína y disminuía la absorción del anestésico local a los tejidos. Esta idea fue utilizada por Heinrich F. W. Braun, quien en 1903 utilizó la epinefrina como "torniquete químico», ya que al inducir vasoconstricción disminuía la absorción de la cocaína, prolongando su efecto y disminuyendo la toxicidad (Miller R. et al 2005; Morgan et al 2007).

En 1905 aparece una alternativa a la cocaína, la procaína, sintetizada por Alfred Einharn. Se comercializó bajo el nombre de novocaína y es el AL más importante hasta la década de 1940. A partir de aquí van surgiendo distintos anestésicos locales hasta los que conocemos actualmente (Leonard M. et al, 1998).

Con el desarrollo de nuevas agujas (en 1836 F. Rynd inventa la primera aguja metálica en Irlanda), anestésicos locales más seguros y las mejoras en las medidas de esterilidad, disminuyeron los efectos adversos y se produjo un desarrollo progresivo de la anestesia regional. El siglo XX viene marcado por el descubrimiento de nuevos anestésicos locales y el desarrollo de otras técnicas como la anestesia epidural (descrita por primera vez por un cirujano militar español Fidel Pages en 1921) (Pérez-Cajaraville J. et al, 2005); o la anestesia regional intravenosa, descrita por Bier en 1908, que utilizó procaína como anestésico y no tuvo mucha repercusión (Torres LM. et al, 2001).

Gaston Louis Labat publica el libro L'anesthesie Regionale, donde presenta el bloqueo paravertebral para cirugía abdominal en 1920 (L'anesthesie Regionale París, Ed. Gastón Doi, $349 \mathrm{Pp})$. El libro se consideró el texto definitivo sobre AR durante al menos los 30 años siguientes a su publicación. En 1935, Rovenstine organiza un departamento de anestesia en el Bellevue Hospital de Nueva York, con gran interés en el bloqueo nervioso para la 
analgesia. Se funda el American Board of Anesthesiology (1938) (Marhofer P. et al, 2005; Miller R. et al, 2005; Pérez-Cajaraville JD. et al, 2005; Morgan E. et al, 2007).

Ya que uno de los objetivos de la anestesia regional es el tratamiento y manejo del dolor postoperatorio, parece interesante mencionar la creación por parte del Doctor John Bonica de la primera unidad dedicada al tratamiento del dolor en Washington. En 1953 publica un libro de 1.500 páginas exclusivamente sobre tratamiento del dolor, "The Management of Pain", permaneciendo hoy en día como referencia a nivel mundial (Bonica JJ, 1953; Pérez-Cajaraville JD. et al, 2005).

Como veremos, la realización de anestesia o analgesia regional requiere la inyección de anestésicos locales y otros fármacos lo más cerca posible a la localización de los nervios correspondientes. De ahí, que se hayan desarrollado diversas técnicas para la determinación de su localización anatómica, entre las que destacan la electroneuroestimulación, la ultrasonografía, la tomografía computarizada (TC) y la resonancia magnética (RM). La primera descripción de la utilización del método de electroneuroestimulación la realizó Von Perthes en 1912, pero debido a las dificultades tecnológicas de la época, no tuvo mucho éxito clínico ni aceptación y el método fue abandonado (Ruiz MC, 2010). En 1962 Greenbalt y Denson demostraron que era posible estimular el componente motor de un nervio mixto sin producir dolor en el paciente, mediante el uso de un neuroestimulador portátil con salida de corriente variable. La técnica fue estableciéndose en la práctica clínica durante los años sucesivos y generalizándose su empleo. La introducción de estimuladores de corriente constante y agujas aisladas con teflón, permitió un gran avance en la aplicación clínica para la localización de nervios periféricos, ya que hasta ese momento su localización se basaba en referencias anatómicas (Aliaga L. et al, 2006; Del Olmo C. et al, 2010).

La ecografía es una técnica de imagen que nació vinculada al radiodiagnóstico, pero progresivamente diferentes especialidades han comenzado a utilizarla de forma independiente, introduciéndola poco a poco en su actividad diaria. El desarrollo de la ecografía comienza a finales del siglo XIX. En 1881, Jacques y Pierre Curie publicaron los resultados obtenidos al experimentar con la aplicación de un campo eléctrico alternante sobre cristales de cuarzo y turmalina, los cuales producían ondas sonoras de muy altas frecuencias (Del Olmo C, 2010). En 1971 la introducción de la escala de grises en sistemas 
ecográficos, marca el comienzo de la creciente aceptación mundial del ultrasonido en el diagnóstico clínico. Su mayor atractivo es la ausencia de efectos secundarios en comparación con la radiología que utiliza radiaciones ionizantes.

Su empleo inicial en anestesiología, y dentro de esta en el campo de la anestesia regional, fue más como técnica sonográfica (Doppler) que como técnica de imagen. El año 1978 marca el inicio de los bloqueos nerviosos con ecografía, cuando La Granje y cols., emplearon los ultrasonidos para la realización de un bloqueo en el plexo braquial por abordaje supraclavicular, identificando mediante Doppler la arteria y la vena subclavia. En este momento, el conocimiento detallado del aspecto ecográfico de las estructuras nerviosas era pobre, y la tecnología del ultrasonido no era adecuada para la visualización de los nervios (Alonso P. et al, 2009). En 1981, Abramowitz utiliza la ecografía en pacientes con dificultad para identificar la arteria axilar a los que se les iba a realizar un bloqueo del plexo axilar, mencionándose en ambos trabajos un mayor índice de éxito del bloqueo y una menor incidencia de punción vascular. Posteriormente, Ting y Sivagnanratnam en 1989 describen la difusión ecográfica del AL durante un bloqueo axilar utilizando un transductor de baja frecuencia (3,5 MHz) (Denny NM. et al, 2005; Diéguez P. et al, 2007; Alonso P. et al, 2009).

Es a partir de 1990, con los avances en la tecnología de los ultrasonidos y el desarrollo de los transductores de alta frecuencia, cuando su utilización en anestesiología comienza a incrementarse. En 1994 Kapral y cols., publican el primer artículo usando ultrasonografía directa para un bloqueo supraescapular del plexo braquial bajo la observación directa de la distribución del fármaco (Kapral S. et al, 1994; Denny NM. et al, 2005; Diéguez P. et al, 2007; Kapral S. et al, 2008; Alonso P. et al, 2009). A partir de entonces, hay un claro desarrollo y un gran aumento del interés por las técnicas ecográficas, publicándose una gran cantidad de artículos en las principales revistas de anestesiología (Del Olmo C. et al, 2010).

Este aumento de interés y la inversión de los fabricantes, llevó a crear máquinas portátiles para su uso alejado de las salas de radiodiagnóstico (quirófanos, áreas de urgencias, reanimación...), y con software específicamente diseñado para anestesia regional, permitiendo así su uso generalizado en la práctica anestésica. Han pasado ya dos décadas desde las primeras descripciones del uso del ultrasonido, que como se ha mencionado, se 
considera una técnica de imagen inocua ya que no emite radiaciones. Puede realizarse en un mismo individuo en tantas ocasiones $y$ durante el tiempo que fuera necesario, proporcionando información en tiempo real (Ting PL. et al, 1989; Kirvela O. et al, 1992; Shung K, 2006).

\section{I.I.2. Ecografía y Anestesia Regional}

La correcta ejecución de la anestesia regional depende de varios factores. Por una parte, es imprescindible un buen conocimiento de la anatomía que nos permita saber tanto donde se realizará un bloqueo nervioso, como las zonas que van a ser afectadas por el mismo. De esta forma, se podrán valorar diferentes opciones dependiendo de la región que queramos anestesiar. Además, se necesitará un método lo suficientemente preciso como para permitir acercarnos a la proximidad de un nervio, un plexo o una zona determinada donde al depositar el anestésico local se consiga el efecto deseado. Por último y no menos importante, deben ser evitados los efectos adversos que se pueden producir durante la realización de esta técnica, como la punción de estructuras no deseadas (vasos, pleura...), la inyección intraneural o intravascular del anestésico local, o la sobredosificación del mismo. En este sentido, la aplicación de la ecografía en AR constituye un método que, al menos en teoría, cumple con la mayoría de los criterios arriba expuestos (Miller R. et al, 2005; Martínez Navas A, 2006; Morgan E. et al, 2007; Koscielniak-Nielsen Z, 2008; Neal JM, 2010; Del Olmo C. et al, 2010; Marhofer P. et al, 2010; Antonakakis JG. et al, 2011; Sites BD. et al, 2012).

Durante años, los métodos empleados para la práctica de la anestesia regional se apoyaban en la identificación de estructuras anatómicas de referencia, más o menos constantes, en cuya vecindad debían encontrarse los distintos componentes nerviosos a bloquear. Cuando se procedía a la inserción de la aguja para la inyección del anestésico local se buscaban los "clics" o "chasquidos" que se producían al atravesar con dicha aguja los diferentes tejidos, como las fascias que envuelven o separan los músculos, y también parestesias o respuestas motoras cuando se puncionaba directamente el nervio que se deseaba anestesiar. Una vez localizada la zona deseada, se realizaba la infiltración del campo. En ocasiones, también se realizaban inyecciones perivasculares o transarteriales 
cuando anatómicamente el nervio a bloquear se situaba en la proximidad de un vaso (Miller R. et al, 2005).

Todas estos procedimientos de localización de estructuras nerviosas, se consideran "ciegos", puesto que la aguja una vez que atraviesa la piel deja de visualizarse y el anestésico local se inyecta donde se intuye que es el lugar correcto, sin observarse su distribución en las estructuras nerviosas. Debido a la gran variabilidad interindividual y lo poco predecible que a veces es la anatomía humana, con estas técnicas en ocasiones, se requerían multitud de ensayos y errores, lo que hacía que se perdiera exactitud y fiabilidad y se incrementara el número de lesiones potenciales (Williams SR. et al, 2003; Martínez A, 2006; Muñoz M. et al, 2007). Esto llevó al escaso éxito de muchos de los bloqueos nerviosos periféricos, y contribuyó en gran parte a la antipatía que se tenía hacia la anestesia regional, llegando incluso a dudarse de su efectividad (Griffin J. et al, 2010; Blanco R. et al, 2011).

La aparición de los neuroestimuladores como método de localización nerviosa supuso una revolución, al permitir una mejor identificación de los plexos y nervios, a la vez que evitaba, al menos en teoría, la punción y lesión de dichos nervios (Alonso P. et al, 2009). Como ya se explicó anteriormente en otro capitulo de esta tesis, los neuroestimuladores, son aparatos que emiten una corriente eléctrica que se transmite a la aguja de punción, y mediante la cual se estimula la función del nervio que se desea localizar. Actualmente, la intensidad de esta corriente que nos asegure que la aguja está suficientemente cerca del nervio para conseguir un bloqueo exitoso, pero a una distancia lo bastante segura como para evitar la lesión del mismo, es desconocida (Ruiz MC, 2010). En la práctica clínica, se acepta como válida una respuesta motora bajo un rango de intensidad de corriente entre 0,2-0,5 mA (Aliaga L. et al, 2006; Ban $\mathrm{CH}$. et al, 2007). Por encima de 0,5 mA se incrementa el porcentaje de bloqueos nerviosos fallidos debido a la mayor distancia entre aguja y nervio, mientras que con una corriente de menos de 0,2 $\mathrm{mA}$ aumenta mucho el riesgo de inyección intraneural (Winnie AP, 1984). En la bibliografía revisada no existen diferencias en el patrón de estimulación en niños con respecto al adulto. Las agujas son similares a las empleadas en los adultos (Tobias JD, 2001).

En la actualidad, en muchos centros hospitalarios la neuroestimulación sigue siendo la técnica más habitual para la localización nerviosa, por su simplicidad, versatilidad y bajo 
coste. Se asocia a un índice de éxitos superior al de las técnicas previas de acercamiento a los nervios periféricos. Sin embargo, la neuroestimulación es también una técnica ciega que realiza la punción percutánea según referencias externas (Koscielniak-Nielsen Z. et al, 1998; Diéguez P. et al, 2007; Del Olmo C. et al 2010).

El empleo de técnicas de imagen, y en concreto la ecografía, implica un cambio conceptual como método de acercamiento al nervio. Este cambio, radica en que la técnica se realiza con visión directa de la punción y por ello resulta mucho más anatómica (Sheppard DG. et al, 1998). Es precisamente esta posibilidad, la que proporciona a la ecografía aplicada a la AR una serie de ventajas potenciales frente a otras técnicas, como son fundamentalmente, la observación directa de los nervios y la distribución adecuada del anestésico local a su alrededor en tiempo real (Retzl G. et al, 2001; Greher M. et al, 2002; Williams SR. et al, 2003; Sandhu NS. et al, 2002 y 2004; Marhofer P. et al, 2004 y 2005).

La ecografía no excluye el uso simultáneo con la neuroestimulación, aunque con el aumento de la experiencia en el manejo del ecógrafo, el uso del neuroestimulador disminuirá progresivamente. El uso combinado con el neuroestimulador como un medio adicional de verificación de la correcta colocación de la aguja, añade una visión funcional a la precisión de la ultrasonografía y, en fases de aprendizaje, permite la confirmación de lo que se está "viendo". Ayuda en imágenes de mala calidad o si se tienen dudas si una estructura es un nervio o por ejemplo un tendón (Marhofer P. et al, 2010; Neal JM. et al, 2010; Bubnov RV. et al, 2011). La mayoría de autores recomiendan su utilización conjunta, aprovechando las ventajas que nos brindan cada una de ellas (Hopkins PM, 2007; Tsui B, 2007; Dufour E. et al, 2008). Lo que no parece claro es si los ultrasonidos mejorarán los resultados en aquellos médicos con amplia experiencia con el estimulador, pero incluso a estos, les podría ayudar a utilizar menos dosis de anestésico, tener una mayor duración del mismo y mayores tasas de éxito si cabe (Hite BW. et al, 2007). Además, los nervios no son estructuras estáticas ni rígidas y se desplazan con los movimientos corporales o por el propio anestésico local infundido. El empleo de la tecnología de ultrasonidos de alta resolución ha confirmado en tiempo real los hallazgos de Selander y cols. Para estos autores, cuando un nervio es abordado por una aguja de bisel corto en un espacio anatómico amplio, raramente es penetrado por la aguja, siendo desplazado al contactar con esta. Sin embargo, cuando el 
nervio es bloqueado en un espacio anatómico reducido, por ejemplo, el nervio cubital en el canal epitroclear, puede ser lesionado debido a su menor movilidad. En relación con esto, Marhofer y cols., han sugerido que el empleo de la ecografía no sólo puede incrementar la tasa de éxito de los bloqueos, sino que también puede evitar las complicaciones relacionadas con la aguja (Selander DE. et al, 1995 y 2005; Marhofer P. et al, 2005).

El inicio de la ultrasonografía en la práctica de la medicina data de mediados de los años 1960. Sus aplicaciones tanto diagnósticas como terapéuticas fueron aumentando con el tiempo de forma paralela a las mejoras tecnológicas que se iban sucediendo. Los primeros artículos de la ultrasonografía aplicada a los bloqueos nerviosos no identificaban la imagen de los nervios, sino las estructuras vasculares adyacentes gracias a la ecografía Doppler. En 1978 La Grange y cols. publicaron el primer trabajo que empleaba el efecto Doppler para localizar la arteria subclavia y facilitar la realización de un bloqueo del plexo braquial en la región supraclavicular. La limitación del material para lograr imágenes ecográficas de alta resolución, retrasó hasta 1994 el primer artículo que establece una visión ecográfica directa del plexo braquial como guía para la realización del bloqueo, junto a la visión en tiempo real de la distribución del anestésico local (Kapral S. et al, 1994).

La calidad de imagen ecográfica garantizada por la tecnología actual, junto con la mejora en la ejecución de esta técnica debida al incremento de la experiencia por la práctica clínica, ha permitido realizar bloqueos muy selectivos y fácilmente reproducibles con un elevado índice de éxitos, minimizando la influencia de factores subjetivos. Esto resulta interesante, ya que en nuestra sociedad el envejecimiento de la población implica una mayor comorbilidad asociada. Es en estos casos donde la anestesia regional proporciona una herramienta más para ampliar la gama de opciones anestésicas, y así poder asegurar una atención óptima y un menor riesgo de complicaciones (Morgan E. et al, 2007).

El uso de la ecografía para AR, permite seguir el trayecto de los nervios desde su origen hasta los extremos distales. Así se podrán abordar y bloquear los nervios en cualquier parte de su recorrido, adaptándonos a cada situación concreta y personalizando la técnica para un paciente determinado (Alonso P. et al, 2009). Está especialmente indicado su uso, en pacientes con dificultad para localizar referencias anatómicas externas (obesos, quemados) y cuando las técnicas de neuroestimulación están contraindicadas, 
desaconsejadas o sean imposibles de realizar, como ocurre en paciente anticoagulados (Bigeleisen P, 2006), pacientes amputados con prótesis vasculares, hematomas o edemas (Plunkett AR. et al, 2006), o la presencia de férulas para evitar contracciones musculares dolorosas (Marhofer P. et al, 2004). También aumenta la seguridad en neuropatías (que imposibilitan una respuesta motora normal) o en bloqueos de nervios sensitivos puros (especialmente en pacientes poco colaboradores como niños o pacientes con deterioro cognitivo) (Alonso P. et al, 2009).

Asimismo, la visualización de la difusión del anestésico local durante su inyección es imprescindible, ya que nos permitirá redireccionar la aguja si es preciso para rodear con el anestésico un nervio o bien conseguir una disección de fascias musculares. Por ejemplo, en el bloqueo de la pared abdominal (TAP: Transversus Abdominis Plane) visualizamos el punto de inyección del anestésico, el cual se localiza entre las aponeurosis de los músculos oblicuo interno y transverso, y se verá durante la infusión del anestésico local la difusión del mismo entre estos dos músculos y no la inyección intramuscular, haciendo eficaz dicho bloqueo (Marhofer P. et al, 1998; Sandhu NS. et al, 2004; Abdallah FW. et al, 2012). Por último, la ecografía permite al anestesiólogo, "desplazarse" fuera de estructuras anatómicas "sensibles" como son las arterias y venas o la pleura, o también evitar la punción neural siempre que se reconozcan dichas estructuras (Domingo V. et al, 2004; Alonso P. et al, 2009).

En la actualidad, respecto a las complicaciones con el uso de la ecografía en anestesia regional, no existen datos concluyentes basados en la evidencia científica de que disminuya el número de lesiones neurológicas, aunque si la incidencia de punción vascular (Abrahams MS. et al, 2009; Walker KJ. et al, 2009; Danelli G. et al, 2012). Lo que parece evidente es que la incidencia de complicaciones variará según la experiencia del anestesiólogo (Denny NM. et al, 2005; Koscielniak-Nielsen ZJ, 2008; Vadeboncouer TR. et al, 2008). Además, aunque la ecografía no es sino otra forma de localización de los nervios, las lesiones nerviosas son procesos multifactoriales relacionándose entre otros, la neurotoxicidad de los anestésicos locales, el tipo de bisel de la aguja, las condiciones subyacentes del paciente (por ejemplo diabéticos), y los traumatismos relacionadas con la cirugía. Debido a que la incidencia de lesión neurológica o toxicidad por anestésico es muy baja, es prácticamente imposible demostrar que la ecografía puede ser mejor que la neuroestimulación, así como tampoco ha 
demostrado disminuir la incidencia de toxicidad por anestésico local (Schafhalter-Zoppoth I. et al, 2004; Chan VW, 2005; Bigeleisen PE, 2006; Horlocker TT. et al, 2007; Sites BD. et al, 2007 ; Loubert C. et al, 2008; Ganesh A. et al, 2009; Liu SS. et al, 2009; Neal JM, 2010; Koscielniak-Nielsen ZJ. et al, 2012; Sites BD. et al, 2012).

A pesar de que con respecto a las complicaciones la ecografía no pueda demostrar que es mejor que métodos "ciegos" tradicionales como la neuroestimulación (excepto como ya se ha dicho, en el caso de la punción vascular), desde la primera publicación anteriormente referida en 1994, hay cada vez mayor peso científico (> 1.500 documentos) que apoyan el uso de esta técnica en anestesia regional. Existen ya múltiples revisiones sistemáticas comparando esta nueva técnica con la neuroestimulación u otras técnicas de aproximación nerviosa, y además hay grupos con más de 15 años de experiencia en el uso habitual y rutinario de la ecografía que han demostrado su alta seguridad y eficacia (Marhofer P. et al, 2010).

Así por ejemplo, en el estudio de Chan y cols. (2007) se llevó a cabo un ensayo aleatorizado y controlado de 188 pacientes sometidos a bloqueo del plexo braquial axilar, comparando el ultrasonido con técnicas de estimulación nerviosa. La tasa de éxito fue más alta con el ultrasonido $(82,8 \%, p=0,01)$, en comparación con la neuroestimulación $(62,9 \%)$. No se informó de complicaciones en ninguno de los dos grupos (Chan VW. et al, 2007). En ese mismo año, Sandhu y cols. presentó un trabajo con una muestra de 1.146 pacientes a los que se les realizó un bloqueo infraclavicular guiado por ultrasonido. Los bloqueos fueron realizados por 88 médicos jóvenes supervisados por 37 anestesistas diferentes, y por lo tanto, representaban un escenario del "mundo real". En éste estudio se observó un noventa y nueve por ciento de éxito (se lograron 1138 de 1146 bloqueos), la punción arterial fue menor del 1\% y ningún paciente presentó toxicidad local o síntomas de lesión del nervio periférico (Sandhu NS. et al, 2007). Orebaugh realizó un estudio con una muestra de 248 pacientes comparando ambas técnicas en distintos bloqueos (interescalénico, axilar, femoral, poplíteo), concluyendo que se necesitaban menos intentos y menos tiempo para producir el bloqueo con ecografía $(P<0,001)$. Sin embargo, no mostraron una diferencia estadísticamente significativa en la tasa de fracaso entre los dos grupos (Orebaugh S. et al, 2007). 
En la revisión de Abrahams se incluyen ensayos clínicos desde 1990 a 2008 con un total de 946 pacientes; concluyen que con la ecografía se tiene más probabilidad de éxito (definida la tasa de éxito como el porcentaje de bloqueos que permiten a los pacientes someterse a una intervención quirúrgica sin suplementación ni conversión a anestesia general o anestesia espinal). Además se realizaban más rápido (una media de un minuto antes), con un inicio de acción más rápido y una duración más larga; todo con resultados significativos. También se reducía la tasa de punción vascular (Abrahams MS. et al, 2009).

En el estudio de Liu SS y cols. se incluye una búsqueda sistemática desde 1966 a 2009 donde se observó un bloqueo de inicio más rápido, con mayor calidad y mayor duración. Existe un nivel de evidencia 1B con un grado de recomendación grado A de que la ecografía mejora la calidad del bloqueo con su uso. No se encontraron estudios en los que la ecografía fuese inferior a los métodos ciegos tradicionales, incluida la neuroestimulación (Liu SS. et al, 2009 y 2010).

Otros estudios, ratifican estos resultados que avalan que la AR con ecografía permite obtener puntuaciones significativamente más altas en la calidad anestésica comparada con la realizada con neuroestimulador. Se reduce significativamente el número de veces que es necesario redirigir la aguja y por tanto las inserciones de la misma, disminuye la punción de los vasos, y aumenta significativamente la aparición de casos de bloqueo completo (sensitivo y motor) en 30 minutos, con una analgesia postoperatoria superior (Buist RJ. et al, 1990; Auroy Y. et al, 1997; Marhofer P. et al, 1997; Ballantyne JC. et al, 1998; Rodgers A. et al, 2000; Urwin SC. et al, 2000; Beattie WS. et al, 2001; Borgeat A. et al, 2001; Auroy Y. et al, 2002; Grau T. et al, 2002; Chelly JE. et al, 2003; Williams SR. et al, 2003; Hadzic A. et al, 2004 y 2005; Willschke H. et al, 2005; Casati A. et al, 2007; Chan VW. et al, 2007; Marhofer P. et al, 2007; Kapral S. et al, 2008; Perlas A. et al, 2008; Bubnov RV. et al, 2011).

Con el uso de la ecografía, se ha apreciado una disminución en la dosis de anestésico local por consenso en torno al 30-50\%, lo que podría disminuir la incidencia de complicaciones como la toxicidad sistémica. Volúmenes tan bajos como de $5 \mathrm{ml}$ se han utilizado con buen efecto clínico para la analgesia postoperatoria en un bloqueo interescalénico (Marhofer P. et al, 1998; Marhofer P. et al, 1999; Sandhu NS. et al, 2006; Casati A. et al, 2007; Marhofer P. et al, 2007; Riazi S. et al, 2008; Eichenberger U. et al, 2009). 
Esta disminución en la dosis, permite la posibilidad del empleo de la anestesia regional para actuar en dos extremidades a la vez en un mismo acto quirúrgico (por ej. por varias fracturas) o evitar la extensión anestésica a otros territorios que no se deseen bloquear (Alonso P. et al, 2009; Holborow J. et al, 2010).

Otra ventaja a considerar importante en tiempos de ajustes y recortes económicos como los que vivimos actualmente, es el análisis coste-efectividad de estos procedimientos. Los bloqueos nerviosos periféricos cumplen bastantes características de la anestesia ideal en el paciente intervenido, tanto en régimen de ingreso (por ejemplo, si comparamos anestesia general vs bloqueo supraclavicular para cirugía de hombro), como en régimen de cirugía mayor ambulatoria (CMA). Presentan un análisis coste-efectividad favorable, ya que producen anestesia en el área quirúrgica específica, minimizando los efectos de la anestesia general (opiodes y el aumento de náuseas y vómitos), evitan la manipulación instrumental de la vía aérea y aportan generalmente mayor estabilidad hemodinámica que la anestesia general y la anestesia neuroaxial. Estas ventajas implican reducir la intervención de enfermería, mejorar el bienestar del paciente, facilitar en CMA la recuperación temprana y el alta precoz (en el día) y, en último término, reducir el coste por proceso (Chan VW. et al, 2001; Hadzic A. et al, 2002 y 2005; McCartney CJ. et al, 2004; Sandhu NS. et al, 2004; Gonano C. et al, 2009).

En la siguiente tabla se muestran de forma resumida las ventajas de la ecografía para la realización de los bloqueos regionales (tomado de Ortega A. et al, 2008):

- Visualización directa de nervios, trayectos de la aguja y relación con las estructuras anatómicas más próximas.

- Visualización directa o indirecta de la distribución del anestésico local durante la inyección, junto a la posibilidad de reposicionar la aguja en caso de distribución inadecuada.

- Puede evitar efectos secundarios graves (inyección intraneural o intravascular).

- Reducción de la dosis de anestésico local.

- Más rapidez en la instauración del bloqueo y mejor calidad del mismo.

- Mayor confort del paciente, gracias a la rápida identificación de los nervios a bloquear y la posibilidad de prescindir de las respuestas motoras de la neuroestimulación. 
Después de describir las bondades de la ecográfica aplicada a la anestesia regional, cabe ahora preguntarse si esta técnica está o no exenta de fallos. Hay razones que hacen que dicha técnica pueda fracasar; como una mala orientación de la sonda, la no visualización de la aguja o la mala interpretación de los artefactos. También el comportamiento del principiante en sus inicios podría aumentar el riesgo de lesiones (Sites BD. et al, 2004 y 2007). Por tanto, su seguridad y su fiabilidad dependen en gran medida de la experiencia del anestesiólogo, sus limitaciones no son las de la técnica o las del equipo, sino las de uno mismo como explorador. Por ello, es imprescindible actualizar y profundizar en nuestros conocimientos de anatomía, conocer los principios físicos y aplicar prudencia y sentido común (Díaz-Rodríguez N. et al, 2007). Los bloqueos guiados por ecográfica no eliminan requisitos tradicionales tales como una dosificación adecuada de los anestésicos, la aspiración antes de la inyección del anestésico local, detener la inyección si se produce dolor en el paciente y hacer la inyección sin resistencia. También se recomienda la sedación apropiada del paciente seguido de una vigilancia y un control después del bloqueo adecuado (Sites BD. 2009; Neal JM. et al, 2010).

No se conocen contraindicaciones para el uso de la ecografía aplicada a la anestesia regional, salvo aquellos inherentes a las condiciones del paciente (coagulopatía, neuropatía...), por lo que habrá que individualizar su uso, ya que en la mayoría de los casos son contraindicaciones relativas (Morgan E. et al, 2007). Sus principales inconvenientes son el coste económico del equipo y la necesaria curva de aprendizaje. Las nuevas generaciones de anestesiólogos están demostrando un gran interés y cada vez existen más cursos de formación en bloqueos locorregionales guiados por ecografía. Además, también existe una mayor demanda por parte de los usuarios (Danelli G. et al, 2009; Liu SS. et al, 2009; Tedore TR. et al, 2009; Bubnov RV. et al, 2011). La ecografía, es una técnica ideal para el aprendizaje de la anestesia regional, ya que muestra la anatomía individual en el sujeto vivo (Retzl G. et al, 2001; Royse CF. et al, 2006; Chin KJ. et al, 2008).

Podemos concluir a la vista de los trabajos arriba presentados, que si bien hasta hace dos décadas se ha considerado el neuroestimulador como el "gold standard" entre los métodos de aplicación de la anestesia regional, actualmente se está imponiendo la ecografía (Greher M. et al, 2002; Peterson MK. et al, 2002; Hopkins PM. et al, 2007). De hecho, para 
algunos autores (entre los que nos encontramos nosotros), es ya hoy la técnica de elección en este tipo de anestesia (Ruiz MC. et al, 2010).

\section{I.2. IMPORTANCIA DEL CONOCIMIENTO ANATÓMICO PARA LA ANESTESIA REGIONAL}

La Sociedad Francesa de Anestesiología y la New York School of Regional Anesthesia, han elaborado unas guías de actuación que van orientadas a reducir el riesgo de complicaciones relacionadas con la práctica de los bloqueos periféricos; entre dichas recomendaciones, figura como algo imprescindible, el conocimiento adecuado de la anatomía (disponible en http://www.nysora.com). Sin embargo, a pesar del número cada vez mayor de anestesias regionales, muchos anestesiólogos no se sienten cómodos en la realización de los bloqueos nerviosos periféricos, entre otros motivos, porque refieren haber perdido parte de las nociones anatómicas que recibieron durante su etapa académica (Kopacz D. et al, 2002; Bartusseck E. et al, 2004).

El conocimiento de la anatomía topográfica y seccional de los plexos (origen, trayecto y relaciones con estructuras vecinas), permite al anestesiólogo elegir la técnica apropiada para el procedimiento quirúrgico o analgésico previsto, e incluso, complementar con anestésicos locales los bloqueos inadecuados (por ejemplo, reforzar el bloqueo del nervio mediano en su trayecto por el brazo ante un bloqueo axilar incompleto). Si no se domina la anatomía, el éxito del bloqueo depende en exclusiva de la suerte o del azar, en lugar de basarse en la destreza (Miller R. et al, 2005).

El anestesiólogo, debe conocer la anatomía de superficie para saber localizar el punto óptimo de realización de un bloqueo y la anatomía profunda, para saber o intuir que zonas atraviesa la aguja con la que administramos el anestésico. De este conocimiento, se derivan algunas de las potenciales complicaciones que se pueden producir, como por ejemplo, la punción de una arteria que acompaña al nervio o el riesgo de un neumotórax por la proximidad de la cúpula pleural. A medida que aumentamos el conocimiento anatómico, aumentamos la eficacia y reducimos los riesgos de complicaciones (López S. et al, 2009). 
En el caso que usemos la neuroestimulación, como método de localización de los nervios, el anestesiólogo valorará las repuestas motoras que se producen al estimular los distintos componentes de un plexo nervioso o un nervio individual. Las fibras nerviosas que se afectan en este caso son las sensitivas y motoras, que difieren en grosor y grado de mielinización y, por lo tanto, en el periodo refractario y velocidad de conducción. Esto permite ajustar la intensidad y duración del impulso en el electroneuroestimulador, de forma que sea posible estimular las fibras motoras y no las sensitivas. Así obtenemos una respuesta motora indolora, independientemente de la distancia entre la punta de la aguja y el nervio (Roques V. et al, 2007). Un análisis erróneo de los movimientos producidos por el neuroestimulador conduciría a un fracaso de la técnica (Ruiz MC, 2010).

Si usamos la ecografía, el anestesiólogo deberá familiarizarse con la "sonoanatomía" o lo que es lo mismo, la anatomía en un corte o sección ecográfica. La anatomía seccional cobra un papel fundamental en la anestesia regional con ecografía, puesto que en realidad lo que se realiza con una exploración ecográfica no es más que un corte o sección en una zona determinada. Además, será imprescindible el conocimiento de la imagen ultrasonográfica que presentan las estructuras anatómicas más importantes, como son los nervios, vasos, huesos, músculos o pleura (Muñoz M. et al, 2007).

Hay otras muchas implicaciones clínicas derivadas del conocimiento exhaustivo de la anatomía; ya que las variantes anatómicas dentro de un plexo son extremadamente comunes, y pueden ser consideradas la regla y no la excepción. Muy pocas estructuras son coincidentes en tamaño, forma y localización entre individuos, así como en lados opuestos de un mismo individuo (Neal JM, 2002; Rouvière H. et al, 2012). También influye, en esta localización anatómica de estructuras, la posición y características del paciente (por ej. el paciente obeso). Estas diferencias en la sistematización de los plexos de un individuo a otro, es lo que justifica que a veces en algunos casos, no se pueda predecir de forma exacta el grado de bloqueo periférico obtenido (Kerr AT, 1918; McCann PD, 1991; Partridge BL. et al, 1997). En estos casos la utilización de la ecografía permitirá identificar estas diferencias anatómicas y facilitar la realización del bloqueo (Alonso P. et al, 2009).

Como se ha mencionado, dependiendo de la zona sobre lo que se va a operar o donde queremos obtener analgesia, se realizará o elegirá una u otra técnica. Debemos 
conocer tanto el componente motor como sensitivo de cada nervio objeto del bloqueo. Es importante conocer por tanto los dermatomas, miotomas y osteotomas (Gallardo J, 2008).

Se denomina dermatoma al área de piel cuya inervación es suplida por la raíz dorsal (sensitiva) de cada nervio espinal. Cada segmento se dispone horizontalmente, con excepción de $\mathrm{C} 1$, que no tiene componente sensitivo. Hay una variabilidad substancial entre sujetos, quizás debido a interconexiones entre raíces.

Se denomina miotoma a la inervación segmentaria del músculo esquelético por la rama ventral (motora) del nervio espinal. El movimiento causado por el estímulo de los nervios es más específico a nivel distal donde ya se han separado del plexo común.

Finalmente, la inervación de los huesos (osteotomas o esclerotomas) que no suelen tener el mismo patrón segmentario que la inervación de los tejidos blandos (piel y músculos), en parte por sobreposición y reordenamientos complejos de los nervios durante la embriogénesis (Gallardo J, 2008). En la siguiente figura se muestra una representación esquemática de los territorios de inervacion sensitiva y motora del miembro inferior en la región anterior y en la región posterior. Observesé la falta de superposición estricta entre dermatomas, miotomas y esclerotomas (Fig. 1). 


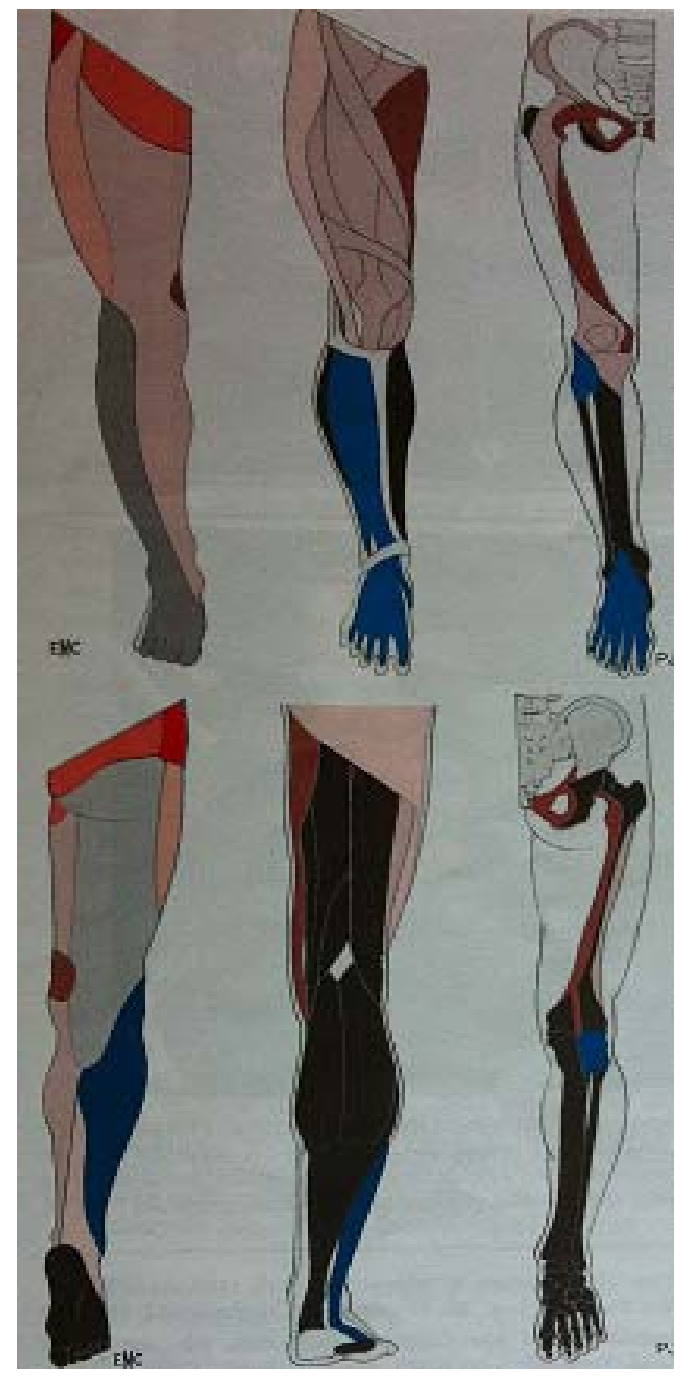

Figura 1: Visión anterior y posterior de la extremidad inferior donde se muestran los dermatomas, miotomas y esclerotomas.

Pero no sólo es importante el conocimiento de la anatomía macroscópica, también es interesante el conocimiento de la microestructura de los nervios. Por ejemplo, la envoltura más externa de los nervios (el perineuro), es una estructura de tejido conectivo que permite un cierto grado de estiramiento sin que se produzca daño en las fibras nerviosas. Esta circunstancia, quizás tenga un rol "protector" durante los bloqueos nerviosos, permitiendo que los nervios sean "empujados" en lugar de "penetrados" por la aguja durante las técnicas de bloqueo. Otra curiosidad, por ejemplo, es que el plexo braquial está formado por un número variable de fascículos, y algunos nervios, en un momento de su trayecto pueden estar constituidos por un solo fascículo. En el plexo braquial, esto es más frecuente a nivel de los nervios espinales, las divisiones anterior y posterior del tronco primario superior y en 
los orígenes de los nervios supraescapular y musculocutáneo. En estos puntos, en los que el nervio es monofascicular, una lesión que provoque disrupción del perineuro, como teóricamente sucedería con la punta de una aguja, podría tener peor pronóstico (Bollini CA. et al, 2003 y 2007).

Una vez visto la importancia del conocimiento anatómico, cabe preguntarnos de que herramientas disponemos para su enseñanza. Para el aprendizaje de la anatomía, existen diferentes modelos como prácticas en cadáveres, talleres con animales, modelos de plástico, videos de enseñanza, archivos grabados en pacientes reales, atlas...así como modelos más instructivos en 2D-3D, de pacientes virtuales que se utilizan para superar ciertas limitaciones de los modelos más simples. Con estos modelos, se trata de facilitar el aprendizaje anatómico y así realizar luego en la práctica clínica habitual adecuadamente las técnicas y entender por qué, por ejemplo, al realizar un bloqueo interescalénico se puede producir el bloqueo del nervio frénico y secundariamente, insuficiencia respiratoria debido a la proximidad entre ambos (Bröking K. et al, 2006; Alonso P. et al, 2009).

Los distintos modelos de aprendizaje (por ejemplo, el cadáver o dibujo), varían el grado de abstracción y la capacidad de permitir la visión desde múltiples ángulos de visión. En la neuroanatomía por ejemplo, las ilustraciones de los atlas utilizados para enseñar la superficie del cerebro se suelen presentar sobre cuatro puntos de vista: superior, inferior, lateral y medial. Sin embargo, en la vida real, un modelo del cerebro puede ser examinado a partir de muchos más puntos de vista que esos cuatro (Levinson AJ. et al, 2007).

Con el gran desarrollo de la tecnología y con ella de la realidad virtual, se han creado simuladores que reproducen entornos realistas, con escenarios estandarizados y reproducibles, sin poner en peligro a los pacientes (Issenberg S. et al, 2008; Scalese RJ. et al, 2008). Más recientemente, sofisticadas simulaciones por ordenador, tales como el "Visible Human Project" (se comentará más adelante), han permitido visualizar la anatomía de una forma más "real".

A lo largo de la exposición de esta tesis, mostraremos el procedimiento tecnológico que hemos desarrollado para la formación en anestesia regional. Con él, se ha pretendido conseguir la integración entre conocimiento anatómico y ecográfico, junto con el necesario 
conocimiento teórico. Para ello, se mostrará de forma simultánea la imagen ecográfica de un paciente modelo, con su correspondiente sección axial de RM y la anatomía tridimensional e interactiva del cuello o de la extremidad seleccionada. Junto a esto, se mostrarán las explicaciones necesarias para la realización apropiada de un bloqueo determinado.

\section{I.3. NUEVAS TECNOLOGIAS EN LA FORMACIÓN MÉdICA}

En la sociedad en la que vivimos, la información y el conocimiento tienen cada vez más influencia en el entorno laboral y personal de los ciudadanos; sin embargo, los conocimientos tienen fecha de caducidad. El modelo tradicional de aprendizaje consistente en saber escribir y leer, ya no significa hoy ser una persona alfabetizada. Hemos pasado del papel y lápiz, a la pantalla del ordenador y el teclado. Aunque la lectura y la escritura siguen constituyendo la base para el aprendizaje, no son suficientes para acceder a la información que sobre casi cualquier tema circula por Internet. Surge un nuevo modelo en el que las personas se deben familiarizar con las nuevas tecnologías. Este nuevo modelo de enseñanza, hace que si no se sigue la línea de las nuevas tecnologías, se produzca lo que algunos han denominado analfabetización tecnológica o exclusión social (Martín-Laborda R, 2005).

Es evidente que el proceso educativo ha cambiado. Antiguamente, una persona pasaba por las diferentes etapas del sistema educativo (desde Infantil a la Formación Profesional o Universitaria) antes de poder iniciar su vida laboral. A partir de ahí, a excepción de algunos cursos de actualización ofrecidos en su ambiente profesional, se consideraba que la persona ya estaba preparada (Martín-Laborda R, 2005). En la actualidad, la velocidad a la que se producen las innovaciones, el crecimiento acelerado de los conocimientos científicos y los cambios tecnológicos, exigen una actualización permanente de los mismos. Surge la necesidad de la formación continuada, o lo que es lo mismo, el aprendizaje a lo largo de toda la vida. La formación continuada es ampliamente reconocida como una parte indispensable de la vida laboral de los médicos. Las posibilidades para reciclarse se amplían al poder aprender, ya sea formalmente a través de cursos on-line organizados por centros, o de forma más informal, participando en foros, redes temáticas, chats, videoconferencias o comunicaciones de correo electrónico entre colegas nacionales o del extranjero (Choudhry NK. et al, 2005). 
La aparición de lo que en su momento se llamaron "Nuevas Tecnologías" en las últimas décadas del siglo XX ha sido la causa de la llamada "Revolución Digital", revolución que, a diferencia de otras anteriores, ha conseguido que los cambios y las transformaciones derivadas se hayan producido muy rápidamente en todos los ámbitos de la sociedad. Internet se ha desarrollado e incorporado a la vida de los ciudadanos a una velocidad vertiginosa. Se ha configurado la "Sociedad del Conocimiento", que se caracteriza por la posibilidad de acceder a volúmenes ingentes de información y de conectarse con otros colectivos o ciudadanos (Martín-Laborda R, 2005).

La diseminación de las webs en la década de los 90 del pasado siglo, introdujo la idea de que la formación a distancia vía Internet iba a ser el sustituto natural de la formación tradicional presencial. Añadía accesibilidad y posibilitaba la formación sin restricciones de tiempo, espacio y sin la interacción alumno-profesor, pero seguía manteniendo el mismo esquema de transmisión unidireccional de conocimientos, por lo que en realidad supuso para algunos un retroceso a nivel pedagógico (Hugenholtz NI. et al, 2008). La llegada de wikis, podcasts, blogs, microblogs, redes, comunidades sociales etc..., aporta nuevos elementos que tienen un gran potencial. La versatilidad en el uso de diferentes formatos, la interactividad y la posibilidad de trabajar a tiempo real desde diferentes puntos del planeta, abren la puerta a un nuevo enfoque en la educación médica. El siguiente paso consistirá, según parece, en individualizar los contenidos y accesos a la red, lo cual permitirá diseñar planes docentes "a la carta" en función de las necesidades formativas de cada cual (Gavilan $E, 2010)$.

El anglicismo e-learning que es a veces llamado el aprendizaje en línea, enseñanza asistida por computadora, o el aprendizaje basado en Internet, se refiere al uso de las tecnologías de Internet para ofrecer una amplia serie de materiales didácticos que mejoren el conocimiento de los estudiantes y en último término su rendimiento (Rosenberg M, 2001; Ruiz JG. et al, 2009).

Han surgido mucho términos que no son siempre sinónimos o intercambiables como: educación a distancia, educación abierta, educación tecnológica, teleformación, aprendizaje en redes, comunidades de aprendizaje, aprendizaje colaborativo, e-learning, blended learning... Como la educación médica debe ser continua para hacer frente a nuevos retos 
sociales, científicos y pedagógicos las aplicaciones e-learning pueden mejorar la eficiencia y la eficacia (Ozuah PO, 2002). Asegurar la disponibilidad de una gama cada vez mayor de materiales e-learning de alta calidad, parece ser una excelente manera de aprendizaje (Prince NJ. et al, 2010).

Una de los principales ventajas pedagógicas del e-learning reside en su interactividad (Clark D, 2006). El concepto de interactividad es todavía aún hoy controvertido, careciendo incluso de una clara definición aceptada (Yacci M. et al, 2000). Según el diccionario de la Real Academia Española (RAE), se define como el modo de trabajo entre un terminal y el ordenador que permite el diálogo entre usuario y ordenador.

En EE.UU es ya una herramienta potente para el aprendizaje y la enseñanza. Los primeros estudios tendían a comparar e-learning con los métodos estándar de enseñanza, sin embargo, ahora existe un mayor interés en el 'blended learning'; que es la utilización conjunta de las estrategias de e-learning y de los métodos de enseñanza más tradicionales en las escuelas de medicina (Ruiz JG. et al, 2006). El efecto de los programas de formación médica continuada basados en nuevas tecnologías, es hoy todavía motivo de controversia. Para algunos el efecto es comparable al de los métodos tradicionales (Wutoh R. et al, 2004; Curran VR. et al, 2005).

Fordis y cols. (2005) encontraron que la formación basada en nuevas tecnologías, puede conducir a un mantenimiento del conocimiento superior a las medidas tradicionales. Continua siendo interesante estudiar la persistencia de los conocimientos obtenidos con el tiempo, y aún más importante es estudiar el impacto del e-learning en la práctica profesional. Los materiales impresos se han utilizado ampliamente durante siglos, por lo que su persistencia en el tiempo es la prueba de su utilidad. La historia del e-learning, es relativamente reciente e influyen varios factores, aunque la mayoría de los encuestados (hasta un 79\%) los evalúa favorablemente (Fordis M. et al, 2005).

El alumno toma en la actualidad un papel más activo, crítico y autónomo gracias al acceso a la información. Ya no vale con lo que cuenta el profesor. El alumno, ya sea de forma individual o en grupo, debe aprender a buscar la información, a procesarla, es decir, a seleccionarla, evaluarla y a convertirla en última instancia, en conocimiento. El beneficio 
para la medicina en particular de estos nuevos medios de compañía virtual es que con unos "clics" de ratón accedemos a un número ilimitado de consultas, en cualquier momento y en cualquier lugar (Muller M. et al, 2008).

Por otro lado, la actualización de materiales e-learning puede suponer costos similares o incluso mayores, pero en ocasiones, la relativa facilidad en la redistribución de dichas actualizaciones de contenidos, compensa los costes (Ruiz JG. et al, 2009). Esta enseñanza tecnológica a distancia presenta a su vez nuevos problemas u obstáculos, ya que se requieren nuevos requisitos a los ya existentes tales como, conocimientos informáticos o inversión económica en equipos (Zapata M. et al, 2005).

De forma general, la información en la red está compuesta por pequeñas partes que en general se conocen como recursos. Cada recurso disponible en la red, tiene su propia dirección electrónica única conocida como localizador uniforme de recursos (URL: "Uniform Resource Locutor"). Cuando se teclea un URL en un navegador, se encontrará el recurso desde su lugar de depósito que puede estar en cualquier sitio, en cualquier lugar del mundo físicamente hablando y lo mostrará en la pantalla del lector. En la red hay mucha información médica fiable disponible; sin embargo, el desafío para el ocupado profesional médico reside en encontrarla de una forma eficaz e ignorar la información no válida. Lo prudente es ejercitar el juicio y confiar en las fuentes de procedencia conocida (Libkind A, 2004). Los sitios Web médicos abarcan un amplio abanico, desde los que publican artículos con revisión científica externa, a información sesgada o fraudulenta por intereses comerciales (D’Alfonso J. et al, 2002; Prince NJ. et al, 2010).

En definitiva, Internet se ha convertido en una herramienta imprescindible para la práctica médica diaria. La base fundamental del conocimiento médico actual, son los artículos publicados con revisión científica externa, que constituyen la bibliografía médica. Las guías de práctica clínica revisadas por expertos o consensuadas, son también de la máxima utilidad clínica. Una buena fuente para obtener guías prácticas médicas es la National Guideline Clearinghouse (NGC) en www.guideline.gov. Otro sitio fiable y que contiene un valioso material orientado clínicamente es MEDLINE, controlado por la National Library of Medicine (creada por un cirujano del ejército de los EEUU en 1836). MEDLINE contiene más de 21 millones de citas bibliográficas de más de 4.600 publicaciones 
biomédicas. Desde que comenzó el siglo XX ha sido la biblioteca médica más grande del mundo. Contiene sencillas entradas bibliográficas desde 1953 (Fig. 2).

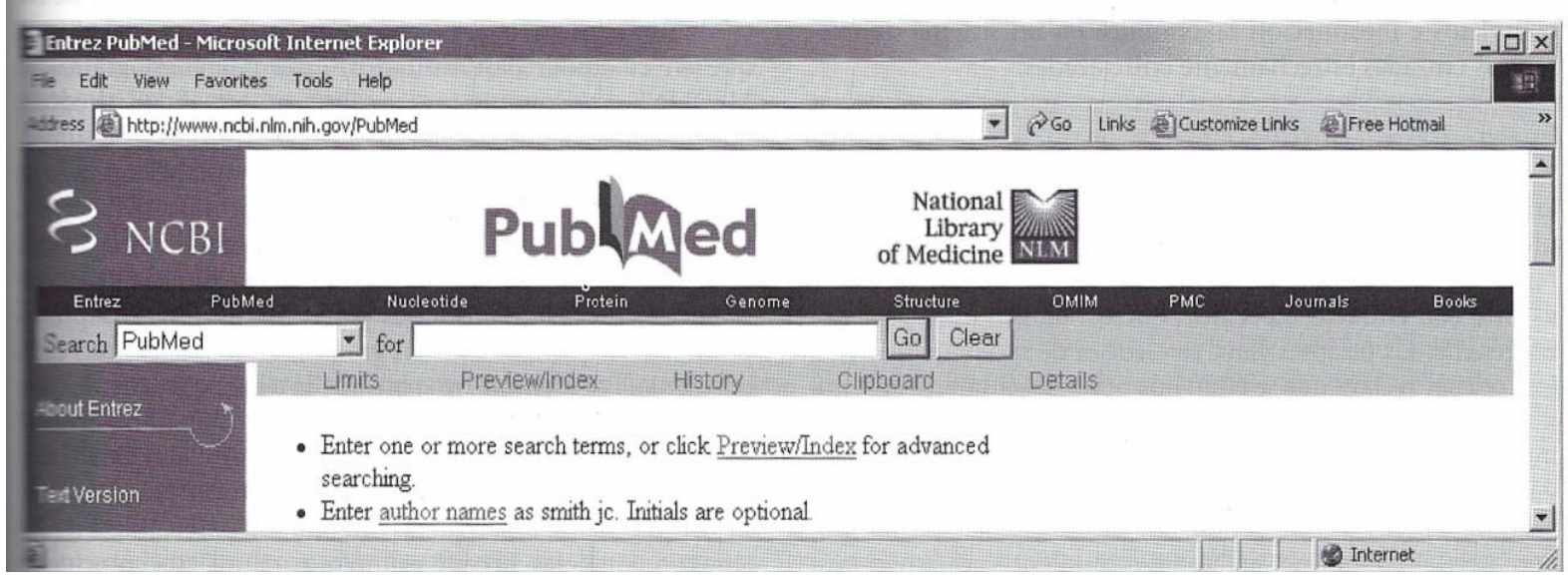

Figura 2. Imagen del buscador Pubmed donde se introducen las palabras clave para realizar las búsquedas bibliográficas.

Son muchas las páginas web dedicadas a anestesia locorregional (http://www.sosalrspain.es/; $\quad$ http://www.esra-spain.org/; http://www.nysora.com/; http://www.asra.com/; http://www.nerveblocks.net/... (Libkind A, 2004). Muchos otros recursos están disponibles en la red para los médicos. Una lista completa de ellos no cabría en este espacio.

Mencionar también otro gran avance tecnológico, los llamados teléfonos inteligentes ("smartphones"), que es un término comercial para denominar a un teléfono móvil que ofrece más funciones que un teléfono común. Disponibles en el mercado desde el año 2007, permiten la funcionalidad completa de un organizador personal. Disponen de pantallas táctiles y sistemas operativos con funciones multitarea. Están suponiendo una revolución, ya que cada vez son más las aplicaciones médicas disponibles.

De otros avances tecnológicos al servicio de la profesión médica se hará mención en el capítulo de simuladores, que junto con lo que aquí se ha mencionado, justifican nuestro procedimiento tecnológico para la enseñanza de bloqueos en anestesia regional. 


\section{I.4. IMPORTANCIA DE LA IMAGEN MÉDICA TRIDIMENSIONAL}

Una imagen es una colección de medidas o valores en el espacio bidimensional (2D) o tridimensional (3D). En imágenes 2D, la posición de cada medida se conoce como píxel y en imágenes 3D, se le llama voxel. Tradicionalmente, la TC y la RM producen imágenes estáticas en 2D sobre una película. Para producir imágenes 3D se realizan muchos "cortes" o escaneos, que combinados por un ordenador, producen modelos 3D que pueden ser manipulados según nuestro propósito. Con el incremento en tamaño y número de imágenes médicas, se ha hecho necesario el uso de potentes computadoras para facilitar el procesamiento y análisis de las mismas (Medina J, 2000).

El veloz desarrollo y la proliferación de las tecnologías de adquisición de imágenes médicas están revolucionando la medicina. Estas imágenes juegan un papel muy importante en el diagnóstico y tratamiento de enfermedades, debido a que nos permiten obtener información vital observando el interior del cuerpo humano de una forma no invasiva (Juanes JA. et al, 2010 y 2011).

Aunque Everett Koop, cirujano general de los E.E.U.U. opinó en 1993 que: "el conocimiento médico que tenemos es hoy 20 veces más grande que cuando estudié, pero los métodos de enseñanza no han cambiado mucho"; en anatomía, se ha pasado en pocos años del estudio sobre disecciones de cadáveres, o sobre libros y atlas de láminas plegables, a un estudio con métodos que se aproximan lo máximo posible a la realidad. Así a partir del año 1989 se desarrolla el "Visible Human Project" (VHP), que es el primer modelo totalmente realista de la anatomía del hombre y la mujer (Fig. 3) y que ha contribuido a facilitar la comprensión de la anatomía y con ello ha ayudado en los diagnósticos y tratamientos.

Las innumerables investigaciones derivadas del VHP, muchas de ellas dirigidas a la elaboración de atlas, subrayan la importancia de la visualización 3D de estructuras, tanto con fines formativos, como de cara a la planificación o simulación quirúrgica (Cabrero FJ. et al, 2010; Juanes JA. et al, 2010; Prats A. et al, 2010; Juanes JA, 2011; Juanes JA. et al, 2011; Rodríguez Maj. et al, 2011; Juanes JA. et al, 2012). Visible Human set Available from http://www.nlm.nih.gov/pubs/factsheets/visible_human.html. Además, como ya señalara 
Grigore C. y cols. en 2003, la enseñanza interactiva de la anatomía es necesaria puesto que el entrenamiento con cadáveres es escaso y no repetible (Grigore C. et al, 2003).

Estos métodos de visualización de imágenes tienen una gran aceptación entre los estudiantes. Por ejemplo, en un modelo de aneurisma de aorta abdominal que se presentó a 160 alumnos, el 93\% encontraron ventajas con este sistema de aprendizaje frente al modelo tradicional, y el $96 \%$ encontraban beneficioso su introducción en los planes de estudio. La tecnología 3D facilita el estudio tanto a un alumno de 10 de medicina que se enfrenta por primera vez a la asignatura, como al clínico en su práctica habitual (Vuchkova J. et al, 2011; Brown PM. et al, 2012).

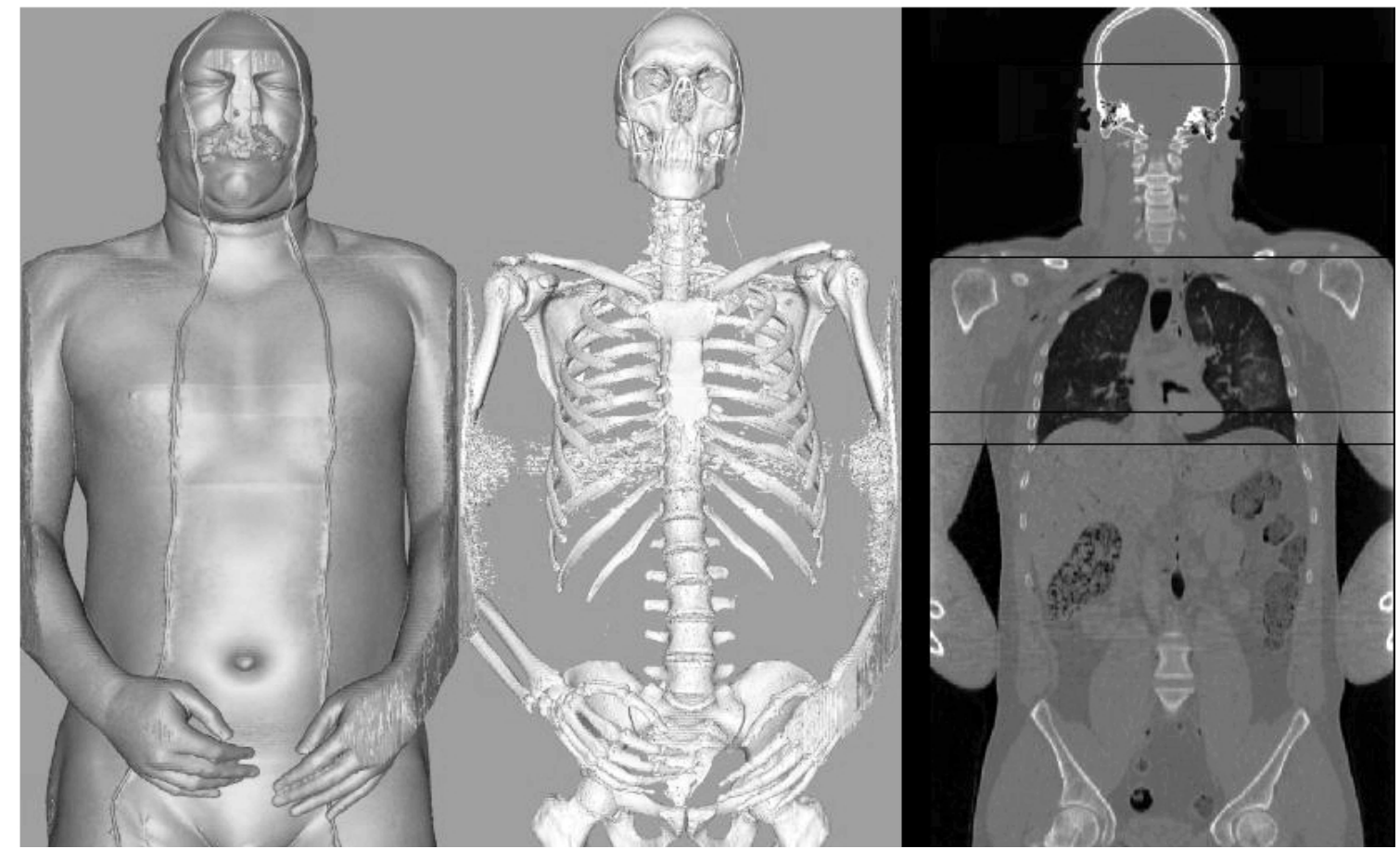

Figura 3. VHP, imágenes obtenidas por diferentes técnicas a partir del cadáver de un varón, disponibles desde 1994. Posteriormente se obtuvieron imágenes de una mujer. Se realizaron cortes de $1 \mathrm{~mm}$ de espesor.

Recientemente, el Servicio de Radiología del Hospital General de Massachusetts de la Universidad de Harvard y el Instituto de Investigaciones Biomédicas de Barcelona, revisaron la aportación de las representaciones 3D a partir de la ecografía en el conocimiento de la anatomía funcional de la válvula mitral del corazón y sus aplicaciones clínicas. Concluyeron que las reconstrucciones 3D aportan conocimientos únicos, tanto anatómicos como 
funcionales, que mejoran el conocimiento y tratamiento de distintas patologías asociadas (Solis J. et al, 2009).

La mayor parte de la información que recibe el cerebro humano se elabora a través del sistema de percepción visual y con las imágenes tridimensionales el alumno o profesional de la medicina tiene una visión más real que la obtenida por métodos clásicos (arriba-abajo, izquierda-derecha), lo que facilita al cerebro la interpretación de las imágenes desde la teoría a la práctica (Khan ZU. et al, 2011; Wedmid A. et al, 2011).

\section{I.4.I. LOS SIMULADORES TECNOLÓgICOS COMO HERRAMIENTAS DE ENTRENAMIENTO PARA LA FORMACIÓN MÉDICA}

Al avance tecnológico imparable en medicina, se ha añadido la cultura de la seguridad y de la prevención de errores e incidentes críticos. En caso de una emergencia en anestesiología, existe la necesidad de personal entrenado. La falta de capacitación y conocimiento sobre por ejemplo, el equipo de anestesia, se convierte en un problema para el anestesiólogo que trabaja con él (Weller JM. et al, 2009)

En medicina, estos programas de prevención de incidentes críticos se introdujeron por anestesiólogos en la década de los 60, y ha sido a partir del año 2000 cuando se ha extendido a la medicina en general. La publicación del Institute of Medicine de América "To Err is human", definió que el $80 \%$ de los errores médicos son evitables y consecuencia de la interacción del equipo y de éstos con el sistema. Este hecho, ha impulsado la enseñanza por simulación de situaciones en las que existen interacciones complejas dentro del equipo asistencial, permitiendo la exposición de éste a escenarios críticos poco frecuentes en la práctica, con el fin de mejorar la coordinación, facilitar la labor de cada uno de sus miembros y en último término, mejorar los resultados (Cumin D. et al, 2007). La simulación ha adquirido categoría académica y científica. El gran desarrollo de la educación médica basada en las simulaciones ha estimulado la creación de sociedades científicas sobre esta temática; así en 2004 se fundó la Society for Simulation in Healthcare y en el 2006 apareció su revista oficial que está indexada (http://www.simulationinhealthcare.com). En nuestro país en junio del año 2009 en Santander, con ocasión de unas jornadas sobre simulación, se dio el primer paso para constituir la Sociedad Española de Simulación en Salud que pretende agrupar a 
distintas especialidades médicas y quirúrgicas, enfermería y profesionales no sanitarios, como docentes, ingenieros, psicólogos y las principales empresas del sector con el fin de compartir objetivos y puntos de vista que permitan el desarrollo de estas nuevas metodologías en educación.

Hoy en día, la práctica de la anestesia clínica parece muy segura debido a que los avances en la monitorización aportan una información cada vez más precisa del estado del paciente. Junto a esto, la aparición de fármacos con menos efectos secundarios y una preparación cada vez mayor de todo el personal que realiza el cuidado de los pacientes, ayuda a minimizar los errores. Pero no hay que olvidar que la anestesia es una disciplina eminentemente terapéutica, en la que de forma habitual se administran fármacos que actúan de forma muy rápida y son potencialmente letales. La ventaja del uso de simuladores en medicina y concretamente en anestesiología, es que permiten la creación de entornos realistas y reproducibles, que no ponen en peligro a los pacientes (Wong AK, 2004).

Los antecedentes de la filosofía y de la tecnología actualmente empleada para la simulación en medicina, provienen de la industria de la aviación. Así, en la Primera Guerra Mundial se diseñó el "Link Trainer", un modelo estático para que los pilotos conocieran los aviones y ya en la Segunda Guerra Mundial se introdujo un nuevo concepto, simuladores para "sentir" el comportamiento dinámico del avión. En la década de los 50 se produjeron importantes avances en tecnología electrónica, en los 70 se mejoró la tecnología de las computadoras, y en los años 80 se introdujeron los ordenadores personales. Esto último ha permitido el desarrollo y una mayor utilización de los sistemas de simulación (Good ML. et al, 1989).

La simulación pretende la representación artificial, casi siempre simplificada, de un proceso complejo del mundo real con la suficiente fidelidad para lograr un objetivo específico, valorar una competencia profesional o la ejecución de una determinada acción (Doyle DJ, 2002). Así, se considera la simulación como la herramienta disponible actualmente con mejores características para la evaluación, si bien su uso en este campo está poco desarrollado, aunque se empieza a difundir en algunas universidades de Medicina (Levine Al. et al, 2008). 
El entrenamiento para la resolución de situaciones de crisis o incidentes críticos poco frecuentes es el terreno habitual donde se emplean sistemas complejos de simulación. Esto es así, porque sería imposible preparar a cualquier equipo para que actúe de forma coordinada, ordenada y eficaz ante situaciones clínicas a las que no han estado nunca, o muy poco expuestos (Weinger MB. et al, 2007).

El hecho de que cada vez sea más frecuente administrar técnicas anestésicas a pacientes con patología asociada para procedimientos quirúrgicos agresivos, hace que exista una situación de peligro potencial indefinible que subyace cada vez que realizamos una determinada técnica anestésica. Es en estas situaciones de peligro potencial, donde la simulación previa va a tener un papel importante (Juanes JA. et al, 2011).

Un simulador simplemente es un producto que se usa para "simular" algo. Puede ser un maniquí a escala real, conectado a un sistema de ordenadores, que incluso nos habla y responde, en un medio que reproduzca un quirófano con todos sus elementos, incluidos cirujanos operando, enfermeras y otro personal. Pero también lo es, por ejemplo, un dispositivo supraglótico que se inserta en una cabeza de un maniquí. No toda la simulación requiere un dispositivo simulador, así, el "role playing" o actuación, es un ejemplo de simulación que no precisa ayuda física (Hu J. et al, 2007; Pott LM. et al, 2007).

Se denominan simuladores de anestesia a los sistemas informáticos que reproducen algunos o todos los aspectos de la anestesia y que son útiles para su aprendizaje, o para mejorar el rendimiento de los anestesiólogos. En medicina, el primer maniquí médico se introdujo en los años 1960 para enseñar la reanimación cardiopulmonar básica con ventilación boca-boca, y a partir de entonces, se han desarrollado de forma constante distintos maniquíes, bien para técnicas concretas o para simular el ambiente complejo de una situación clínica. El "Sim One" se considera el primer simulador realista de anestesiología, fue descrito en 1969 y desarrollado por la Universidad de California (Denson JS. et al, 1969). Se abandonó por su alto coste y por la falta de soporte de la microinformática de la época (Cumin D. et al, 2007). 
En el pasado, en el mercado existían dos grandes grupos de sistemas que atendían a dos conceptos diferentes de simulación: simuladores de pantalla y simuladores de escala real.

- Simuladores de pantalla: se basan en un programa informático que representan en el monitor del ordenador algunos aspectos de la práctica clínica. Para reproducir las condiciones del paciente, cuentan con un terminal que en estos simuladores es el monitor del ordenador personal. En la pantalla del ordenador se representan gráficamente todos los datos que reproducen al paciente con sus características clínicas, la monitorización y los parámetros de la ventilación, así como imágenes de la vía aérea del paciente. El médico, a través del ratón del ordenador, indica sus secuencias de actuación mediante menús de opciones que aparecen en la pantalla. Los signos vitales del paciente evolucionan en tiempo real según modelos matemáticos y fisiológicos, y el sistema recoge y procesa estas acciones y varía el curso de la simulación. El ASC o Anestesia Simulator Consultant es el simulador de pantalla más extendido y fue desarrollado por el doctor Howad Shwid de la Universidad de Washington y su equipo en 1986, de esta tecnología se han derivado posteriormente modelos de simuladores para la medicina crítica y de urgencias.

- $\quad$ Simuladores a Escala Real: a diferencia de los anteriores, se instalan en espacios físicos similares a donde se presupone que se desarrolla el caso clínico (box de urgencias, quirófano, reanimación, etc). Un maniquí simula al paciente, hay aparatos de monitorización, respirador, personal de enfermería, y todo el material y medicación del que se pueda disponer en cada una de estas áreas. El médico procede como lo haría en su ambiente de trabajo: realiza la anamnesis, la exploración física, solicita las pruebas complementarias y ejecuta las técnicas tanto diagnósticas como terapéuticas que crea oportunas. El sistema recoge y procesa estas actuaciones, variando el curso clínico del paciente según las decisiones que el médico haya tomado (Schwid HA. et al, 1990; Schwid HA. et al, 1999; Rabanal JM. et al, 2003).

Los simuladores basados en pantalla son los más baratos, no precisan tutor, el alumno puede verlo tanto tiempo como quiera y, aunque no permiten enseñar habilidades, son muy útiles. Los anestesiólogos disponemos de varios de ellos comercializados y muy 
difundidos, como el BODY, que simula la actuación durante una anestesia general y se pueden programar casos completos, o el GasMan de farmacocinética de los anestésicos inhalatorios. Actualmente existen también los simuladores basados en la realidad virtual ( $\mathrm{Hu}$ J. et al, 2007). En la práctica, lo que es realmente útil es combinar diversos tipos de simuladores. Por ejemplo, se puede observar en pantalla cómo utilizar un laringoscopio de Bullard y luego ensayarlo con un laringoscopio real, en una cabeza con una vía aérea simulada. Los resultados son muy buenos, y el balance coste resultado muy ventajoso (Pott LM. et al, 2007).

En las revisiones de Cumin y Merry, de Doyle y de Gouvitsos y cols. se puede encontrar información extensa de 83 simuladores comercializados, cuyo precio oscila entre 80 euros y más de 40.000 euros. Además se proporcionan las páginas web para obtener información y las habilidades que enseñan varios dispositivos disponibles (Gouvitos F. et al, 1999; Doyle DJ, 2002; Cumin D. et al, 2008). Continuamente se van sumando nuevos programas o dispositivos que se diseñan para problemas concretos en anestesiología (Hassan ZU. et al, 2008).

En anestesia regional el número de simuladores basados en realidad virtual para fines docentes es limitado (Hu J. et al, 2007; Ullrich S. et al, 2007 y 2008; Bibin L. et al, 2008; Cannon-Bowers JA, 2008). Los Métodos de entrenamiento en AR incluyen la utilización de cadáveres, la enseñanza mediante vídeos y modelos simples de paciente virtuales (Broking $\mathrm{K}$, et al, 2006).

Como se puede observar, la enseñanza por simulación en medicina es un campo amplio, con diferentes niveles de complejidad tecnológica, que no se basa únicamente en complicados y costosos simuladores. No sustituye a otros métodos docentes, mucho menos a la práctica clínica, si no que los complementa y debe ser integrada en ella (Doyle DJ, 2002).

Puede aplicarse a cualquier nivel de la docencia de la anestesiología como pregrado, médicos residentes o especialistas. También, a equipos multidisciplinares de anestesiólogos, cirujanos, enfermeras, perfusionistas, etc.... Con la tecnología actual se hace posible crear ambientes en los que los maniquís-pacientes "se operan", son "anestesiados" o sometidos a tratamientos intensivos (Medelez E. et al, 2003). 
Sin embargo, la simulación está infrautilizada en anestesiología como en todos los campos de la medicina, y la causa es que se ha considerado sólo adecuada aquella que se realiza en escenarios complejos, en centros de simulación, imposibles para el uso cotidiano de los profesionales. A este respecto, existen grandes centros de simulación de realidad virtual. En Europa, los primeros dedicados a la formación de anestesiólogos tanto para su práctica intrahospitalaria como en las emergencias extrahospitalarias, se abrieron en Bruselas, Leiden, Lille y varios en Alemania. Actualmente hay muchos más. En España existe uno bien organizado en Santander. Un centro de simulación de realidad virtual con maniquí, equipamiento y personal cuesta alrededor de 700.000 euros y más de 300.000 euros al año para mantenimiento. El coste hace que sólo se disponga de estos centros en determinadas instituciones y si no hay un amplio apoyo organizativo y económico de las instituciones, la rentabilidad de estos centros es limitada (Hariri S. el al, 2004; Gurusamy K. et al, 2008; Palés JL. et al, 2010).

En el tema de la educación hay pocas evidencias científicas sobre eficacia porque la investigación es difícil. Algunos autores argumentan que no sirve para todo ni sustituye al aprendizaje clínico, pues siempre lo simplifica en exceso e incluso llegan a manifestar que son una pérdida de tiempo y simplemente juguetes. Pero de todos modos, existen bastantes datos para afirmar que la simulación de bajo coste, como la distribuida por programas de simulación en Internet, es útil en determinados campos de la medicina. Si estos sistemas tienen métodos de autoevaluación y puntuación del alumno, mucho más (Bryson EO. et al, 2008). Issenberg y cols. (2005) publicaron la primera revisión sistemática sobre la enseñanza por simulación en un período de 34 años, desde 1969 a 2003. Los datos sugieren que las simulaciones médicas en medios realistas facilitan el aprendizaje si se dan las condiciones adecuadas y que complementan a los métodos tradicionales. Estas condiciones son: a) que tengan bien definidos de antemano los resultados a obtener, b) que proporcionen feedback al alumno y c) que permitan la práctica repetitiva. Respecto a esto último, cabe preguntarse cada cuánto hay que repetirlo para mantener las competencias determinadas, aspecto que aún no se ha estudiado. Cuando tras el aprendizaje por simulación el profesional está expuesto habitualmente a esa misma circunstancia clínica, probablemente mantendrá sus competencias en ese campo, pero cuando se trata de situaciones raras o infrecuentes, al cabo de un determinado tiempo debería volver a exponerse a la simulación. Para cada tipo 
de objetivo docente, la periodicidad de la repetición será diferente, pero hay que tenerla en cuenta si lo que se pretende realmente es aumentar la seguridad de los pacientes. Otros muchos estudios han tenido resultados dispares debido en parte a la heterogeneidad de los métodos utilizados o porque las muestras eran pequeñas, pero en líneas generales han sido positivos y considerados como una forma muy motivadora de aprendizaje (Greenhalgh T, 2001; Murray D, 2005; CooK DA. et al, 2008; Davis J. et al, 2008; Okuda Y. et al, 2009; Hadley J. et al, 2010; Kulier R. et al, 2010). Por tanto, se considera que la enseñanza por simulación es efectiva con la práctica repetitiva y con múltiples estrategias de aprendizaje individualizado, representando un cambio de paradigma en las prácticas de entrenamiento o "training" (Gallagher AG. et al, 2005).

Podemos concluir que el desempeño seguro de la anestesiología y en particular de la anestesia regional, requiere unos conocimientos teóricos y buenas habilidades manuales. La realidad virtual a base de simuladores, puede ofrecer a los alumnos un ambiente seguro para aprender y practicar diferentes técnicas. Sin embargo, actualmente los simuladores disponibles son escasos e incluso de uso experimental, lo que limita su uso para un entrenamiento realista. Por último se muestran algunas imágenes de simuladores e imagen en 3D de múltiples especialidades, obtenidas en su mayoría a través del buscador de imágenes de Google (Figs. 4-20):

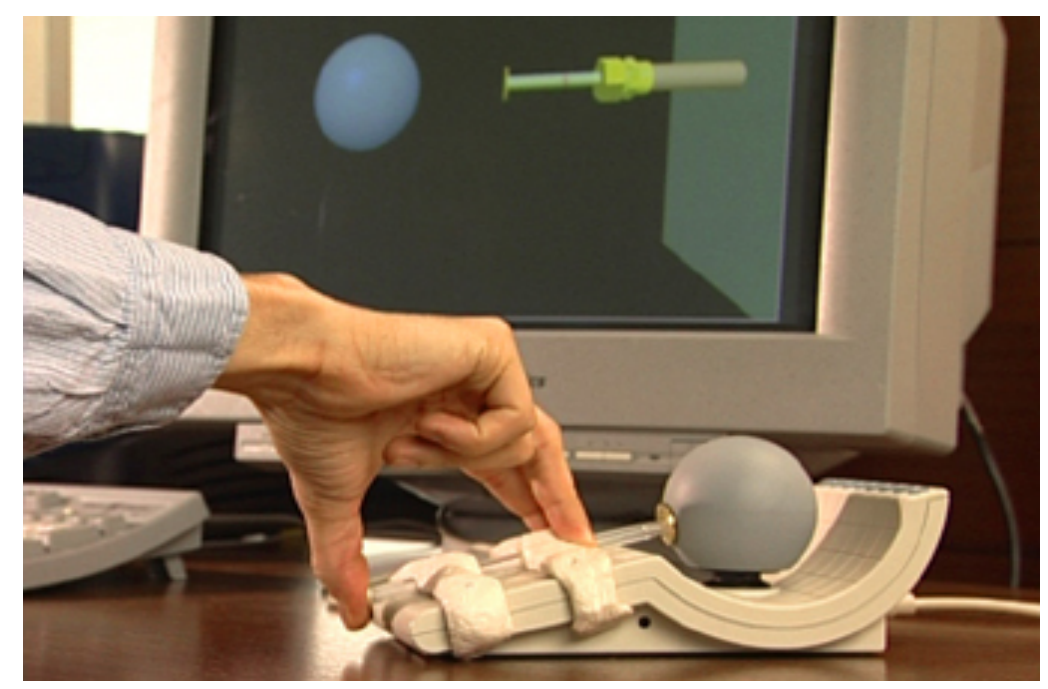

Figura 4. Simulador experimental de punción lumbar en el que el operador es capaz de percibir las distintas resistencias que ofrecen las estructuras al atravesarse. 

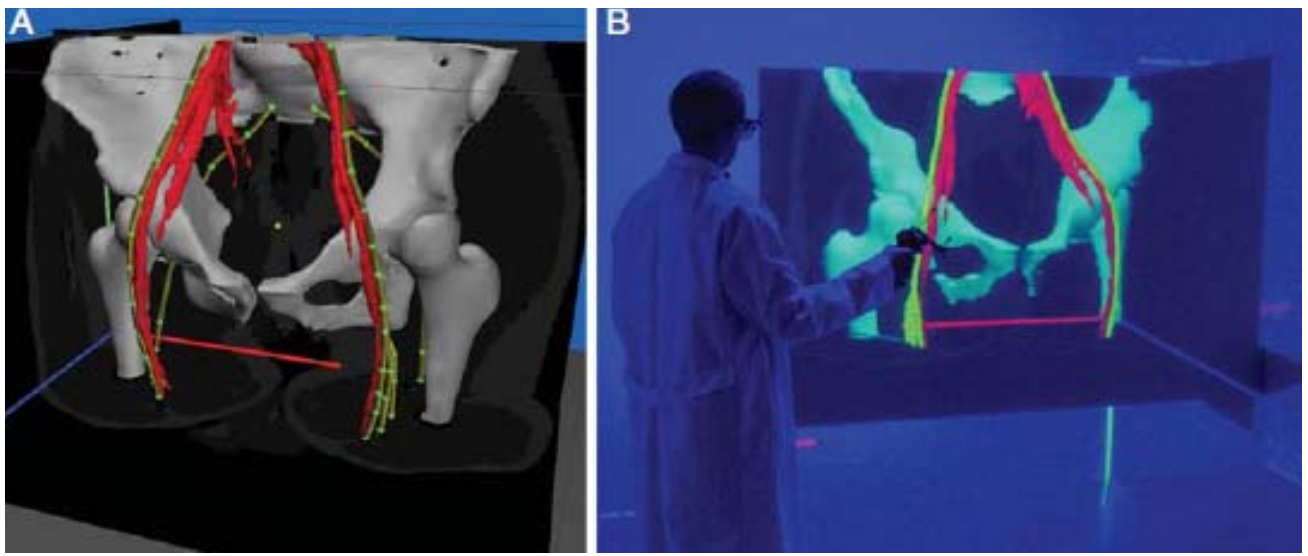

Figura 5. Región inguinal con la combinación de conjuntos de datos 3D (segmentación de los huesos y vasos sanguíneos) (Fig. A). Estos conjuntos de datos también pueden ser visualizados y manipulados en grandes entornos de inmersión virtual (Fig. B). Imágenes obtenidas del artículo de Grottke O. et al, 2009.

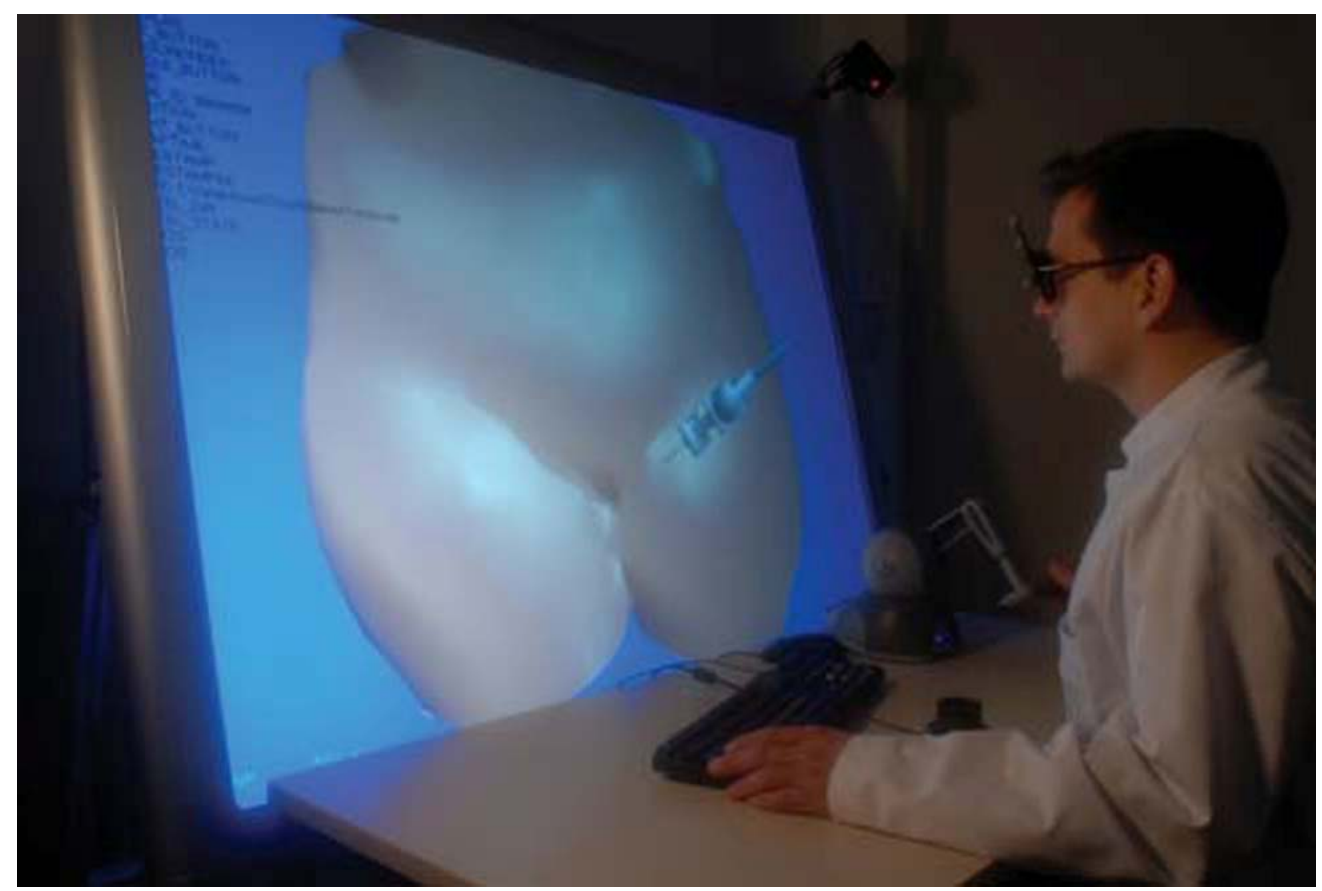

Figura 6. Aplicación para la simulación en anestesia regional. El aprendiz controla la aguja virtual a través de un dispositivo. Imágenes obtenidas del artículo de Grottke O. et al, 2009. 


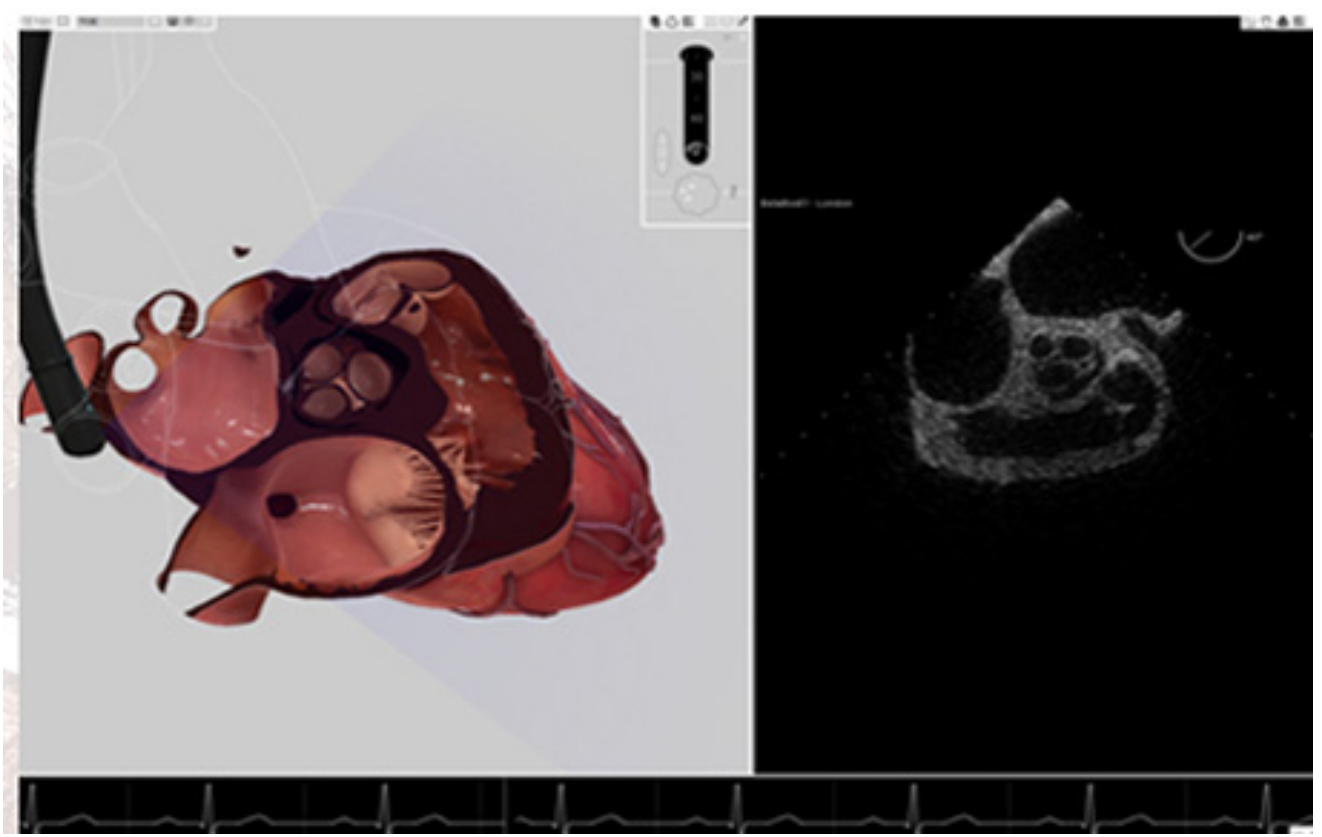

Figura 7. Simulador de ecocardiografía; muestra imágenes dinámicas del corazón desde todos sus ángulos.

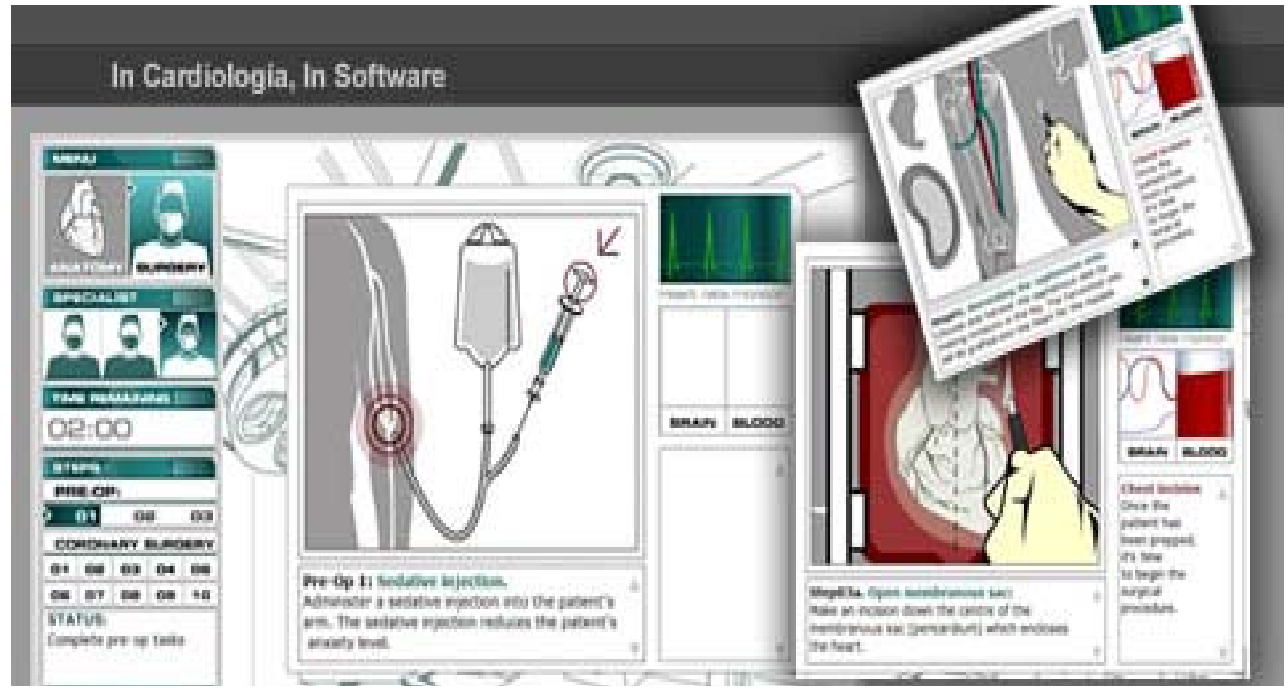

Figura 8. Simulador para cirugía cardiaca by-pass coronario. 


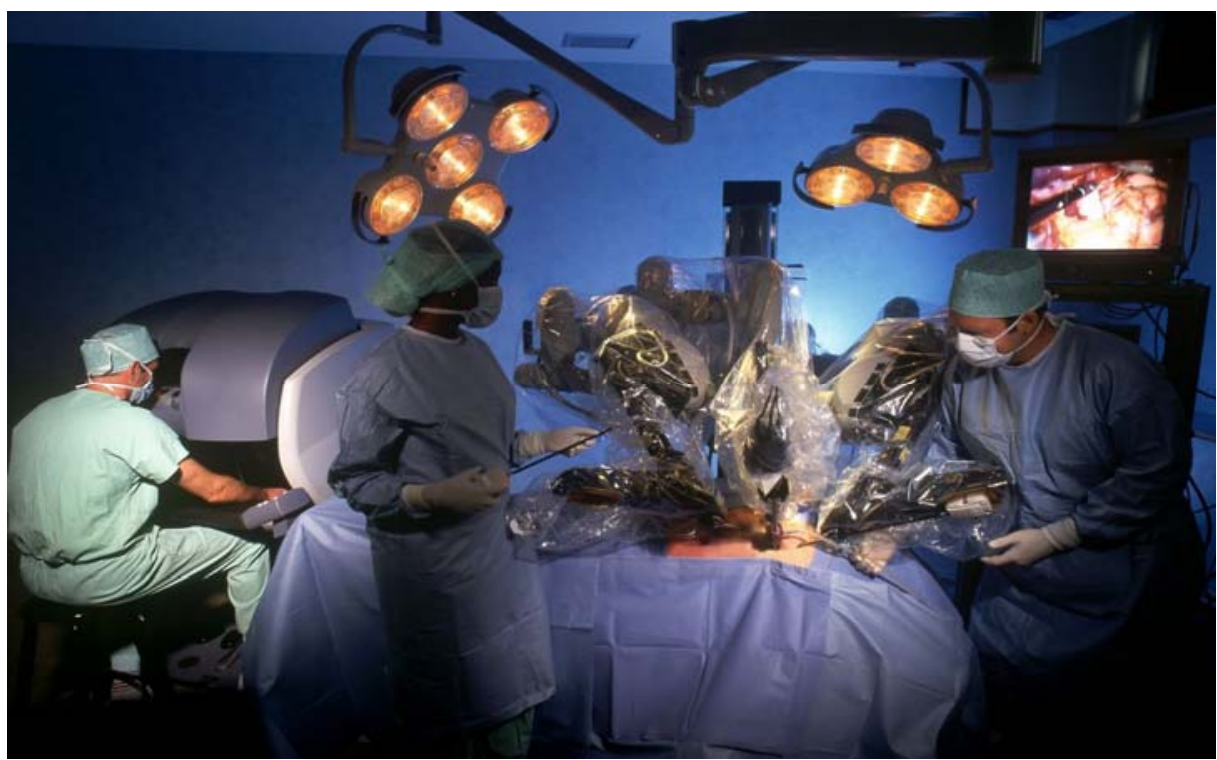

Figura 9. Cirugía general: sistema quirúrgico denominado "Da Vinci", permite al cirujano realizar intervenciones con gran precisión y seguridad desde una consola desde donde maneja unos brazos robotizados. Con este "Robot" se obtienen mejores resultados para el paciente.

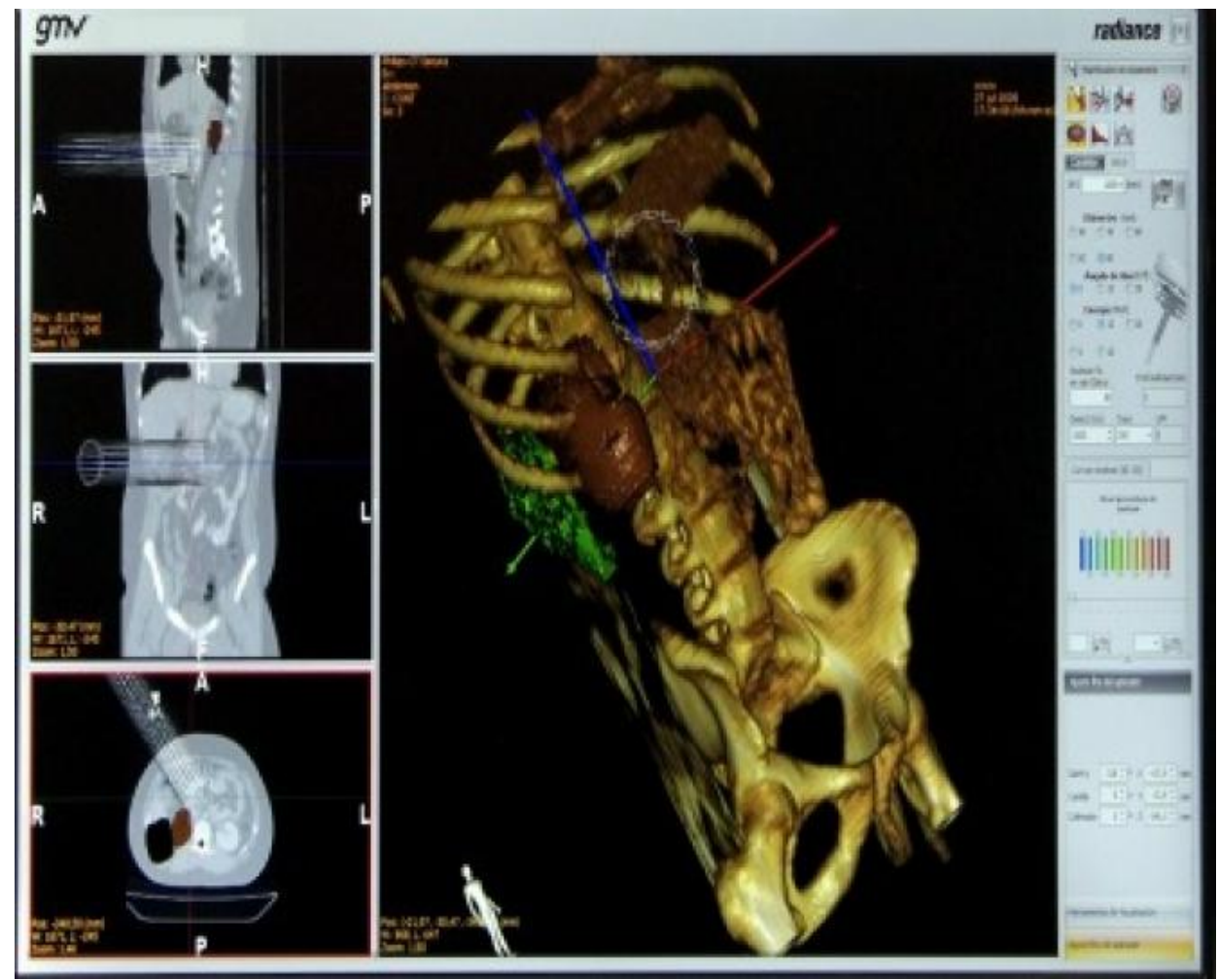

Figura 10. Imagen del simulador para cirugía oncológica del Hospital Gregorio Marañón. En él, los cirujanos pueden simular la cirugía previa a la intervención para minimizar los errores. 


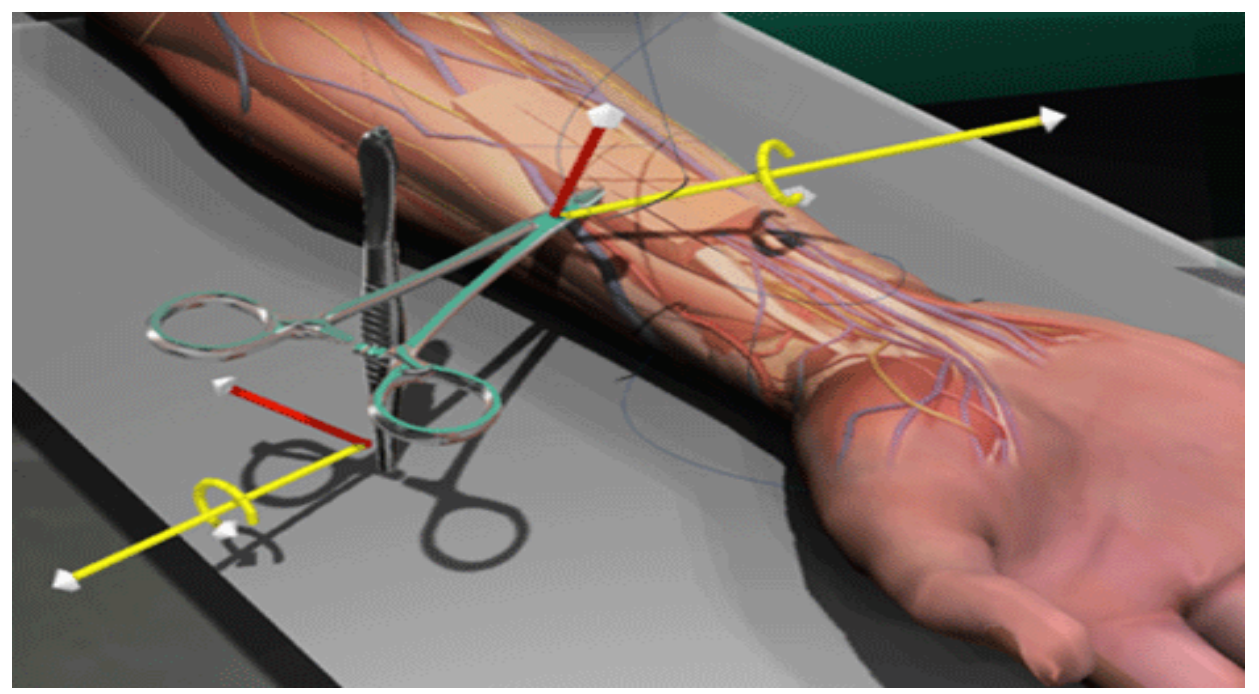

Figura 11. Simulador de cirugía, permite realizar suturas visualizando la anatomia del brazo.

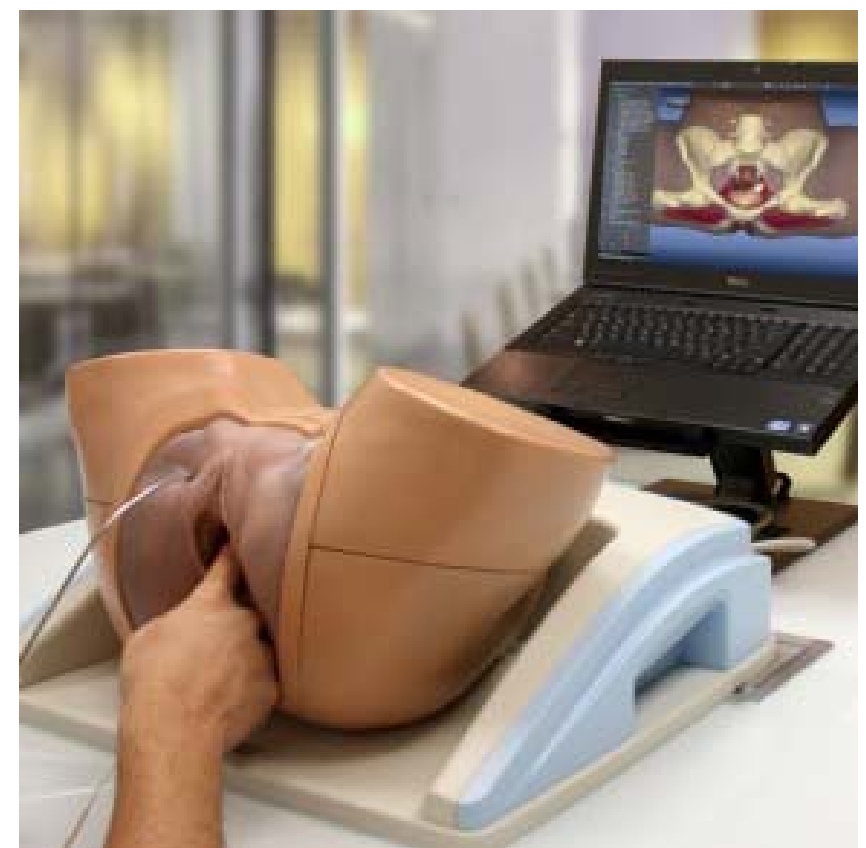

Figura 12. Simulador para exploración prostática en Urología. 


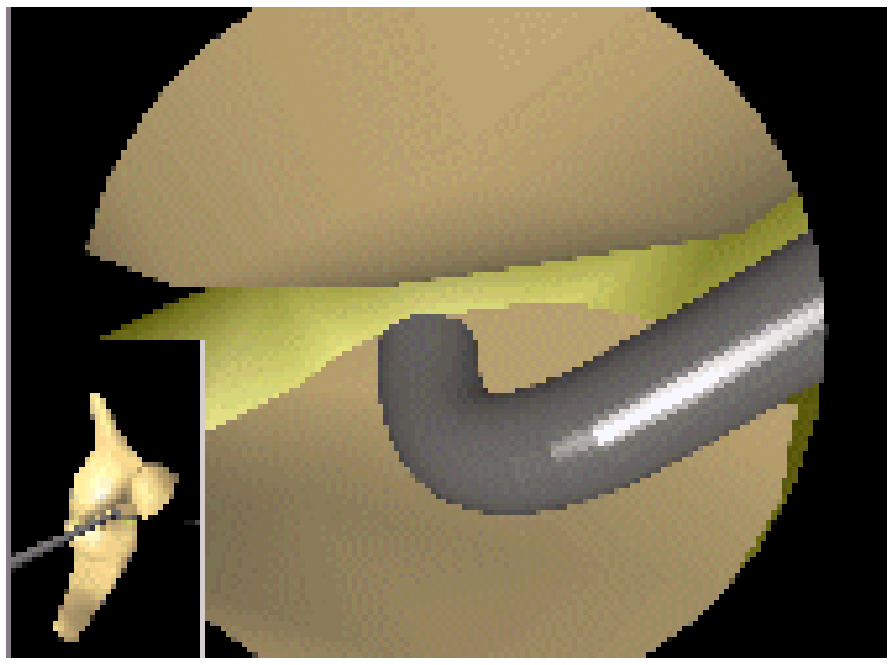

Figura 13. Traumatología: Simuladores de prótesis.

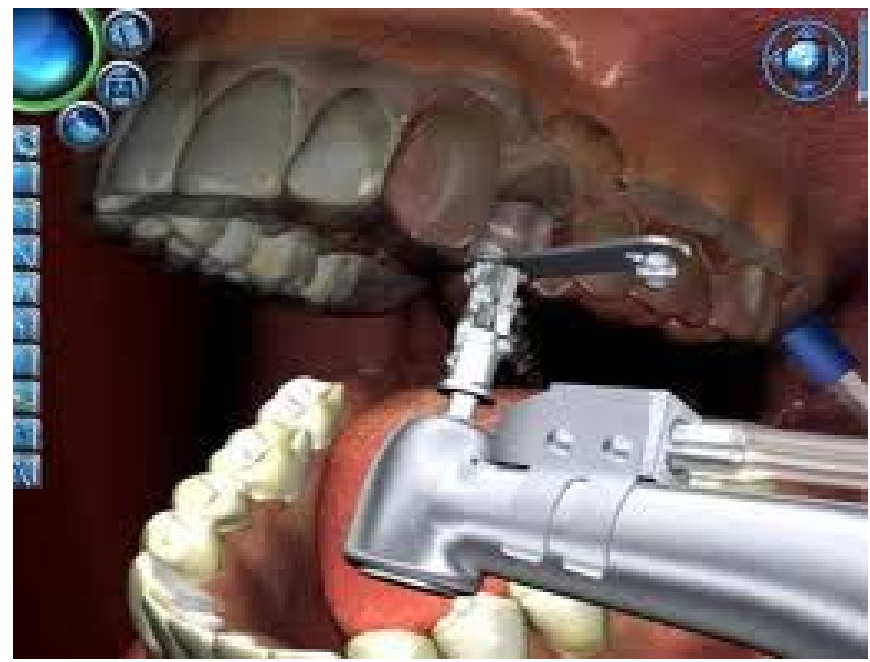

Figura 14. Odontología: Planificación de implantes. 

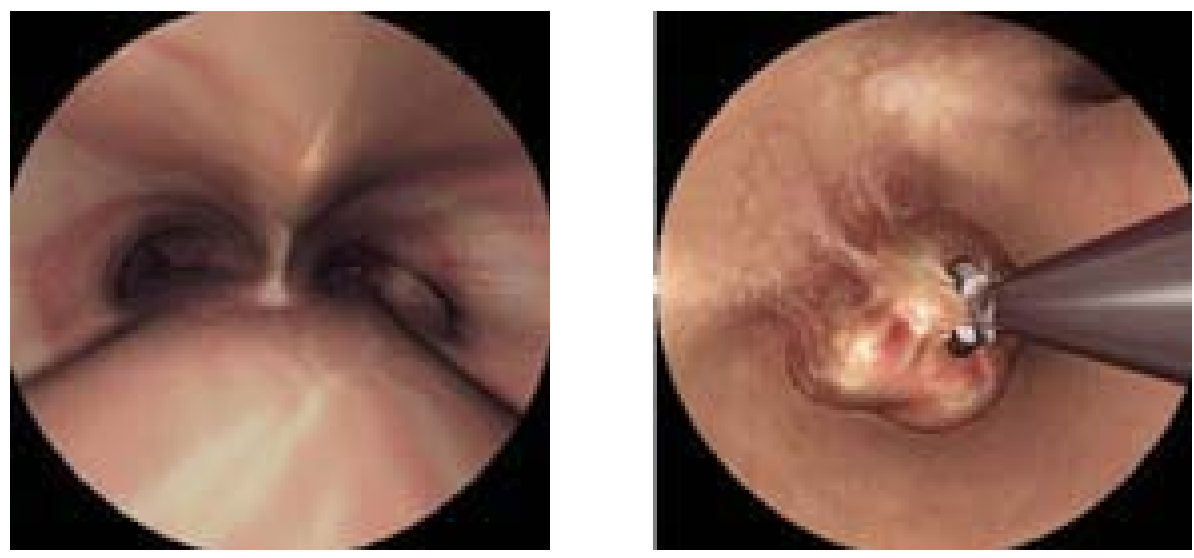

Figura 15. Simulador de broncoscopias.
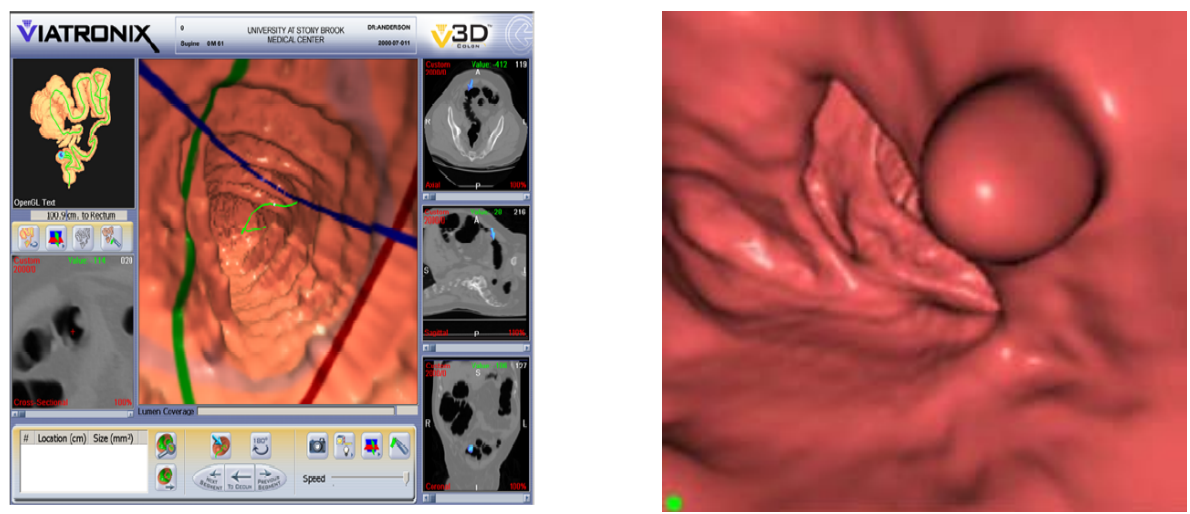

Figura 16. Colonoscopia virtual.
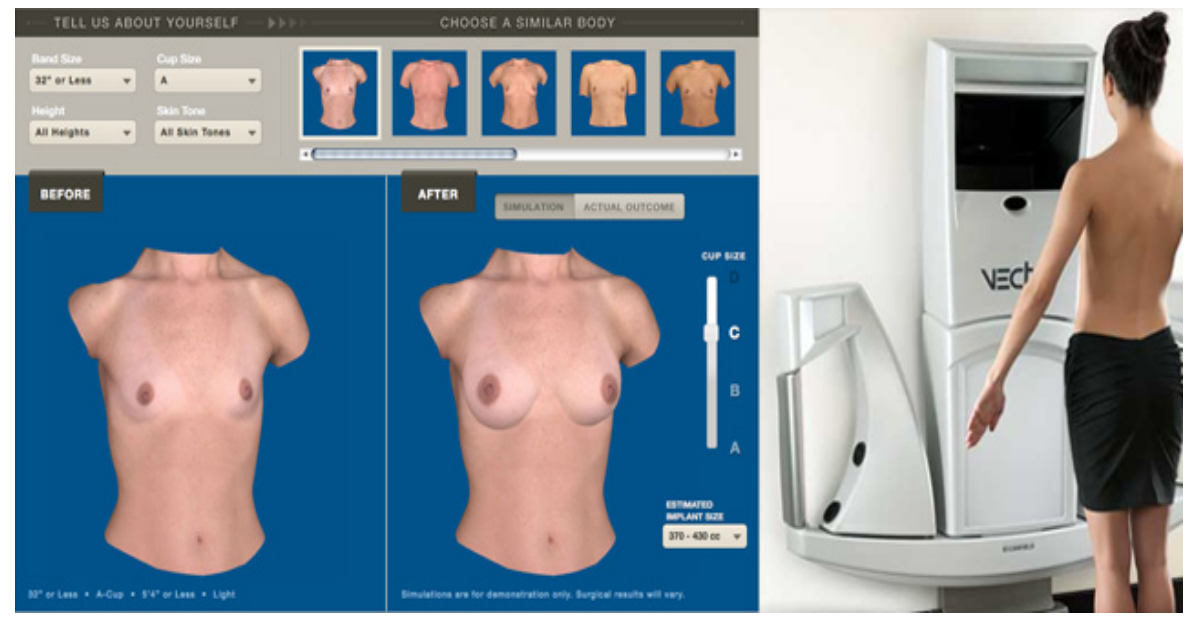

Figura 17. Simulador de cirugía estética. 


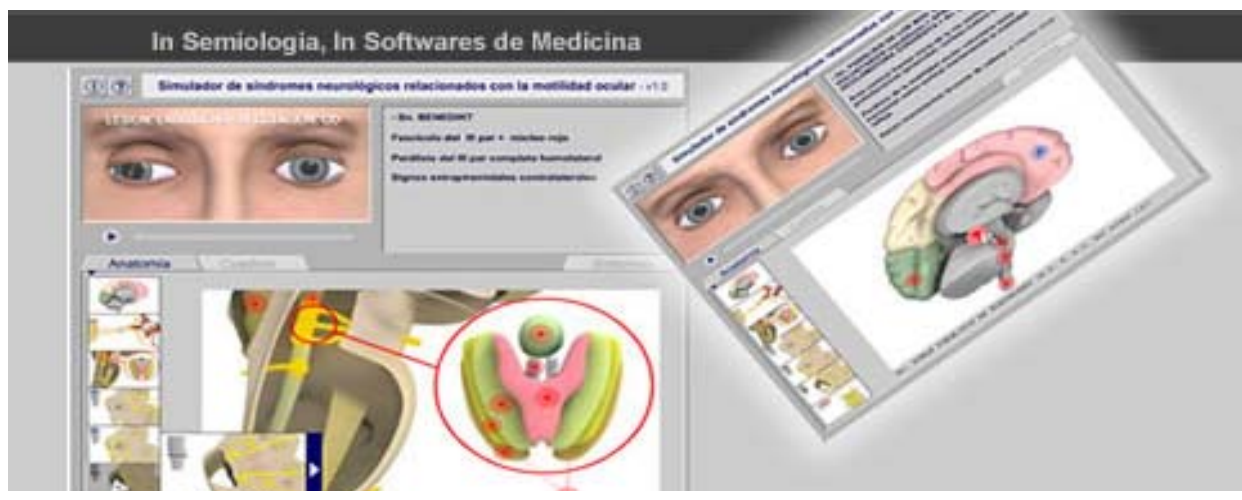

Figura 18. Simulador de neurología para valorar los síndromes de alteración de la motilidad ocular.

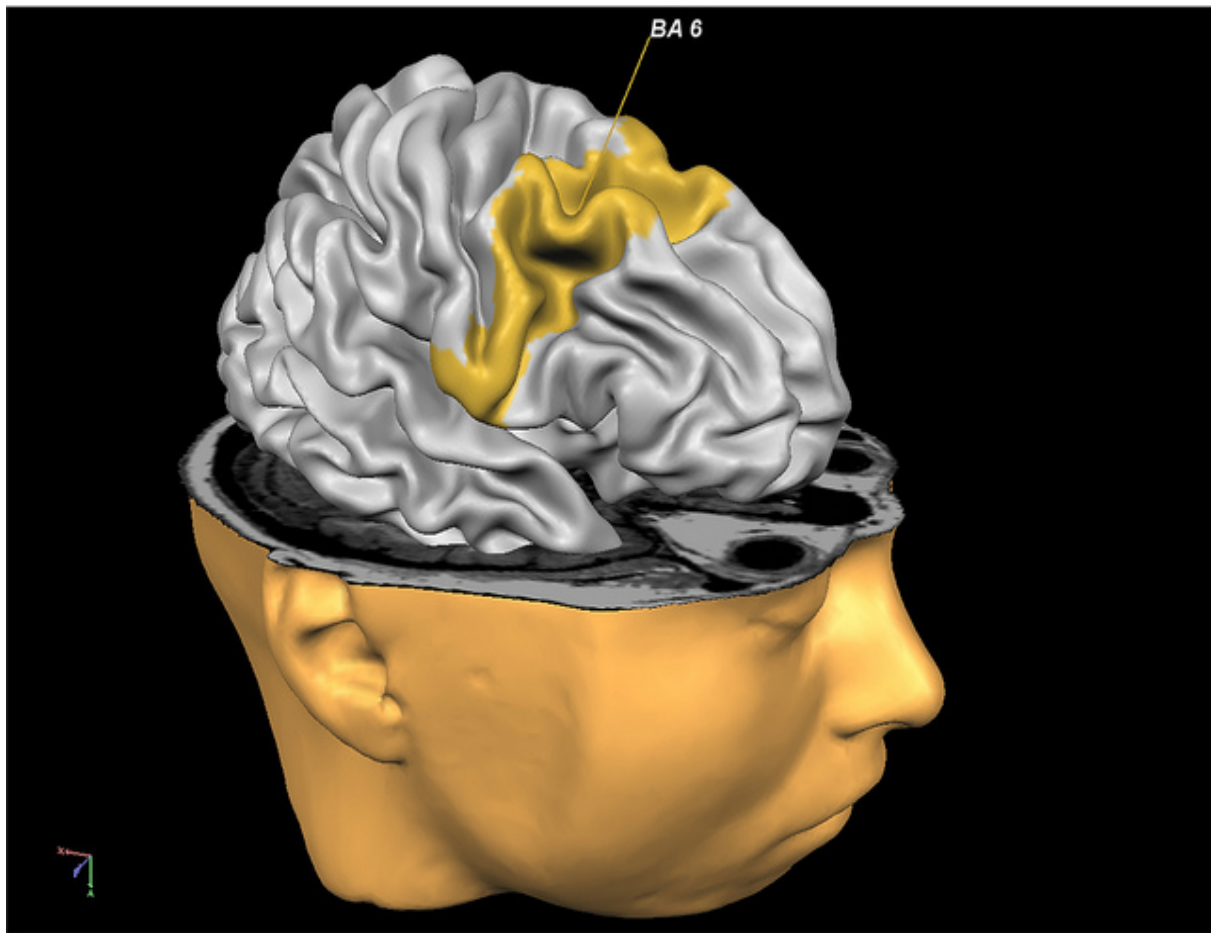

Figura 19. Neurocirugía: Cirugía por navegación. Permite delimitar con precisión los límites de la lesión y así evitar dañar estructuras y la funcionalidad del paciente. 


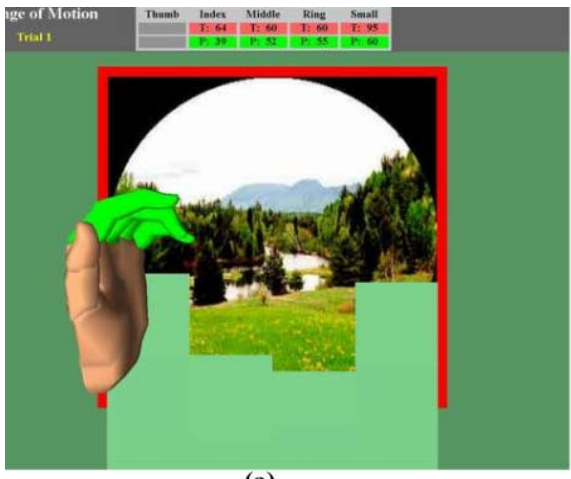

(a)

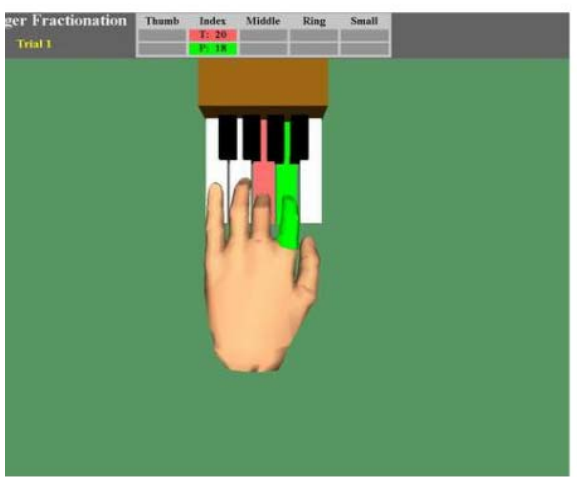

(c)

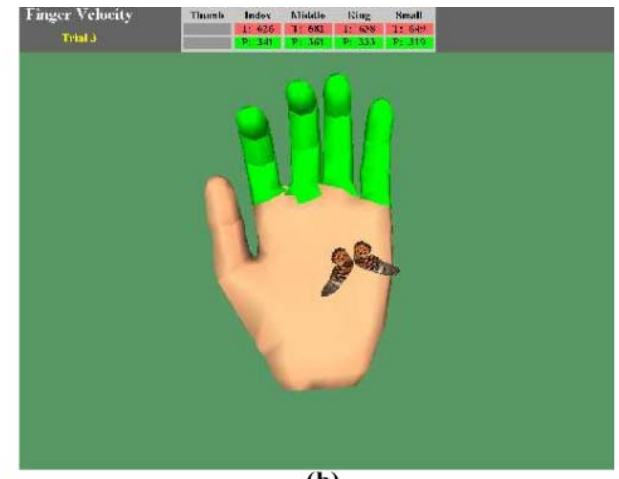

(b)

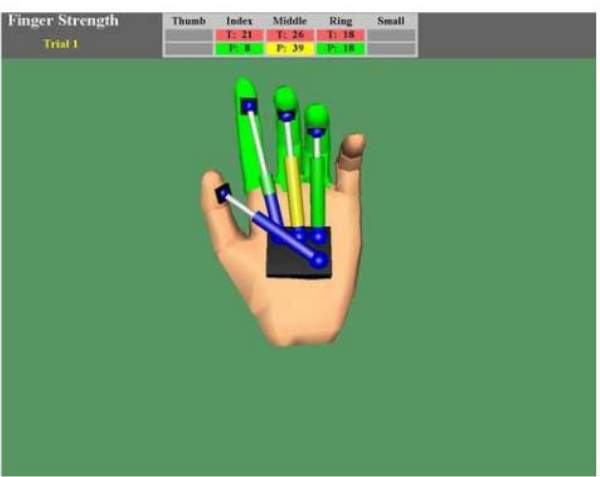

(d)

Figura 20. Simulador para Rehabilitación. 


\section{CAPITULO 2}

Planteamiento del Trabajo 

En el ámbito de la anestesiología, la formación de los profesionales ha experimentado numerosos cambios en la década pasada, desarrollándose subespecialidades como la anestesia cardiotorácica, neuroanestesia, anestesia obstétrica, pediátrica, cirugía mayor ambulatoria (CMA) y el tratamiento del dolor. De forma similar, se puede considerar el área de la anestesia regional y de los bloqueos nerviosos periféricos, como una subespecialidad (Blanco R. et al, 2011).

Se ha señalado, en el primer capítulo de esta tesis, como han crecido de forma significativa el número de publicaciones de relieve en el campo de la anestesia regional, y con ellas, se han introducido nuevas técnicas y procedimientos. La práctica de los bloqueos nerviosos periféricos ha ido en aumento desde las últimas décadas y este crecimiento en la demanda, se debe, entre otras muchas causas, a la mejor relación coste-beneficio, a la favorable recuperación postanestésica de los pacientes y al alto grado de satisfacción que manifiestan estos (Evans H. et al, 2005).

El uso de los ultrasonidos en la AR ha llegado de la mano del desarrollo tecnológico, con la aparición de sistemas más portátiles y sobre todo con una gran capacidad de resolución en la imagen; dando lugar a una creciente popularización en este tipo de técnicas, quedando relegadas a un segundo plano (en aquellos centros donde se dispone de ecografía) las técnicas anteriores o "ciegas", en las que no se visualizaban las estructuras (Alonso P. et al, 2009).

Como contrapartida, al anestesiólogo se le plantean una nueva serie de retos, entre ellos la familiarización con los sistemas de ultrasonidos y la necesidad de un conocimiento exhaustivo de la anatomía seccional, no siendo suficientes los conocimientos topográficos de las regiones que se van a bloquear (Blanco R. et al, 2011).

En la $A R$, al igual que en otros procedimientos médicos de exploración y análisis, el entrenamiento previo es un requisito para el éxito y seguridad. De hecho, se atribuyen complicaciones con la práctica de estas técnicas debido a un inadecuado aprendizaje, o al déficit de este durante la formación del especialista (Hadzic A. et al, 2002). 
Este trabajo intenta dar respuesta a estos retos, por un lado ayudar en la formación y familiarización con los ultrasonidos (interpretar imágenes de nervios, vasculares, artefactos...) y por otra parte, facilitar el conocimiento de la anatomía que va a permitir una mejor realización del bloqueo. Para conseguir este objetivo didáctico, el procedimiento tecnológico que se va a desarrollar, se presentará en un formato muy atractivo y visual, con la sensación de tener a un paciente a "disposición" del usuario en cualquier momento, facilitando asi la formación en anestesia regional.

Se revisaron las bases de datos bibliográficas accesibles a través de PUBMED y Biblioteca Cochrane Plus (www.cochrane.org) y la mayoría de los libros publicados hasta el año 2012 de anestesia regional y ecografía en español e inglés, considerados como de gran interés por el currículo de sus autores o la originalidad del mismo.

En Pubmed se utilizaron varios filtros de búsqueda. En un primer momento, se emplearon múltiples palabras clave como anestesia y ecografía, simulación en medicina/anestesia, historia de la medicina/anestésicos locales/anestesia regional, complicaciones anestesia regional, bloqueos en anestesia regional, bloqueos nerviosos periféricos con neuroestimulación, revisiones anestesia regional y ecografía, e-learning y nuevas tecnologías en educación y medicina. Los registros resultantes fueron limitados considerándose sólo aquellos bajo las siguientes categorías: anestesia regional y ecografía, simulación en anestesiología y e-learning en anestesiología o que fueran revisiones, ensayos clínicos y estudios controlados y randomizados. Finalmente, se realizó la última selección en función del contenido del título y las palabras clave de los registros obtenidos.

En los capítulos anteriores, se han expuesto las ventajas que supone la utilización de la ecografía en el campo de aplicación de los bloqueos para la anestesia regional, basadas en la evidencia de las publicaciones médicas encontradas. También, se ha comentado la importancia de las nuevas tecnologías en la enseñanza médica; así como de la simulación y de la imagen médica tridimensional. A la vista de la revisión bibliográfica realizada, existen muchas aplicaciones informáticas que analizan con detalle la anatomía radiológica del cuello y de las extremidades. Varias de estas aplicaciones son atlas anatómicos que se pueden considerar como "fríos" o "estáticos"; en contraposición, lo que aquí se presentará será 
"dinámico" e "interactivo". Se tratará de una aplicación abierta, de bajo coste, para la representación de escenas virtuales en plataformas Windows ${ }^{\circledR}$.

Existe la necesidad de formación, tanto de los residentes como de los especialistas en el campo de la anestesiología y más concretamente en los bloqueos periféricos guiados por ecografía. La forma de aprendizaje y de formación médica como el que proponemos en este trabajo de tesis doctoral, hace que se contemple como una alternativa y un complemento a las técnicas de enseñanza empleadas hasta el momento actual.

Durante el tiempo que lleva empleándose la ecografía en la anestesia regional, se ha observado que una de las mayores dificultades que encuentran quienes se inician en la técnica, es el establecimiento de la relación que existe entre la imagen que se ve en la pantalla del ecógrafo y la propia anatomía del paciente (Alonso P. et al, 2009). Esta imagen ecográfica no es más que un corte o sección anatómica, habitualmente transversal, de la zona que se está explorando (Alonso P. et al, 2009).

Para facilitar esta integración entre ecografía y anatomía de forma práctica, en este trabajo de tesis se obtendrán una serie de imágenes ecográficas de las zonas de los miembros superior e inferior y el cuello, donde se verán los plexos nerviosos o nervios individuales en las cuales se puede realizar un bloqueo (anestesia) con facilidad. En esta misma zona, se realizará un corte anatómico axial, mediante resonancia magnética, de forma que el usuario de nuestro sistema, pueda relacionar de forma intuitiva la anatomía seccional del paciente con la imagen ecografía.

El uso de las simulaciones para el entrenamiento del estudiante o profesional en las diferentes áreas de la medicina han demostrado ser herramientas eficaces que ayudan a elevar la calidad de la docencia (Grottke O. et al, 2009; Pales JL. et al, 2010; Juanes JA. et al, 2010 y 2011). El procedimiento tecnológico que proponemos, presentará un visor anatómico 3D que permitirá valorar los diferentes sistemas neuromusculares del cuello y de la extremidad superior e inferior, dependientes del plexo cervical, braquial y lumbar/lumbosacro respectivamente. 
Este visor constituirá un verdadero atlas dinámico e interactivo para el estudio de los diferentes sistemas neuromusculares de las partes citadas.

El estudio con RM de alta resolución permitirá identificar las principales estructuras de las extremidades obteniendo una excelente visualización anatómica para su identificación, delimitación y posterior reconstrucción en 3D. Por tanto, se espera que el procedimiento tecnológico sea un buen método de visualización 3D, teniendo como referencia la sección de RM en el plano axial.

La aplicación que nos proponemos desarrollar, permitirá visualizar imágenes anatómicas y radiológicas (ecográficas y de RM) que pueden tener multitud de aplicaciones (aprendizaje de bloqueos guiados por ecografía, aprendizaje de la anatomía en estudiantes de carreras sanitarias, radiólogos, traumatólogos, rehabilitadores...), e incluso, puede ser útil en residentes de neurofisiología (puesto que también habrá un apartado en el que se podrán visualizar videos de pacientes reales en los que se observa la respuesta motora a la neuroestimulación de varios territorios nerviosos, lo cual le dará mayor realismo a la aplicación).

Ante estas consideraciones previas, nos planteamos un trabajo para optar al Título de Doctor por la Universidad de Salamanca, bajo el título: "Procedimiento tecnológico de visualización anatómica y ecográfica para la formación en anestesia regional”, con el cual buscamos los siguientes objetivos:

1‥- Llevar a cabo una generación volumétrica de estructuras anatómicas (del cuello y de las extremidades) a partir de secciones del "Visible Human Project", que ilustren iconográficamente las estructuras en su morfología 3D en diferentes posiciones espaciales y que sirvan de apoyo en los procesos formativos.

2‥- Desarrollar un sistema para la simulación de una exploración ecográfica sobre un paciente virtual y establecer la correlación de dicha exploración tanto con un modelo anatómico tridimensional, como con un corte seccional de RM.

3․-- Mostrar la neuroestimulación en la práctica clínica habitual de ese territorio sobre el que se va a realizar el bloqueo periférico. 
4o.- Facilitar la compresión e interpretación de la sonografía básica para así, con la utilización repetida de esta herramienta, obtener óptimos resultados durante la realización de un bloqueo anestésico.

5o.- Proporcionar una colección iconográfica ecográfica y de RM del aparato locomotor y su correlación con la imagen 3D, que sirva de apoyo a la docencia. Ser una aplicación altamente didáctica para la enseñanza de alumnos de la rama sanitaria, residentes, adjuntos de anestesia y otras especialidades como la radiología.

60.- Reducir los tiempos de aprendizaje en anestesia regional de los residentes de anestesiología.

70.- Valorar su aplicación en la práctica clínica habitual mediante el grado de satisfacción de los usuarios al utilizar este procedimiento informático. 



\section{Capitulo 3}

MATERIAL Y MÉTOdOS 



\section{I. MATERIAL}

\section{I.I. PARTICIPANTES Y APARATOS}

Para la adquisición de las imágenes ecográficas y de RM de los plexos y nervios periféricos del cuello y las extremidades se exploraron e hicieron estudios de dos pacientes modelo (de edades 34 y 42 años y ambos sexos). Ambos sujetos voluntarios, fueron elegidos por presentar unas características adecuadas para la visualización de diferentes estructuras nerviosas mediante ecografía, para lo cual se realizó una exploración previa. Se realizaron fotografías de superficie del modelo masculino. Dichas fotos de superficie, tanto del cuello como de la extremidad superior e inferior, sirvieron para la clasificación de los grupos de bloqueo. Se obtuvieron las imágenes de proximal a distal que por conveniencia y comodidad para el explorador fueron del lado izquierdo del cuerpo. En la imagen del cuello, por ejemplo, se incluyeron los bloqueos interescalénico, supraclavicular e infraclavicular. Con otras 3 imágenes se completó la extremidad superior izquierda, asignando a cada imagen los bloqueos de los nervios que se pueden localizar en la misma. De la extremidad inferior izquierda se obtuvieron 5 imágenes desde la región inguinal al tobillo, tanto visiones anteriores como posteriores para visualizar todos los trayectos nerviosos.

Para la adquisición de imágenes para la realización del visor ecográfico se utilizó el ecógrafo portátil Aplio Toshiba MX y el ecógrafo de Esaote Mylab 25 (Fig. 21). Este último se empleó para obtener los trayectos de los nervios con una sonda lineal multifrecuencia de 5 a $12 \mathrm{Mhz}$ en la mayoría de los bloqueos. La sonda convex multifrecuencia de 2,5 a 6,5 Mhz se utilizó para la realización del bloqueo en los que el nervio estaba más profundo (ciático subglúteo). Tras localizar el punto óptimo de visión ecográfica de los nervios, se seleccionó la mejor imagen estática con el ecógrafo de Toshiba, ya que dicho ecógrafo ofrece mayor calidad de imagen. Se realizó y grabó el seguimiento de los nervios a través de todos los trayectos a estudio de cada imagen de la anatomía de superficie (del cuello a la zona supraclavicular, de axila a codo y de este a muñeca; en extremidad inferior a nivel inguinal, de la zona subglútea a hueco poplíteo y de aquí al tobillo). Se creó un atlas ecográfico. El cursor se transformó en la sonda ecográfica y se crearon los grupos de bloqueo por regiones de superficie. 
Para la adquisición de imágenes de RM se utilizó un equipo de 1.5 Teslas (T) marca Signa Horizon General \& Electric. Los cortes no se obtuvieron de forma aleatoria, si no que se correspondiesen con las zonas de bloqueo (como por ej. en el cuello en la zona del interescalénico). El protocolo de adquisición consistió en secuencias centradas en cuello y en extremidades en el plano axial, sagital y coronal con los siguientes parámetros para musculoesquelético: FSE (fast spin-echo) T1 (tiempo de relajación longitudinal), FSE T2 (tiempo de relajación transversal), STIR (short time inversión recovery), DP (densidad protónica), Gradiente T2, Repetition Time $=412 ;$ Echo Time $=6.4 ;$ Inversion Time $=300$; Thickness $=4 \mathrm{~mm}$; Slice Spacing $=0.8-1 \mathrm{~mm} ;$ Matrix $=256 \times 520 ;$ Flip Angle $=90$ ․ El formato de los ficheros de datos originales fue DICOM (Digital Imaging and Communication in Medicine). Se obtuvieron vóxeles cúbicos de $0.8 \mathrm{~mm}$ y dimensiones de $276 \times 276 \times 200$ px. Por motivos de seguridad, se confirmó que el sujeto no llevase marcapasos o materiales ferromagnéticos durante la exploración. Se le explicó que durante el procedimiento debería permanecer inmóvil. Por conveniencia todos los estudios son del lado izquierdo del paciente, ya que resulta más cómodo para el explorador.

Posteriormente seleccionamos las imágenes de ecografía y RM del mismo individuo, de forma que la anatomía se correspondiese en un corte y en otro. Sobre estos cortes se procedió a resaltar y dibujar mediante un programa informático las estructuras anatómicas identificadas, especialmente las implicadas en el bloqueo nervioso.

Para la obtención de los videos de neuroestimulación, se seleccionaron pacientes que iban a ser intervenidos. Se les pidió consentimiento informado a aquellos que se iban a someter a la grabación de dicho procedimiento. Se utilizó el Neuroestimulador y agujas ambos de la marca Vigon ${ }^{\circledR}$ con una frecuencia de impulso de 2-3 $\mathrm{Hz}$ y un tiempo de duración del impulso de 0,3 ms. La intensidad de estímulo ideal para la búsqueda de las contracciones musculares producidas por la estimulación del nervio fue de 1-1,5 mA, reduciéndolo a 0,5 mA en la fase de localización.

Las exploraciones radiológicas se llevaron a cabo, previo consentimiento informado y sin remuneración económica por su participación, en los servicios de radiodiagnóstico del Hospital Clínico Universitario de Salamanca. 
El trabajo se acompañó de una encuesta de satisfacción, con respecto al valor formativo de la visualización combinada de ecografía- RM- visor 3D para realizar bloqueos periféricos en anestesia regional, dirigida a evaluar la percepción subjetiva, tanto de residentes de tercer y cuarto año que ya habían tenido "contacto" con procedimientos de anestesia regional, como adjuntos con varios años de ejercicio. Este estudio empírico sobre la eficacia del visor estuvo formado por una muestra de 75 anestesiólogos de diferentes hospitales españoles.

Esta encuesta de validación contiene 8 ítems y utiliza la escala Likert como herramienta de medición (1-Totalmente en desacuerdo, 2-En desacuerdo, 3-Ni de acuerdo ni en desacuerdo, 4-De acuerdo, 5-Totalmente de acuerdo). Las entrevistas fueron anónimas y distribuidas tanto en formato papel, como a través de correo electrónico a varios centros españoles (ver gráfica más adelante).

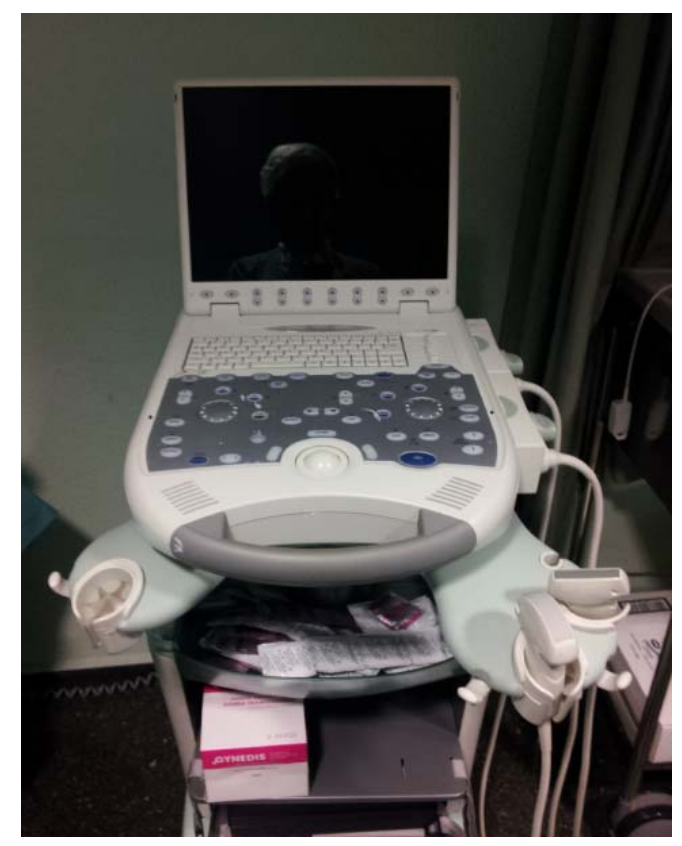

Figura 21. Imagen del Ecógrafo portátil Mylab 25 usado para las exploraciones. 


\section{I.2. SOFTWARE}

Empleado en la generación volumétrica de estructuras de las extremidades:

- Se utilizaron múltiples secciones axiales de $1 \mathrm{~mm}$ de espesor procedentes del cadáver de un varón y de alta resolución, con un tamaño original de 576 x 768 px, obtenidas a partir del Visible Human Male CD Version 2.0 de la Nacional Library of Medicine de EEUU, bajo licencia autorizada número HW1-020645 para uso con fines docentes y de investigación.

- Para la generación volumétrica no probabilística de estructuras anatómicas se utilizó Autodesk ${ }^{\circledast}$ Maya $^{\circledast}$. Es un software de animación en 3D que proporciona un conjunto completo de funciones creativas con herramientas para realizar animación, modelado, simulación, renderización, rastreo de movimiento y composición dentro de una plataforma de producción sumamente ampliable. Maya ${ }^{\circledR}$ ayuda a cumplir los exigentes requisitos de producción con herramientas específicas para creación de efectos visuales, desarrollo de juegos, postproducción y otros proyectos de animación en 3D.

- La adaptación de tamaño y formato de las imágenes se realizó mediante Pixresizer Software version $2.0 .4^{\circledR}$. El formato final fue jpg de 380 píxeles de ancho, optimizadas para la presentación en resoluciones de pantalla 800 × 600 píxel.

- La delimitación del área de respuesta para la localización de la estructura diana de cada tarea se realizó con Image Mapper versión $1.0^{\circledR}$. Dicho área se definió a partir de las coordenadas $(x-y)$ establecidas para cada una de las imágenes empleadas, que oscilaron de 50 a 500 coordenadas según la estructura.

- Se empleo de software Visual C++ para la programación de todo nuestro desarrollo informático.

\section{I.3. CLASIFICACIÓN DE LOS BLOQUEOS Y REFERENCIAS BIBLIOGRÁFICAS}

Se clasificaron los bloqueos de la región del cuello, la extremidad superior e inferior. Para la terminología/nomenclatura anatómica se utilizó la nómina de la Federative Committee on Anatomical Terminology (FACT) (1998). Thyeme. Stuttgart. 
El sistema de citas y referencias bibliográficas en este trabajo se basa en las normas y convenciones establecidas por el Comité Internacional de Editores de Revistas Biomédicas (ICMJE), la Biblioteca Nacional de Medicina de los EE.UU. (NLM) disponibles en: http://www.nlm.nih.gov/bsd/uniform_requirements, así como en la página web de la Sociedad Española de Anestesiología, Reanimación y Terapia del Dolor. Coinciden con la Normativa de la International Standarization Organization (Documentation Références bibliographiques- contenu, forme et structure. Norme international ISO 690:1987. 2a ed. Genève: ISO, 1987, 11 p.).

\subsection{PROCEDIMIENTO}

\subsection{INSTALACIÓN DE LA APLICACIÓN}

El procedimiento tecnológico de visualización anatómica y ecográfica para la formación en anestesia regional, se ha diseñado para formato $C D$ y para su instalación en ordenadores con los siguientes requisitos del sistema:

Hardware (mínimo):

- Pantalla de 1280 × 800 con tarjeta de vídeo a 512 MB o superior.

- Procesador de $1 \mathrm{GHz}$ o superior.

- $1 \mathrm{~GB}$ de memoria RAM.

- 1 GB de espacio libre en el disco duro.

- Unidad de DVD-ROM o CD-ROM.

Hardware (recomendado):

- Pantalla de 1280 × 800 con tarjeta de video a 1 GB o superior.

- Procesador de $1.2 \mathrm{GHz}$ o superior.

- 2 GB de memoria RAM.

- 2 GB de espacio libre en disco duro.

- Unidad de DVD-ROM o CD-ROM. 
Software:

- Sistema operativo Windows XP, Vista o Windows 7, 32 y 64 bits.

- Software de Direct 9.0 o superior.

- Microsoft. NET Framework 3.0 o superior.

- Adobe Acrobat Reader 5.0 o superior.

- Adobe Flash Player 10.0 o superior.

\subsubsection{DESARROLLO INFORMÁTICO}

La aplicación informática está desarrollada para plataformas Windows ${ }^{\circledR}$ y programada en Visual $\mathrm{C}++$, el cual, como entorno integrado de desarrollo nos permitió realizar una programación orientada a objetos (POO) bajo los lenguajes de programación $\mathrm{C}$, $\mathrm{C}++$ y $\mathrm{C}++/ \mathrm{CLI}$, conjuntamente con el sistema de desarrollo SDK (también denominado APIApplication Programming Interface) de Windows.

Visual C++ nos permitió el desarrollo y la depuración de código escrito para las API's de Microsoft Windows, DirectX y tecnología Microsoft .NET Framework.

Por otra parte, al tratarse de un entorno integrado, Visual C++ utiliza otras herramientas complementarias de desarrollo:

- Editor orientado a la codificación $\mathrm{C} / \mathrm{C}++$.

- Compilador/Enlazador incremental, que aceleró el proceso de construcción de nuestro desarrollo informático.

- Depurador visual, que modifica el contenido de variables y áreas de memoria.

- Visor de datos (browser) que permitió fácilmente controlar dependencias y referencias a funciones, datos, etc. Además se visualiza la jerarquía de las clases utilizadas en el programa.

- Herramientas adicionales como un analizador de ventanas (Spy ++) o un trazador de funciones MFC (Microsoft Foundation Classes).

Visual C++ incluye la librería de clases MFC que permite crear y gestionar de manera intuitiva componentes típicos de Windows. Esto es, la MFC es una implementación que 
utiliza el API encapsulando todas las estructuras y llamadas a funciones en objetos fáciles de utilizar. En este sentido y, basándose en la potencia de la MFC, Visual C++ se convierte así en un generador de programas $\mathrm{C}++$ para Windows.

De esta manera, el lenguaje de programación que hemos utilizado para esta aplicación informática para bloqueos anestésicos regionales, es compatible en la mayor parte de su código con este lenguaje, a la vez que su sintaxis es exactamente igual.

Para crear cualquier programa con Visual $\mathrm{C}++$ debemos comenzar creando un proyecto para él, codificando y añadiendo los módulos necesarios a dicho proyecto, y definiendo los recursos asociados.

En Visual $\mathrm{C}++$, la construcción de nuestro procedimiento informático se inscribe dentro del concepto de proyecto (workspace). Un proyecto define los pasos a seguir para alcanzar la construcción de un objetivo (un programa, una DLL, etc.), en realidad es un concepto análogo a lo que se conoce como "makefile" en otros entornos típicos de desarrollo en $\mathrm{C}$. En realidad, Visual $\mathrm{C}++$ genera para cada proyecto dos ficheros que lo definen, el fichero de workspace (con extensión wsp) y un makefile (con extensión mak) estándar que permitiría la utilización del mismo proyecto en otro entorno distinto.

Desde el punto de vista funcional, el proyecto contiene referencias a cada uno de los ficheros fuentes $(\mathrm{C} / \mathrm{C}++$, con extensiones $c$ y $c p p$ respectivamente), objetos, librerías o ficheros de recursos (extensión $r c$ ) que se deben utilizar para construir el objetivo final del proyecto.

Nuestro desarrollo informático, tiene además estas características:

- No utiliza navegador.

- Emplea estándares de manera que la información puede ser visualizada y tratada en las mismas condiciones, con las mismas funciones y con el mismo aspecto en cualquier ordenador.

- El acceso no será restringido ni selectivo. 
- Incluye como elemento básico una interface gráfica común, con un único punto de acceso, de manera que en ella se integran los diferentes elementos multimedia que constituyen el procedimiento tecnológico: texto, gráficos, vídeo, animaciones, etc.

- Realiza la presentación de la información en formato hipermedia.

El interface de usuario se distribuyó en diferentes partes: posicionamiento del transductor sobre el paciente, visualización de la imagen ecográfica del punto óptimo del bloqueo anatómico y descripción anatómica de las estructuras visibles. Por último, correlación con una sección de RM y pantalla 3D de la zona anatómica selecciona para el bloqueo (cuello o extremidades), para poder interactuar dinámicamente con los modelos reconstruidos.

\subsubsection{ADQUISICIÓN DE IMÁGENES PARA LA REALIZACIÓN DEL VISOR ANATÓMICO}

Se han empleado imágenes provenientes de diferentes modalidades de técnicas (RM y ecografía) y secciones de cadáver del "Visible Human Project" (VHP) (Figs.22 y 23).

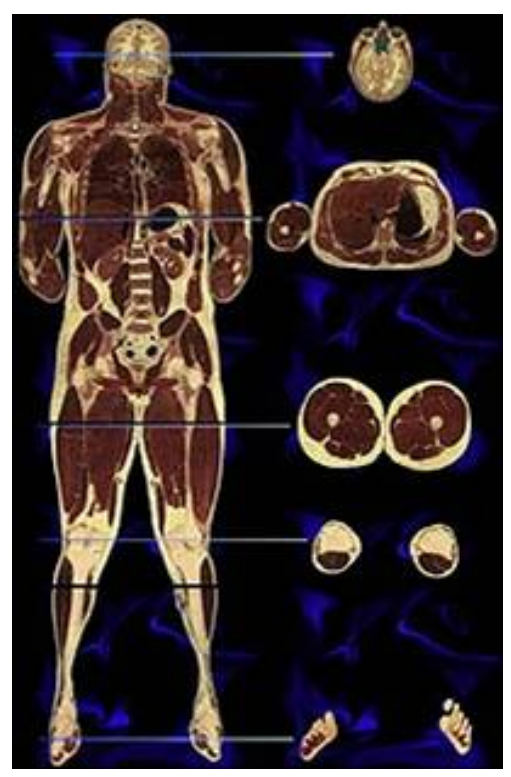

Figura 22. Corte coronal y cortes axiales a diferentes niveles procedentes del VHP. 


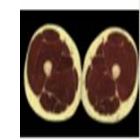

HI2058

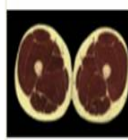

Hi2059

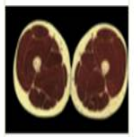

H12060

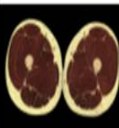

HI2067

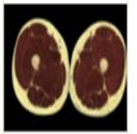

Hi2061

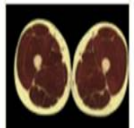

HI2068

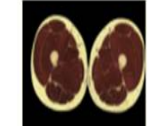

HI2069

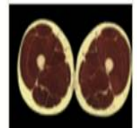

$\mathrm{H}[2070$
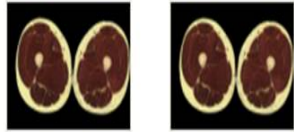

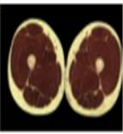

HI2064

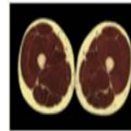

HI207!
HI2075

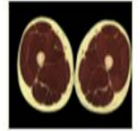

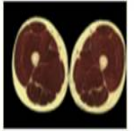

HI2076
HI2077

HI2078

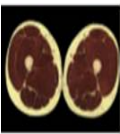

HI2072

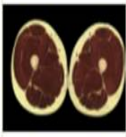

HI2073

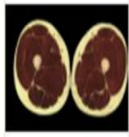

HI2074
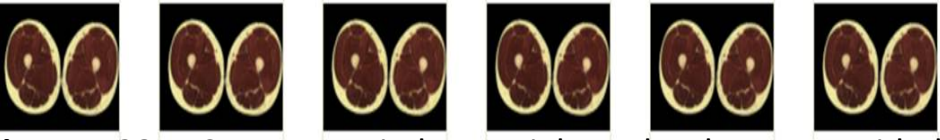

de la extremidad

axiales procedentes del VHP.

En el procedimiento tecnológico para el aprendizaje de la ecografía en anestesia regional, como se ha mencionado, se seleccionaron las imágenes de ecografía y RM del mismo individuo, de forma que la anatomía se correspondiese en un corte y otro, independientemente de la técnica radiológica utilizada. No obstante, la práctica imposibilidad de realizar exactamente la misma sección con la ecografía y la RM, así como la variación anatómica que produce la presión de la sonda de ultrasonidos sobre las diferentes estructuras, hacen que no siempre esta correspondencia sea exacta, aunque si totalmente real. Sobre los cortes del VHP se procedió a resaltar y dibujar mediante el programa informático Maya ${ }^{\circledR}$ las estructuras anatómicas, especialmente las implicadas en el bloqueo nervioso.

\subsubsection{SegMENTACIÓN Y DELIMITACIÓN DE LAS ÁREAS DE INTERÉs (ROIS)}

La segmentación y delimitación de las ROIs consistió en la subdivisión de cada imagen anatómica adquirida en regiones homogéneas. En nuestro caso se usó un kit de herramientas de aplicaciones de interacción de imágenes médicas que se desarrolló para ayudar a la manipulación de datos, registro y la segmentación. 
Se creó una herramienta para la simulación de los cordones nerviosos y vasos (Fig. 24). Cada uno de estos nodos funcionales y curvas representan secciones del nervio definidas por los puntos de control, que pueden ser colocados en el mundo virtual utilizando referencias anatómicas.

\subsubsection{Generación de Modelos TRIDIMensionales}

En la reconstrucción del trayecto nervioso se obtuvieron polilíneas. Para cada nervio y vaso se colocó una serie de puntos de referencia (landmarks) a lo largo de su trayecto. Los diferentes landmarks se unieron mediante polilíneas que fueron utilizadas como base para generar una secuencia de cilindros de pequeño diámetro representando el trayecto nervioso y vascular.

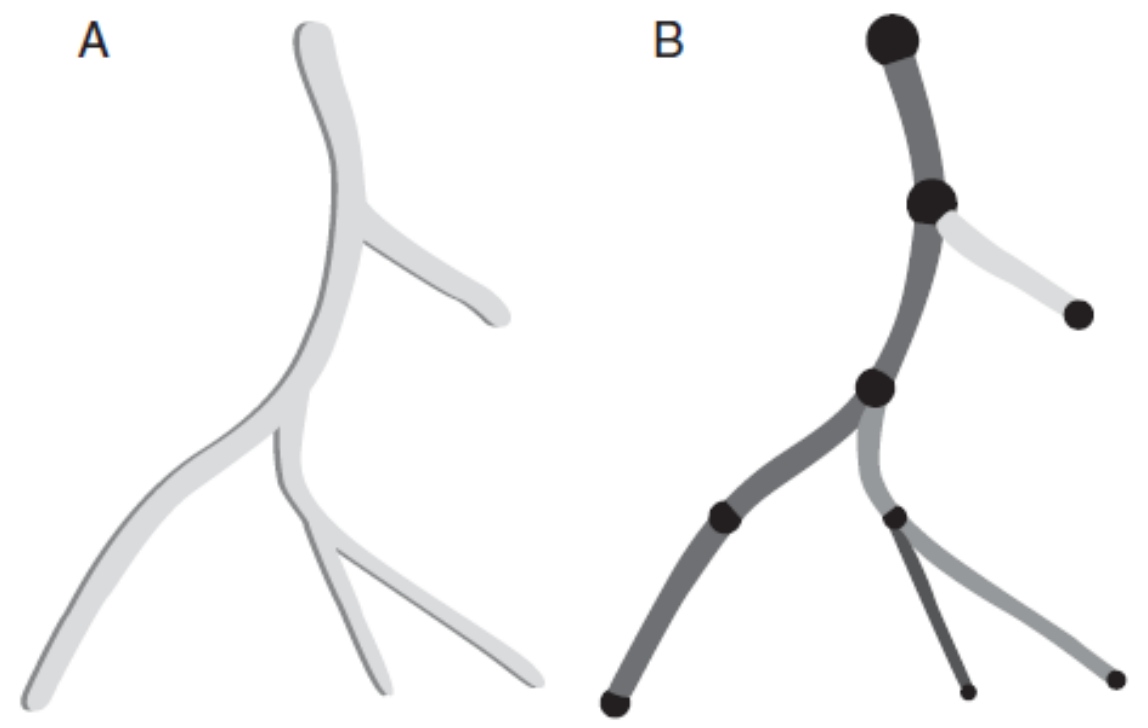

Figura 24. Un árbol de nervios virtual (A) se compone de distintas piezas (splines, sombreados de manera diferente). Entre los puntos y las ramas de control hay puntos compartidos (B).

La segmentación se basó en la delimitación manual empleando Autodesk Maya ${ }^{\circledR}$ y la supervisión por parte de un observador experto (anatomista), aportándole más robustez que otros métodos de segmentación automática disponibles a través de algoritmos. Se procedió a la detección de bordes relativos a las diferentes estructuras anatómicas en base a su forma, tamaño y localización. Un buen proceso de detección de bordes facilita la elaboración de las fronteras de las estructuras 3D a modelar, con lo que el reconocimiento de objetos se 
facilita. Precisamente, dado que el cambio de intensidad o borde entre muchas de las estructuras que nos ocupan es difícilmente perceptible por la falta de nitidez en sus límites, empleamos estrategias de segmentación manuales, en vez de algoritmos de segmentación automáticos. El suavizado de bordes sí se realizó de forma automática, a través del módulo de Maya ${ }^{\circledR}$ correspondiente, basándose en el promediado de los píxeles de una región.

El correcto etiquetado requiere cuidar la forma en la que se hayan escrito los nombres, incluyendo mayúsculas y minúsculas y asegurarse de que se hayan incluido todas ellas. Para ello, se creó un campo de etiquetado (LabelField) para cada uno de los conjuntos de datos con la lista completa de estructuras en orden jerárquico y a los que se les asignó un color diferente. Inicialmente se diferenció entre los diferentes músculos. Posteriormente, se identificaron las estructuras vasculares, a partir del conocimiento anatómico y organización espacial de las distintas estructuras. Se identificaron para su reconstrucción las siguientes estructuras: huesos, músculos, vasos y nervios de la extremidad superior e inferior y cuello (Figs. 25 y 26$)$.

El proceso de segmentación fue muy laborioso y exigente en cuanto a consumo de tiempo, al realizarse de forma individual para cada conjunto de datos y bajo la supervisión de un anatomista. Los diferentes componentes de las extremidades y región cervical se identificaron en las imágenes seriadas del VHP para su posterior labelado manual con diferentes códigos de colores mediante Maya ${ }^{\circledR}$.

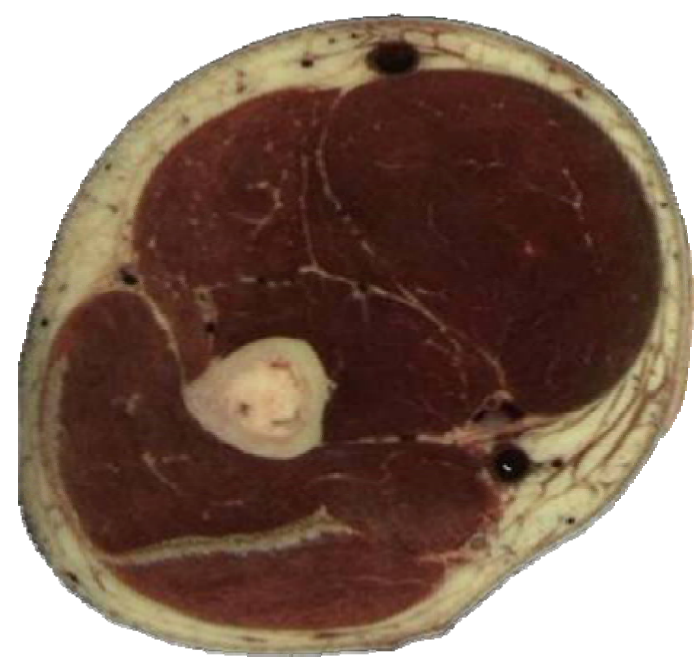

Figura 25. Corte axial de la extremidad inferior procedente del VHP, seleccionado para delimitar las áreas de interés (ROIs). 


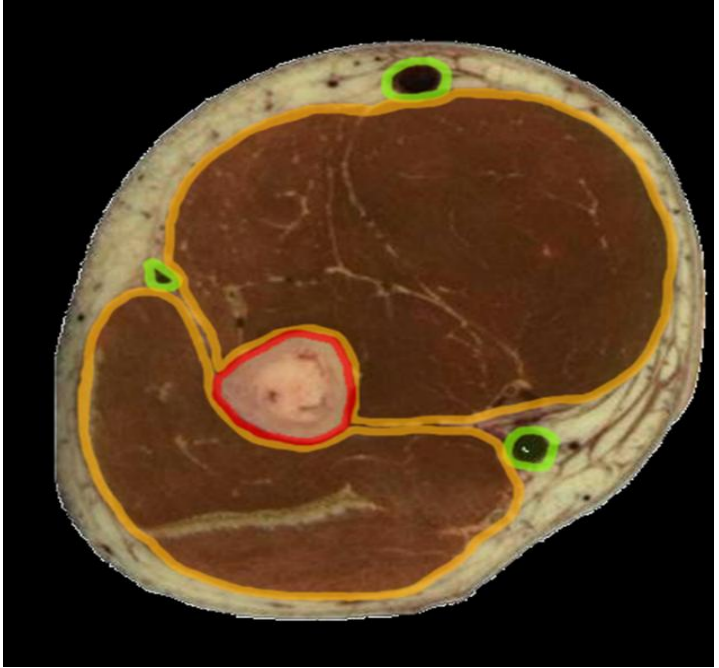

Figura 26. Delimitación de las áreas de interés (ROIs), músculos, nervios, huesos y vasos con diferentes códigos de colores.

\section{Extracción de la suberficie}

La visualización de volúmenes en ordenadores convencionales requiere un paso previo que consiste en la extracción de la superficie. Este paso reduce significativamente el peso de los datos y como resultado, también los tiempos de procesamiento requeridos para su visualización. Consiste en crear representaciones intermedias de la superficie en forma de mallas poligonales, asociadas a las estructuras anatómicas seleccionadas. Contienen la información a partir de la cual se van a renderizar las imágenes. En nuestro caso los elementos empleados para la composición de la superficie fueron estructuras poligonales.

\section{Alineación y Registro}

Consistió en la alineación de los ROIs en los tres planos de referencia y su transformación o edición, para comparar los conjuntos de datos individuales. La alineación supuso la incorporación de los diferentes conjuntos de datos originales, adquiridos desde diferentes orientaciones, a un sistema de coordenadas común. El registro consistió en la comparación y ajuste de la posición y orientación de los conjuntos de datos correspondientes a las imágenes, hasta que la información mutua de los conjuntos de datos se maximiza.

A partir de cada una de las regiones de interés resultantes se obtuvo un modelo de superficie compuesto por una malla mediante el procedimiento de marching cubes. A los modelos se aplicaron algoritmos de decimación para simplificarlos y suavizarlos. Finalmente se exportaron a formato DirectX (Figs 27 y 28 ). 


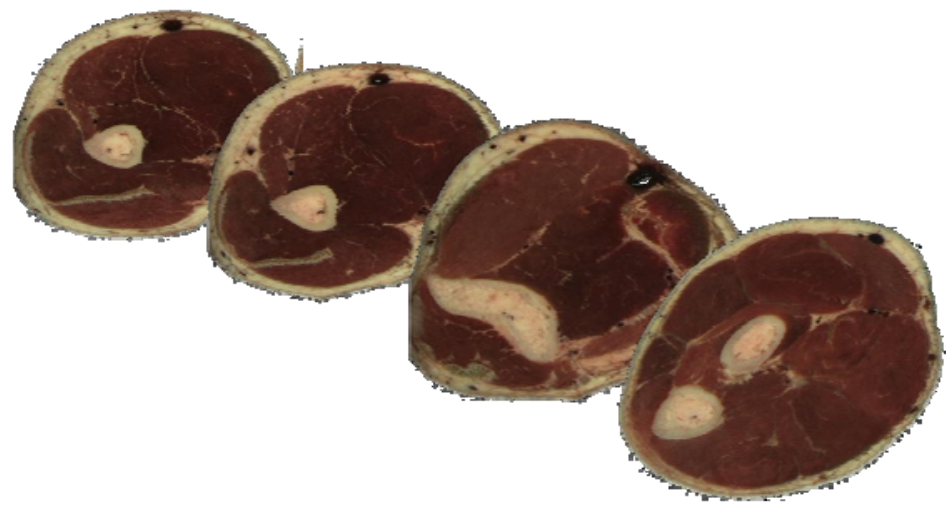

Figura 27. Secciones axiales seriadas del VHP; utilizadas como patrón de referencia anatómica en la generación de modelos 3D.

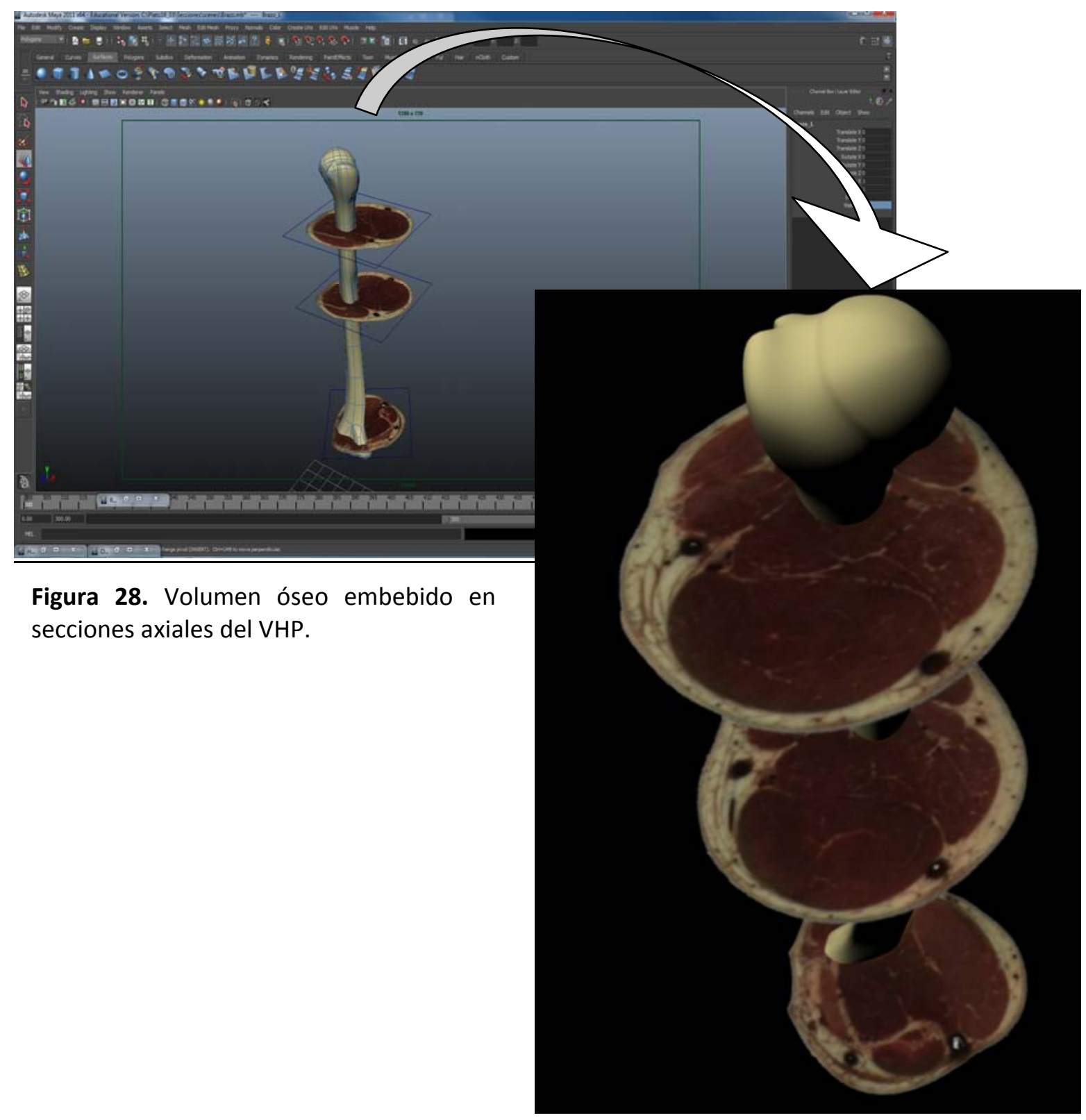




\section{Visualización y renderización}

Imágenes seccionales procedentes del VHP seleccionadas y todos los modelos 3D de superficie obtenidos en la fase anterior, serán visualizados en un visor específicamente desarrollado para esta aplicación informática, programado en Visual C++ y que incluye controles directX para la renderización de imágenes y modelos de malla poligonal (Figs. 29 y 30).

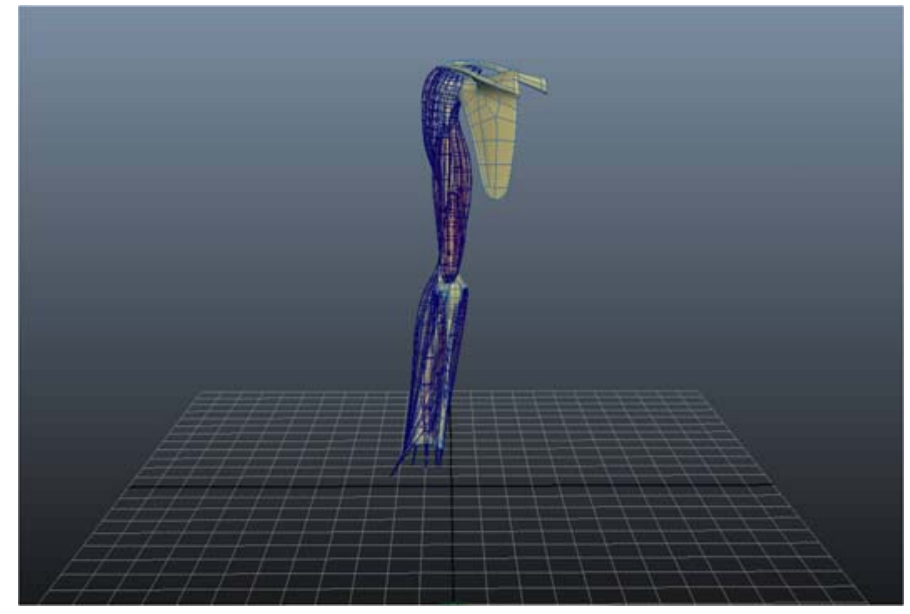

Figura 29. Estructura en malla (o alambre) de la extremidad superior, efectuada con Maya.

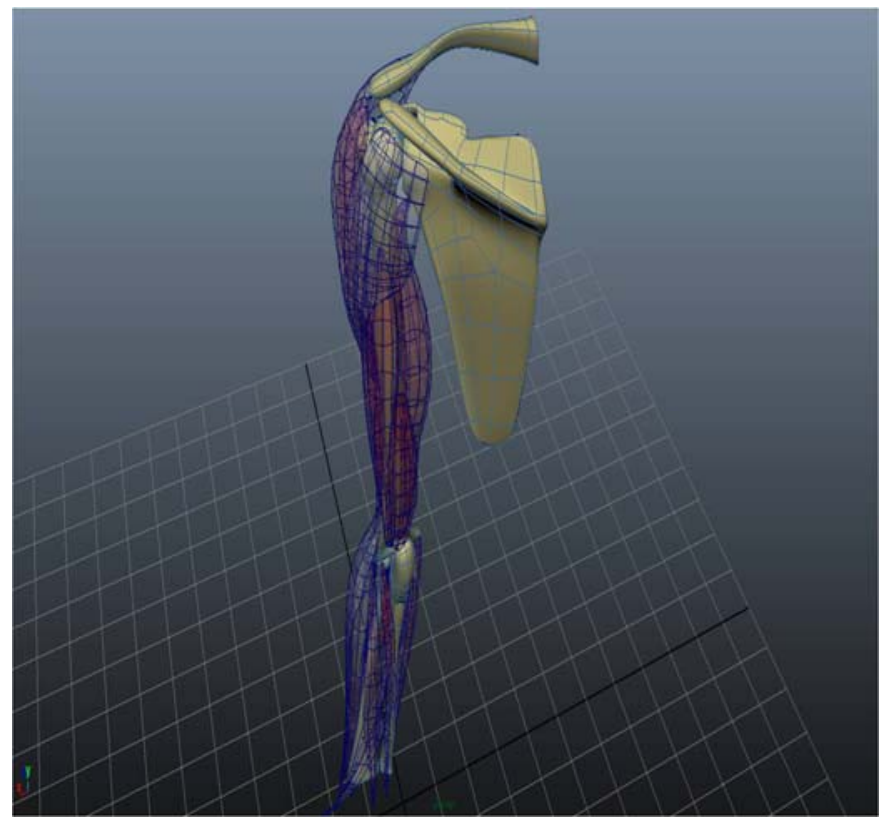

Figura 30. Detalle de la estructura en malla de los huesos escápula y clavícula y de los músculos acompañantes de la extremidad superior. Esta representación de los distintos modelos en malla para las distintas estructuras de la extremidad se produce antes de la generación volumétrica final. 
El renderizado del volumen, consistió en la visualización de datos volumétricos a partir de imágenes correspondientes a las diferentes estructuras anatómicas, mediante la aplicación de color y textura.

El renderizado directo del volumen consistió en la visualización directa de la superficie de una estructura anatómica a partir de los datos del volumen. En este caso, la visualización resultó de la aplicación de un sofisticado algoritmo denominado Proyección de Máxima Intensidad, según el cual, se asignan parámetros de emisión y absorción de luz a cada punto del volumen. Esta simulación del paso de luz a través del volumen, hace posible mostrar los datos desde cualquier dirección sin construir modelos poligonales intermedios.

El algoritmo utilizado fue Marching Cubes que permitió la extracción de mallas poligonales de una isosuperficie a partir de vóxeles. Requiere dividir el espacio en vóxeles formados por los valores de intensidad de los 8 vértices del vóxel, correspondientes a los datos volumétricos originales. El procedimiento de elaboración de modelos en malla a partir del algoritmo Marching Cubes fue seguido de la aplicación de determinados algoritmos con la intención de simplificarlos y suavizarlos.

El guiado visual acompañó todo el proceso, lo que requirió de la visualización simultánea del modelo de superficie y de los planos de la imagen de referencia. Finalmente, se obtuvo un fichero en formato DirectX del modelo de superficie definitivo de la estructura anatómica a reconstruir.

La herramienta empleada durante el proceso de segmentación, edición de superficies, suavizado libre de intersecciones, registro, creación de modelos poligonales y mallas volumétricas necesarias para la simulación avanzada de los volúmenes reconstruidos y el renderizado final, fue Autodesk Maya ${ }^{\circledR}$. A continuación se muestra una imagen del resultado final (Fig. 31): 


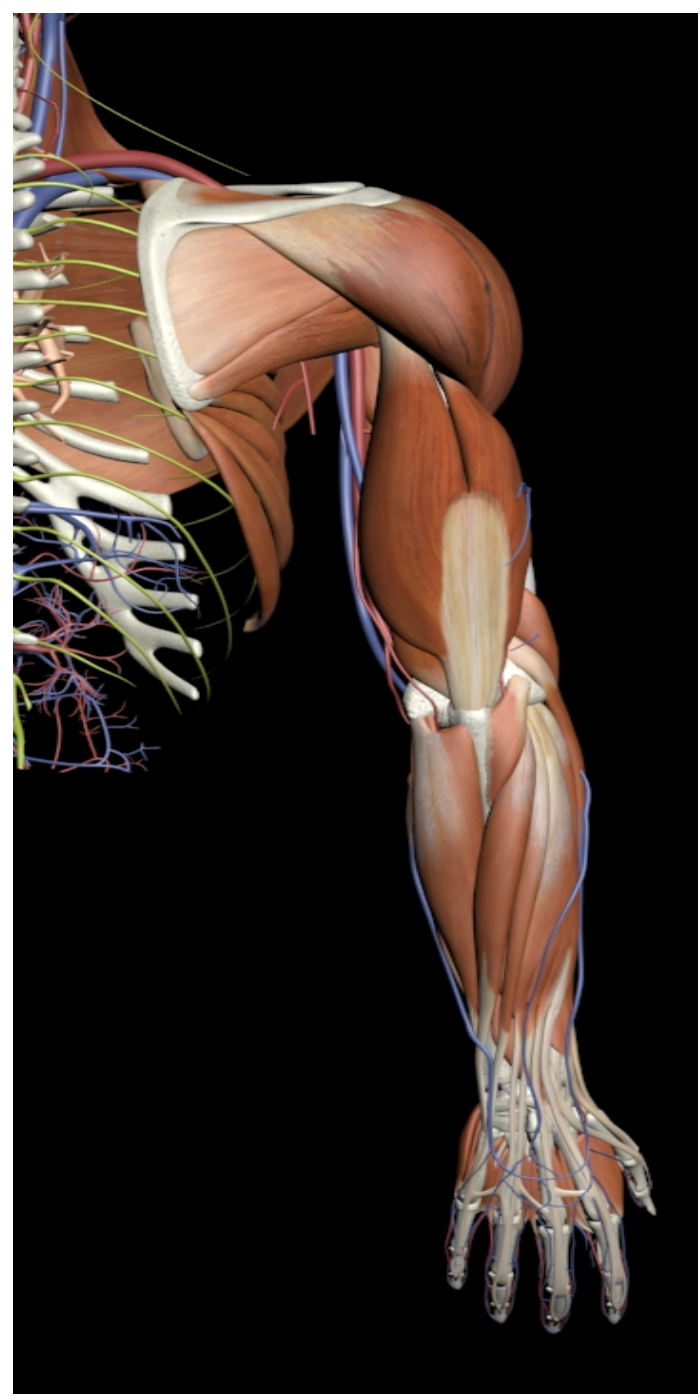

Figura 31. Visor anatómico 3D donde se pueden observar los vasos, músculos, huesos y nervios. Más adelante se verá que este visor permite una interacción total con el usuario.

\subsubsection{Encuesta de Satisfacción Del Procedimiento Tecnológico Para}

\section{LA Formación EN ANESTESIA REgIONAL}

Para valorar el grado de satisfacción del procedimiento informático, se llevó a cabo una encuesta de satisfacción a 75 anestesiólogos tanto residentes de tercer y último año como adjuntos, a los que se les presentó el programa, basada en 8 ítems y utilizando la escala Likert como herramienta de medición. El procedimiento informático fue distribuido por diferentes servicios de anestesia de distintos hospitales nacionales (fundamentalmente Salamanca, Avila, Zamora y Madrid), gracias a la colaboración de Abbott laboratorios. Todo 
se empaquetó en un dispositivo de almacenamiento CD-ROM. Las entrevistas fueron anónimas y distribuidas tanto en formato papel como a través de correo electrónico por Internet a varios centros españoles. Los ítems formulados fueron las siguientes: 1. Es un producto totalmente novedoso. 2. Resulta fácil de manejar. 3. Es una herramienta que facilita el aprendizaje de los bloqueos regionales guiados por ecografía. 4. Es útil para nuestro trabajo diario. 5. Su contenido es semejante a lo que vemos en la práctica clínica habitual. 6. Facilita la comprensión de la anatomía de las extremidades. 7. Es un método de autoaprendizaje adecuado. 8. Lo recomendaría a otros compañeros e incluso a estudiantes de anatomía y radiología. 



\section{Capitulo 4}

RESUlTAdOS 



\section{I. DESCRIPCIÓN DEL PROCEDIMIENTO TECNOLÓGICO PARA LA FORMACIÓN EN ANESTESIA REGIONAL}

El programa se distribuye en CD ROM. Al introducir el CD en la unidad del ordenador aparecerá un menú indicando que es necesario tener una versión DirectX 9.0 o superior. Si dispone de una versión adecuada de DirectX aparecerá una "V" verde al lado del icono, en caso contrario una " $X$ " roja. En este último caso el programa da la opción de instalar el programa DirectX 9.0 proporcionado por el CD. Aparecen 2 pestañas; una para instalar DirectX 9.0 y otra para instalar la aplicación. Pulsando para instalar la aplicación un asistente le guiará a través de los pasos necesarios para instalar el procedimiento tecnológico.

El programa se instala automáticamente, apareciendo un icono del mismo en el escritorio una vez finalizado el proceso de instalación. Al pulsar dos veces con el botón izquierdo del ratón sobre el icono del programa localizado en el escritorio, se abrirá automáticamente.

\section{Menú principal}

Al entrar en la aplicación se muestra un menú de selección con los distintos bloqueos anestésicos disponibles agrupados por áreas anatómicas. Los bloqueos pertenecientes al cuello y a la extremidad superior (un total de 13) aparecen en el lado izquierdo de la pantalla y los de la extremidad inferior (un total de 15) al lado derecho. Se encuentran organizados de proximal a distal (Fig. 32). 


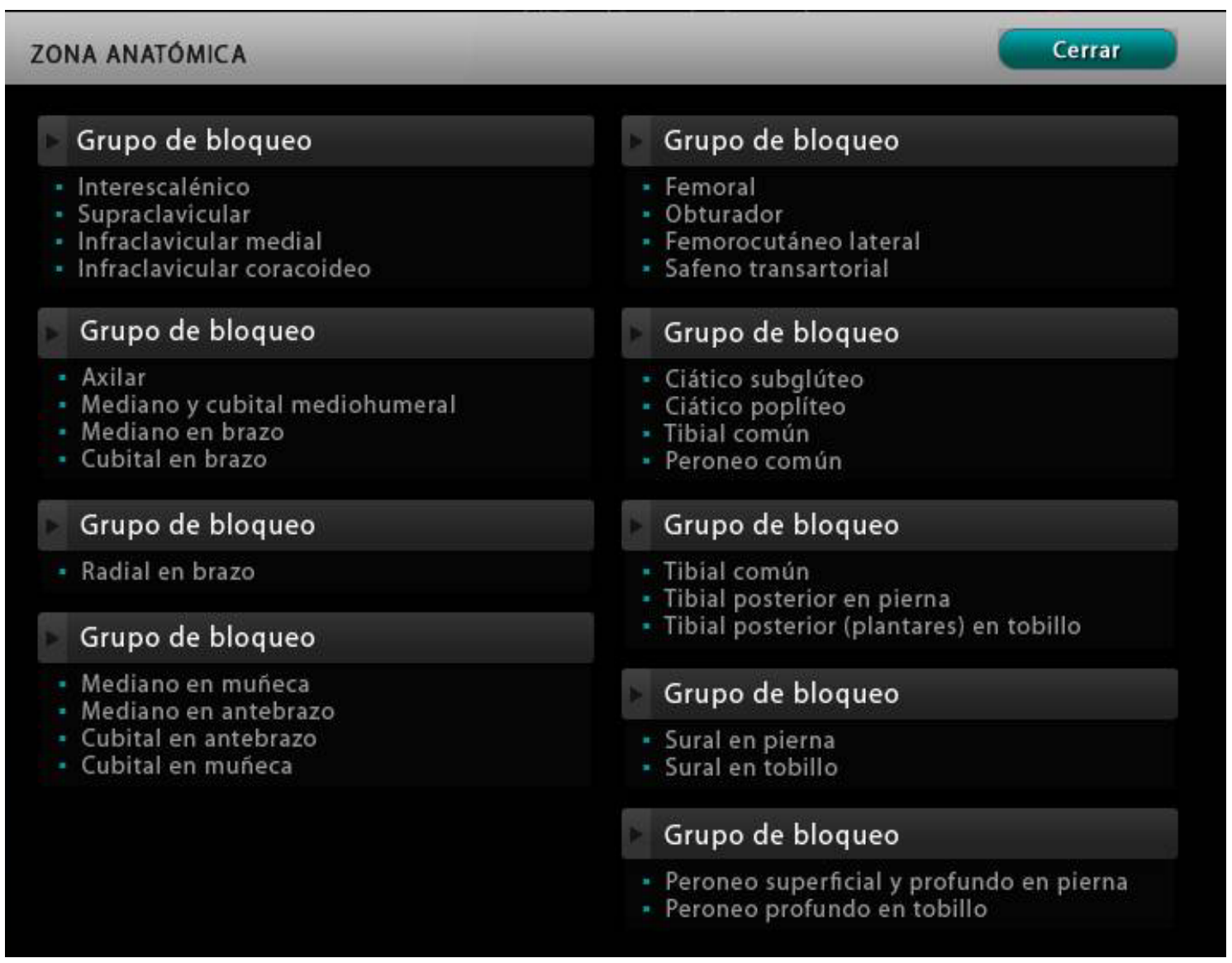

Figura 32. Menú principal de la aplicación; a la izquierda el grupo de bloqueos de cuello y extremidad superior y a la derecha los de la extremidad inferior, ambos grupos ordenados de proximal a distal. Se describen bloqueos tanto por vía anterior como posterior.

Al seleccionar alguno de ellos se cargará la ventana principal de la aplicación, que incluye un visor de ecografía, una fotografía de un paciente virtual sobre el que se podrá pasar el transductor, y un visor tridimensional con los dermatomos y la anatomía en 3D relacionada (Fig. 33). Este menú de los grupos de bloqueo anatómico puede volver a mostrarse en cualquier momento pulsando la opción zonas anatómicas del menú superior. 


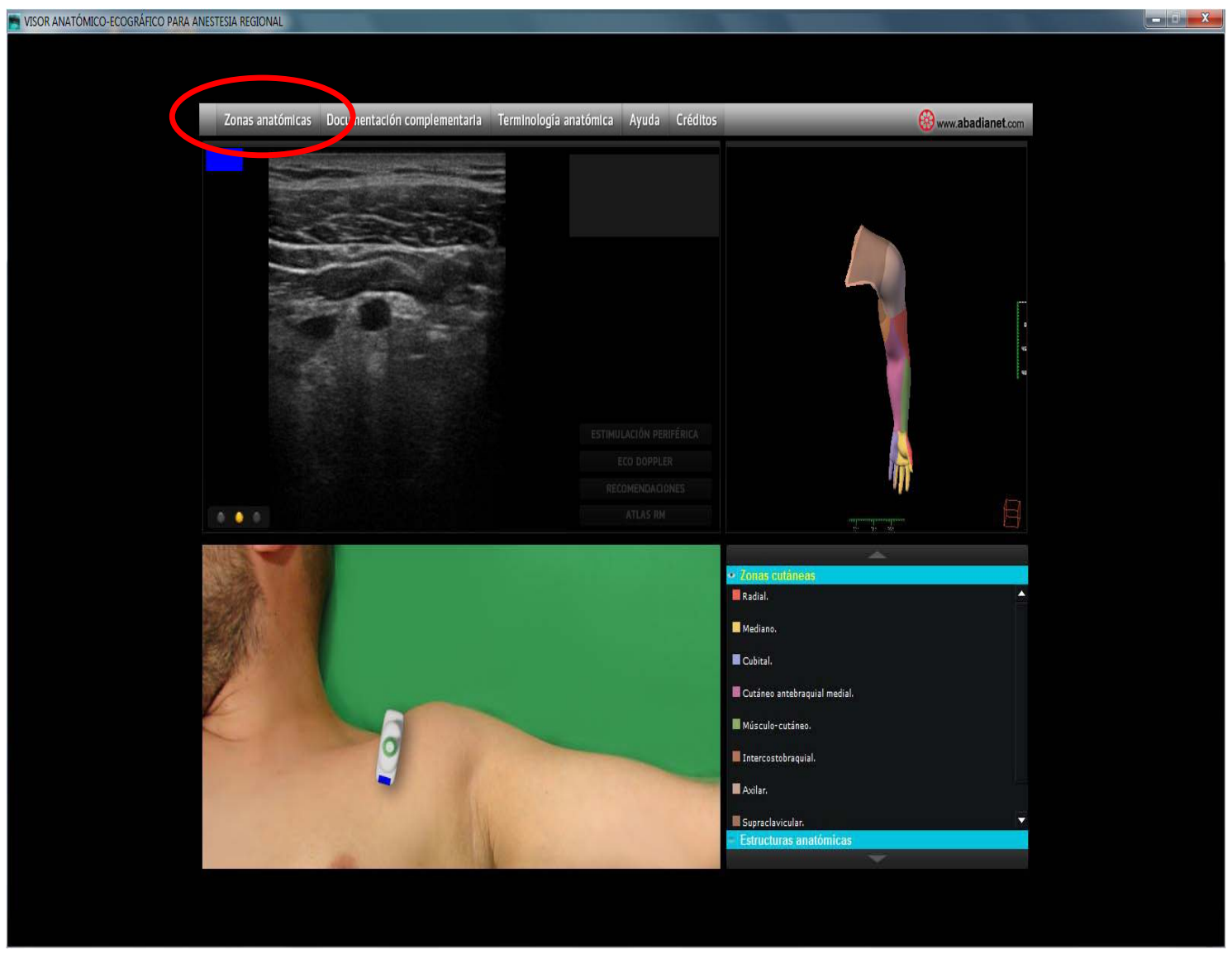

Figura 33. Ventana principal de la aplicación donde se muestra el visor ecográfico, el simulador de superficie y el modelo anatómico tridimensional con los dermatomas correspondientes. Pulsando en la barra superior en zonas anatómicas se vuelve al menú principal donde se muestran los bloqueos.

La aplicación del procedimiento tecnológico para la visualización anatómicaecográfica para anestesia regional nos permite interactuar y conocer bloqueos anestésicos de miembro inferior, superior y cuello relacionados con ecografía (modo M y Doppler color) y su imagen correspondiente en secciones de RM.

En la parte superior aparecen un conjunto de opciones que dan acceso al menú de selección principal, información complementaria referente a la ecografía y los bloqueos anestésicos, terminología anatómica empleada, una ayuda donde se explica el manejo de la aplicación y a los créditos de las responsables y colaboradores científicos del proyecto. 
Por orden de izquierda a derecha:

Zonas anatómicas da acceso al menú de selección principal en el que es posible elegir el grupo de bloqueos al que queremos acceder.

Documentación complementaria da acceso a cuatro archivos "pdf" en los que se exponen diferentes temas relacionados con los bloqueos anestésicos y la ecografía, completando así su faceta docente, entre ellos: Conceptos básicos de ecografía aplicada a la anestesia regional, conceptos prácticos en ecografía, artefactos ecográficos y bases físicas de la ultrasonografía (Figs. 34, 35, 36, 37 y 38) (la documentación complementaria se adjunta en el apartado de anexos)

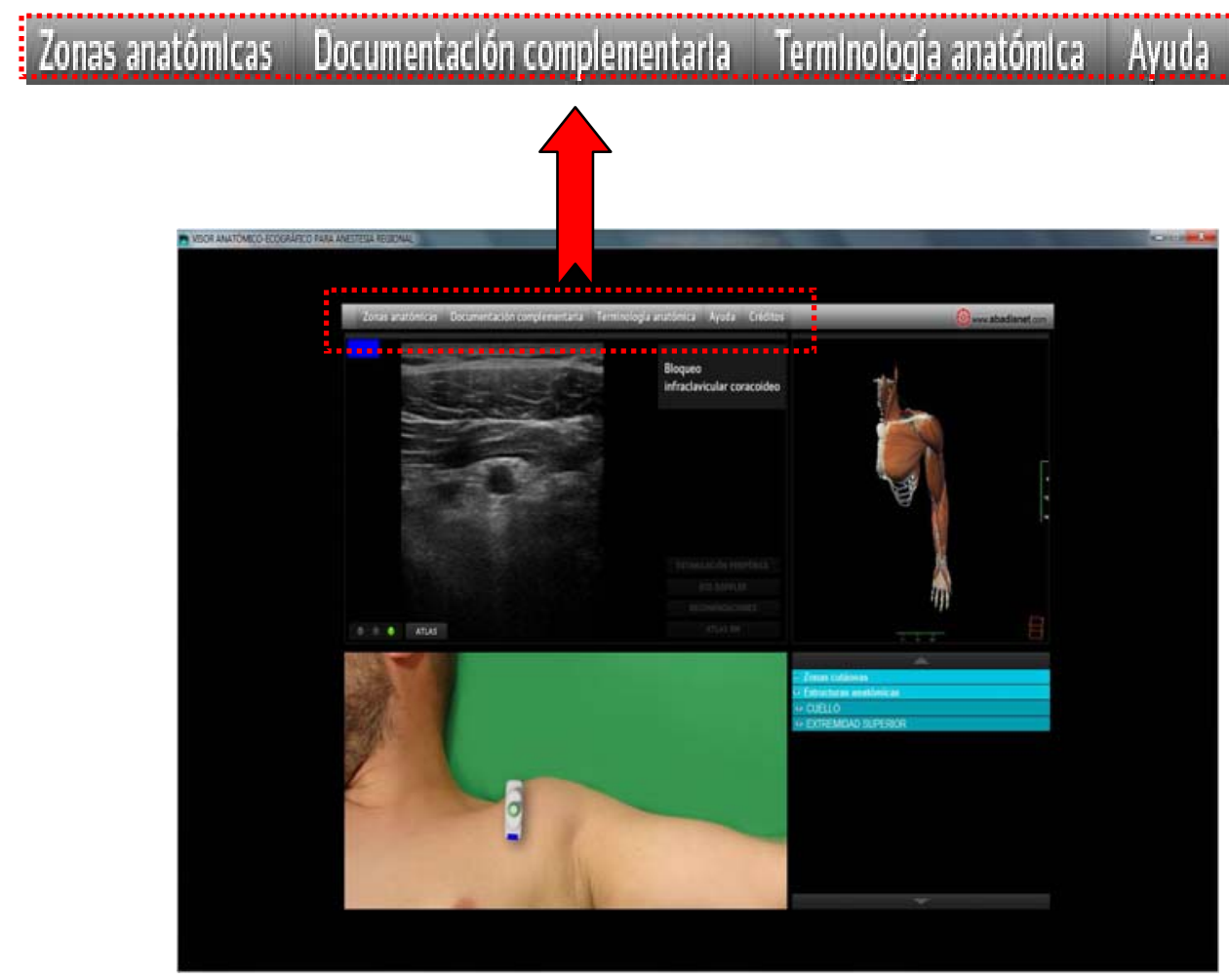

Figura 34. Imagen que muestra la localización del menú principal que da acceso a información complementaria de la aplicación. 


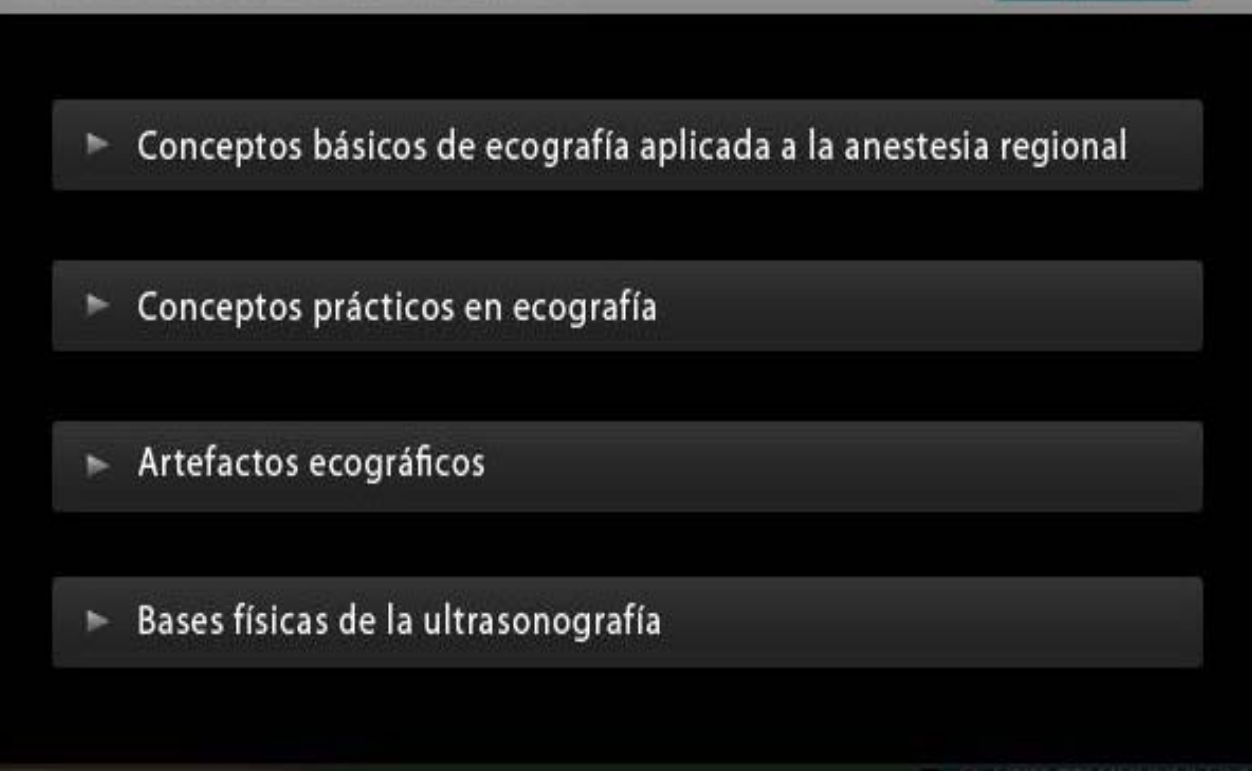

Figura 35. Documentación complementaria, con cuatro documentos PDF, que abordan diferentes temas de interés de los bloqueos guiados por ecografía.

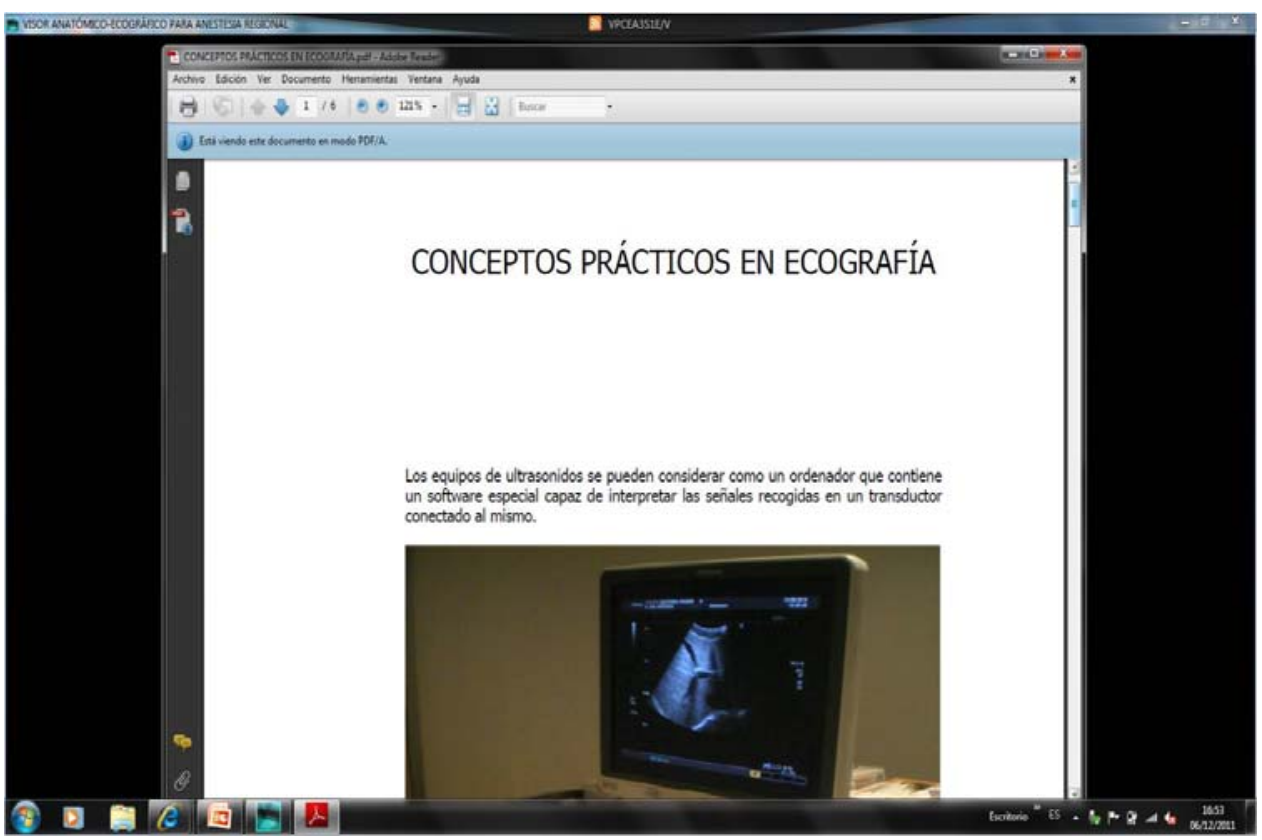

Figura 36. Imágenes donde se muestra un detalle de la documentación complementaria (Consejos prácticos de ecografía). 

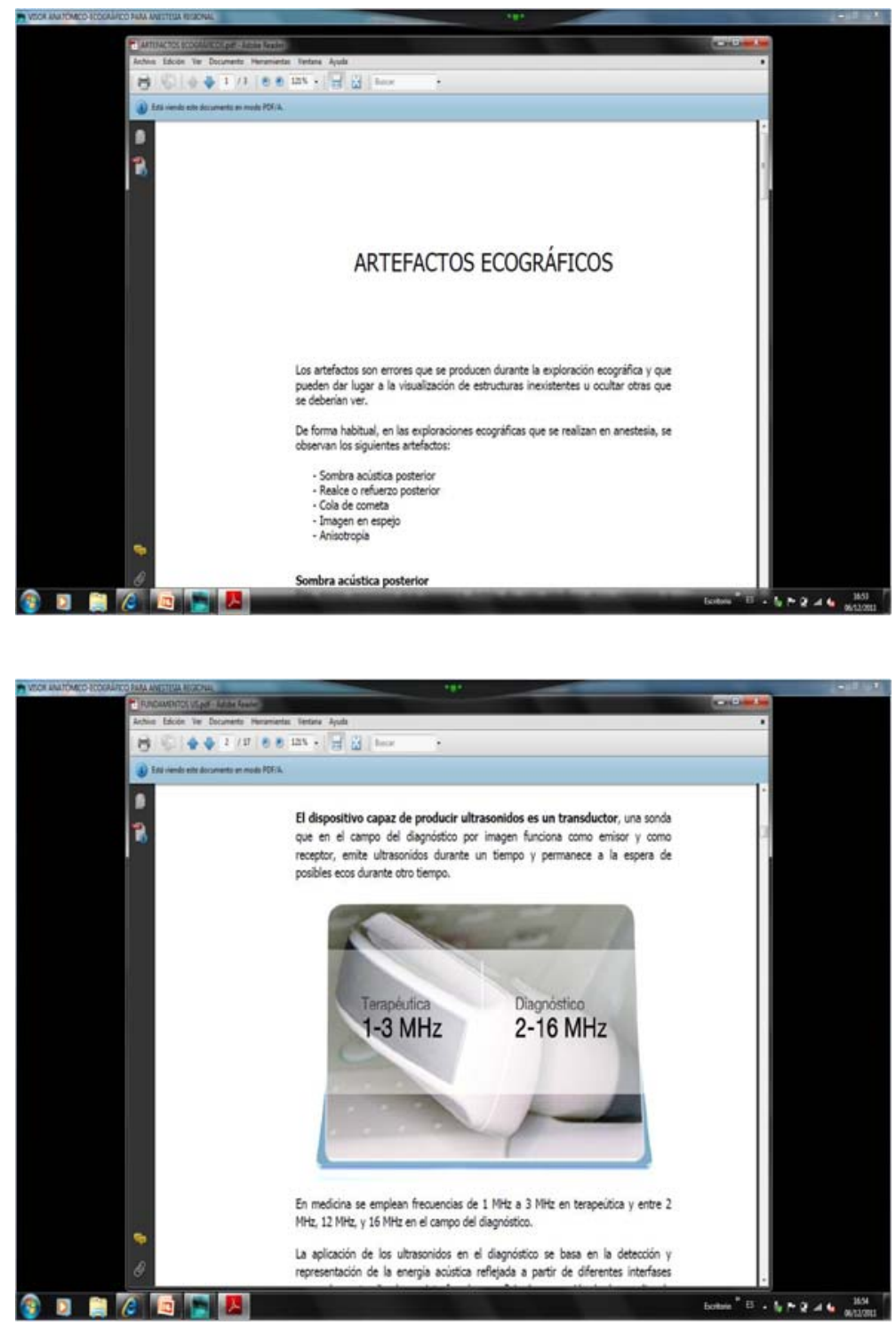

Figura 37 y 38. Imágenes donde se muestran más detalles de la documentación complementaria (artefactos ecográficos y bases físicas de la ecografía).

En la opción terminología anatómica, se obtiene un listado con los distintos términos anatómicos utilizados en la aplicación, ordenados alfabéticamente, y con sinónimos para estructuras concretas; con esto se disminuye el grado de confusión que puede crear la misma nomenclatura anatómica, para por ejemplo, un mismo músculo (Fig. 39) (Ver en anexo). 
TERMINOLOGIA ANATOMICA

FASCÍCULO LATERAL DEL PLEXO BRAQUIAL.

FASCíCULO MEDIAL DEL PLEXO BRAQUIAL.

FASCICULO POSTERIOR DEL PLEXO BRAQUIAL.

GRAN VENA SAFENA. SAFENA MAGNA O MAYOR. SAFENA INTERNA.

MÚSCULO BRAQUIAL ANTERIOR. MÚSCULO BRAQUIAL.

MUSCULATURA PARAVERTEBRAL.

MÚSCULO CUADRADO CRURAL. MÚSCULO CUADRADO FEMORAL.

MÚSCULO ABDUCTOR LARGO DEL PULGAR.

MÚSCULO ADUCTOR CORTO O APROXIMADOR MENOR.

MÚSCULO ADUCTOR GRANDE. ADUCTOR MAYOR. APROXIMADOR MAYOR.

MÚSCULO ADUCTOR LARGO. APROXIMADOR MEDIANO. ADCUTOR MEDIANO.

MÚSCULO ADUCTOR MAYOR. APROXIMADOR MAYOR. ADUCTOR GRANDE.

MÚSCULO ANCÓNEO.

MÚSCULO APROXIMADOR MAYOR. ADUCTOR MAYOR.

Figura 39. Terminología anatómica donde se incluye la nomenclatura más habitual con sus sinónimos para facilitar la comprensión de los lectores.

Volviendo a la pantalla principal de la aplicación, en el cuadrante superior izquierdo, se muestra un visor ecográfico donde se reflejarán las imágenes ultrasónicas en función del movimiento del transductor realizados mediante el movimiento del ratón del ordenador, que simula dicho transductor (Fig.40).

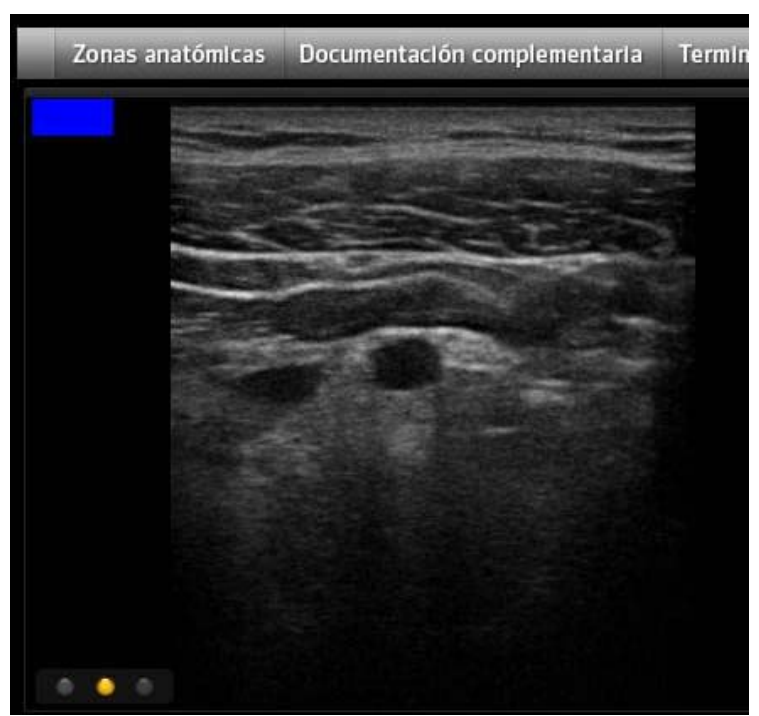

Figura 40. Visor ecográfico. El cuadro azul está representado en la sonda ecográfica simulada y sirve de orientación de la imagen. 
Para poder interactuar con el simulador, hay que pulsar el botón izquierdo del ratón y arrastrar el transductor sobre la imagen del paciente. El transductor se orientará automáticamente en las zonas específicas para ajustarse al recorrido (Figs. 41 y 42).

A modo de referencia, el pequeño cuadrado azul que aparece en el transductor corresponde con la parte izquierda de la imagen que aparece en el reproductor de ecografía.

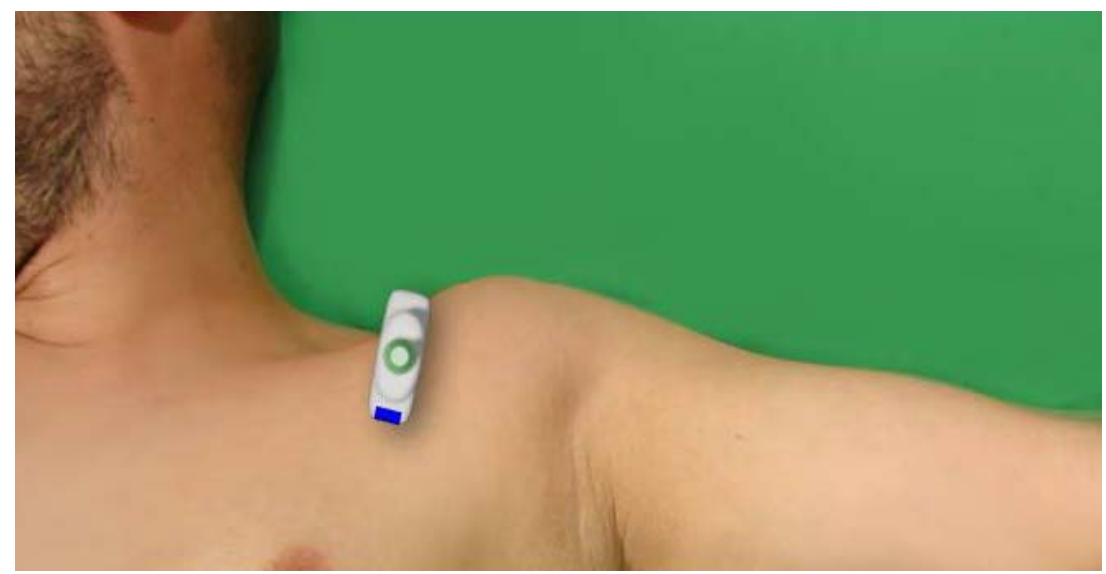

Figura 41. Posicionamiento del transductor sobre la superficie del paciente.

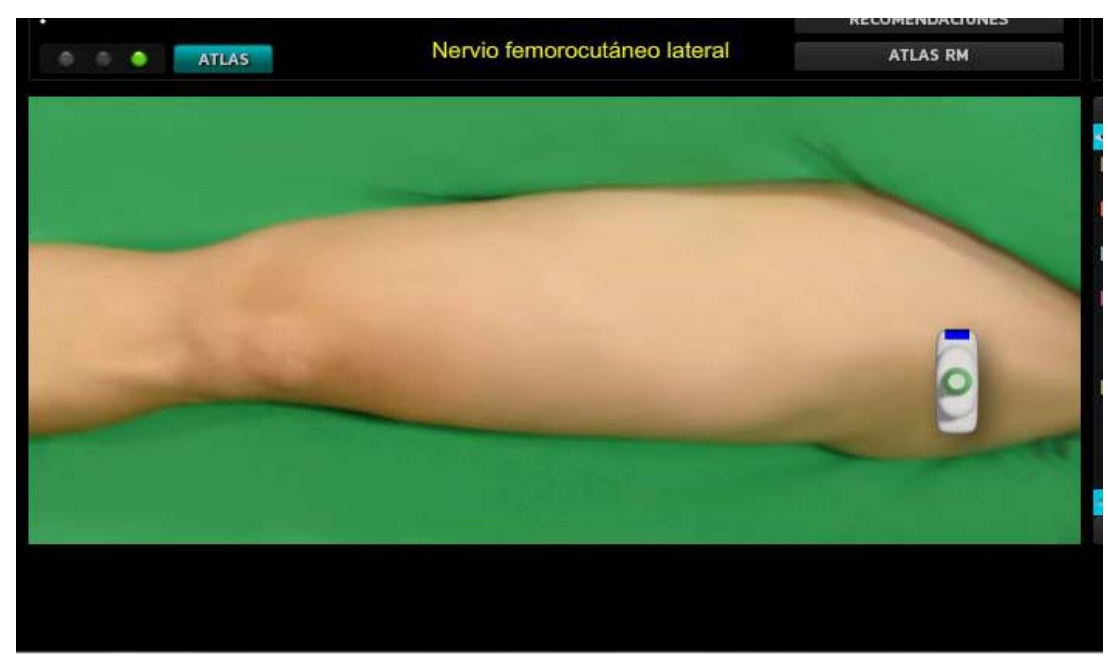

Figura 42. Visor de la anatomía de superficie del muslo. El usuario debe localizar las referencias externas para emular la ecografía de los nervios periféricos a este nivel.

La imagen ecográfica muestra la zona en la que se encuentra el transductor en el simulador de anatomía externa. Esta imagen ecográfica sólo se mostrará en las zonas anatómicas específicas en cada recorrido, mostrándose ruido en caso contrario. Se 
visualizará también un texto con el siguiente contenido: "Sitúe el transductor en las zonas correspondientes".

Con el transductor ecográfico el usuario puede localizar el lugar idóneo en la anatomía de superficie donde realizar el bloqueo. Según la lejanía o cercanía al punto óptimo aparece un código de colores (rojo si se está alejado, amarillo nos estamos aproximando y verde cuando estamos en el lugar correcto). Consideramos que el lugar idóneo es aquel donde mejor se visualizan los nervios. Una vez localizado este punto óptimo, se puede pulsar sobre el icono donde pone atlas, mostrándose un atlas ecográfico en el cual se identifican las estructuras al pasar el ratón mediante un código de colores (por ejemplo vasos en rojo) y aparece el nombre de la estructura señalada.

Al llegar a una zona que se considera óptima para el bloqueo, se activará el botón para dar acceso al atlas ecográfico asociado al bloqueo, y se mostrará en el recuadro superior derecho el nombre del bloqueo localizado (Fig. 43).

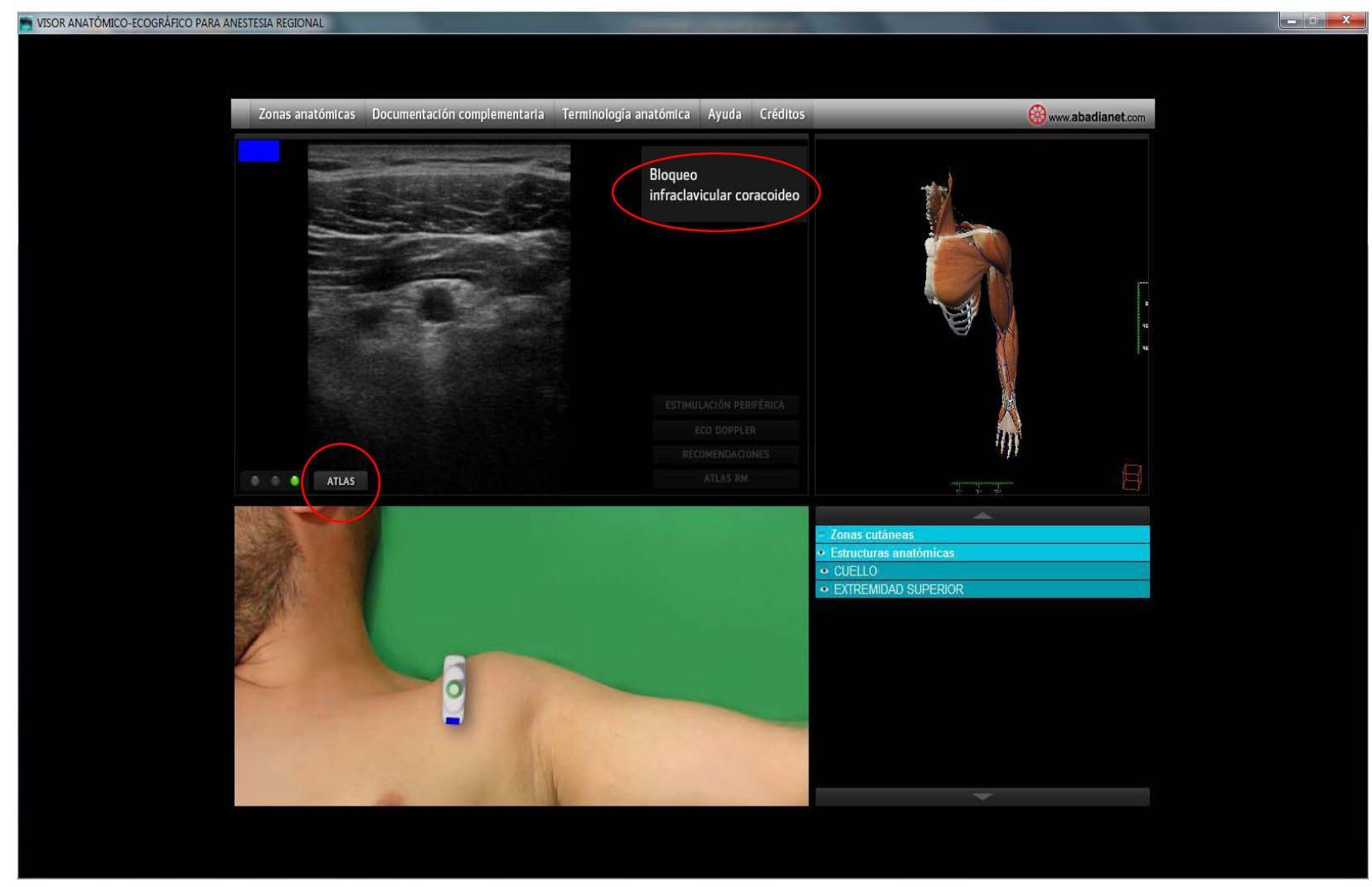

Figura 43. Al localizar la zona cutánea donde se debe realizar el bloqueo el semáforo se pone en verde y aparece el nombre del bloqueo. 
El atlas ecográfico presenta una imagen independiente del reproductor de ecografía, en la que se identifican las distintas estructuras morfológicas al pasar el ratón sobre las zonas concretas. Aparecerán las áreas enmarcadas con el siguiente código de colores: azul para las venas, con el rojo las arterias, amarillo los nervios (Fig.44), en morado los músculos (Fig. 45), blanco los huesos y en azul otras estructuras como la pleura.

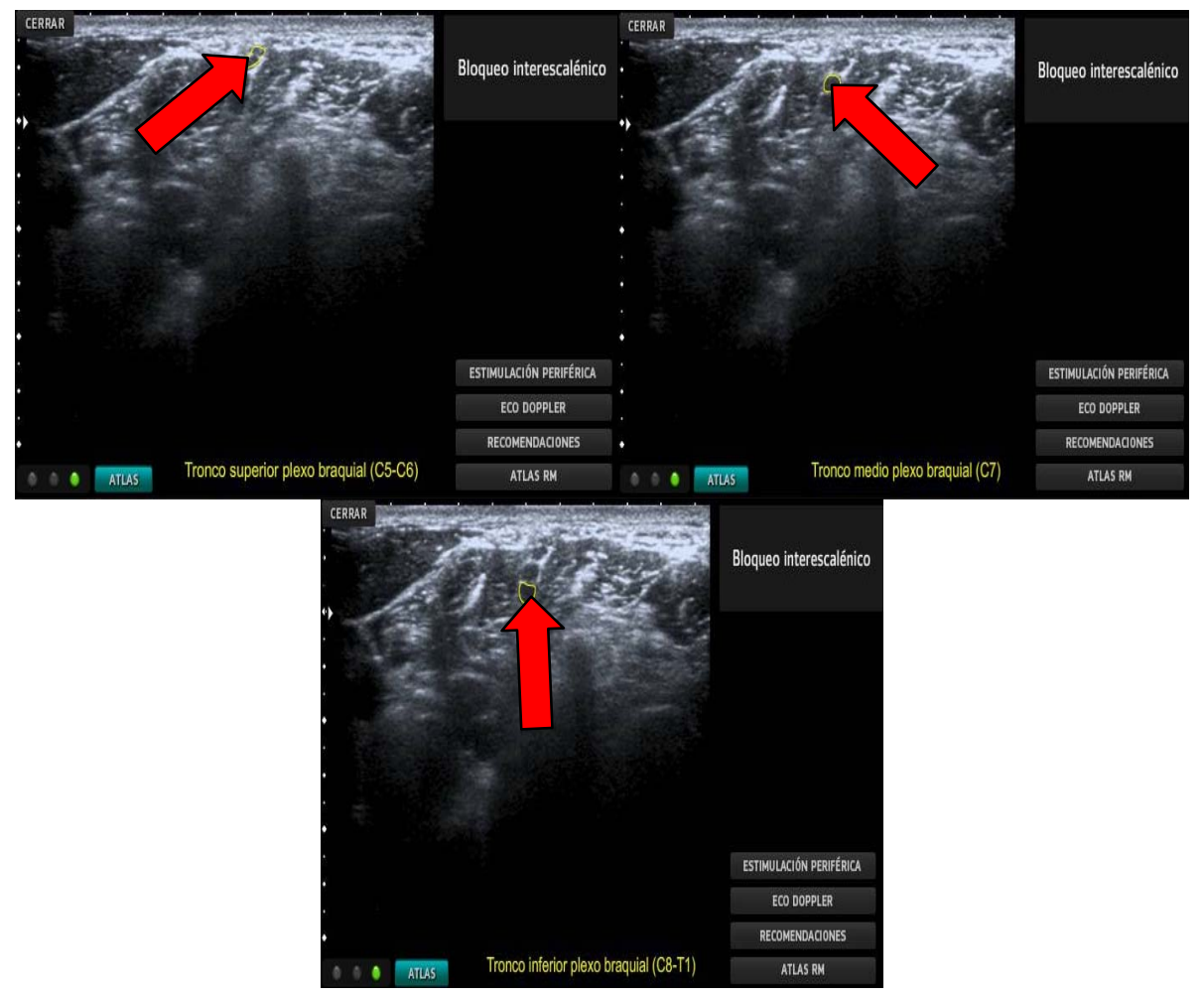

Figura 44. Detalle del tronco superior, medio e inferior del plexo braquial seleccionados en la imagen ecográfica (círculos en amarillo señalados con las flechas roias). 


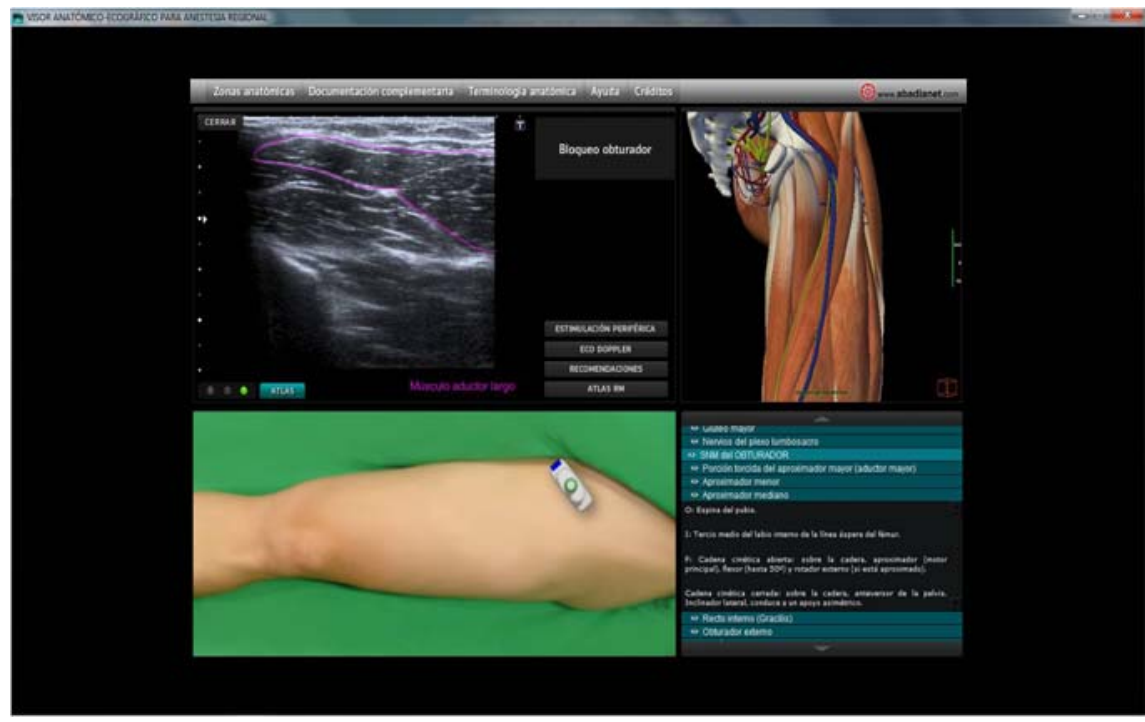

Figura 45. Músculo aductor largo señalado en el atlas de ecografía en morado, perteneciente a la región del bloqueo obturador. Obsérvese la localización en la anatomía de superficie y en el visor 3D. En el cuadrante inferior derecho aparece la leyenda con la descripción de las inserciones y función del músculo.

A continuación, mostramos otro ejemplo con una serie de imágenes de la aplicación en las que aparecen los distintos fascículos del plexo braquial en el bloqueo infraclavicular coracoideo (Figs. 46, 47 y 48 ).

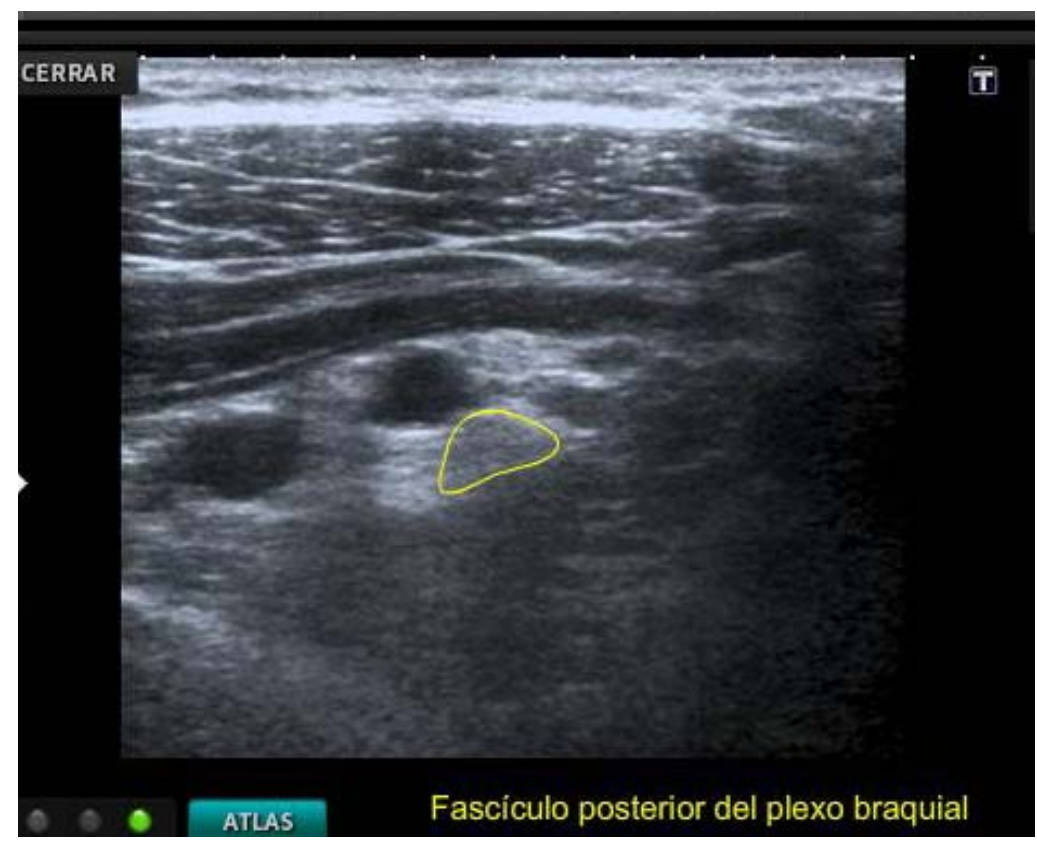

Figura 46. El color verde del semáforo activa el atlas ecográfico; en él se muestra el fascículo posterior del plexo braquial señalado en amarillo. 


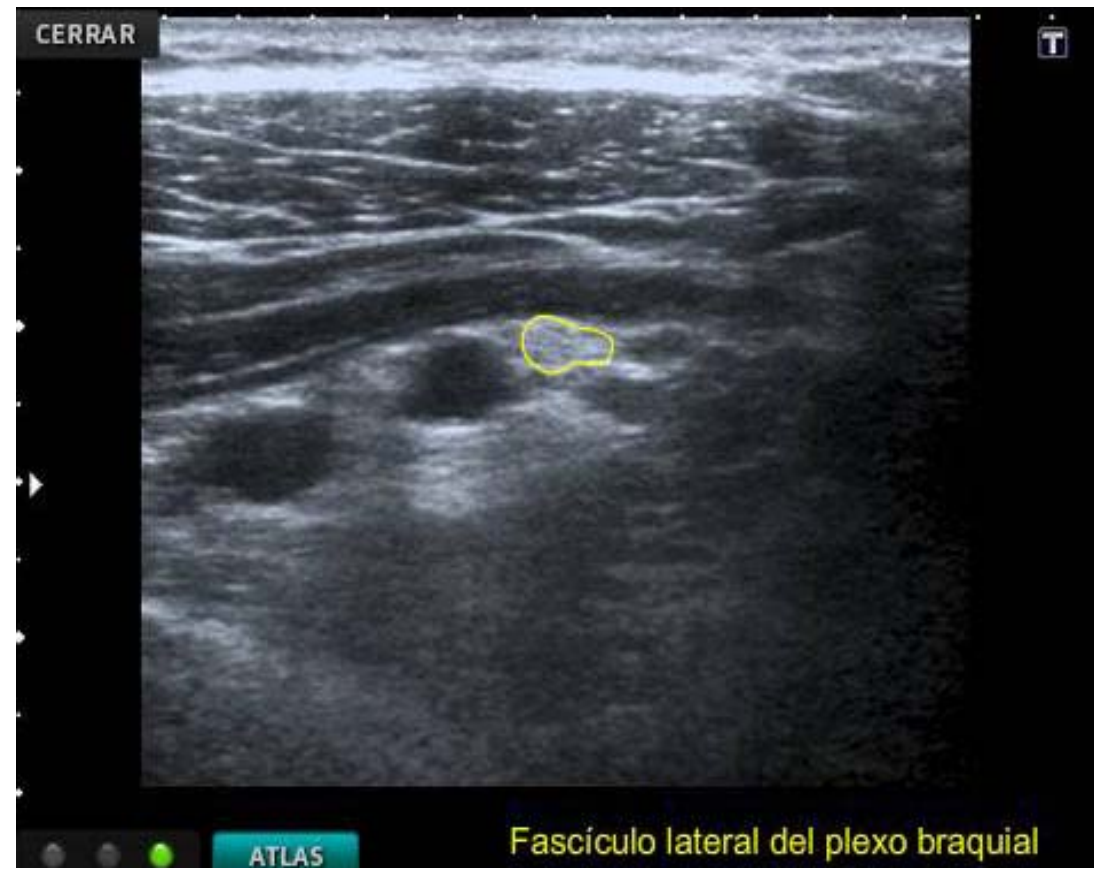

Figura 47. Visualización ecográfica del fascículo lateral del plexo braquial en el bloqueo infraclavicular coracoideo.

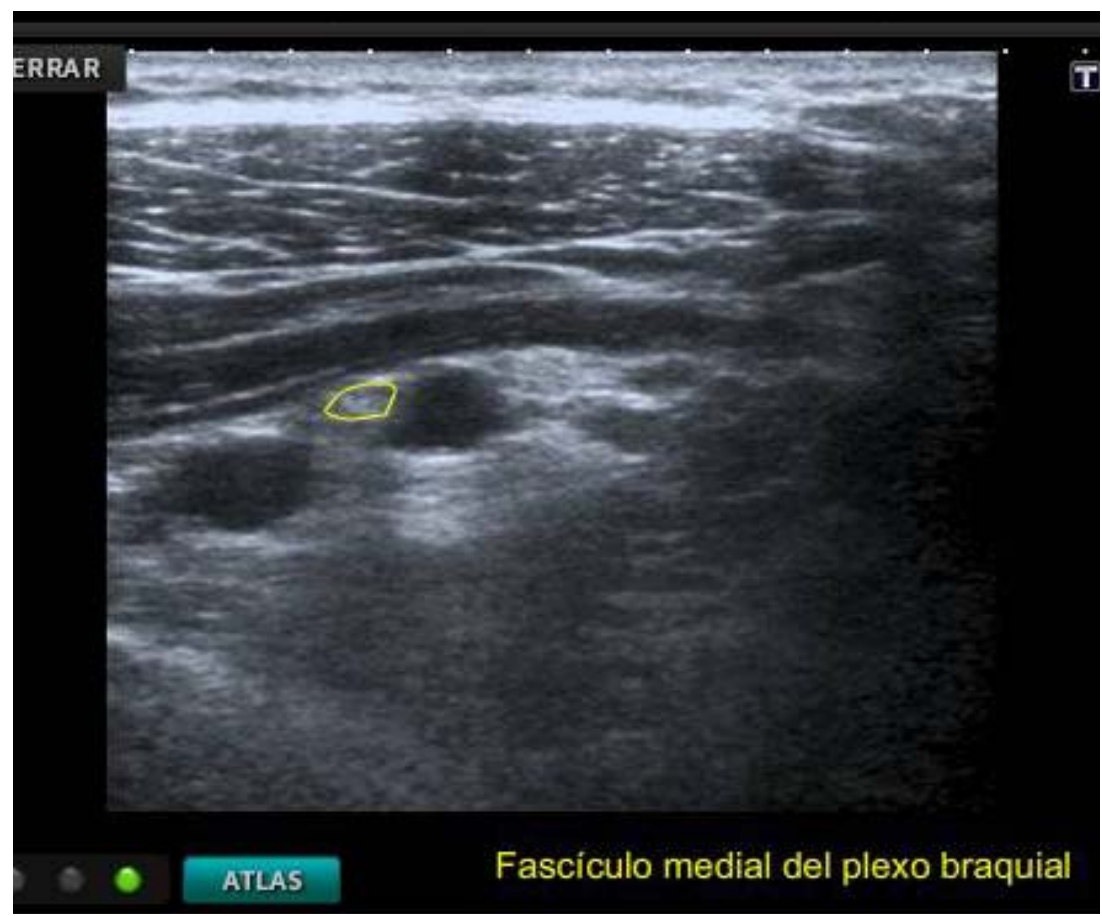

Figura 48. Fascículo medial del plexo braquial en la imagen ecográfica. 
En la imagen siguiente se muestra un ejemplo de bloqueo de la extremidad inferior en concreto del nervio ciático (Fig. 49).

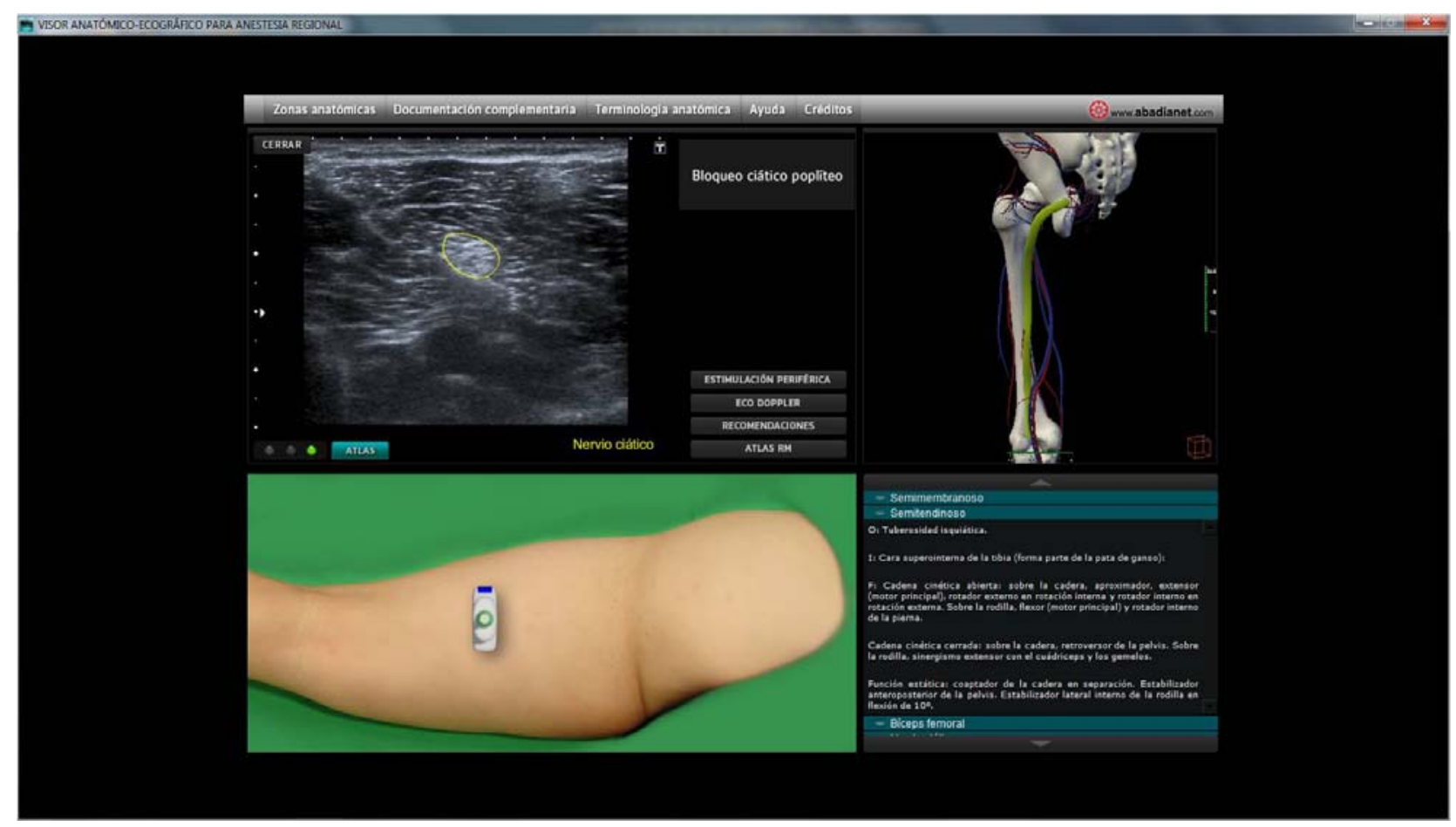

Figura 49. Imagen que ilustra la localización del transductor para el nervio ciático poplíteo. Bloqueo del nervio ciático popliteo de la extremidad inferior.

Este mismo código de colores utilizado para el atlas ecográfico, se mantendrá en las secciones de RM correspondientes a la zona del bloqueo, salvo los huesos que serán de color naranja; detalles que se mostrarán más adelante.

Al hacer clic sobre el altas del bloqueo, se activarán además otros accesos para ver la ecografía en modo Doppler de la zona (Fig. 50), o la estimulación periférica mediante un video de un paciente real (si procede) de los nervios bloqueados (Fig. 51). También, aparecerán una serie de recomendaciones específicas de cada bloqueo, y como hemos dicho, un atlas de resonancia magnética de la sección axial correspondiente a esa zona. 


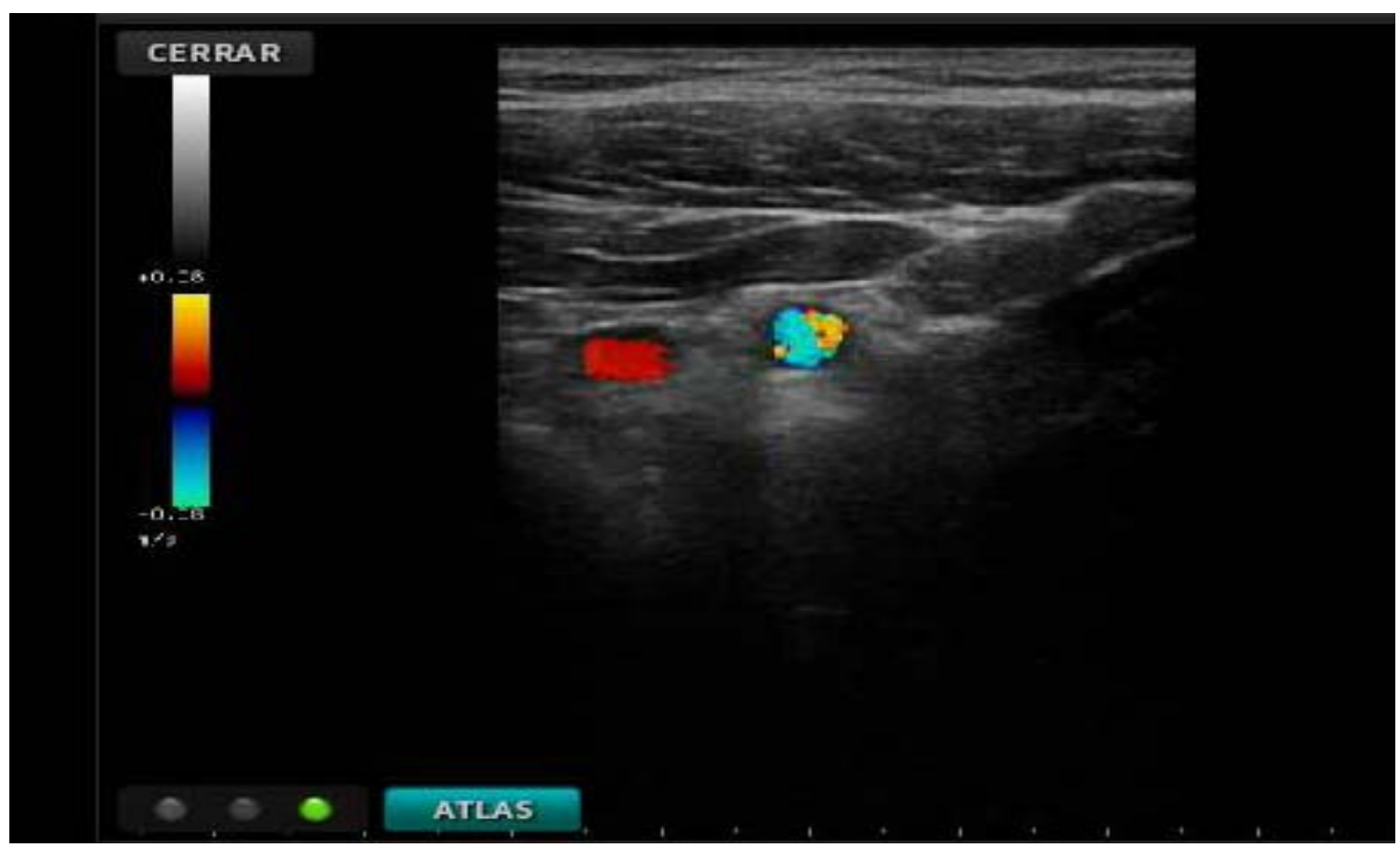

Figura 50. EcoDoppler vascular. Se muestra el color rojo o azul dependiendo de si el flujo se acerca o se aleja de la sonda ecográfica. 

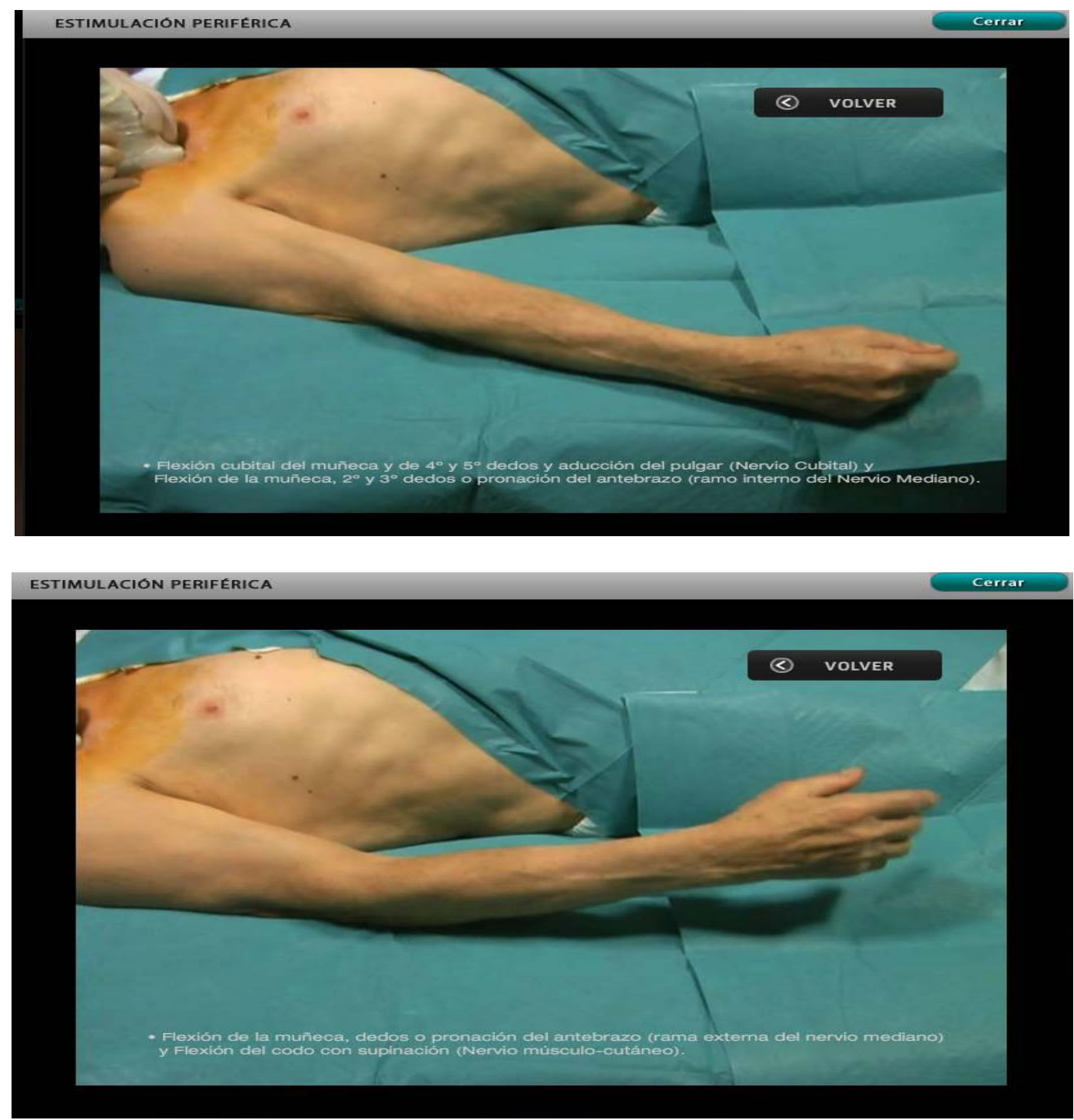

Figura 51. Figura que muestra la estimulación periférica correspondiente al bloqueo seleccionado en pacientes reales (en este caso del nervio cubital, mediano y músculocutáneo). En la parte inferior aparece una leyenda explicando el movimiento que afecta a cada nervio en cuestión. En algunos nervios no se mostrará la neuroestimulación (safeno, femorocutáneo lateral, tibial posterior, sural, peroneo superficial y profundo).

Entre las recomendaciones se muestran las indicaciones quirúrgicas y analgésicas del bloqueo, acompañado de la descripción de otros bloqueos añadidos que habría que realizar (por ejemplo, si la cirugía cursa con isquemia). Se especifica también la dosis de anestésico local más adecuada para cada caso. En un segundo punto las precauciones a la hora de 
realizarlo (por ejemplo según la comorbilidad del paciente, EPOC...). Tercero, las complicaciones (neumotórax, punción arterial...). En cuarto lugar, la posición más adecuada del paciente y la sonda para su mejor abordaje y finalmente, una serie de recomendaciones basadas en la experiencia personal del equipo de anestesistas dedicados a anestesia regional para garantizar el éxito del mismo (como insertar un catéter, variantes anatómicas...) (Fig. $52)$.

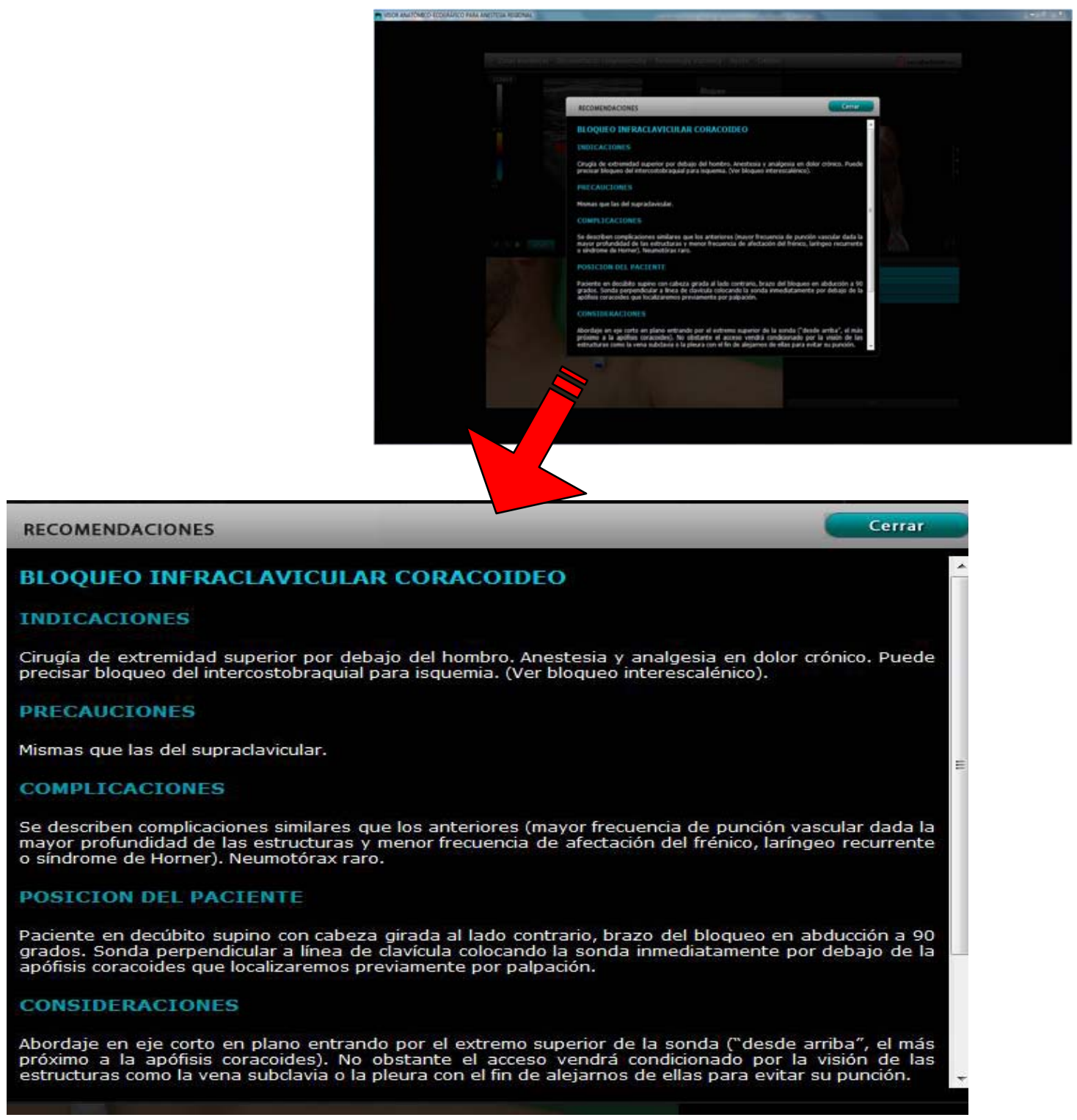

Figura 52. Recomendaciones específicas para ese bloqueo determinado. El procedimiento tecnológico para el aprendizaje de la anestesia regional está diseñado para ser una guía muy completa. 
En la sección de RM se identifica claramente la zona ventral (V), dorsal (D), medial (M) y lateral (L) (Fig. 53).

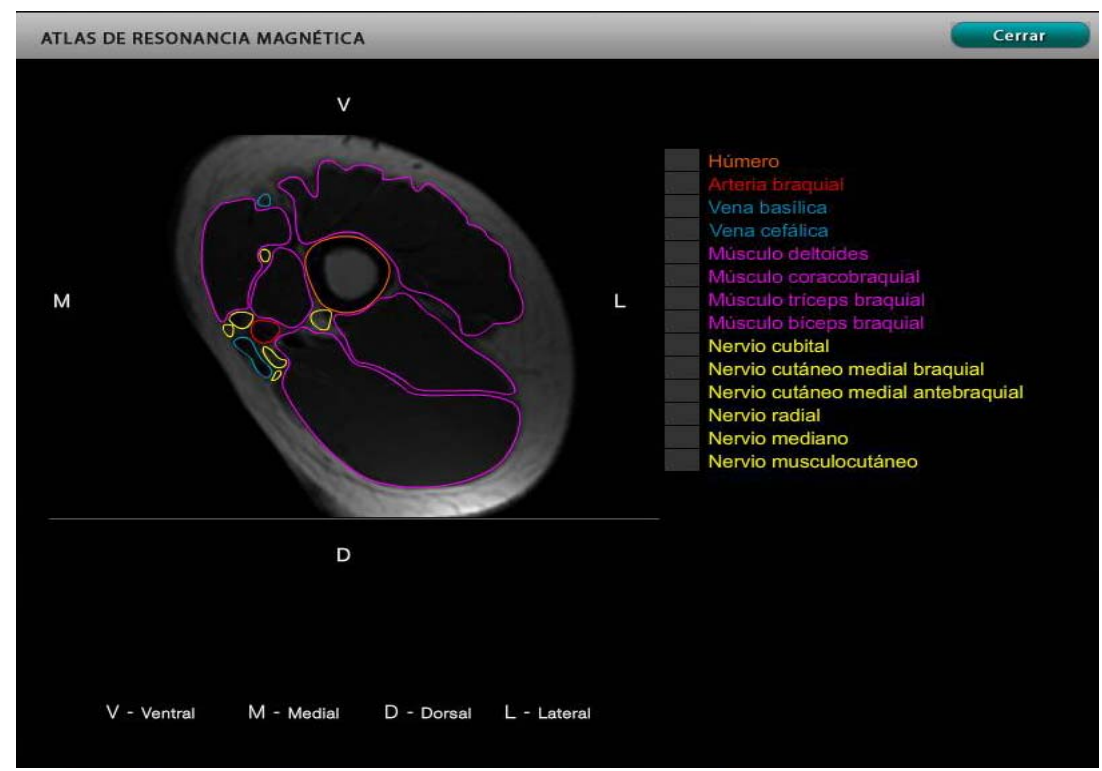

Figura 53. Imagen de RM del bloqueo seleccionado con las estructuras perfectamente identificadas mediante un código de colores (igual al de la imagen ecográfica).

En la sección de RM al arrastrar el ratón por las distintas estructuras del corte se localiza el nombre de la misma mediante la flecha del cursor y cambia el nombre de color; de igual forma al seleccionar un nombre esta estructura se resalta en el corte de la imagen radiológica para que sea identificada (Fig. 54).

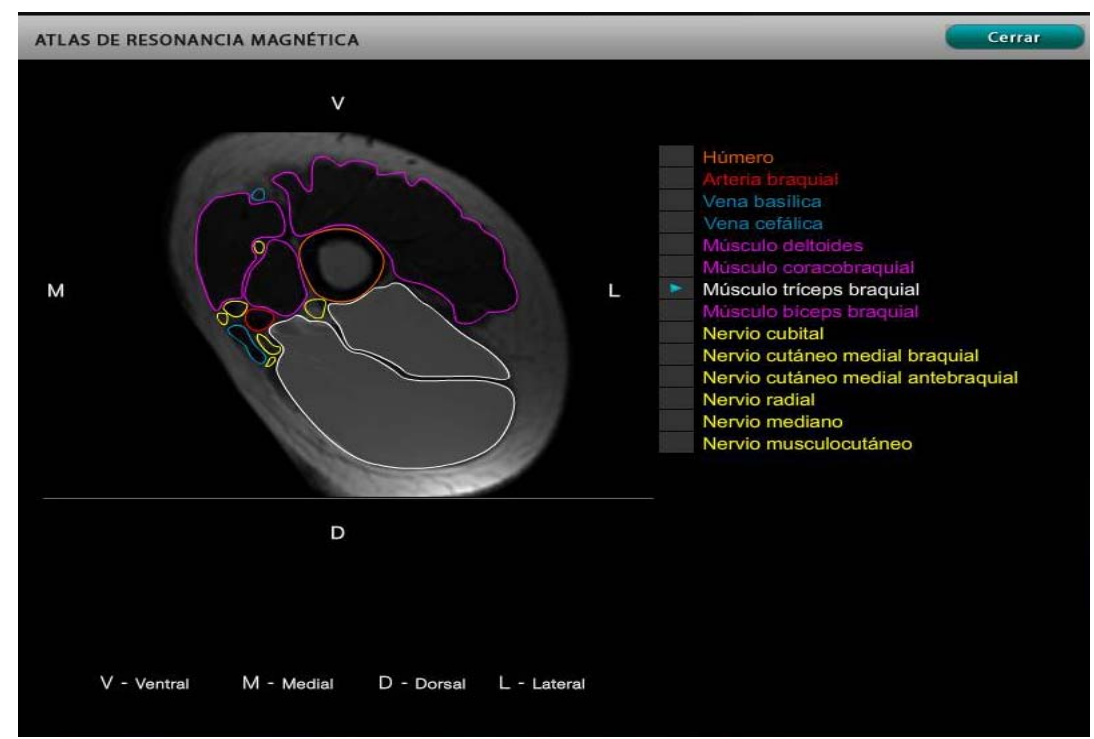

Figura 54. Corte axial de la extremidad superior, resalta la selección del músculo tríceps braquial; se puede hacer desde la nomenclatura o desde la imagen de RM. 
La parte derecha de la pantalla principal se reserva para el visor tridimensional de la zona anatómica relacionada. Todas las interacciones con los elementos de la escena (rotaciones, traslaciones, zoom y selección) se realizan situando el cursor sobre el visor, usando el ratón.

\section{Rotaciones:}

Para rotar la imagen del visor, se mantendrá pulsado el botón principal (izquierdo) del ratón mientras se desplaza el cursor sobre la pantalla (Fig. 55).
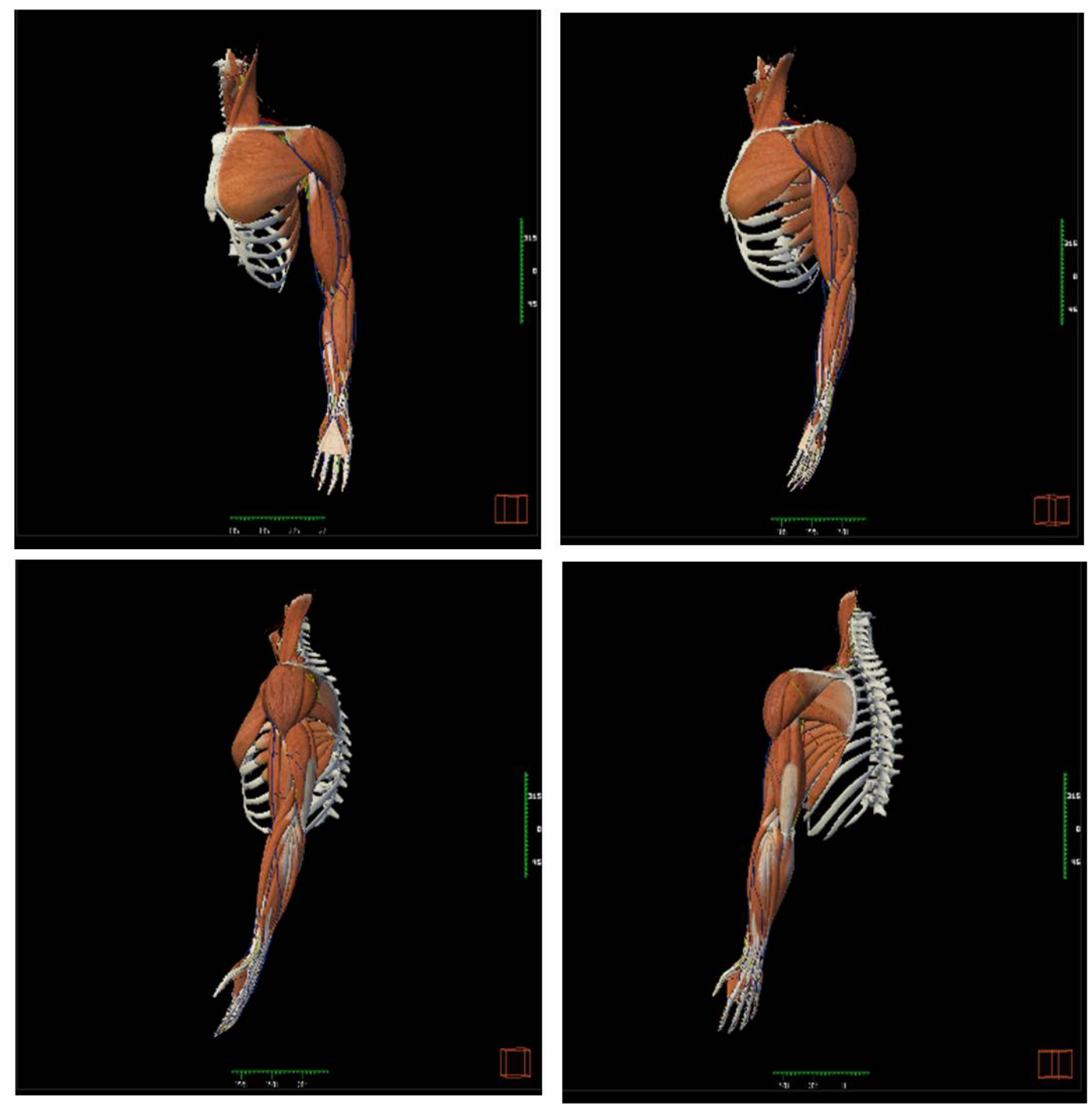

Figura 55. El visor anatómico 3D permite la visualización de las diferentes estructuras anatómicas en cualquier posición espacial. Esta imagen ilustra el movimiento de rotación, desde anterior a posterior. 


\section{Traslaciones:}

Para trasladar la imagen del visor en el plano de la pantalla, habrá que mantener pulsados los dos botones del ratón mientras se desplaza el cursor.

\section{Zoom:}

Para ampliar o reducir el tamaño de la imagen que se muestra en el visor, se mantendrá presionado el botón secundario (derecho) del ratón, desplazando el cursor hacia arriba (ampliar) o hacia abajo (reducir) (Fig. 56).

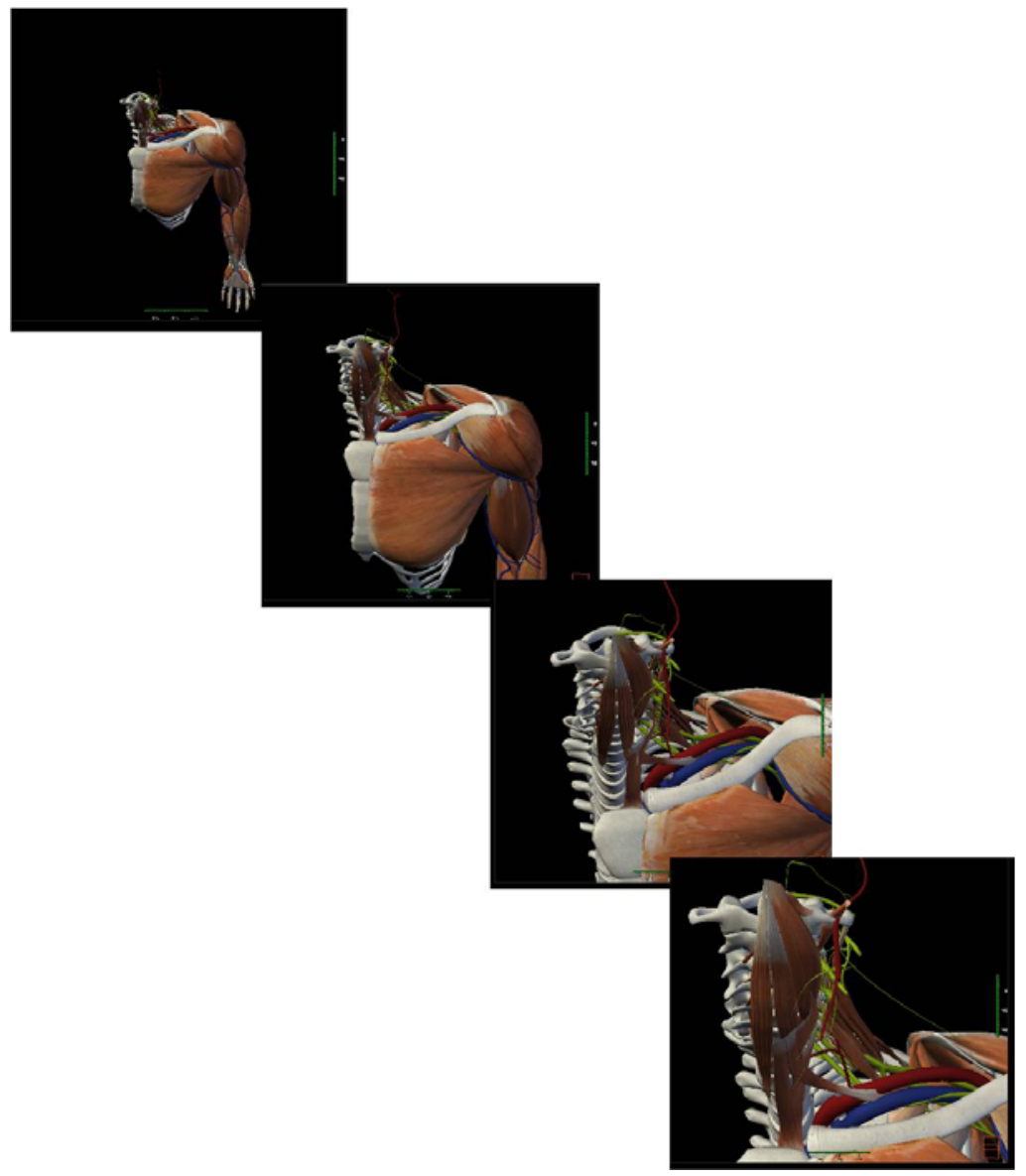

Figura 56. Zoom del visor tridimensional de anatomía en el que logramos apreciar la región anatómica del cuello valorando con detalle los vasos, nervios v plano muscular.

El visor tridimensional permite al usuario una interacción total con la aplicación, se puede visualizar la anatomía correspondiente a la zona donde se va a localizar la ecografía, lo que hace que esta aplicación sea altamente pedagógica (Fig. 57). 


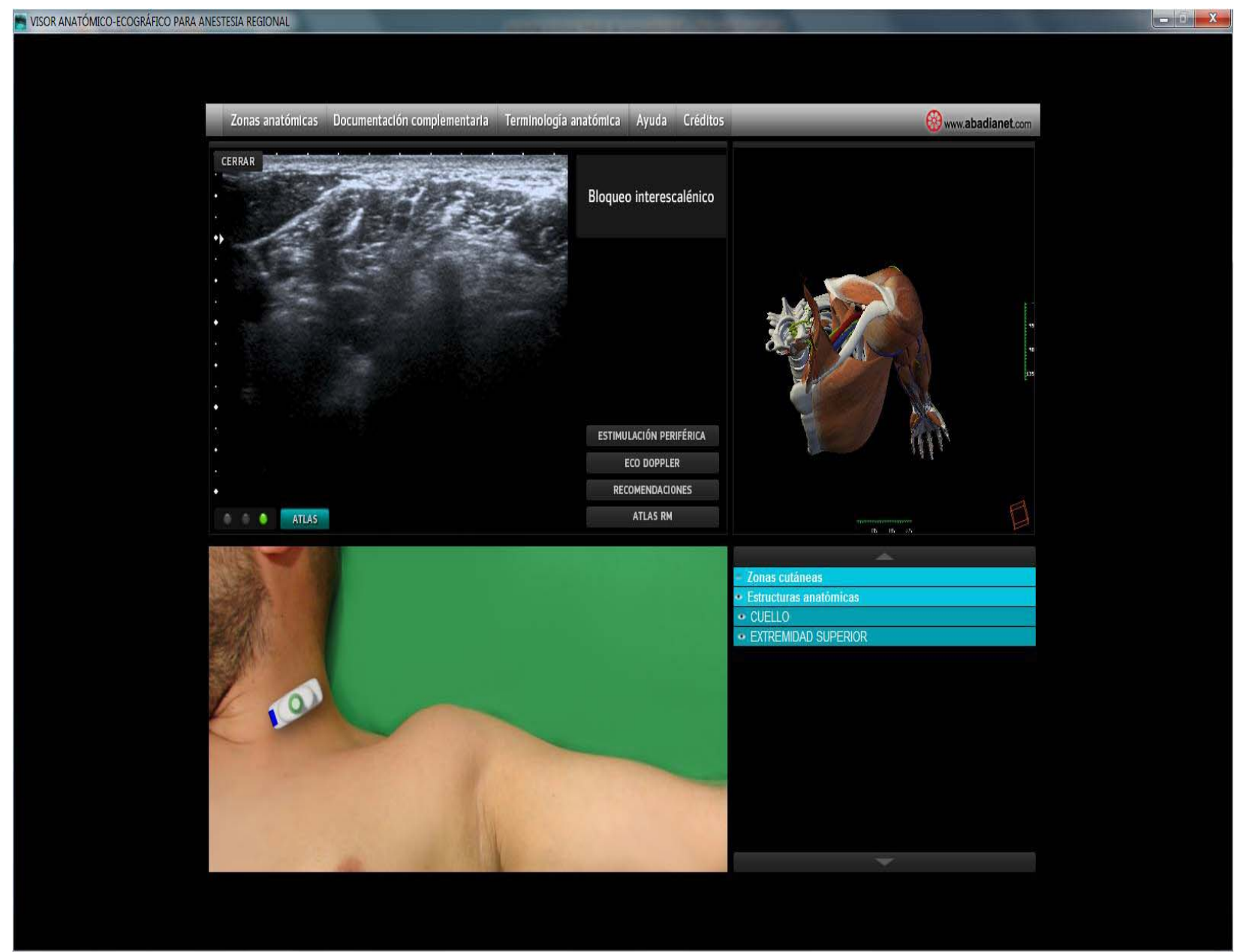

Figura 57. Visión general del interface de nuestro procedimiento informático donde se visualiza la anatomía de superficie, la visión ecográfica y la visión anatómica 3D.

\section{Selección:}

Al pulsar sobre algún elemento interactuable de la escena (músculos y nervios), dicho elemento se mostrará en la sección de documentación inferior, navegando entre los distintos niveles de complejidad. En los elementos inferiores de las estructuras anatómicas se muestra una breve descripción de la estructura en cuestión describiendo su origen, inserción y su función (Fig.58). 


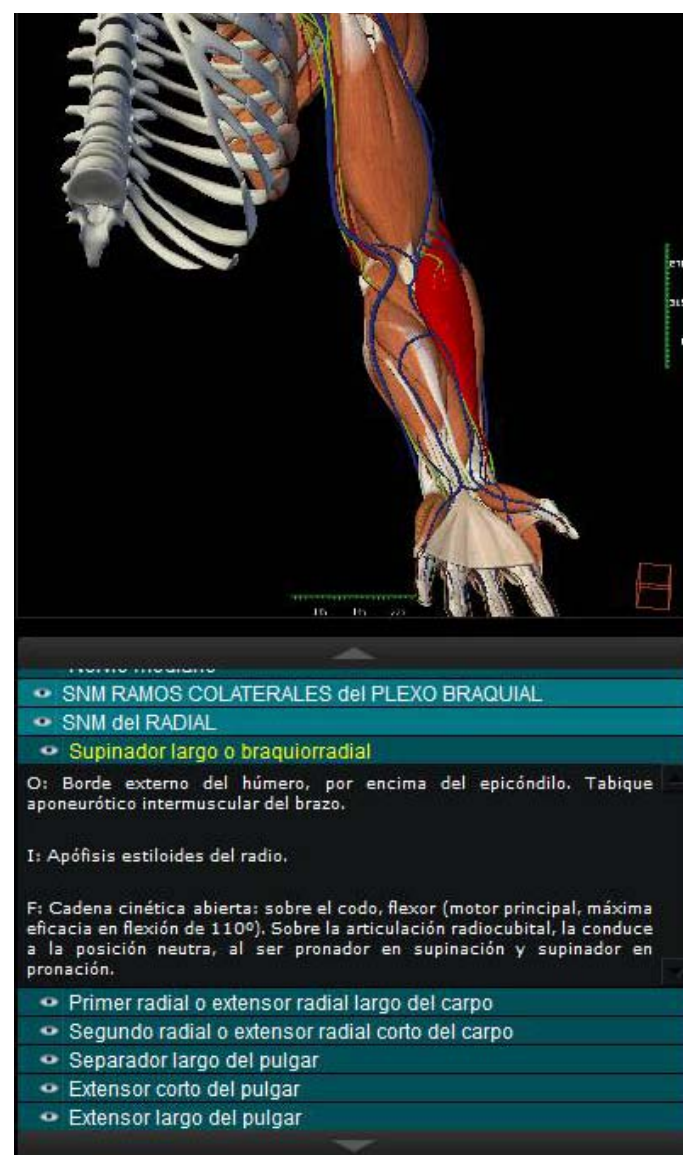

Figura 58. Al seleccionar un músculo se muestra una breve descripción del mismo (O: Origen, I: Inserción y $\mathrm{F}$ : Función del músculo). En la imagen se ha seleccionado el supinador largo o braquiorradial que aparece con otro tono en el visor.

En el visor tridimensional hay dos elementos que se pueden observar: las zonas cutáneas y las estructuras anatómicas.

Las zonas cutáneas muestran la piel coloreada con las distintas áreas de inervación, y una leyenda inferior indicando en cada color el nervio al que corresponde (Figs. 59 y 60). 

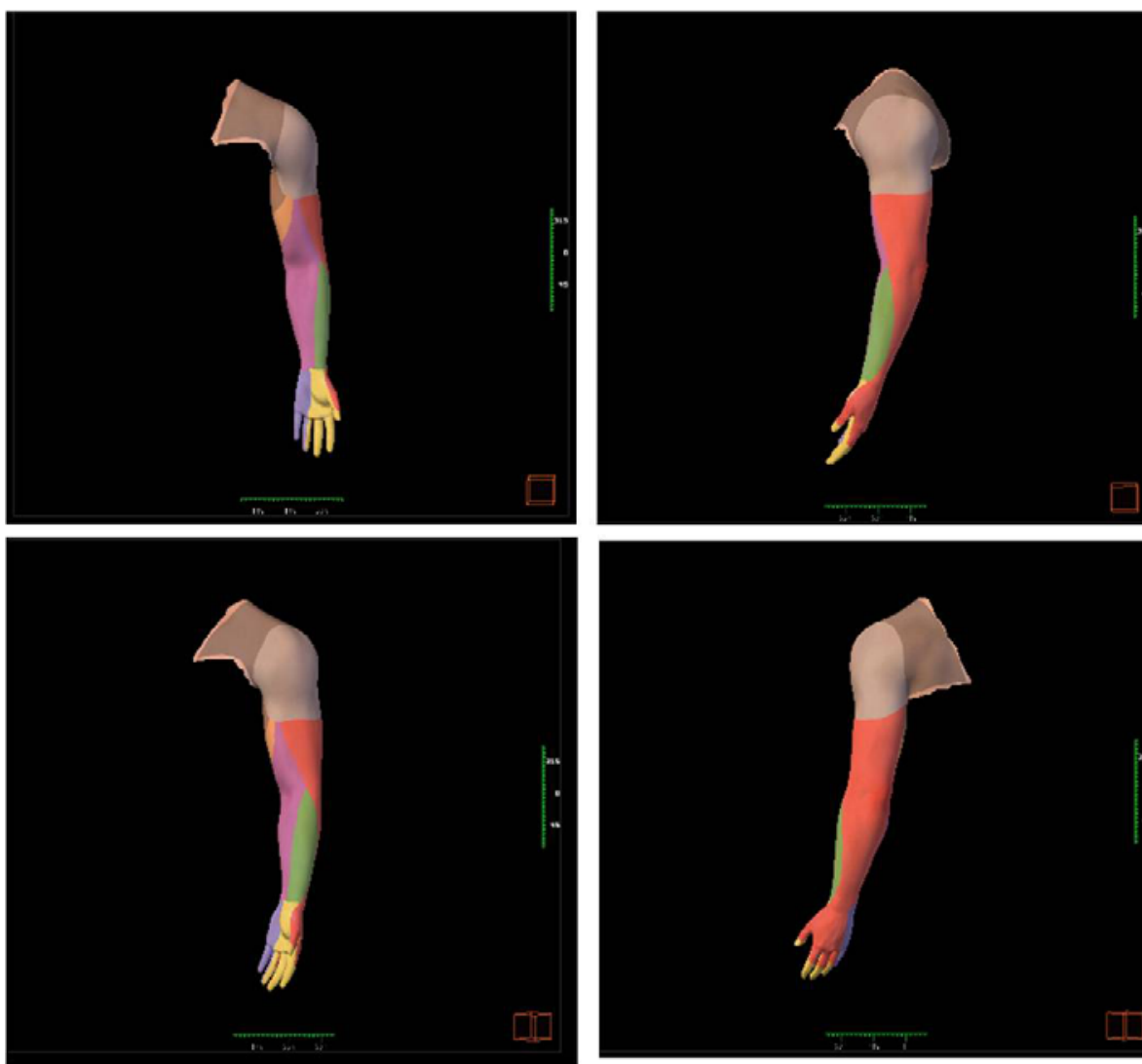

Figura 59. Dermatomas de la extremidad superior desde distintos ángulos de visión.

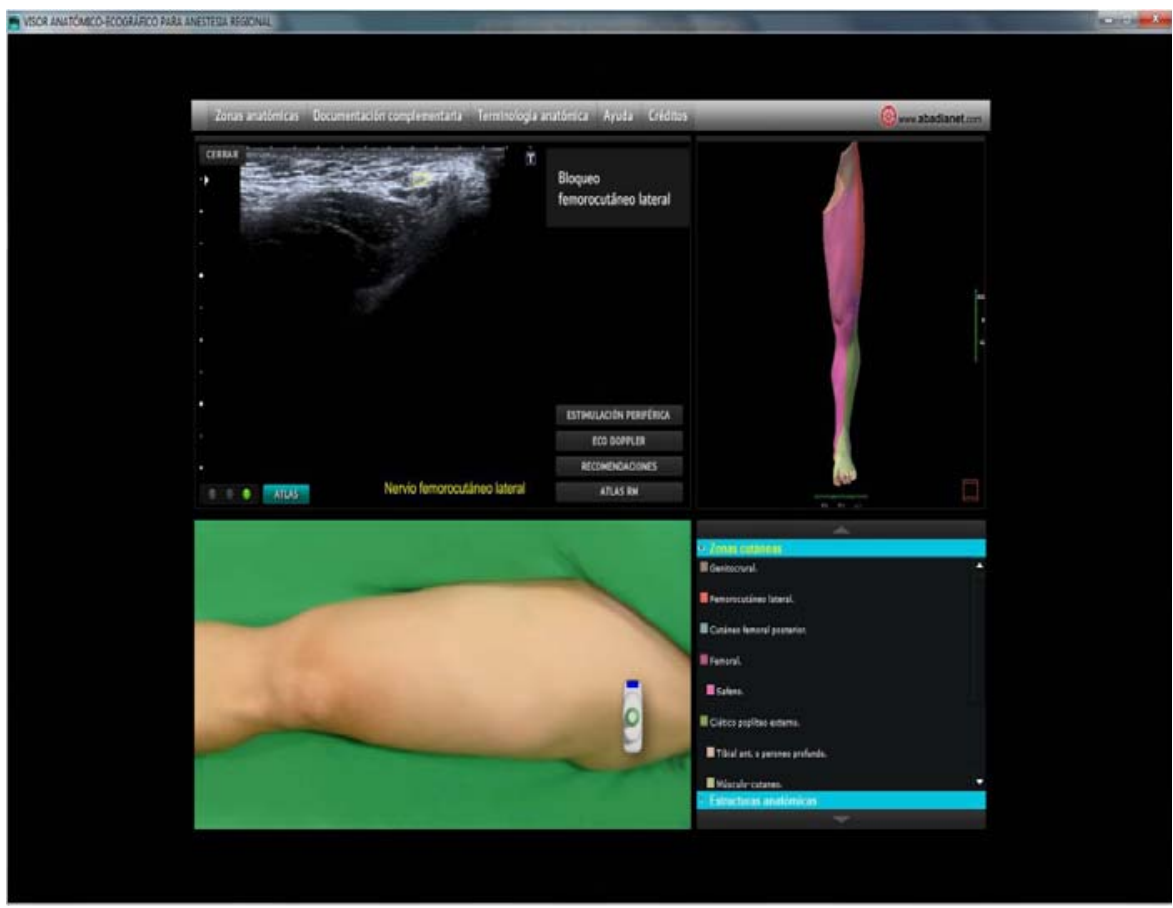

Figura 60. Zonas cutáneas de la extremidad inferior. Obsérvese en la parte inferior derecha de la pantalla la leyenda donde se muestra el nombre del nervio con su color correspondiente. 
Las estructuras anatómicas muestran un sistema jerárquico con los distintos elementos anatómicos relacionados, mostrando tanto huesos como sistema circulatorio de referencia.

El visor tridimensional permite tanto la selección o activación como la deselección o desactivación y visualizar de forma aislada un solo sistema neuromuscular e incluso un músculo en solitario; o lo que es lo mismo, desde la estructura ósea y vascular ir generando con la simple selección de un clic del ratón los distintos sistemas neuromusculares hasta tener la extremidad completa (Figs. 61 y 62).

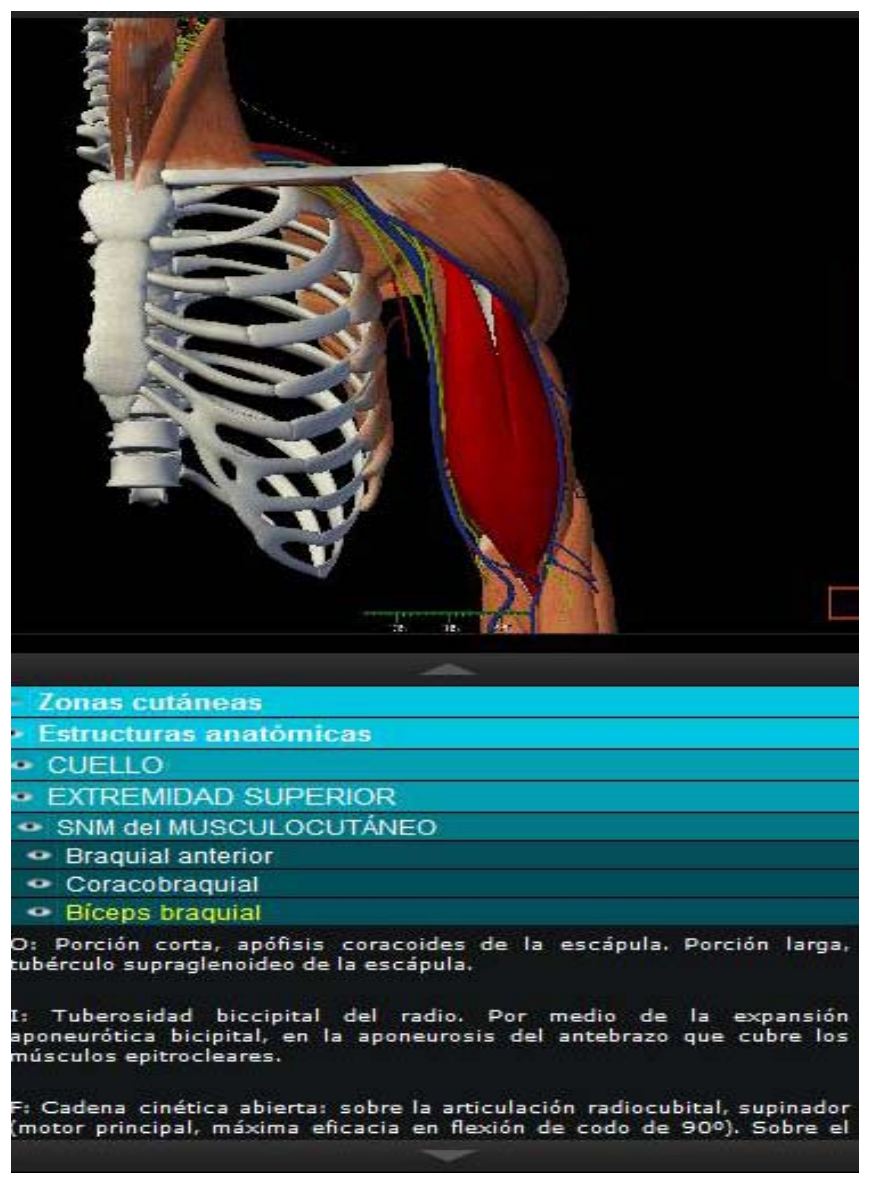

Figura 61. Descripción del bíceps braquial, se observa como destaca con un color más oscuro entre los otros grupos musculares. 


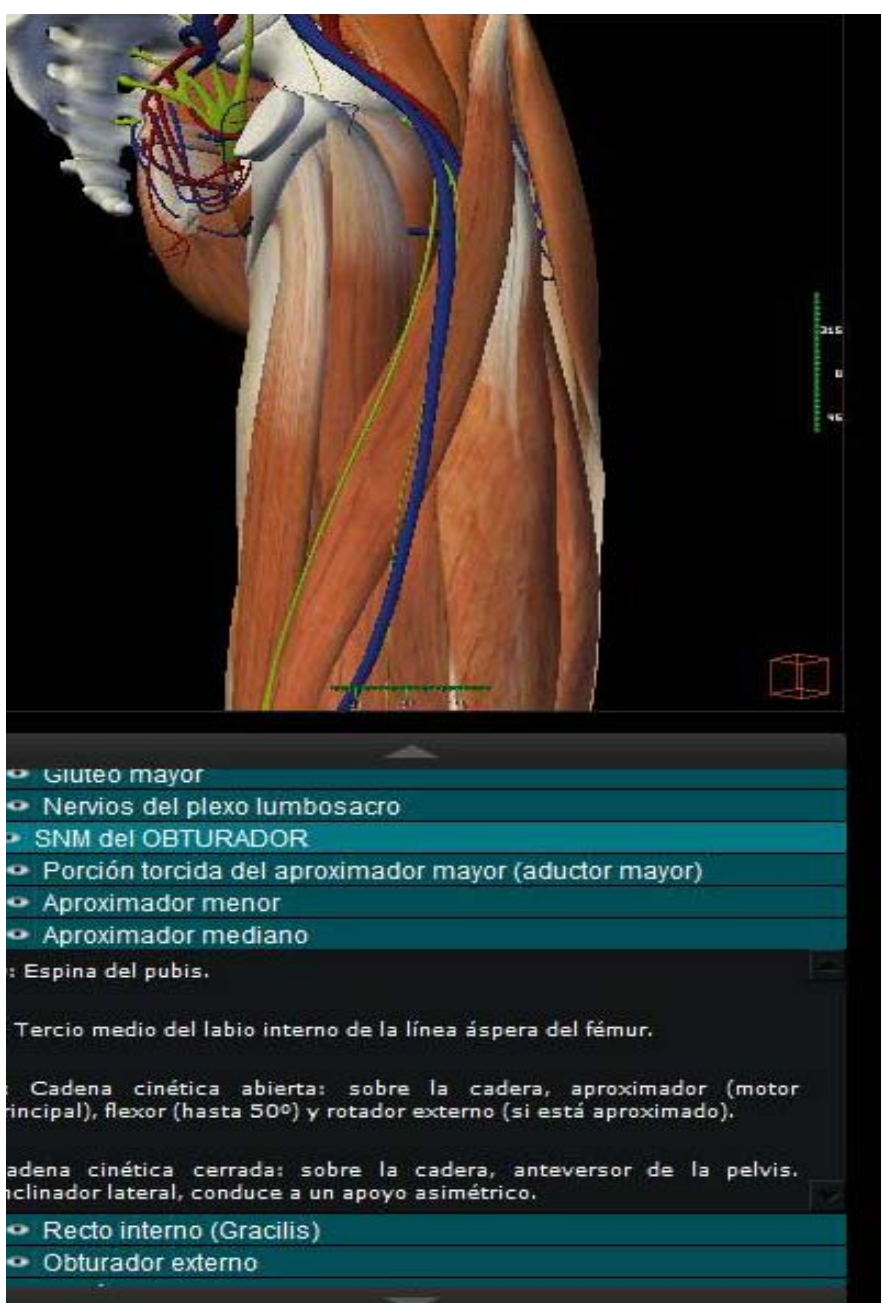

Figura 62. Visor en 3D, en este caso de la extremidad inferior. En la parte inferior de la imagen se muestran los sistemas neuromusculares; al clicar sobre ellos se señalan en el visor y aparece además una breve explicación del músculo seleccionado.

A continuación, a modo de ejemplo describiremos mediante el procedimiento tecnológico un bloqueo característico de la extremidad superior y otro de la inferior, por ser de los bloqueos más utilizados en la práctica clínica diaria. Se realiza sólo esta descripción para evitar la extensión de nuestra tesis doctoral. 


\subsection{DESCRIPCIÓN DEL BLOQUEO SUPRACLAVICULAR Y TIBIAL COMO EJEMPLO DE NUESTRO DESARROLLO INFORMÁTICO.}

\subsection{BLOQUEO SUPRACLAVICULAR}

\section{INDICACIONES}

Cirugía del miembro superior por debajo del hombro. Analgesia de la misma zona. Puede precisar bloqueo del intercostobraquial (ver bloqueo interescalénico).

\section{PRECAUCIONES}

Igual que las indicadas en el interescalénico. Se describe riesgo de neumotórax tardío y por esto se desaconseja en CMA, no obstante, con ecografía, no consideramos que este riesgo exista porque la pleura se ve con facilidad y no se debería puncionar.

\section{COMPLICACIONES}

Síndrome de Horner.

Punción de arteria subclavia (y de otras arterias como la transversa del cuello y la dorsal de la escápula que frecuentemente atraviesan por la zona central del plexo a este nivel).

Bloqueo del nervio laríngeo recurrente.

Bloqueo nervio frénico (menos frecuente que el interescalénico).

Neumotórax.

\section{POSICION DEL PACIENTE}

Decúbito supino con cabeza girada al lado contralateral del bloqueo, brazo pegado al cuerpo (con el brazo en abducción se estrecha mucho el hueco supraclavicular y no se ve bien). 


\section{CONSIDERACIONES}

A este nivel el plexo braquial adquiere aspecto de racimo con un conjunto de estructuras redondeadas hipoecoicas y de borde hiperecoico, que son las divisiones anteriores y posteriores de los troncos nerviosos. Estas estructuras se sitúan habitualmente por encima y laterales a la arteria subclavia, que es la estructura guía en este abordaje, aunque no siempre es así. Para tener la seguridad de bloquear completamente todo el plexo es conveniente hacer un barrido hacia el espacio interescalénico, y desde ahí, de nuevo, ir descendiendo observando cuidadosamente la distribución de las divisiones, a medida que éstas se producen y su relación con la arteria subclavia.

Abordaje en eje corto y en plano, desde el borde más externo de la sonda (parte más lejana a la subclavia y más cercana al plexo). El plexo braquial a nivel supraclavicular puede estar atravesado por arterias. Utilizar Doppler previo al bloqueo y buscar otro plano en el que no se encuentren dichas arterias para evitar su punción. El bloqueo también puede realizarse en eje corto y fuera de plano, previa observación de la profundidad a la que está situado el plexo para no puncionar pleura (Figs 63, 64, 65, 66, 67, 68).

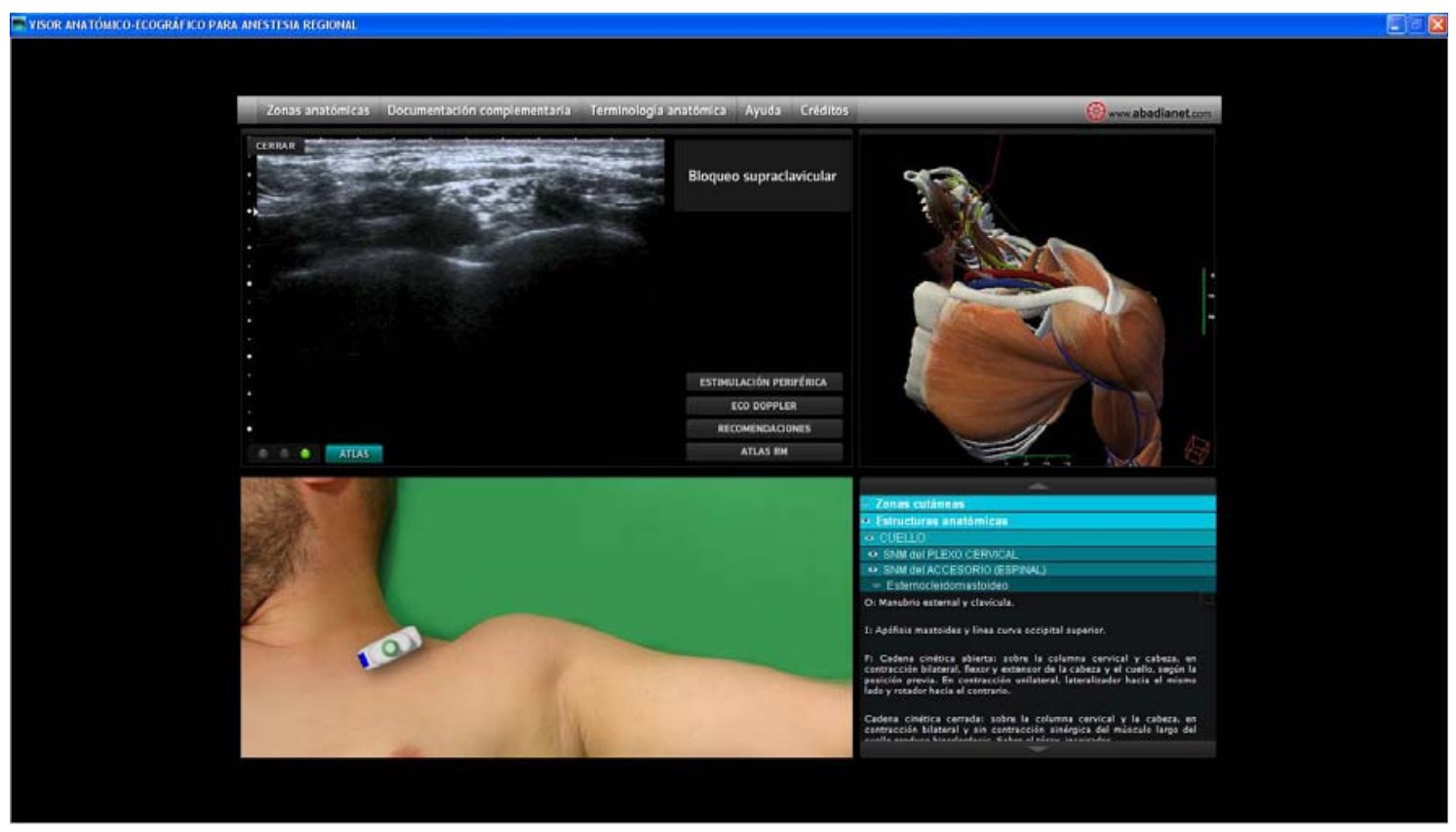

Figura 63. Imagen del procedimiento tecnológico para el bloqueo del plexo supraclavicular. Localización de la sonda para la realización de dicho bloqueo. 


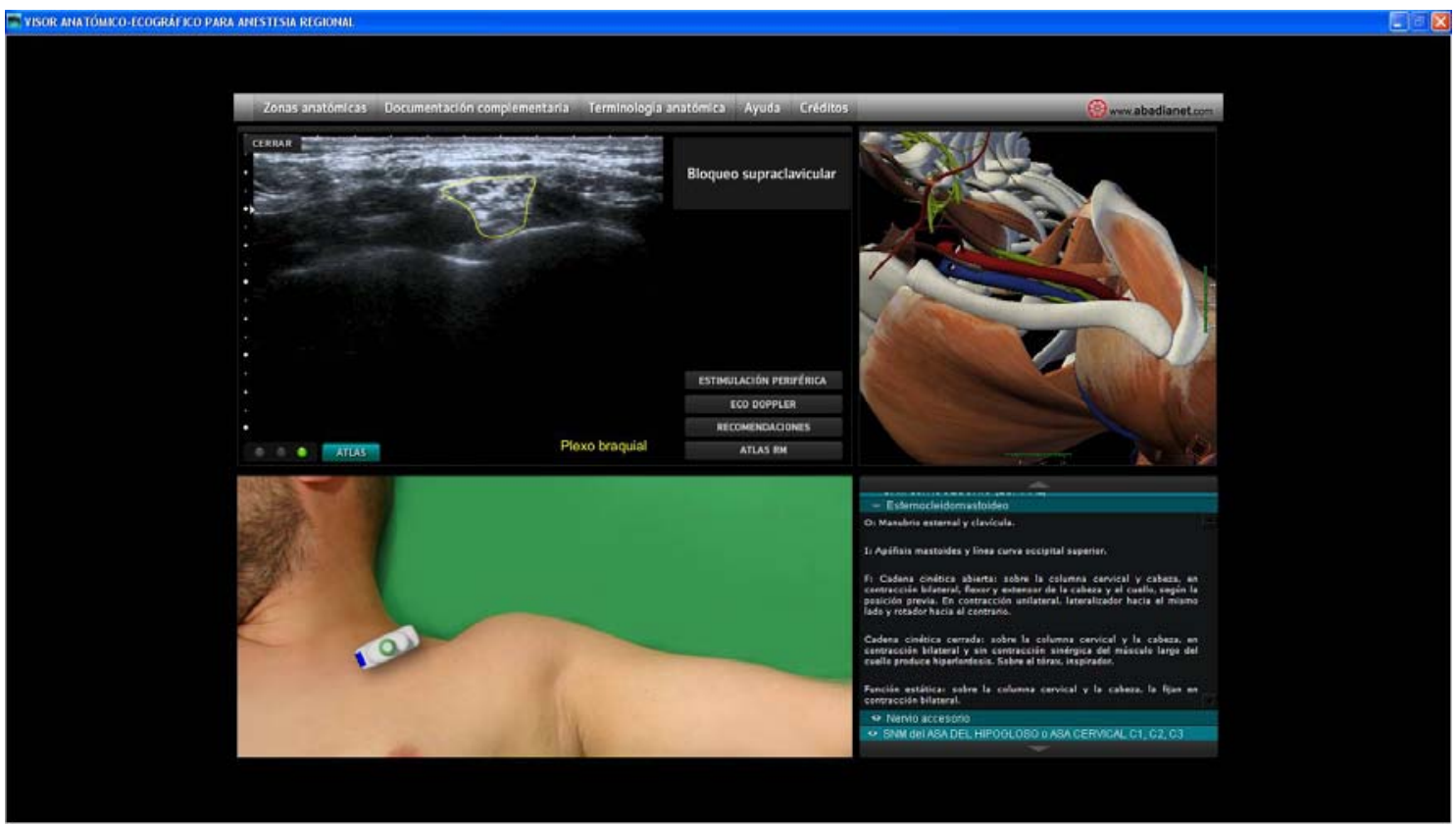

Figura 64. Detalle donde se visualiza la imagen ultrasonográfica del plexo braquial con su correspondiente imagen anatómica desde una visión superior de la clavícula.

En la siguiente imagen (Fig. 65) vemos en aumento el visor 3D desde otra perspectiva:

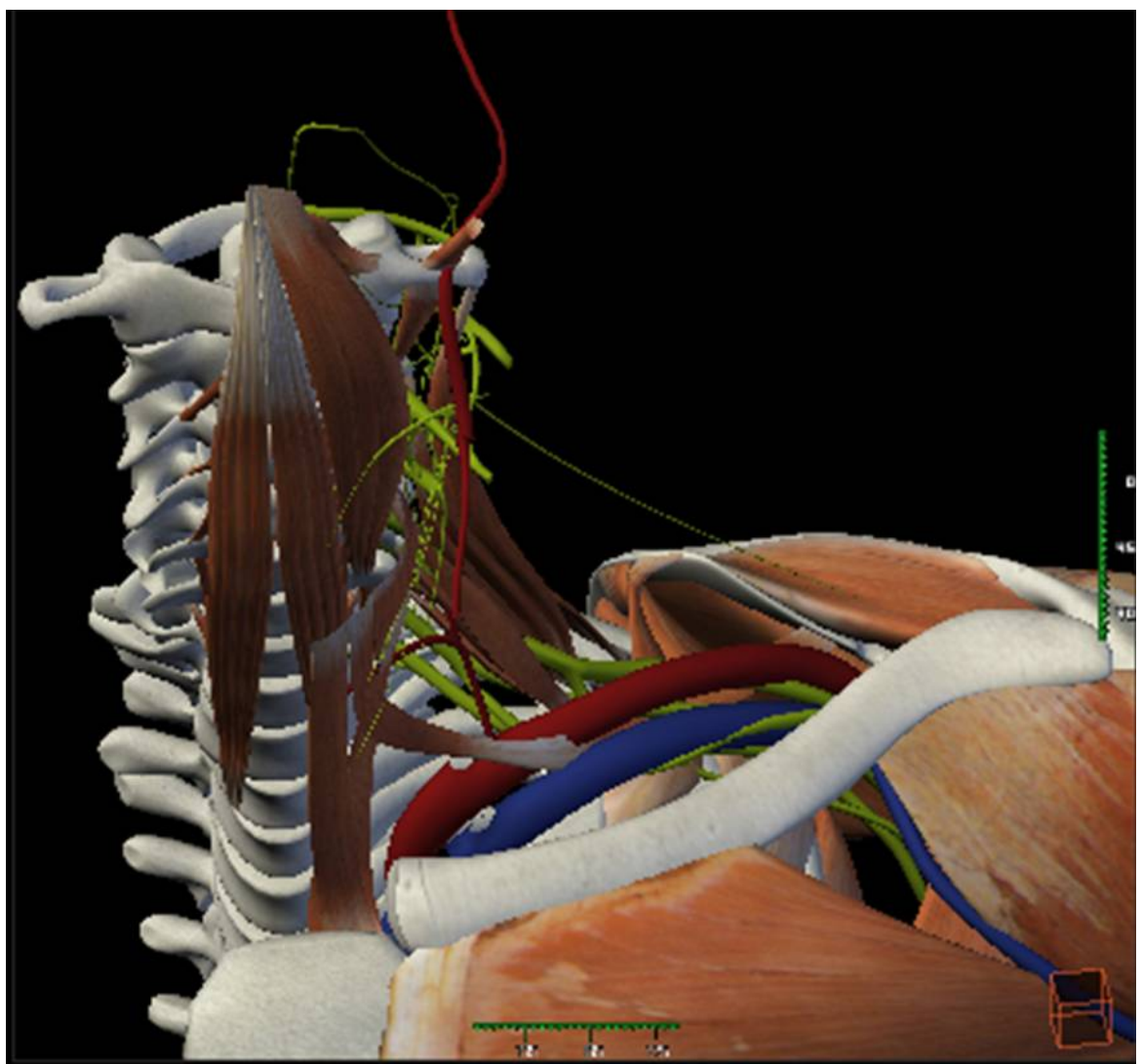

Figura 65: Imagen aumentada del visor anatómico 3D. 
El paquete vascular va intimimente ligado al plexo braquial, es importante la localización de dichos vasos a través de la función eco Doppler para evitar su punción (Figuras 66 y 67).

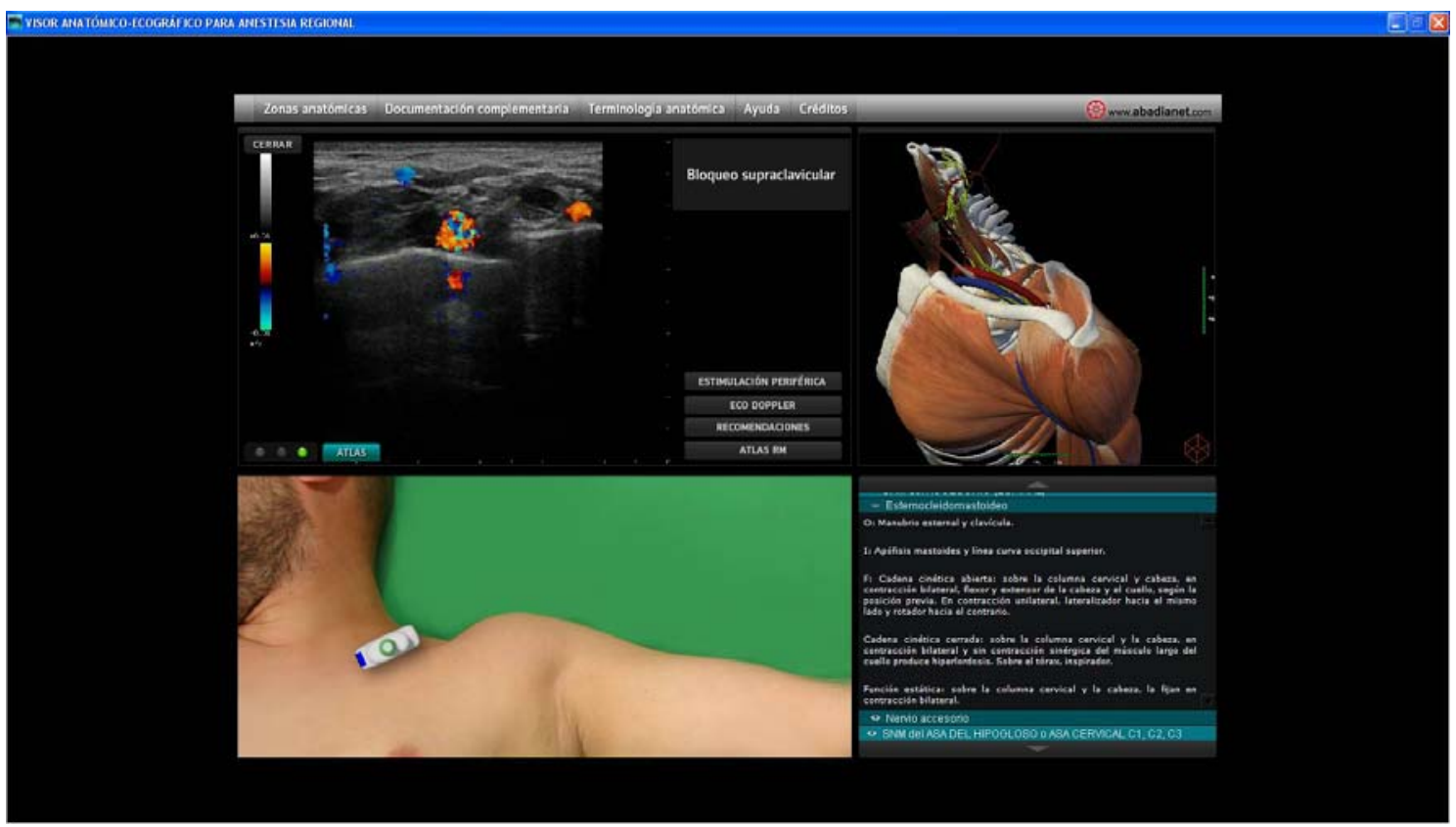

Figura 66. Imagen de la función eco Doppler. Es característico que la vena se colapse con una pequeña presión de la sonda, mientras que la arteria no. Además, la arteria es pulsátil, lo cual se aprecia fácilmente en modo Doppler. Si el movimiento de flujo se aproxima al transductor, aparecerá de colo rojo, si se aleja azul.

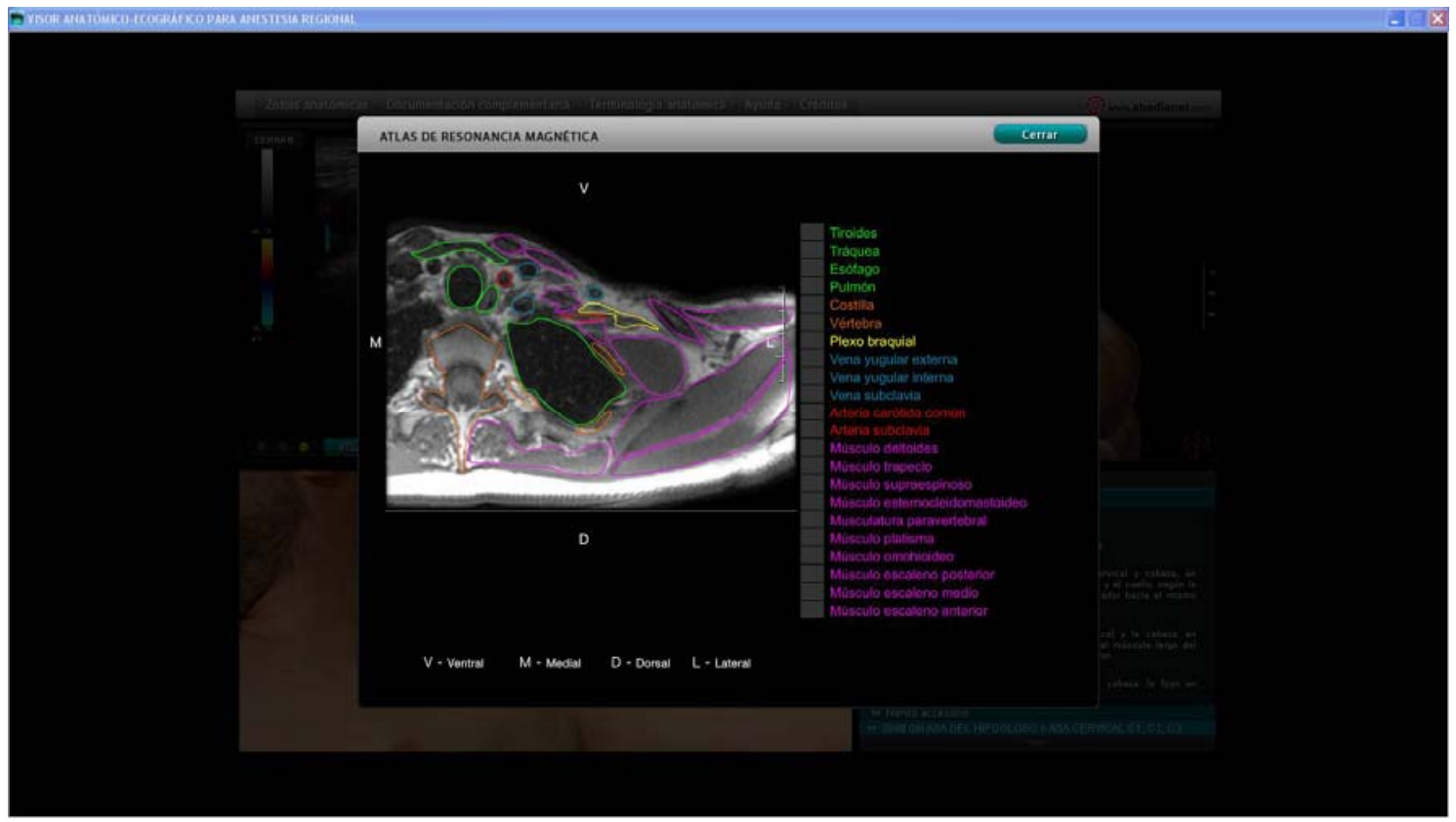

Figura 67. Corte axial de RM correspondiente a la zona de bloqueo a nivel del cuello a la altura aproximada del bloqueo supraclavicular. A la derecha se muestra la leyenda de los códigos de colores que ayudan a diferenciar las estructuras anatómicas. Con el ratón se puede interactuar tanto con la imagen como con la nómina anatómica. 
Para completar la aplicación el procedimiento muestra la estimulación del plexo braquial en un paciente real (Fig. 68).

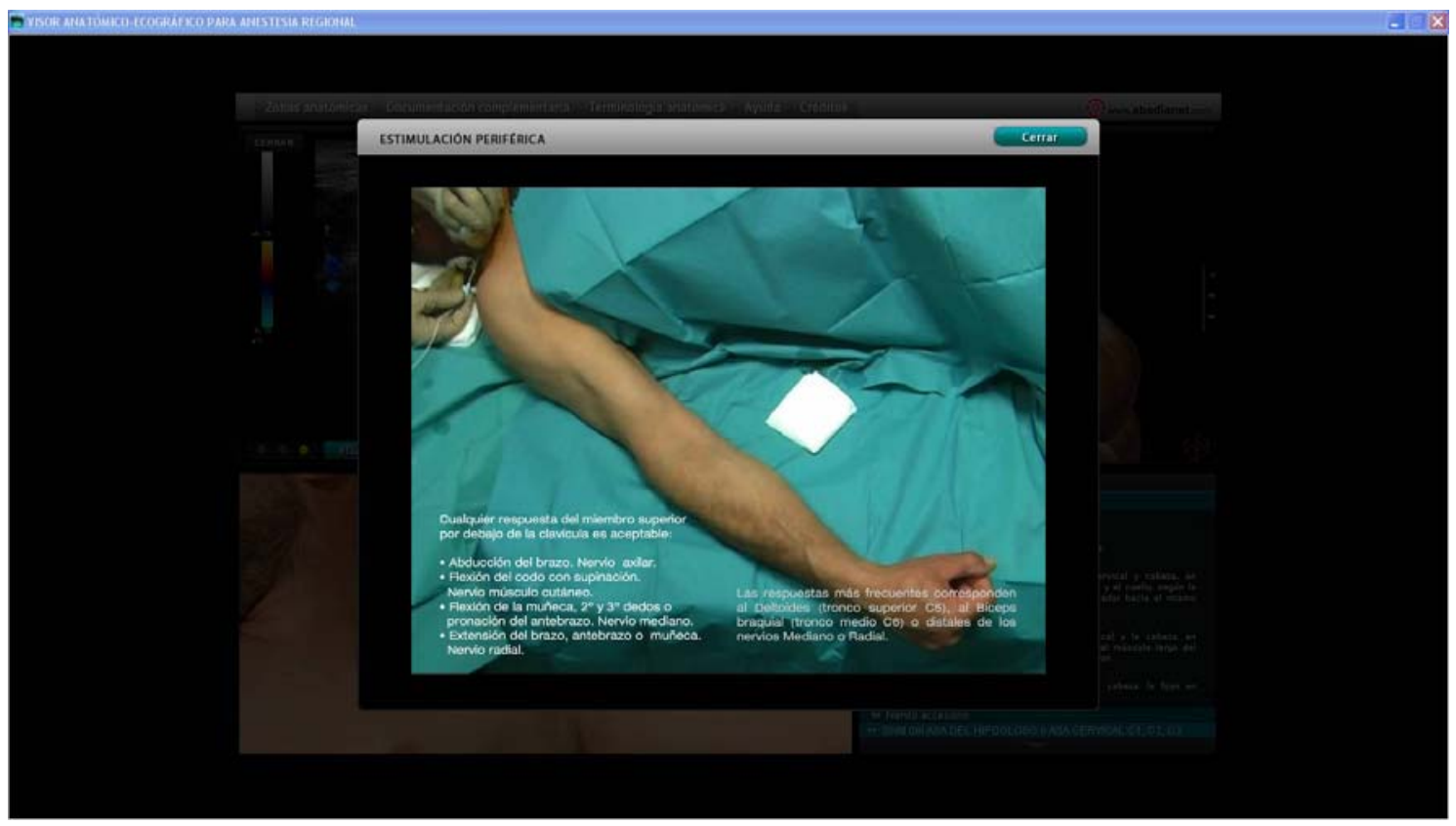

Figura 68. Imagen resumen de la estimulación periférica del plexo braquial con los distintos movimientos que se producen según las ramas del plexo que se estimulen.

\subsubsection{BLOQUEO TIBIAL COMÚN Y POSTERIOR (FIGS. 69 HASTA 83)}

\section{INDICACIONES}

Cirugía y analgesia del tobillo y pie acompañado de bloqueos como safeno y peroneo común. Ver consideraciones sobre isquemia en bloqueo ciático poplíteo y subglúteo.

\section{PRECAUCIONES}

Nervio muy cercano a grandes vasos (vena y arteria femoral denominadas aquí poplíteas).

\section{COMPLICACIONES}

Las habituales. 


\section{POSICION DEL PACIENTE}

Paciente en decúbito prono, tobillo elevado con apoyo para observar fácilmente la estimulación si se realiza. Sonda en hueco poplíteo.

\section{CONSIDERACIONES}

Abordaje en eje corto y en plano desde el borde interno o externo de la sonda.

El nervio tibial va muy superficial en el hueco poplíteo y situado justo por encima de venas y arteria poplítea. Visualizar bien estas venas antes de la punción porque es fácil colapsarlas con la presión de la sonda.

No es frecuente realizar un bloqueo exclusivamente del tibial y se suele acompañar al menos del peroneo común (tener en cuenta que el nervio sural, rama del tibial, tiene también aportaciones del peroneo común).

\section{BLOQUEO TIBIAL POSTERIOR EN PIERNA}

\section{INDICACIONES}

Cirugía de zona afecta (planta del pie) siempre que no se requiera isquemia (salvo isquemia de corta duración). Para cirugía de pie acompañado de otros nervios (sural, peroneo profundo o tibial anterior, peroneo superficial o musculocutáneo). Complemento para bloqueo troncular alto incompleto.

\section{PRECAUCIONES}

Las habituales del bloqueo. Va junto arteria y venas tibiales posteriores.

\section{COMPLICACIONES}

Las generales. 


\section{POSICION DEL PACIENTE}

Decúbito supino con abducción y rotación externa de muslo y pierna. Rodilla semiflexionada apoyada sobre el talón.

\section{CONSIDERACIONES}

Abordaje en eje corto y en plano desde el borde interno de la sonda.

Visualizar previamente venas y arteria tibial posterior. Las venas pueden comprimirse fácilmente con las sonda ya que son muy finas.

El nervio es fácilmente localizable al ir entre fascículos musculares. Si se sigue desde aquí el nervio hasta el maléolo tibial se podrá apreciar su división en plantares.

\section{BLOQUEO TIBIAL POSTERIOR EN TOBILLO}

\section{INDICACIONES}

Cirugía de zona afecta, estructura plantar del pie siempre que no se requiera isquemia (salvo isquemia de corta duración). Acompañado de otros nervios (safeno externo o sural, peroneo profundo o tibial anterior, peroneo superficial o musculocutáneo) para cirugía de pie. Complemento para bloqueo troncular alto incompleto.

\section{PRECAUCIONES}

Las habituales del bloqueo. Va junto arteria y venas tibiales posteriores.

\section{COMPLICACIONES}

Las generales.

\section{POSICION DEL PACIENTE}

Decúbito prono con pie libre o decúbito supino con muslo en rotación externa y rodilla flexionada. 


\section{CONSIDERACIONES}

Abordaje en eje corto y en plano desde borde interno de la sonda (el más alejado del maléolo interno). Se coloca la sonda prácticamente a la altura del maléolo interno o un poco por arriba. El problema surge por la dificultad de colocar la sonda que puede no encajar por el tamaño. Sería más conveniente la utilización de una sonda de tipo "stick" aunque puede no disponerse de ella.

Se puede ver el nervio tibial posterior ya dividido en sus ramas plantar interno y externo, aunque muy agrupadas

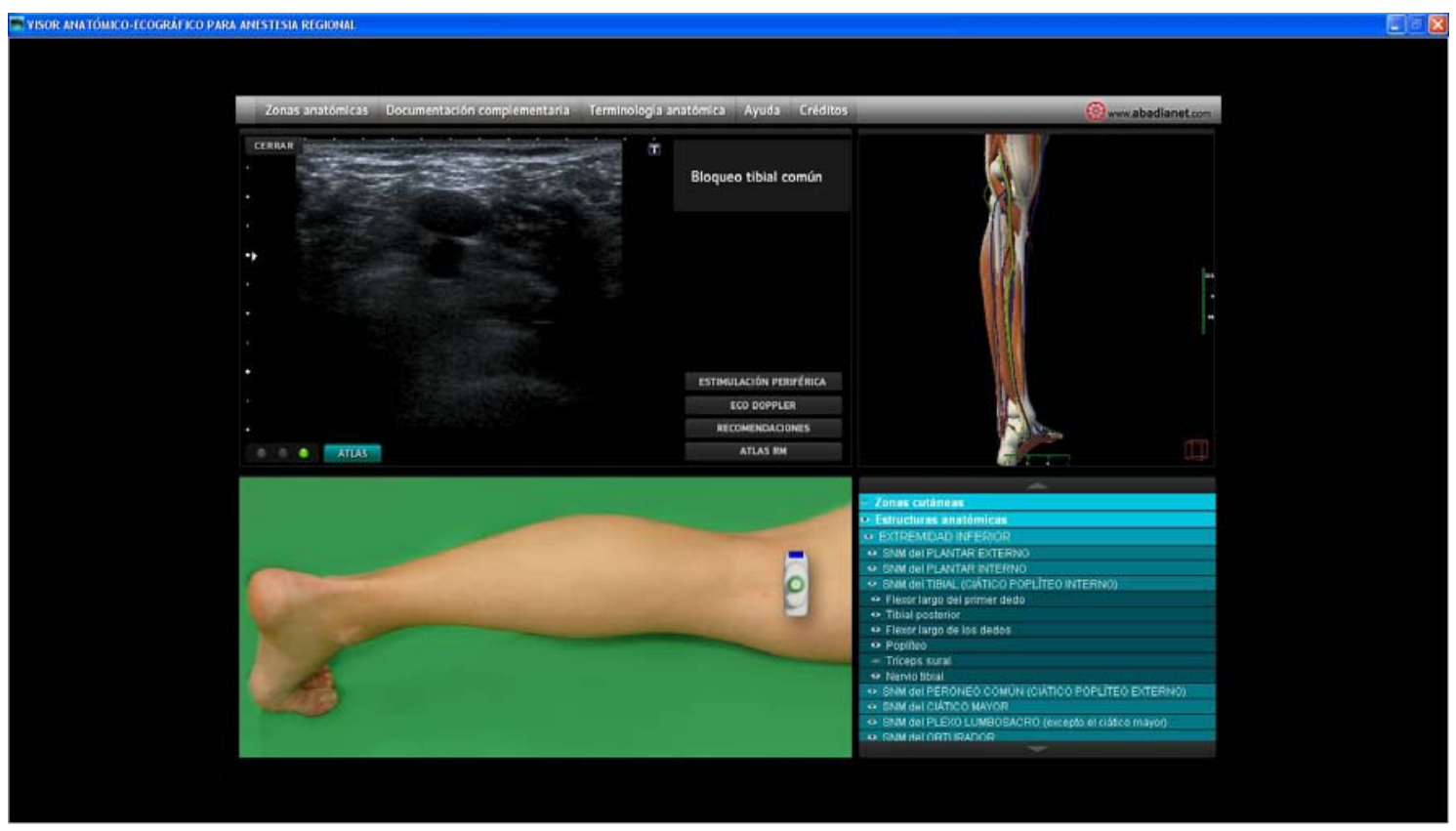

Figura 69. Imagen de la localización del nervio tibial en la anatomía de superficie. En el visor anatómico puede observarse la localización y recorrido del nervio deseleccionando los planos musculares. 


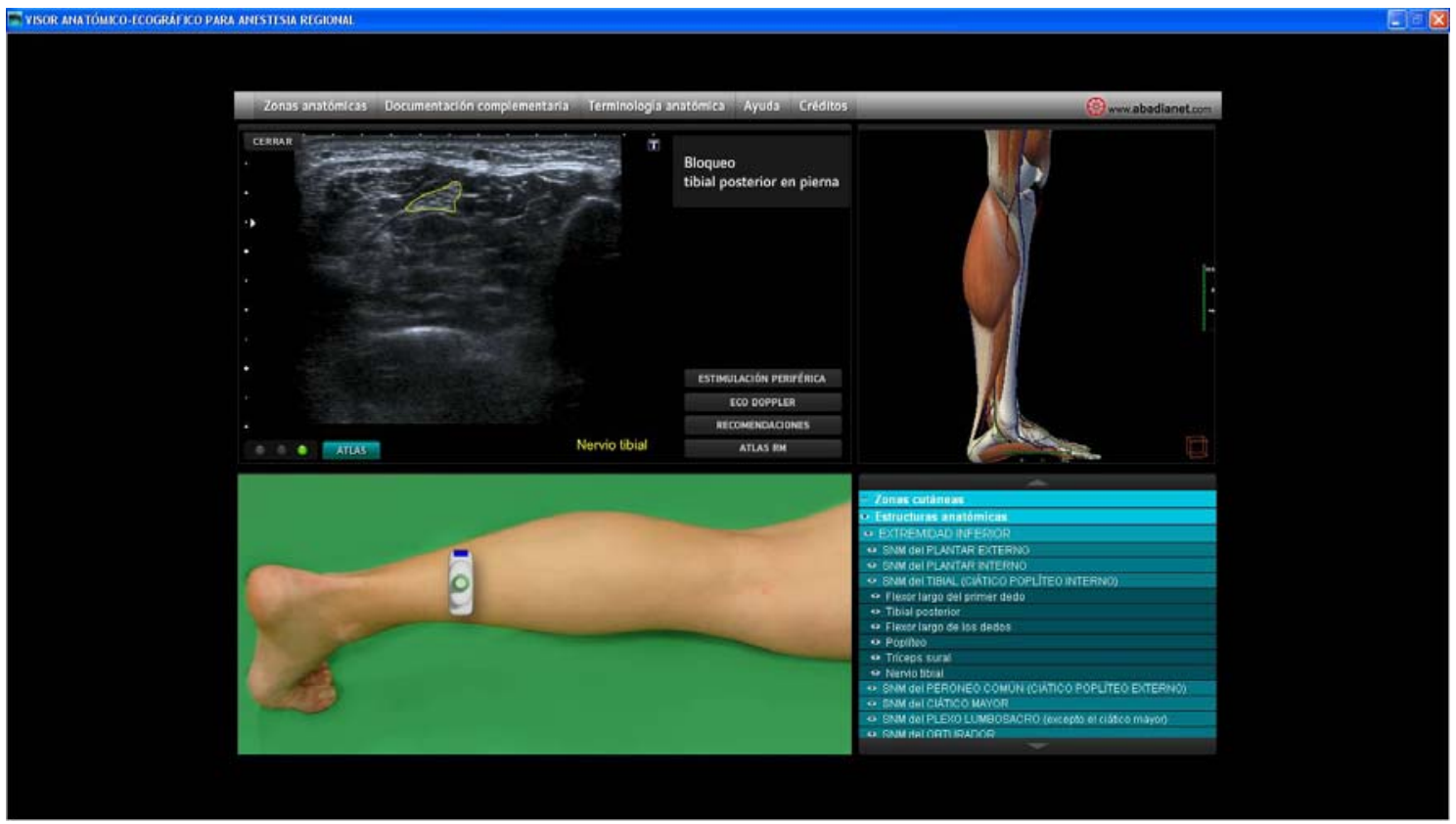

Figura 70. Imagen ultrasonográfica del nervio tibial posterior a altura de la pierna. En amarillo el nervio en el visor ecográfico.

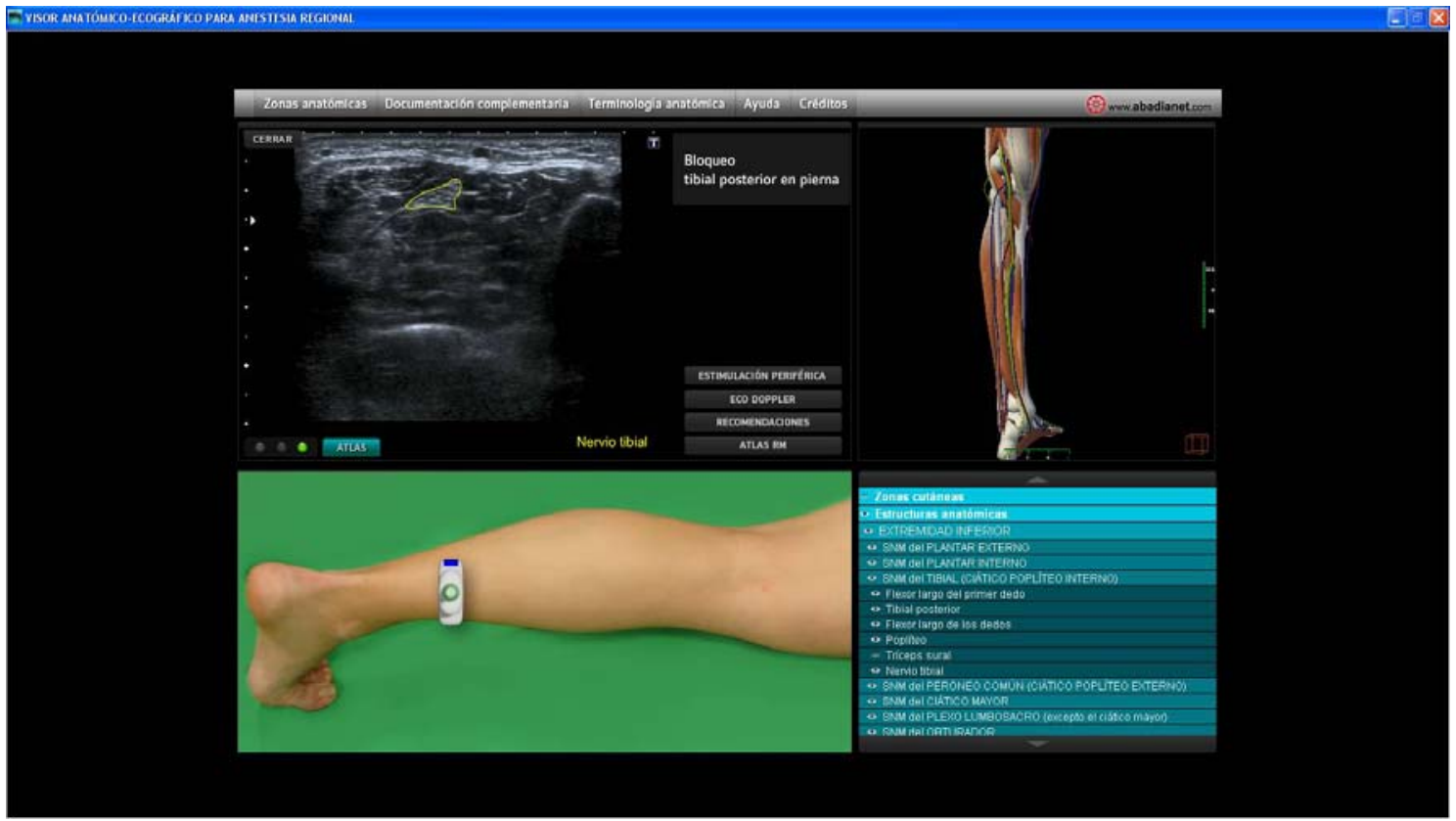

Figura 71. Otra imagen de la localización y detalle del nervio tibial; obsérvese el visor anatómico 3D donde se muestra una imagen de la extremidad inferior desde otra perspectiva. 


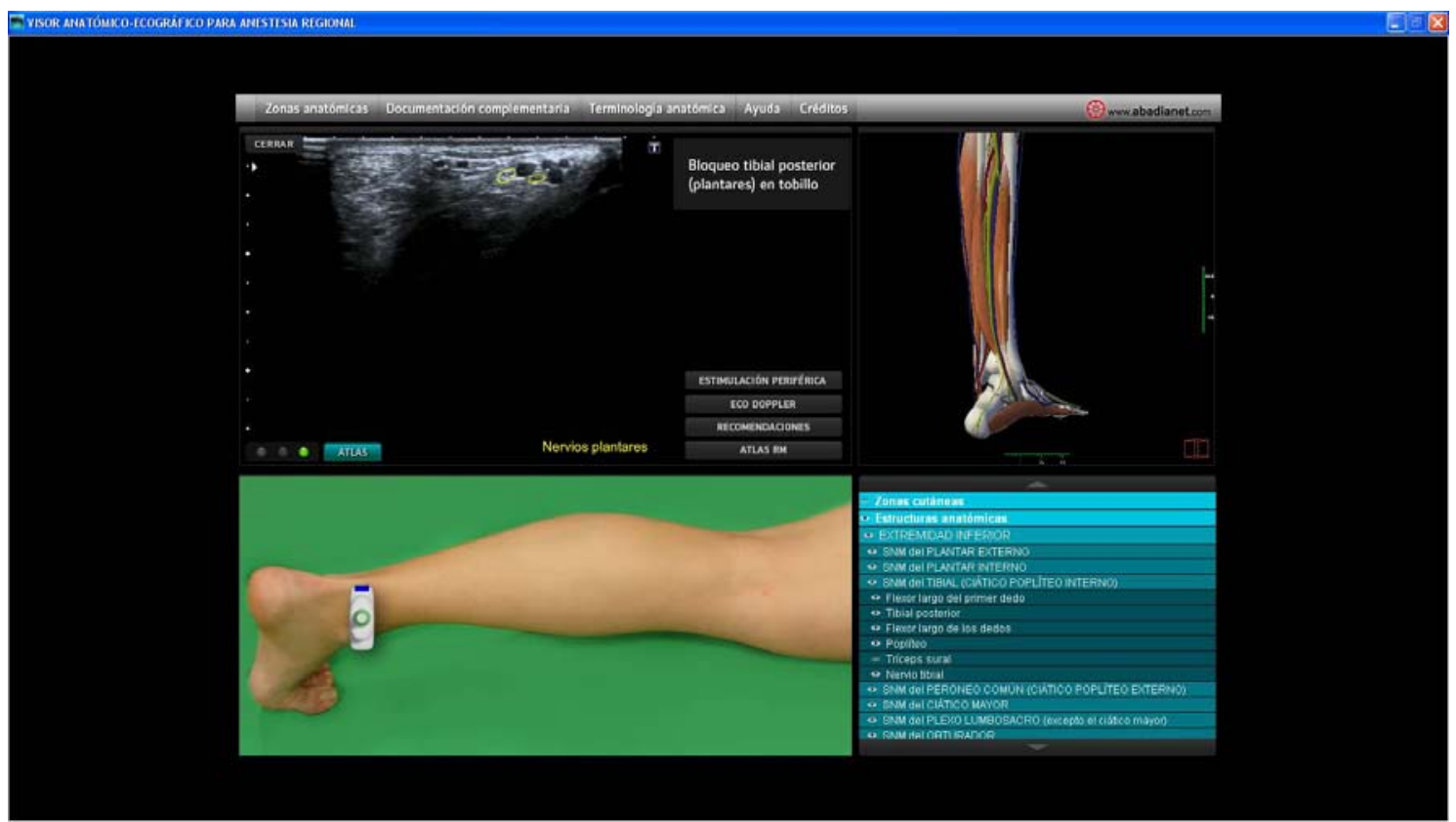

Figura 72. Localización y detalle del bloqueo del nervio tibial a la altura del tobillo.

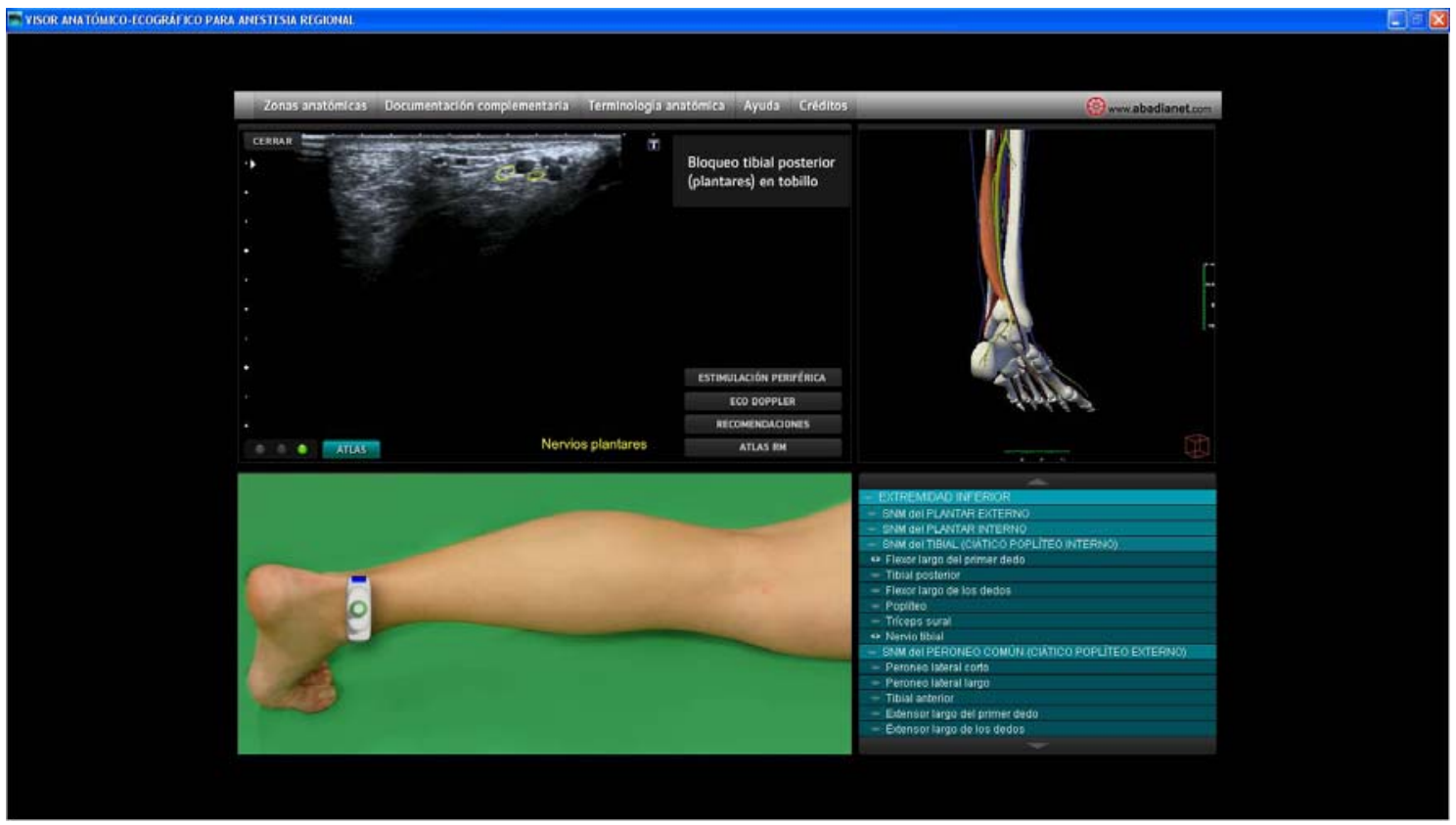

Figura 73. Imagen para resaltar como a través del visor 3D se muestran las estructuras vasculonerviosas suprimiendo (deseleccionando con un clic del ratón) los paquetes musculares. 
A continuación se muestran cortes axiales de RM a distintos niveles de la extremidad inferior desde proximal a distal con el código colores (Figs. 74, 75, 76). También se presenta la imagen Doppler, la neuroestimulación y del visor 3D del pie (Figs. 77, 78, 79).

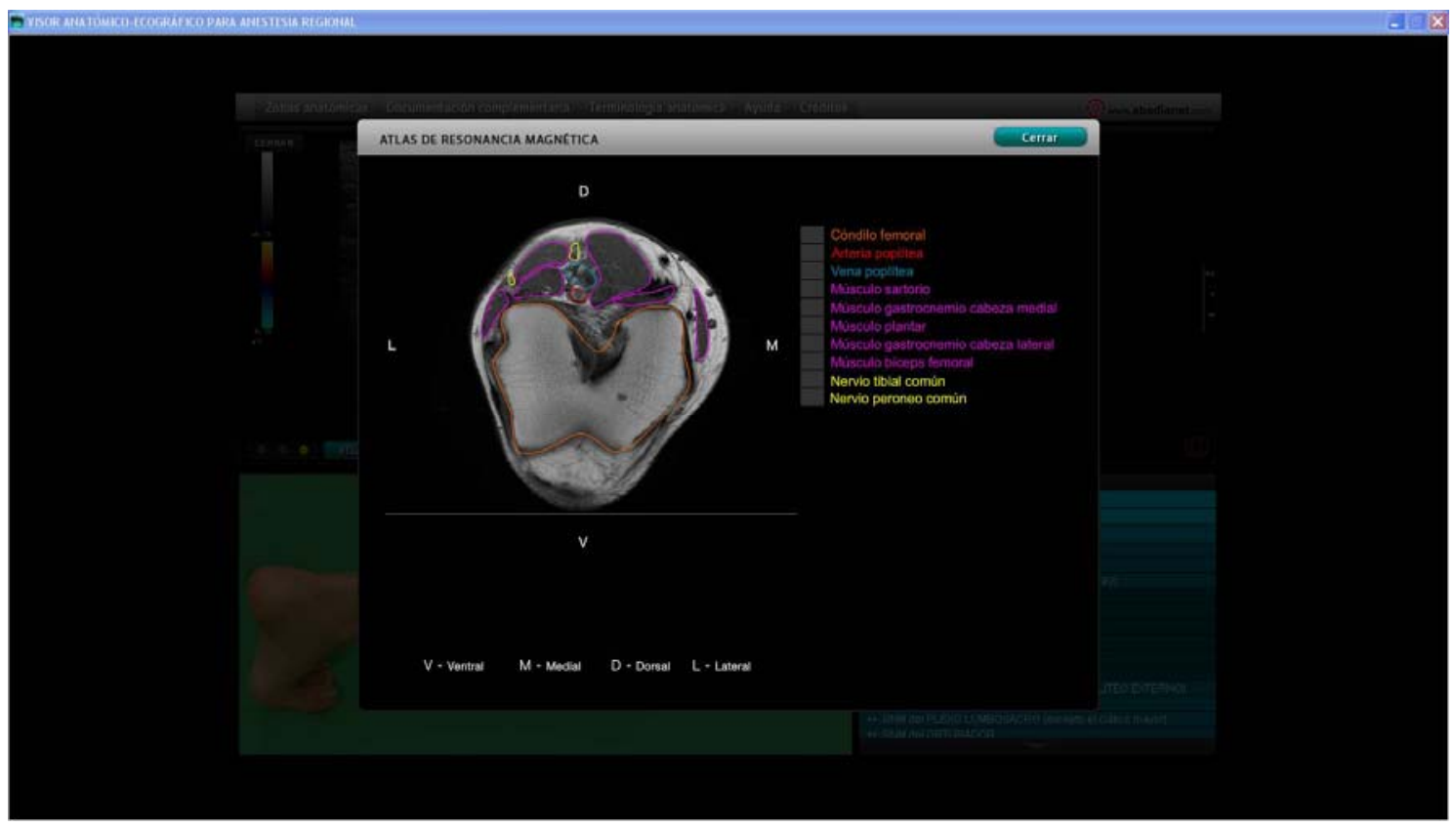

Figura 74. Corte de RM de la extremidad inferior a la altura de la rodilla, cóndilos femorales.

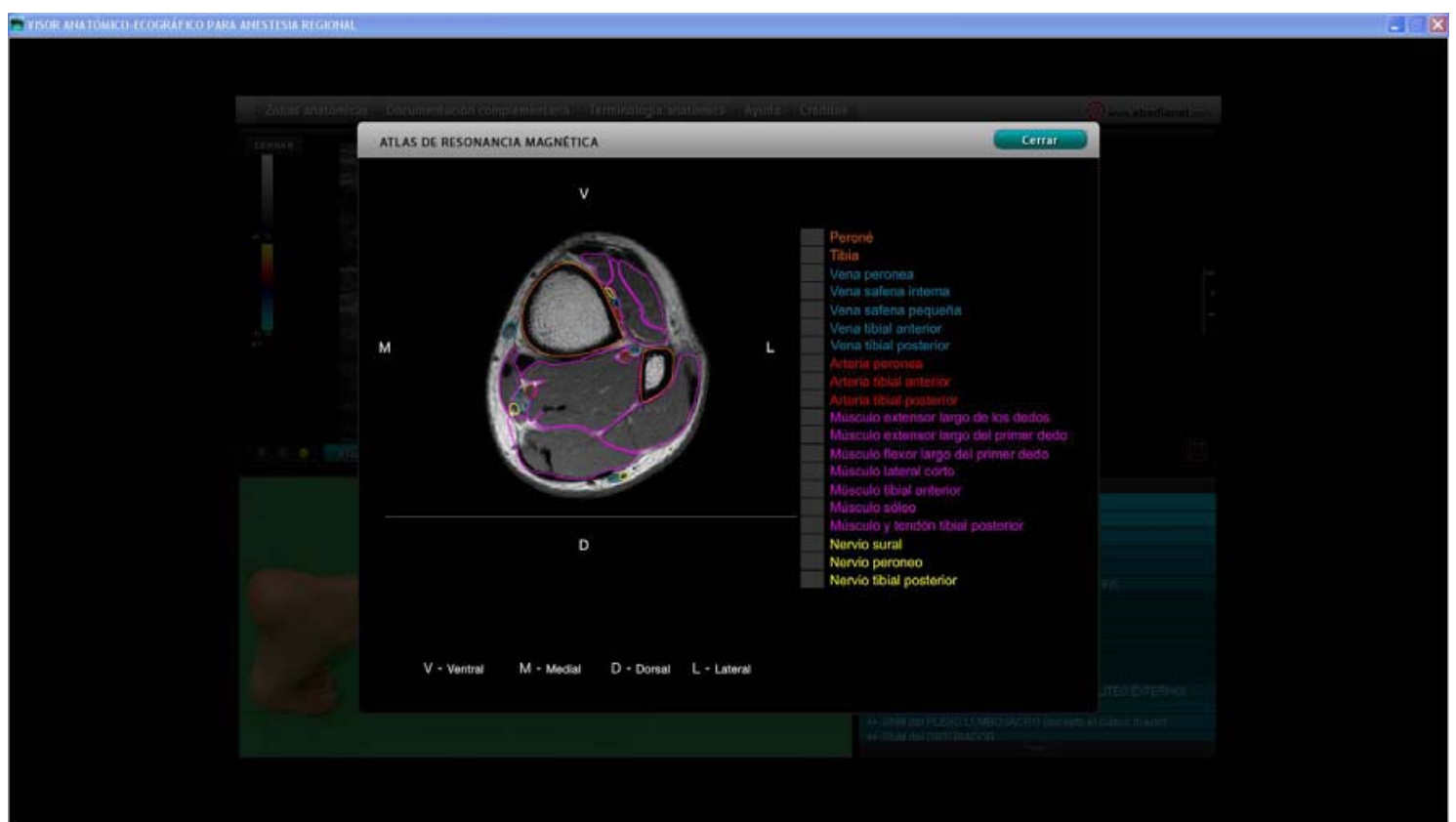

Figura 75. Corte de RM de la extremidad inferior a la altura de la tibia y peroné. 


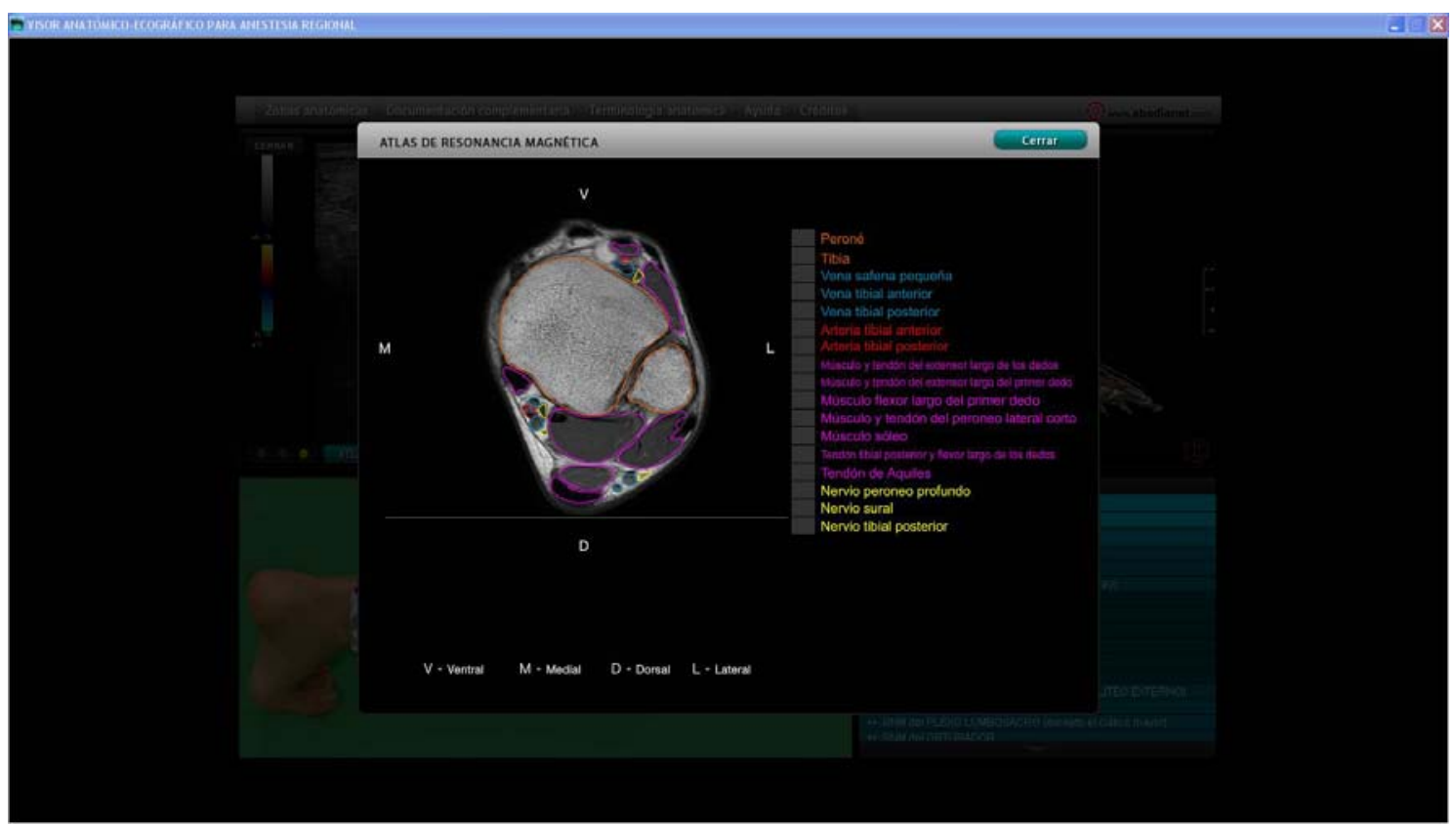

Figura 76. Corte de RM de la extremidad inferior a la altura del tobillo.

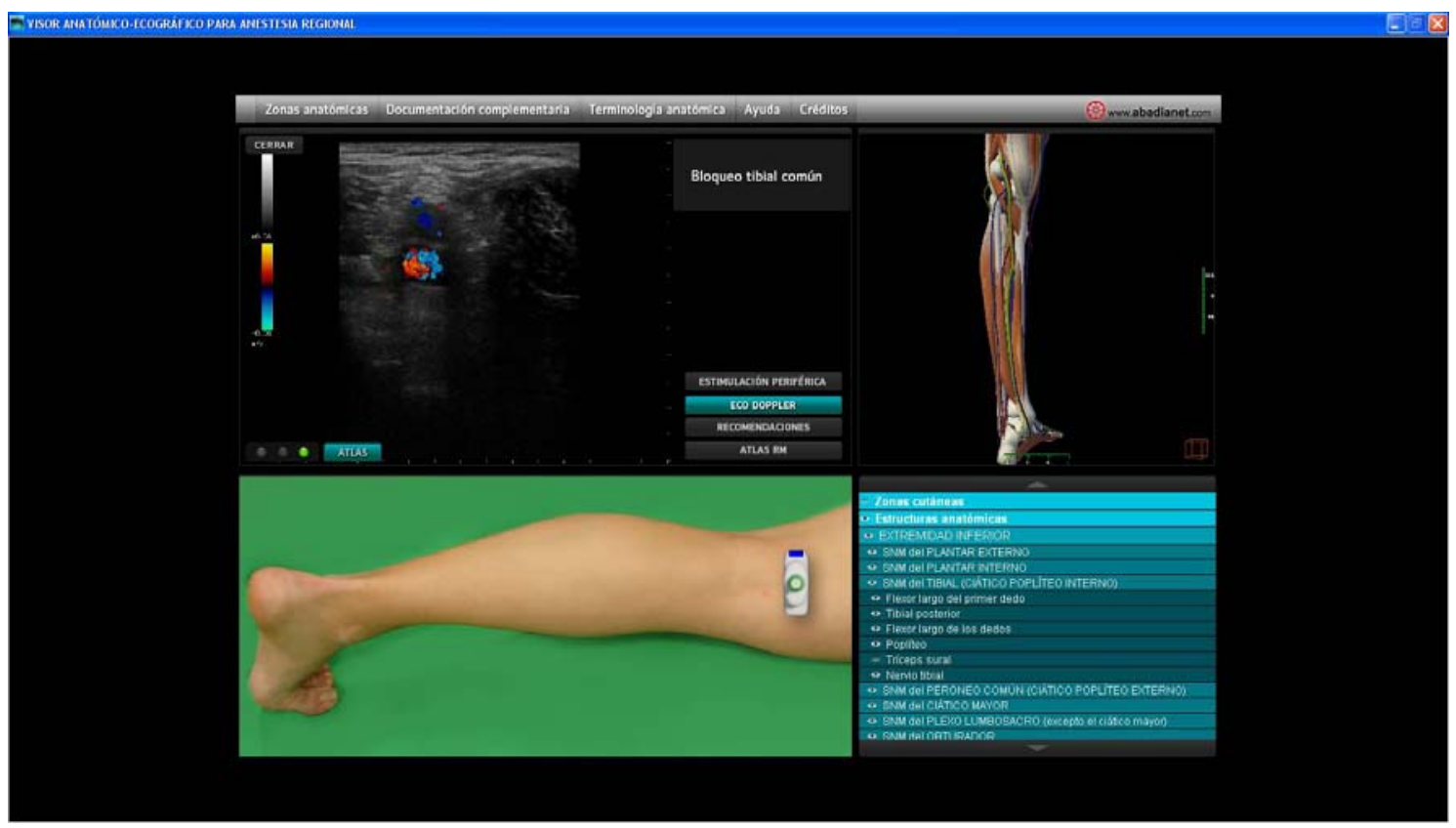

Figura 77. Imagen eco Doppler. En esta localización los vasos suelen visualizarse a nivel inferior del nervio. 


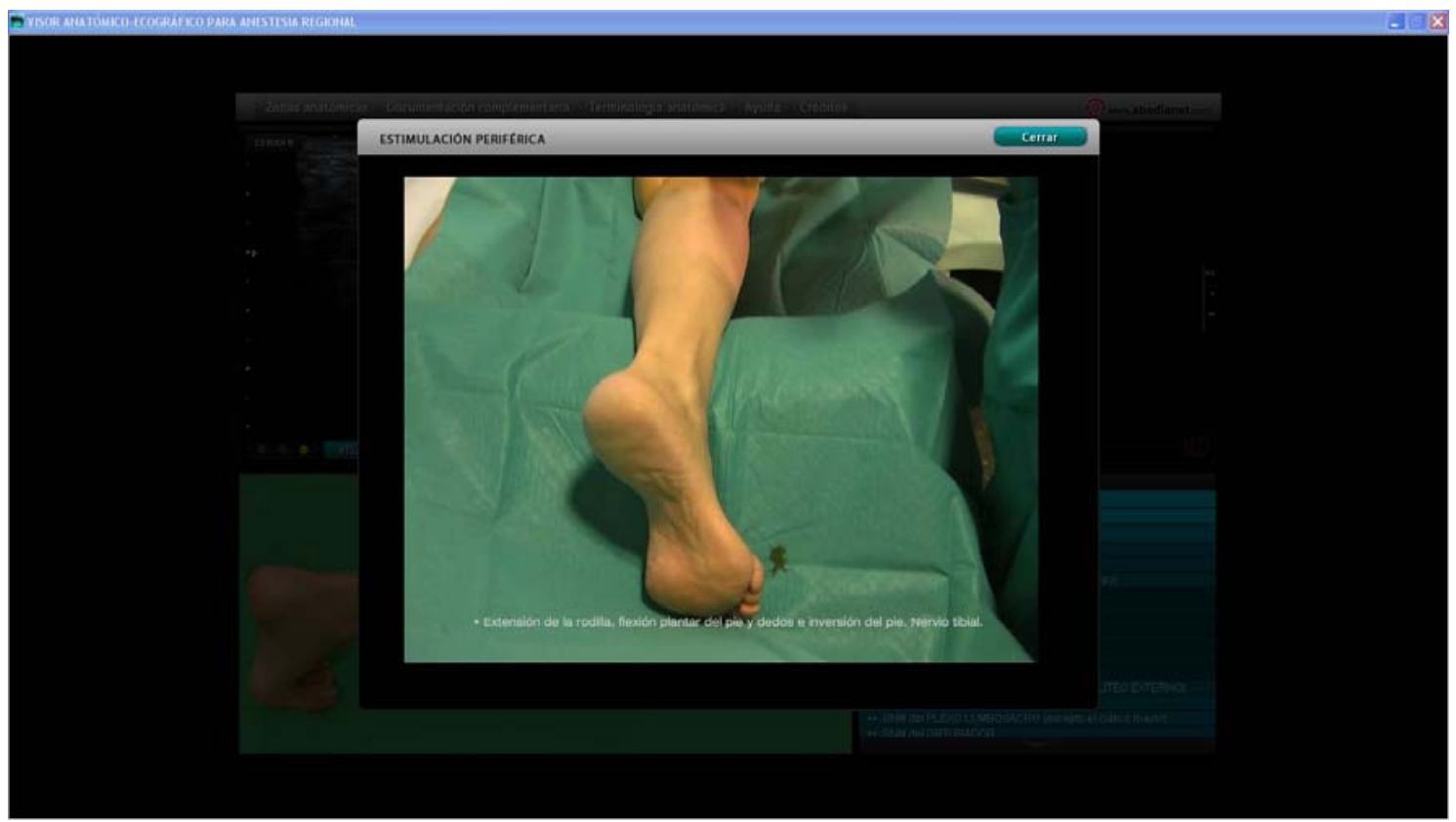

Figura 78. Imagen de video de estimulación nerviosa periférica realizada a un paciente real.

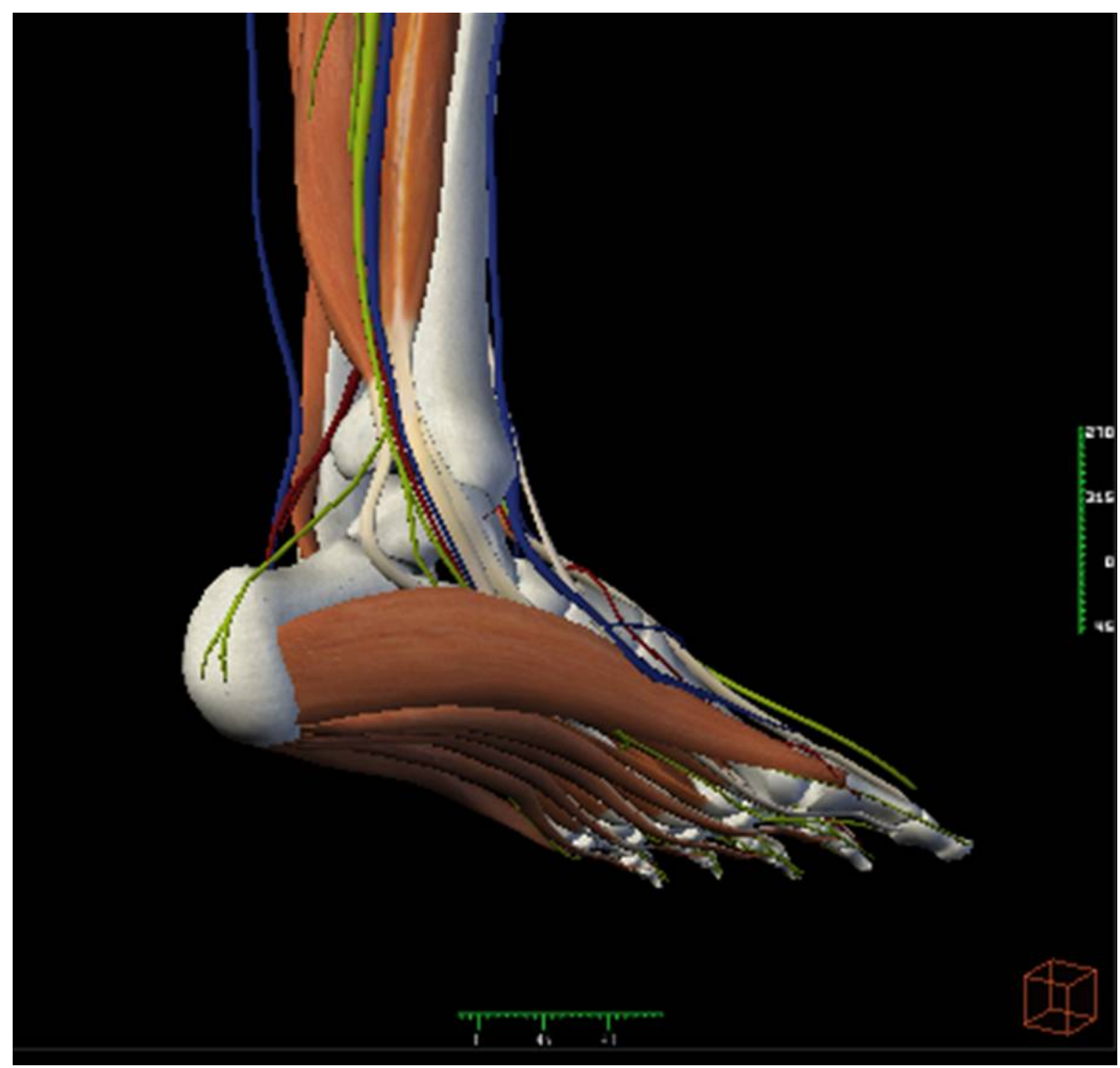

Figura 79. Detalle del Sistema neuromuscular del plantar externo (ciático poplíteo interno). Formado por los músculos: interóseos dorsales, interóseos plantares, flexor corto del quinto dedo, oponente del quinto dedo, separador del quinto dedo, aproximador del primer dedo, cuadrado plantar de Silvio, lumbricales. 
Para mostrar la versatilidad del procedimiento, se muestran distintas imágenes de los músculos en el visor 3D, donde podemos ver una descripción de sus principales características (origen, inserciones y funciones, ver en anexos) (Figs. 80, 81, 82, 83).

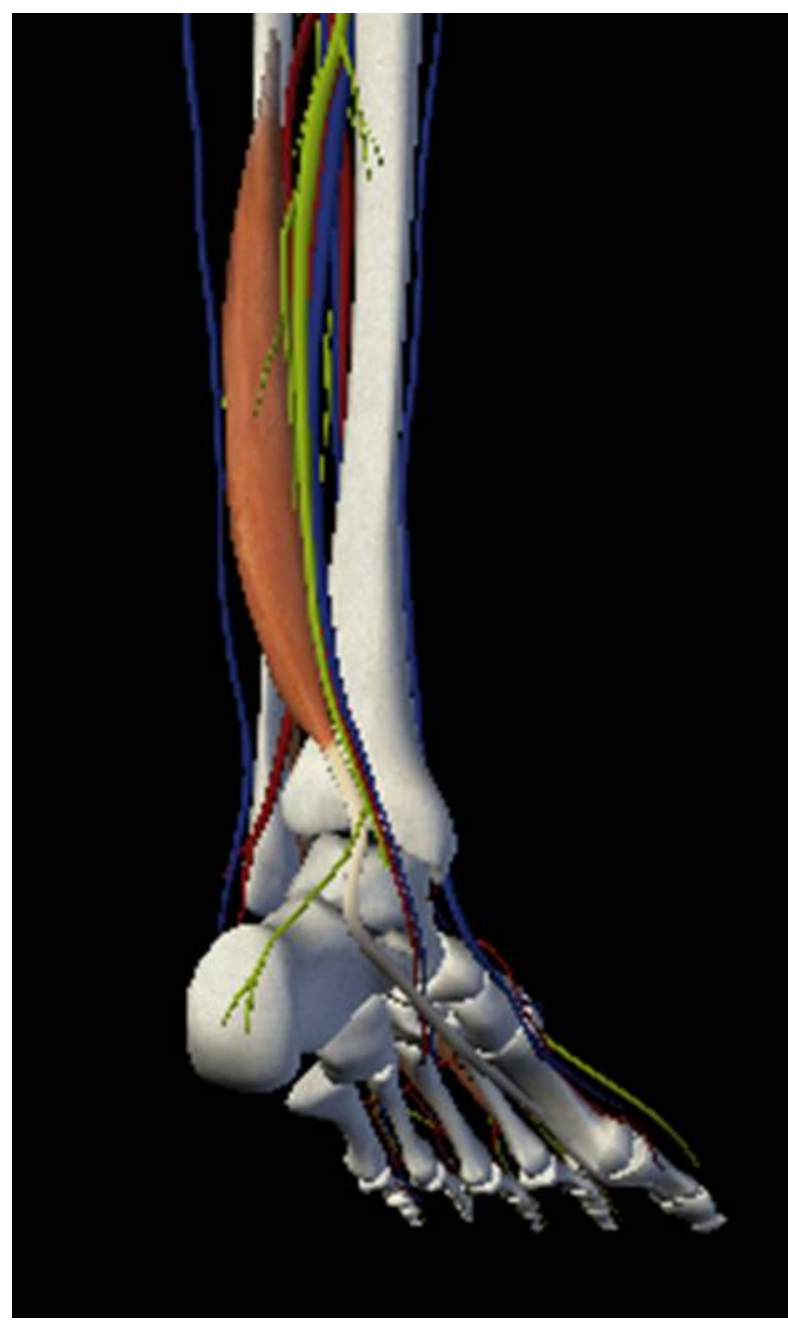

Figura 80. Flexor largo del primer dedo. Origen: Cara y borde posteriores del peroné y membrana interósea. Inserción: Falange distal del primer dedo 


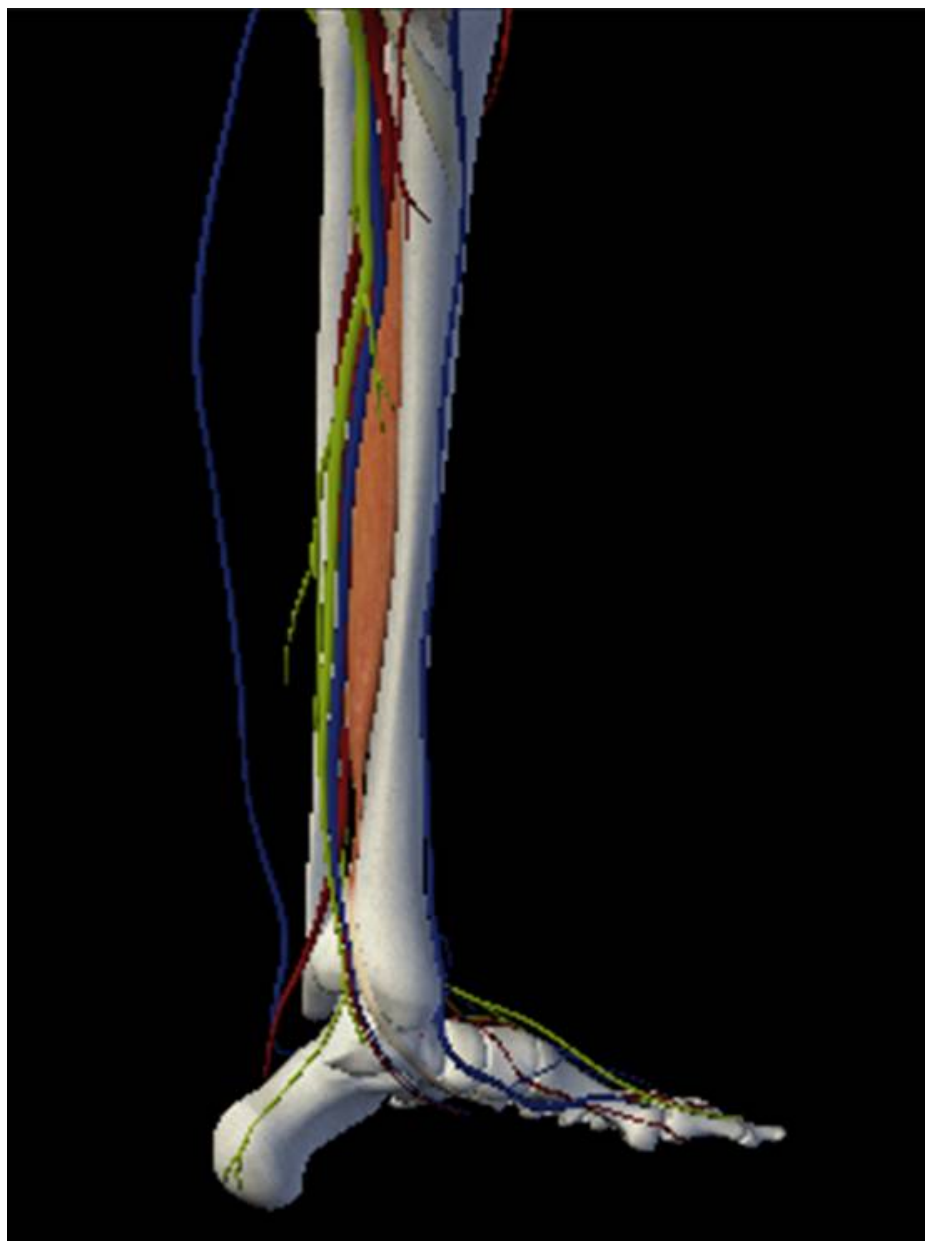

Figura 81. Tibial posterior. Origen: Membrana interósea, tibia y peroné. Inserción: Escafoides y primera cuña. También, mediante expansiones tendinosas, en la segunda y tercera cuñas y base de segundo, tercer y cuatro metatarsianos 


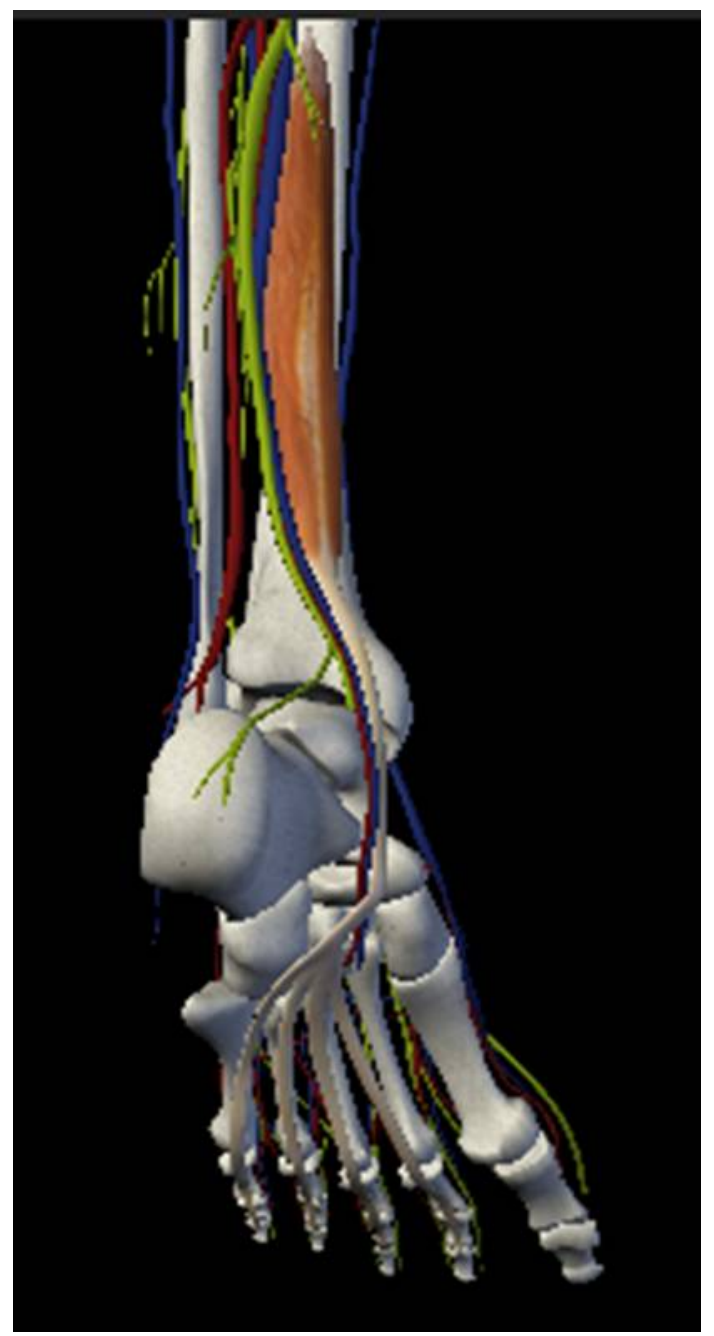

Figura 82. Flexor largo de los dedos. Origen: Cara y borde posteriores del peroné y membrana interósea. Inserción: Falange distal del primer dedo. 


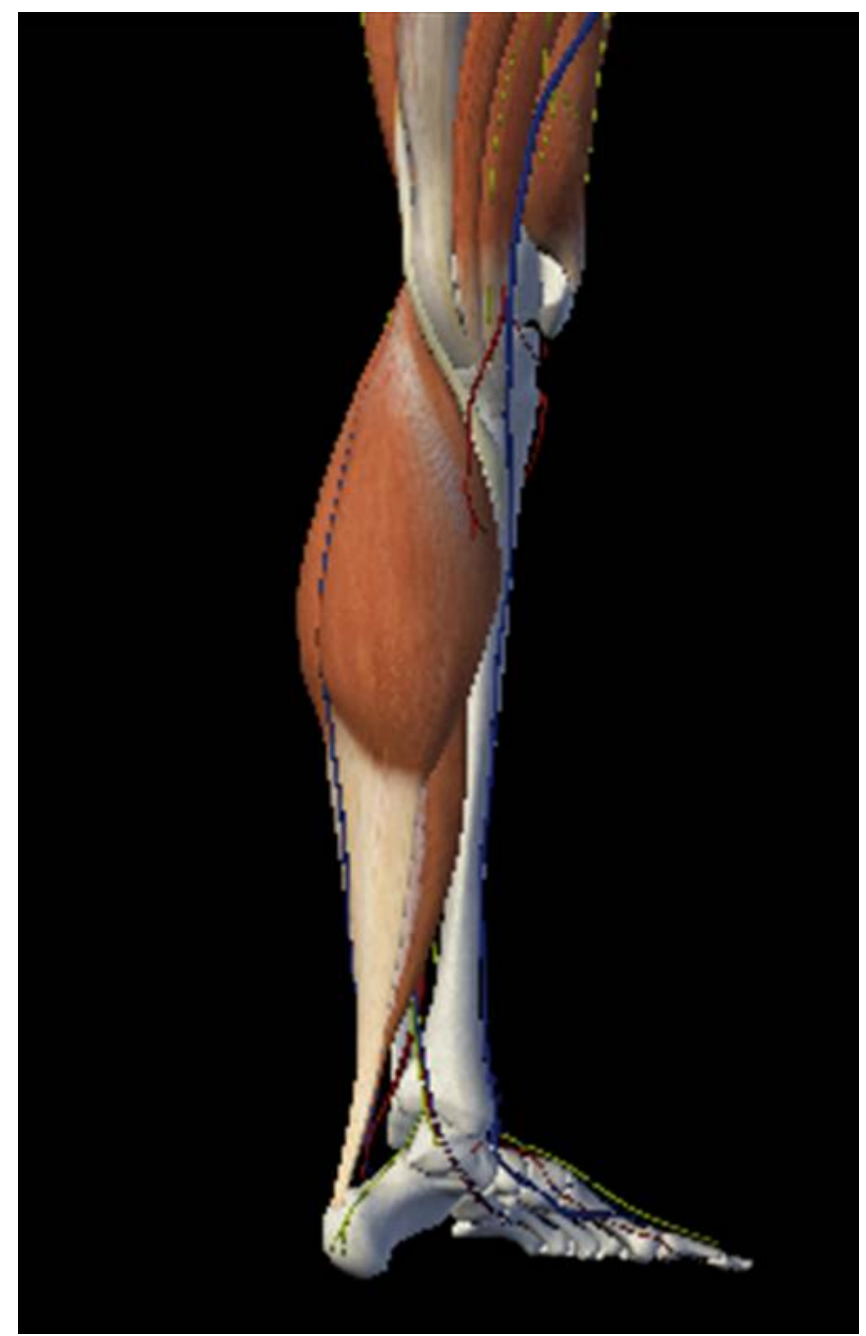

Figura 83. Imagen del triceps sural. Origen: Sóleo, cara posterior, borde externo y cabeza del peroné. Línea oblicua de la tibia. Gemelo medial, cara posterointerna del cóndilo interno del fémur y casquete condíleo medial. Gemelo lateral, cara posteroexterna del cóndilo externo del fémur y casquete condíleo lateral. Inserción: Por medio del tendón calcáneo $\mathrm{o}$ de Aquiles, en el borde posteroinferior de la tuberosidad posterior del calcáneo. 


\subsection{DESCRIPCIÓN ICONOGRÁFICA DEL SISTEMA NEUROMUSCULAR DEL NERVIO RADIAL (FIGS. 84 HASTA LA 95).}

A continuación pasamos a describir otro ejemplo de sistema neuromuscular para mostrar las posibles utilidades que este visor tridimensional tiene, no sólo en el campo de la anestesia regional, si no en muchos otros como cirugía, traumatología, radiología, medicina del deporte...

Seleccionamos en el visor 3D el nervio a lo largo de su recorrido.

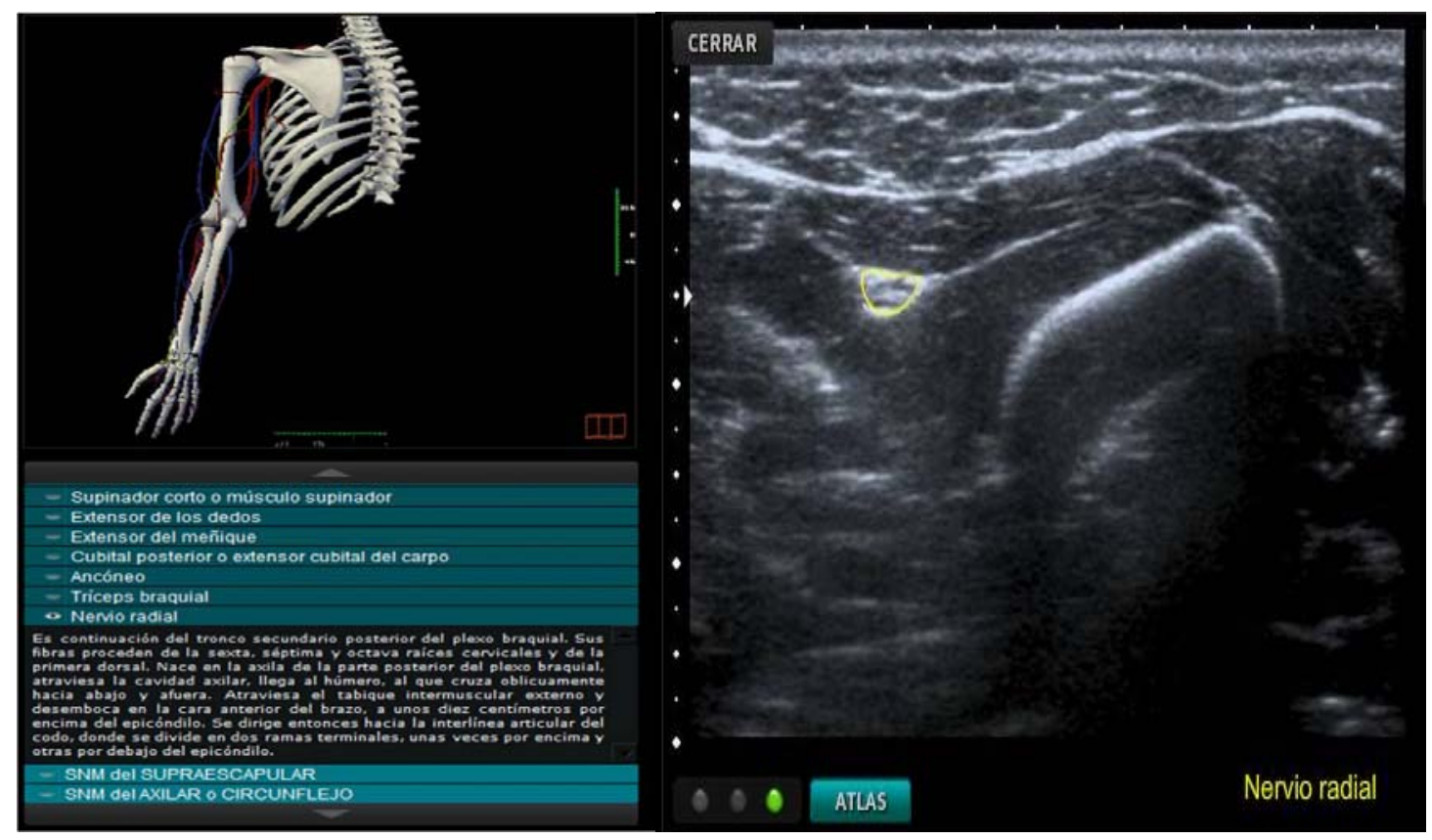

Figura 84. Nervio radial con su imagen ecográfica 


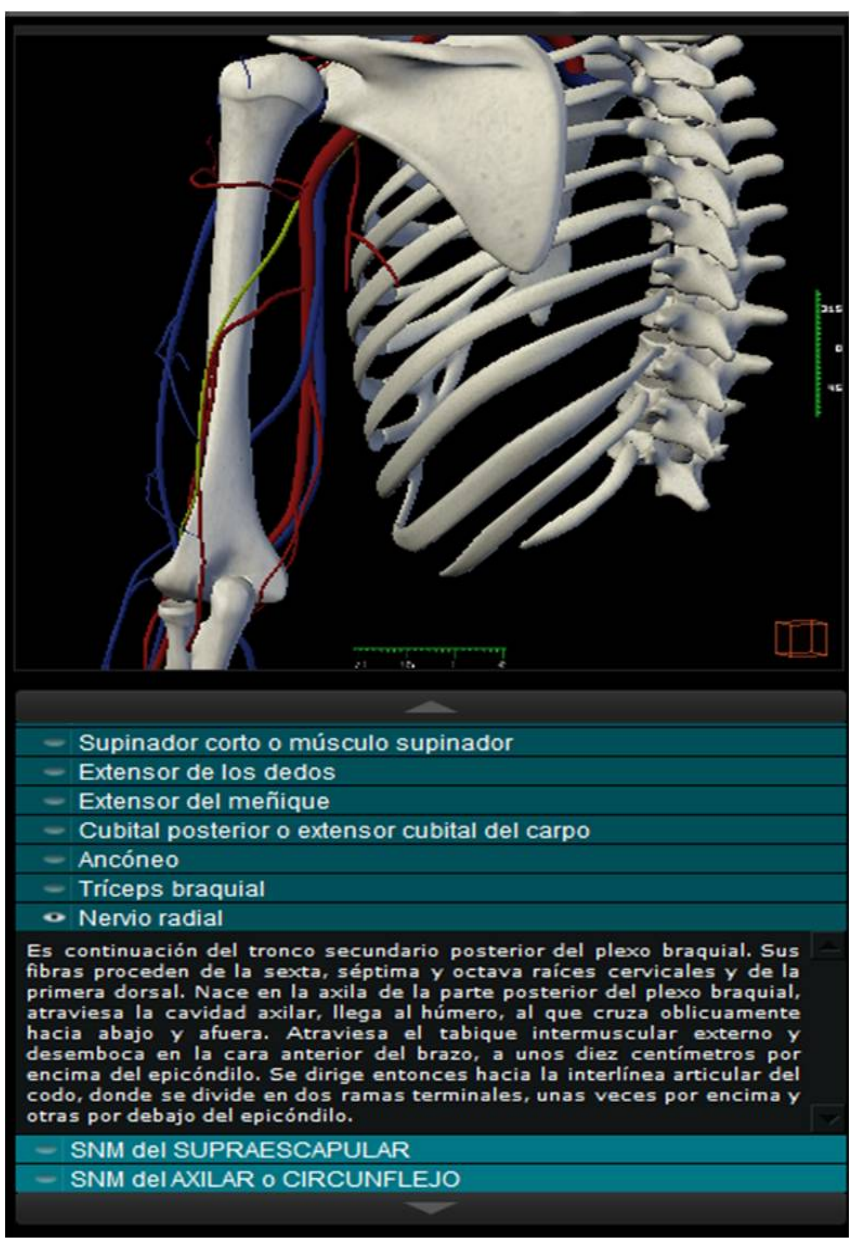

Figura 85. Ampliación de la visión 3D del nervio radial.

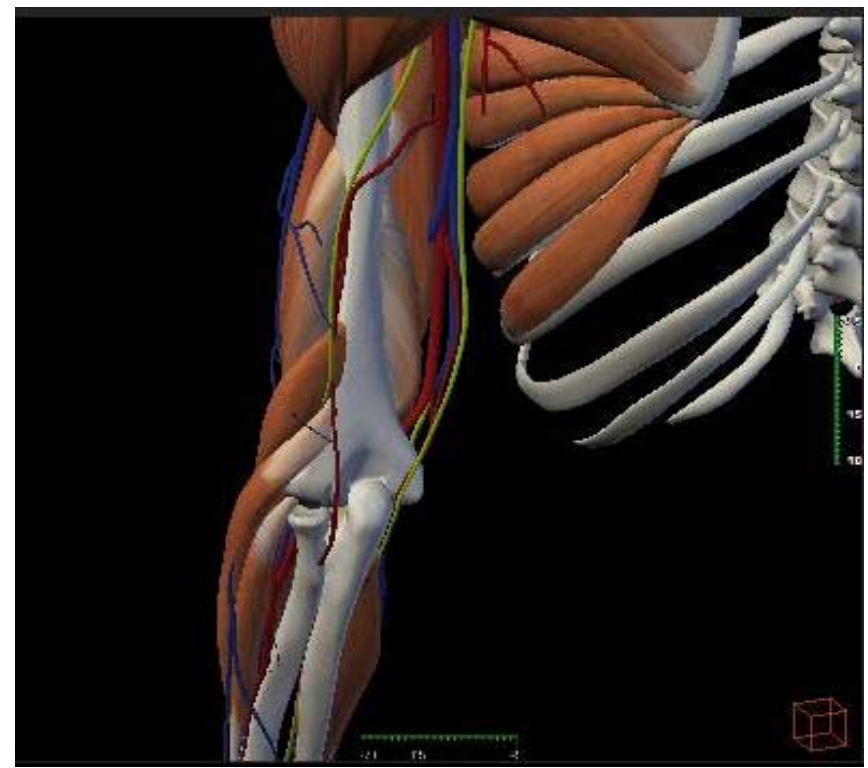

Figura 86. Imagen del nervio radial con el SNM del supraescapular y del axilar o circunflejo. 
Después se realiza una reconstrucción completa del SNM del nervio radial (Figs. 87 y 88).

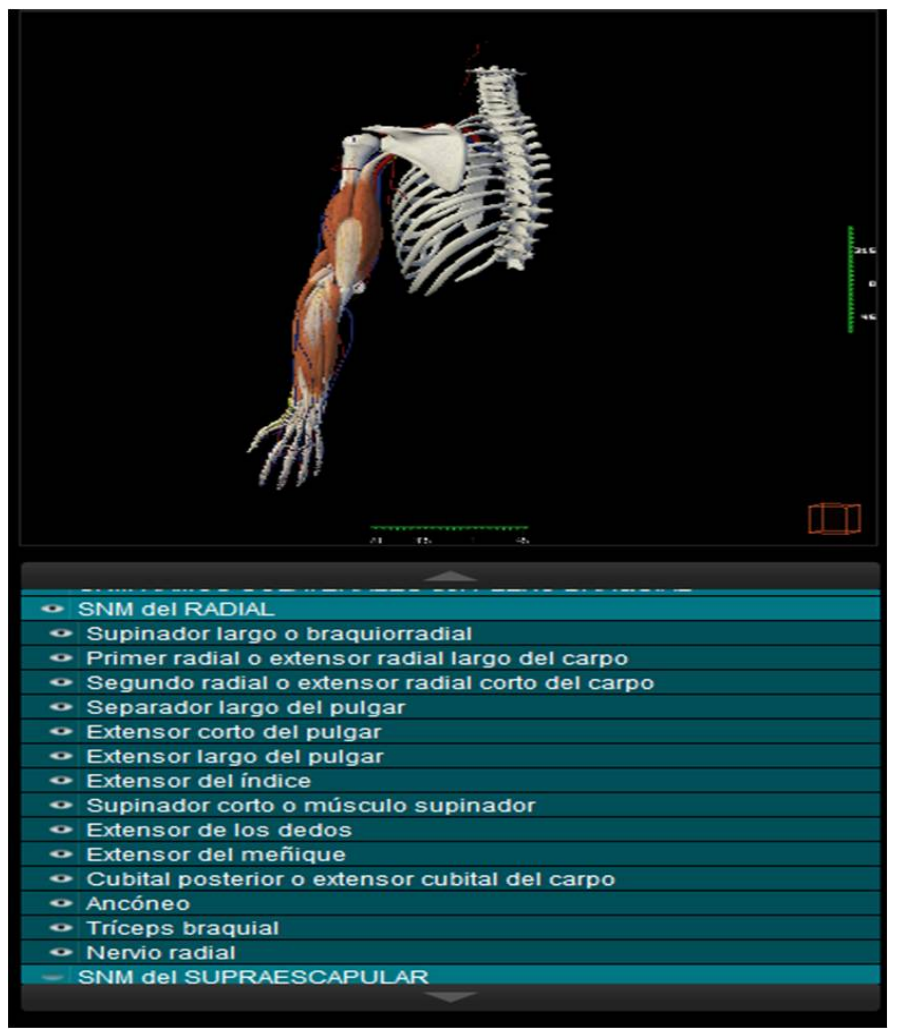

Figura 87. Reconstrucción del sistema neuromuscular del nervio radial completa. Visión posterior.

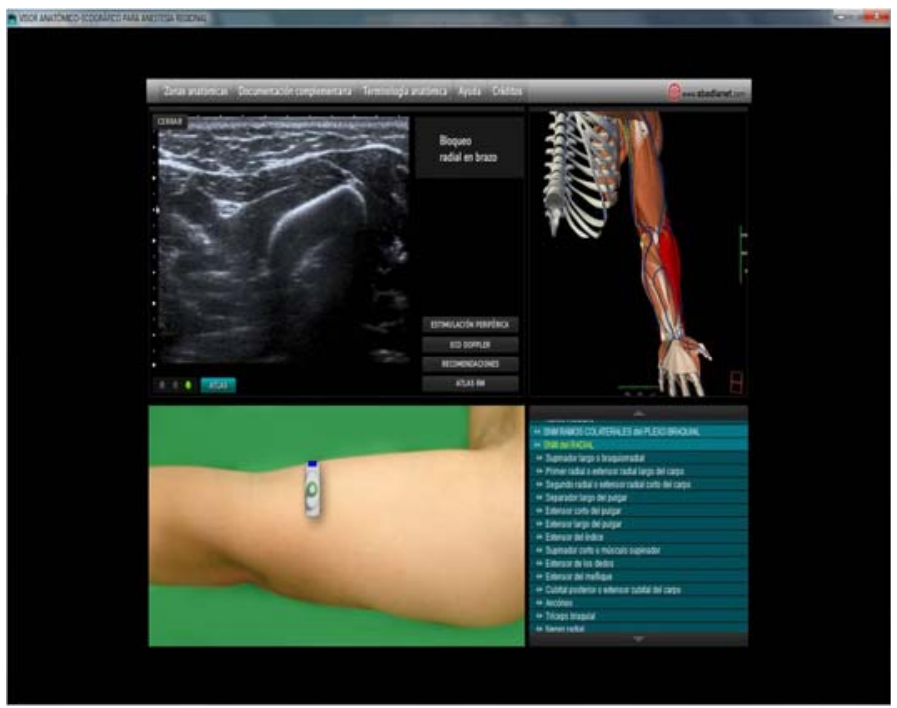

Figura 88. Reconstrucción del SNM del radial en visión anterior. Obsérvese la correlación con el simulador de superficie y con la sección ecográfica. 


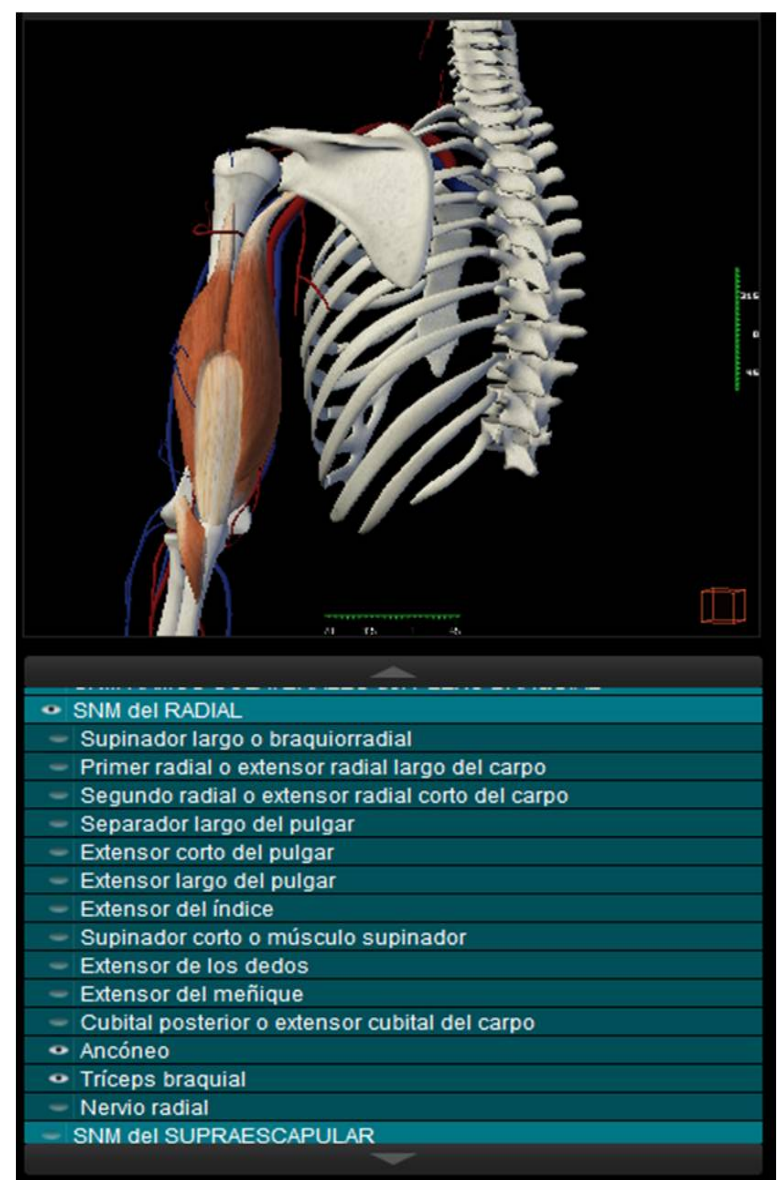

Figura 89. Selección del músculo ancóneo y del tríceps braquial donde se observan sus inserciones. 


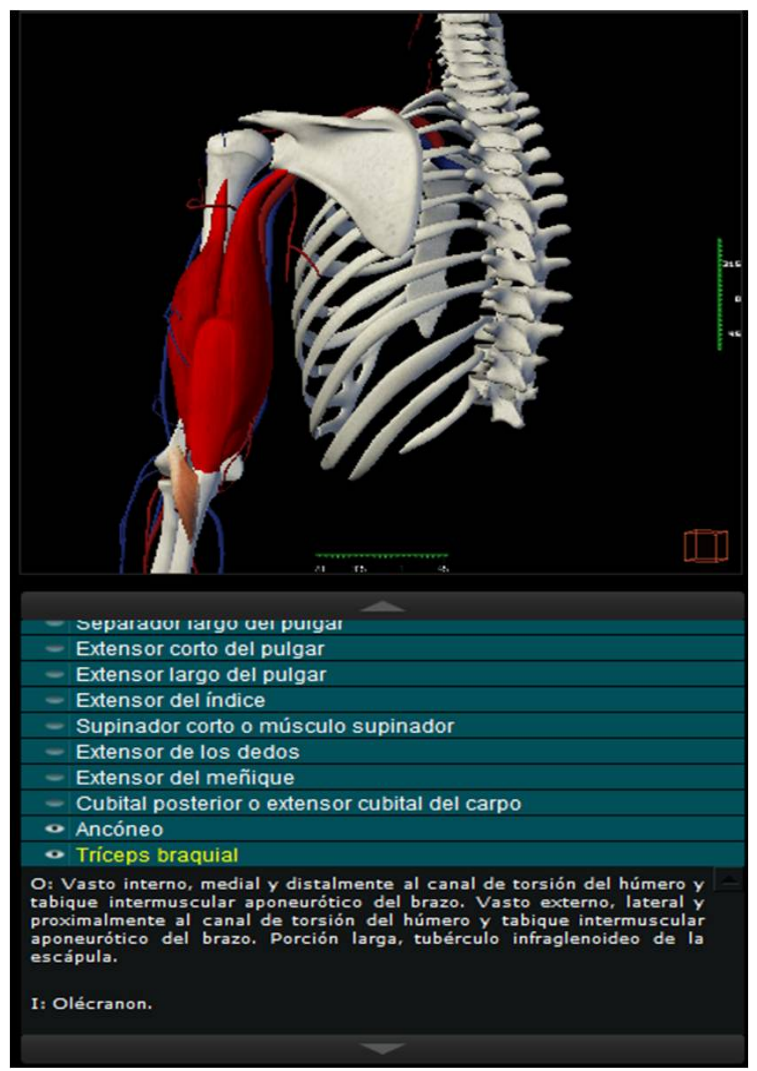

Figura 90. Imagen del músculo ancóneo y del tríceps braquial, este último está seleccionado y tenemos acceso a su descripción.

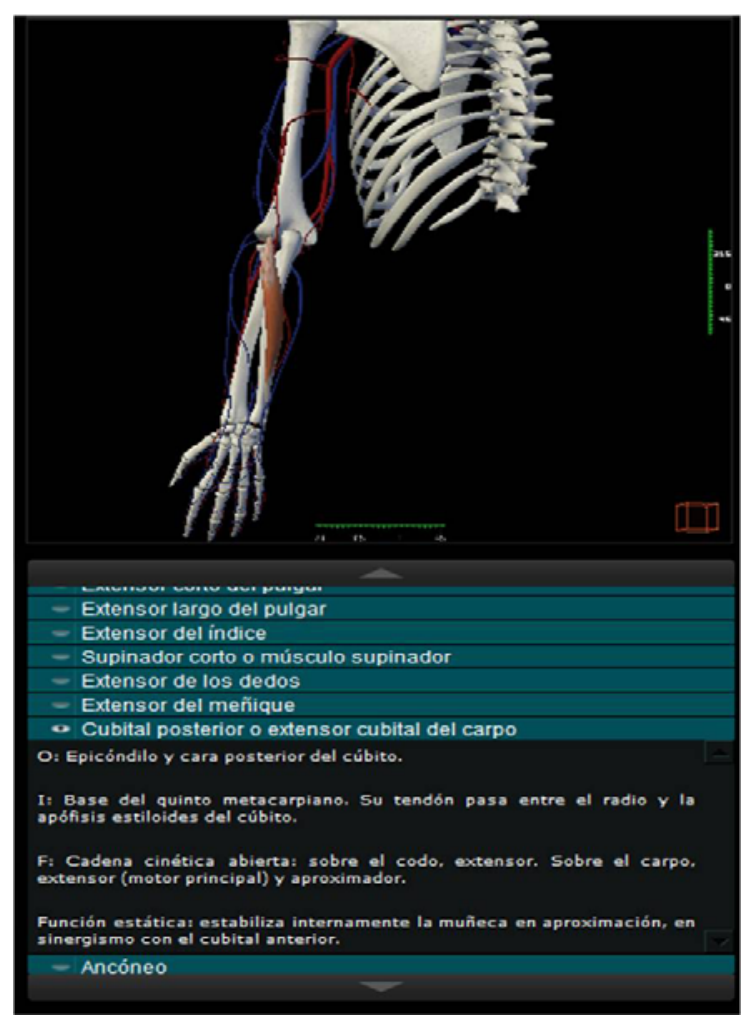

Figura 91. Descripción del cubital posterior. 


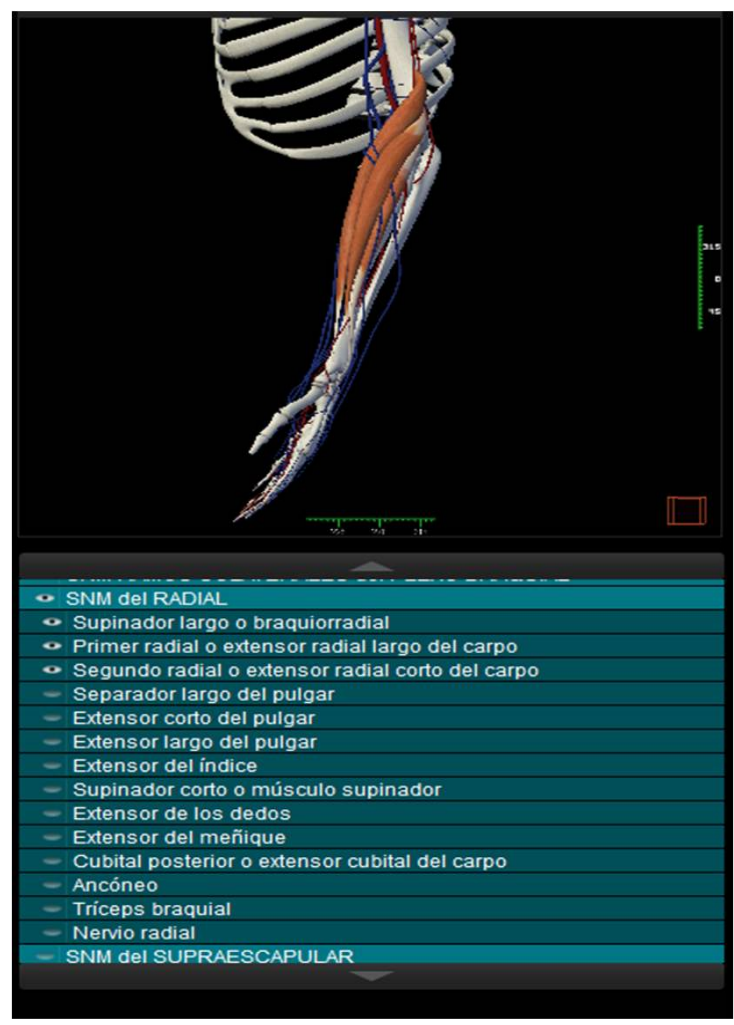

Figura 92. SNM del radial en el antebrazo. Se han seleccionado los músculos supinador largo, primer radial y segundo radial.

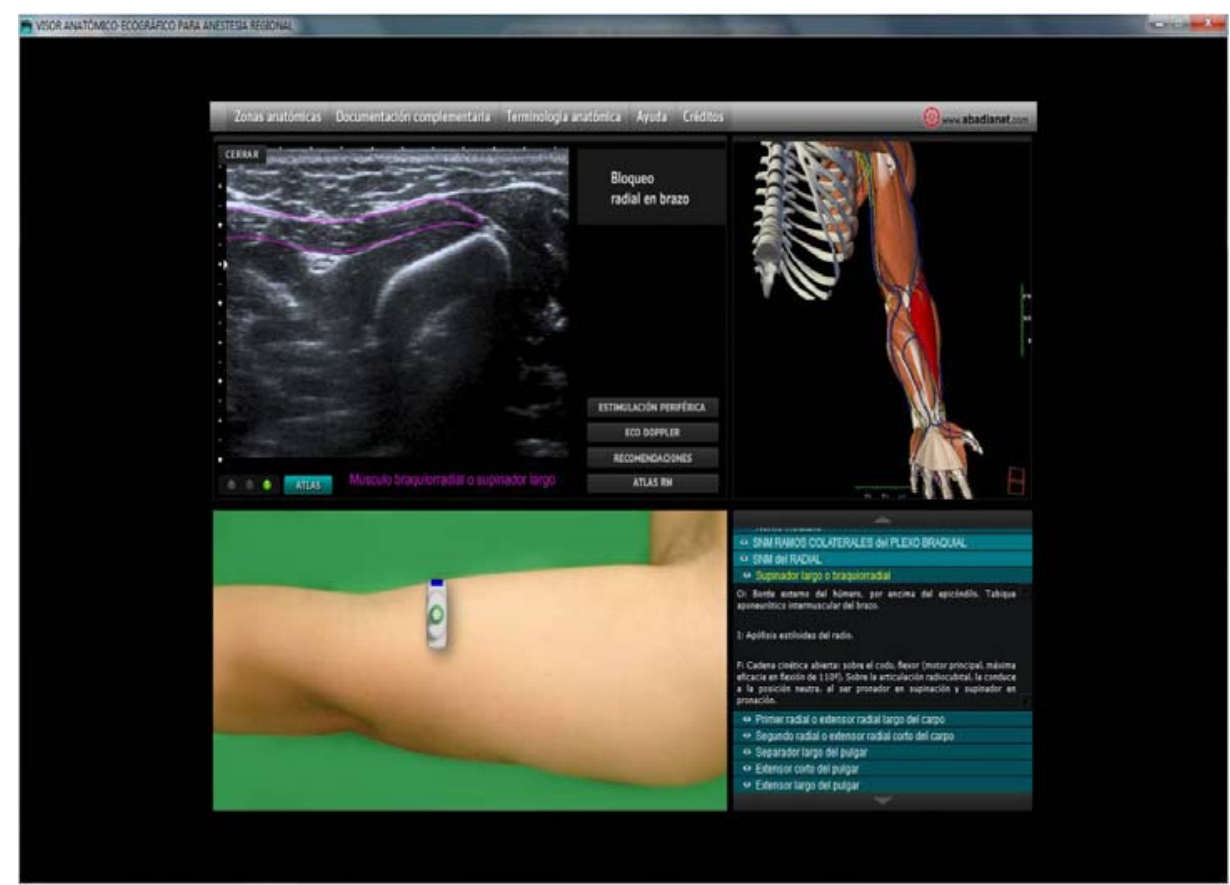

Figura 93. Otra visión del músculo supinador largo o braquiorradial. Se muestra su localización en la imagen ecográfica. 


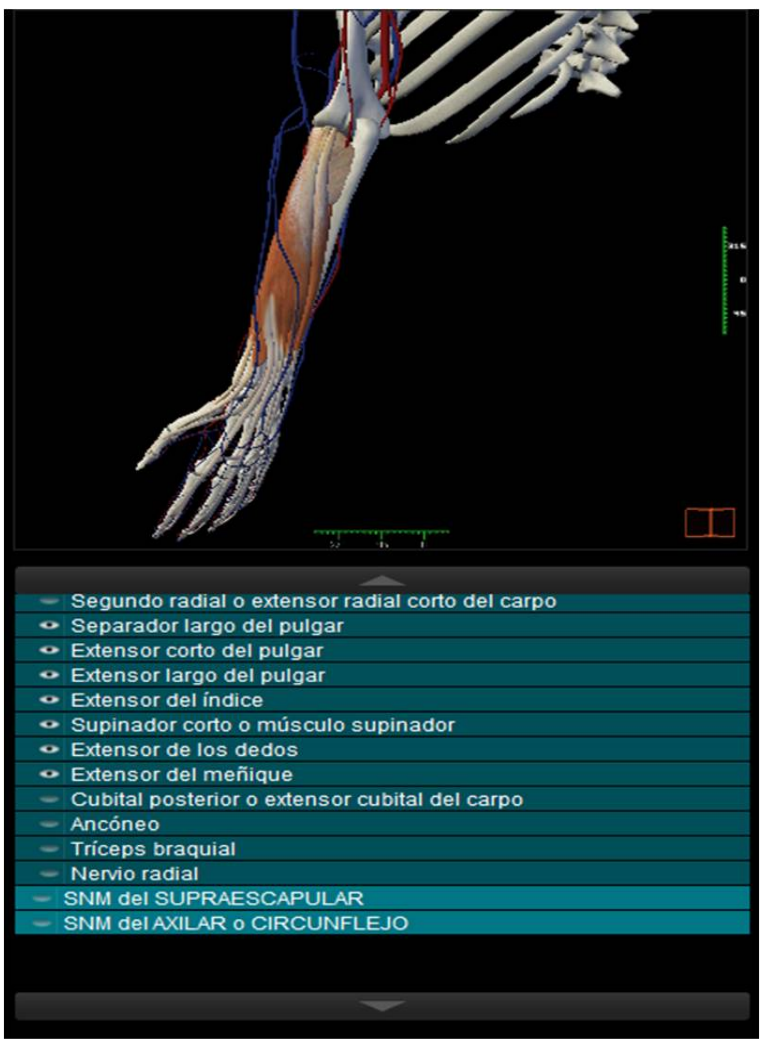

Figura 94. SNM del radial en el antebrazo y en la mano.

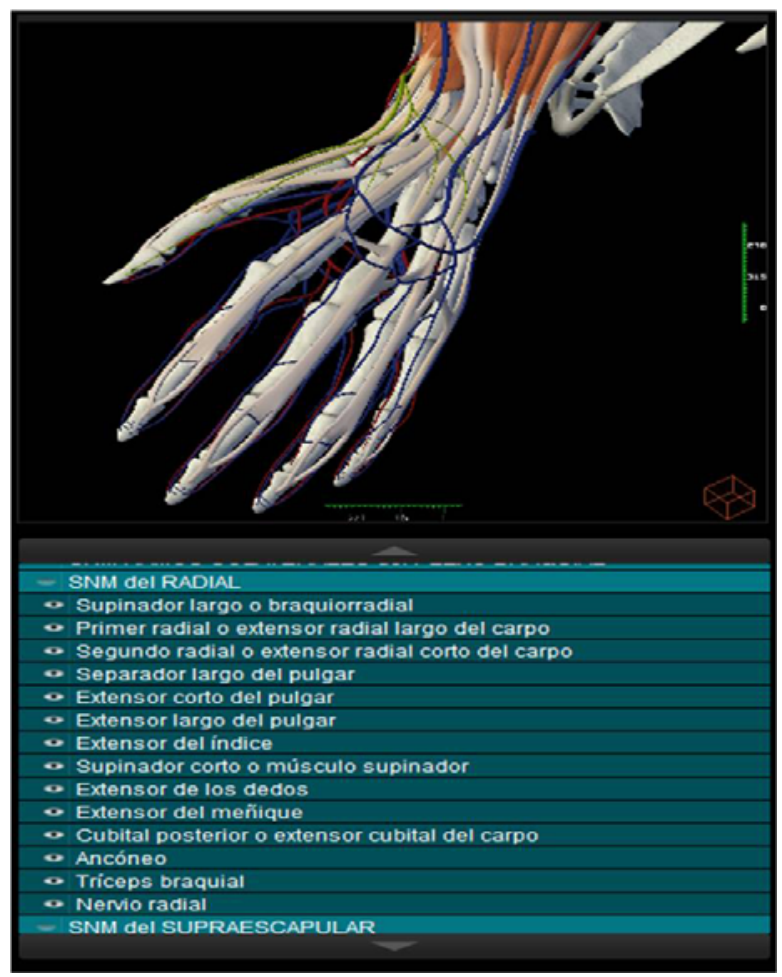

Figura 95. SNM del radial en la mano. 


\subsection{ENCUESTA DE VALIDACIÓN DE LA APLICACIÓN INFORMÁTICA}

\section{Descripción de la muestra}

La muestra estaba formada por residentes de tercer y cuarto año que ya hubieran realizado técnicas de anestesia regional y adjuntos de cualquier año de experiencia. El 20\% eran residentes y el $80 \%$ adjuntos. Por sexos el $57 \%$ eran mujeres sin diferencias estadísticamente significativas (fig. 96).
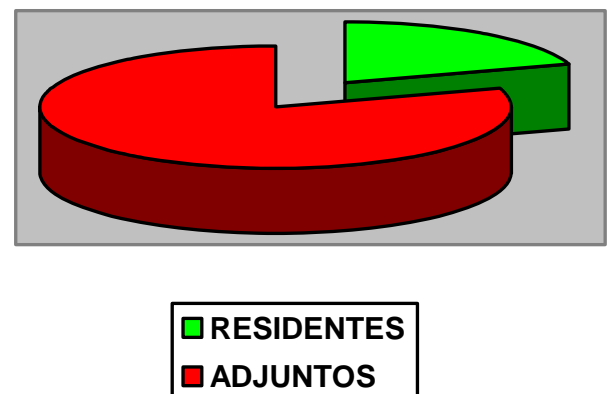

Figura 96. Distribución de la muestra según grado de experiencia. El $80 \%$ eran médicos adjuntos.

En la siguiente gráfica, se muestran los resultados obtenidos a las preguntas del cuestionario elaborado para validar la aplicación; obsérvese que no se obtiene ningún resultado negativo.

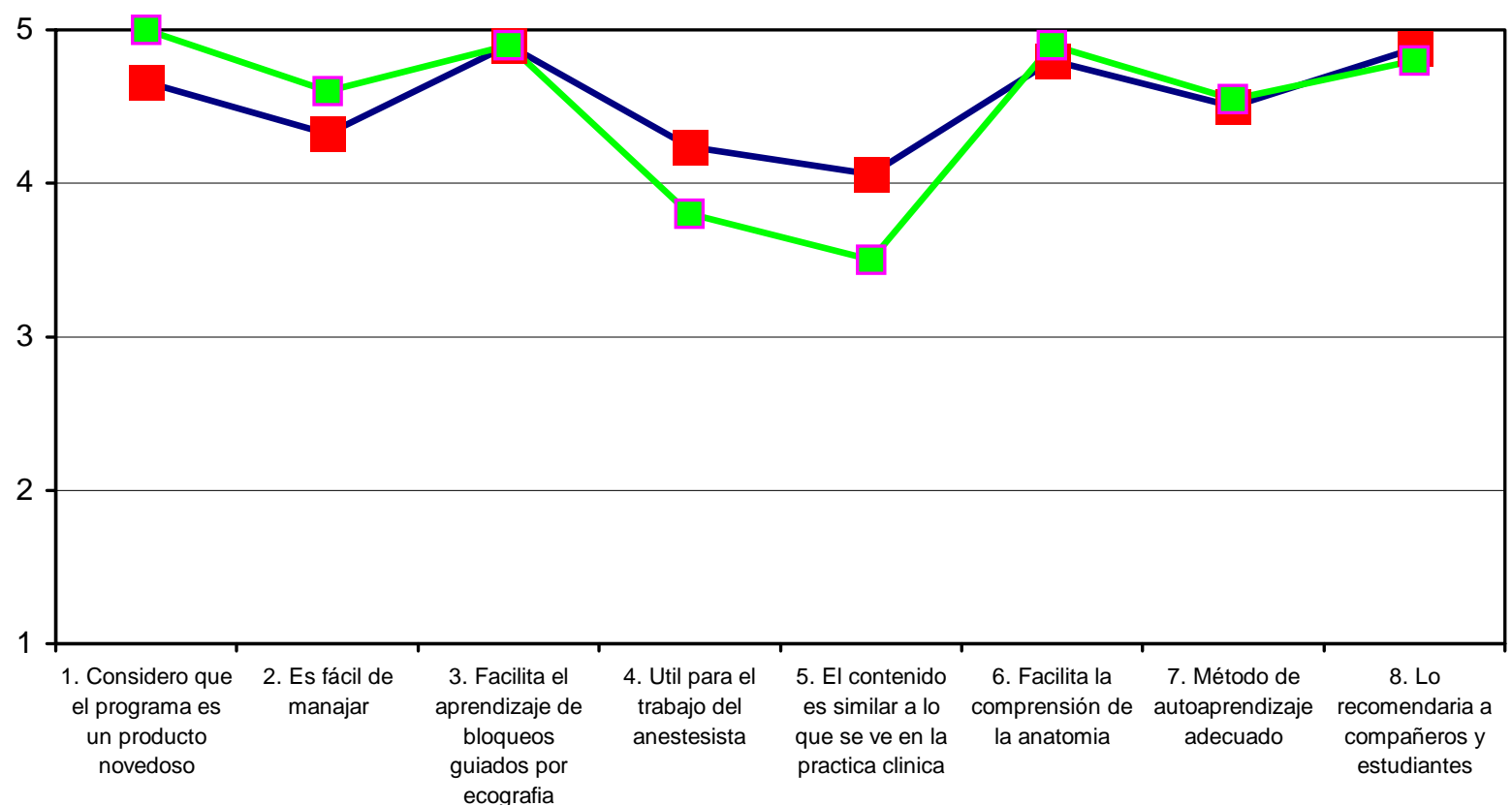

En el eje de ordenadas la escala de Likert:

1. Totalmente en desacuerdo

2. En desacuerdo

3. Ni de acuerdo ni en desacuerdo

4. De acuerdo

5. Totalmente de acuerdo 


\section{Análisis de los Ítems}

1. A la pregunta de si es un producto totalmente novedoso, el $100 \%$ de los residentes estuvieron totalmente de acuerdo. Entre los adjuntos el 93\% estuvo totalmente de acuerdo. Atribuimos este último resultado quizá a la falta de conocimiento de los sistemas de enseñanza actuales para anestesia regional, ya que no existe un producto similar en el mercado.

2. En el segundo ítems están de acuerdo tanto adjuntos como residentes (el $86 \%$ y el $92 \%$ respectivamente), que es fácil de manejar. No existen respuestas negativas al respecto.

3. El $98 \%$ de los adjuntos está totalmente de acuerdo en que es una herramienta que facilita el aprendizaje de los bloqueos regionales guiados con ecografía, disminuyendo este porcentaje al $90 \%$ de los residentes.

4. Respecto a la utilidad en nuestro trabajo diario, el $84 \%$ de los adjuntos está de acuerdo, frente al $76 \%$ de los residentes.

5. Este es el ítem donde hay más discrepancia. Sobre si es similar a lo que se visualiza en la práctica clínica habitual, hay un $81 \%$ de adjuntos que está de acuerdo y un $70 \%$ de residentes. Hay un pequeño porcentaje (20\%), similar en ambos grupos, que no estaban de acuerdo ni en desacuerdo. Imaginamos que estos últimos han tenido en cuenta la variabilidad anatómica de los individuos (que varía incluso con la presión de la sonda), y que unos bloqueos son más representativos de la mayoría, que otros.

6. Están totalmente de acuerdo con que facilita la compresión de la anatomía la gran mayoría de adjuntos y residentes.

7. Es un método adecuado de autoaprendizaje para ambos facultativos un alto porcentaje (aprox. el 90\% en ambos). Como en todo, la voluntad individual influye en el aprendizaje y a este procedimiento tecnológico le falta otro pilar de los bloqueos ecográficos, que es la habilidad manual con la aguja.

8. Recomendarían este procedimiento tecnológico para la formación en anestesia regional con la máxima puntuación el $97 \%$ de los adjuntos y el $96 \%$ de los residentes. El resto, estarían de acuerdo en recomendarlo. 
En conclusión, sumando los resultados resultaría un porcentaje mayor al $90 \%$ en los 8 ítems, lo que refleja el alto grado de aceptación que ha tenido este tipo de aplicación informática. 



\section{CAPITULO $\mathbf{5}$}

DISCUSIÓN 

En anestesiología, al igual que en otras disciplinas médicas, se buscan técnicas menos invasivas y más eficientes, para una mayor comodidad para el paciente. A este respecto, la anestesia regional es un claro ejemplo de este tipo de técnicas. Ha sido nuestro deseo que esta aplicación contribuya a la formación de cualquier anestesiólogo en este área y más concretamente en anestesia regional guiada con ecografía.

Se ha analizado en diferentes publicaciones procedentes tanto de EE. UU. como de Europa la formación y entrenamiento que adquieren los futuros especialistas en este campo de la anestesiología. Así, en un estudio realizado en EE. UU. sobre la formación que reciben en esta área los residentes, se observó que en el año 1980 sólo se practicaba por estos anestesia regional en el 21,3\% del total de los actos anestésicos, en 1990 este porcentaje se incrementó al 29,8\% y en el año 2000 los residentes realizaban el 32\% de las anestesias bajo técnicas regionales. Este discreto incremento, se producía como consecuencia probablemente del cambio introducido en los programas de formación (Kopacz DJ. et al, 2002). Sin embargo, más del $40 \%$ de estos residentes presentaron una formación deficitaria en relación con la anestesia de bloqueos nerviosos periféricos. Según un estudio publicado por Chelly en 2002, sólo el 59\% de los programas de formación en EE. UU. tienen definidos los periodos de rotación en técnicas de bloqueo nervioso periférico (BNP), y la duración de estas rotaciones están comprendidas entre 15 días y 1 mes (Chelly JE. et al, 2002). Resultados similares se publicaron en países como Alemania y Austria, donde los anestesiólogos en formación sólo practicaban el $23 \%$ de los actos anestésicos bajo técnicas locorregionales (Bartussek E. et al, 2004). No es hasta el año 2004 cuando tanto en EE. UU. como en Europa se establecen guías de programas de formación en anestesia regional, y se definen las curvas de aprendizaje o las escalas en el tiempo para el entrenamiento de los profesionales en este campo (Del Olmo C. et al, 2010).

Las habilidades para el ejercicio de la anestesia regional se pueden alcanzar por una mezcla de formación teórica y práctica que abarque el manejo de los equipos de ultrasonido, conocimiento de la anatomía relevante y seguridad del paciente (Sites BD. et al, 2007). En España, el programa de formación de la especialidad de anestesiología nombra la anestesia loco-regional dentro de los conocimientos teóricos y contempla que el residente debe rotar por las unidades de CMA o del dolor, participando en la aplicación de las distintas técnicas y 
métodos (bloqueos nerviosos, implantación de reservorios...); pero no se contempla el tiempo de formación específico en bloqueos periféricos (disponible en la página del ministerio de sanidad http://www.msps.es/profesionales/formacion/docs/ Anestesiologia_y _Reanimacion.pdf).

Diferentes autores coinciden en la opinión de que en el ámbito de la anestesia intradural se precisan un mínimo de 40-50 punciones, y son necesarias entre 50 y 90 técnicas epidurales para obtener el éxito en el 90\% de las anestesias (Konrad C. et al, 1988; Kopacz DJ. et al, 2002). El número de bloqueos nervisos periféricos, como el bloqueo interescalénico, supraclavicular, plexo lumbar o ciático, no ha sido determinado, pero se estima que sea similar al de las técnicas neuroaxiales (Kopacz DJ. et al, 2002). El Residency Review Committee of Anesthesiology de la Acreditation Council for Graduate Medical Education (ACGME) recomienda, en orden de mejorar las competencias, que se realicen un mínimo de 40 intradurales, 50 epidurales, 40 BNP para cirugía y 25 en el tratamiento del dolor, sin especificar qué tipo de bloqueos deben de formar parte del currículo (Bröking K. et al, 2006). Konrad, en relación con el plexo axilar considera un mínimo de 20 bloqueos axilares para obtener el 70\% de éxitos en la técnica (Konrad C. et al, 1998).

Rosenblatt evaluó durante 8 meses a 17 residentes de primer y segundo año de formación en el aprendizaje del bloqueo interescalénico y observó que entre el séptimo y el noveno bloqueo realizado, el 50\% de los residentes podían realizar la técnica sin supervisión, así como que con más de 15 intentos el 87,5\% de los residentes obtenían el éxito del bloqueo y eran autónomos en su realización (Rosenblatt MA. et al, 2003).

Queda claro que la realización de bloqueos exitosos precisa de la adquisición de conocimientos teóricos y habilidades, es decir, de un método de aprendizaje, pero no está clara la mejor manera de adquirir dichas competencias.

Actualmente, las fuentes de aprendizaje son limitadas: atlas, libros de texto, webs y revistas (como por ej. Regional Anesthesia and Pain Medicine). Un programa adecuado de formación debe incluir conocimientos básicos de ultrasonografía, imágenes relevantes para la práctica, habilidades de las manos con la aguja y seguridad del paciente en general. No 
obstante, es necesario definir futuras guías de formación para la adquisición adecuada de habilidades y conocimientos en este campo (Del Olmo C. et al 2010).

En este sentido, las prácticas con neuroestimulación o ecografía, tanto en pacientes reales como en animales o cadáveres, o incluso mediante simulación, son importantes para la formación en anestesia regional. Sin embargo, como se ha señalado en este trabajo, no se debe olvidar que la anatomía es la base fundamental de este campo de la anestesia y que por tanto, unos conocimientos exactos de la misma son esenciales para realizar satisfactoriamente cualquier tipo de bloqueo. Así los talleres de trabajo con cadáveres y voluntarios para el conocimiento de la anatomía de superficie, es tan buena como el aprendizaje mediante la visualización tridimensional, que raramente es utilizada en la educación (Lirk P. et al, 2005). Dado que los pulsos arteriales son un elemento importante en las referencias anatómicas al realizar la técnica, se ha desarrollado un dispositivo neumático portátil, compacto y electrónico que genera artificialmente pulsos arteriales en cadáveres. Un catéter de trombectomía se inserta en una arteria (axilar, subclavia y femoral) y se conectaba a un respirador. Para generar pulsos locales el balón del catéter se insufla rítmicamente. Se insertó en ocho cadáveres donde los pulsos palpables se encontraron en el 91\% de los intentos. El sistema fue utilizado por 189 estudiantes que lo evaluaron en una escala de 1 a 4 . En total, 164 estudiantes (87\%) informaron que era una muy buena experiencia de aprendizaje y $21(11 \%)$ de que era una buena experiencia. En resumen, la simulación del pulso en cadáveres embalsamados parece ser eficaz en la mejora de la enseñanza de bloqueos regionales (Schwarz G. et al, 2002).

Sin embargo, la anatomía en modelos de cadáveres a veces no se corresponde con el ser vivo, de tal forma que a veces las superficies anatómicas son difíciles de enseñar. Lim, desarrolló un modelo en tres dimensiones para el aprendizaje del plexo interescalénico en el que una cámara virtual produce imágenes de la anatomía básica y sus referencias de superficie. Además, este modelo muestra cuándo la técnica se realiza de una forma incorrecta y puede ser un método de gran valor en los profesionales menos aventajados (Lim MW. et al, 2005).

Actualmente en Internet y concretamente sitios web como youtube muestran múltiples videos de simuladores en anestesia regional que tratan aspectos concretos de esta 
disciplina (videos de distintos bloqueos, raquianestesia...), pero en ellos el lector no tiene ningún papel activo, ni interactúa con la imagen. En los últimos años, se han publicado excelentes textos y programas multimedia. Actualmente están disponibles maniquís que facilitan el aprendizaje, programas informáticos en castellano distribuidos por la industria farmacéutica, además de la disponibilidad en Internet de información a través de diferentes webs de sociedades, siendo líder la desarrollada por la New York School of Regional Anesthesia (NYSORA. The New York School of Regional Anesthesia. Available at: www.nysora.com). La disponibilidad de diferentes herramientas como los simuladores hace que se presenten como modelos atractivos para la formación en anestesia regional (AR). Sin embargo, hay pocos simuladores basados en realidad virtual para la AR (Hu J. et al, 2007; Bibin L. et al, 2008). Además, el problema de estos simuladores, es que casi todos se aplican a nivel experimental, por lo que tienen nula aplicabilidad, al menos por el momento en la formación y práctica clínica habitual. Existen simuladores basados en maniquíes, o simuladores con agujas, que se aplican en diferentes áreas biosanitarias como la acupuntura (Leung KM. et al, 2003) o para practicar la punción lumbar (Färber M. et al, 2006).

Las dos técnicas que más aplicaciones tienen para el aprendizaje son la anestesia espinal y los bloqueos epidurales. Existen simuladores, como se ha mencionado, casi todos a nivel experimental, para anestesia regional que utilizan un paciente virtual en 3D con respuesta muscular a la estimulación del nervio (Hu J. et al, 2007). Existen también atlas multimedia de bloqueos nerviosos (Delbos A. et al, 2005; Bibin L. et al, 2008).

Grottke y cols., en el 2009 presentan en el British Journal of Medicine un simulador cuyas imágenes se obtuvieron de la región inguinal de cinco sujetos. A partir de estas fuentes, se crearon imágenes en tres dimensiones y modelos anatómicos de los nervios. La resolución que obtuvieron fue suficiente para realizar simulaciones realistas. Es el único que ofrece variantes anatómicas, pero que se limita a la región inguinal (Grottke O. et al, 2009). Técnicamente, los simuladores de realidad virtual no tienen en cuenta la anatomía de cada paciente y no pueden ser adaptados a las diferentes regiones, como la región inguinal, la columna vertebral, el cuello o el brazo. Nuestra aplicación también presenta esta limitación al estar basada en los datos de un único paciente modelo. 
A diferencia de todos estos simuladores, la aplicación informática que aquí se presenta ha tomado en cuenta todos estos aspectos. No muestra una parcela determinada del conocimiento de la anestesia regional, si no que es un atlas multimedia, ofrece imágenes de un ser vivo, emula una exploración ecográfica y aporta textos como los libros clásicos. En una sola aplicación se unen las metodologías de enseñanzas tradicionales, cuyo resultado ha sido eficaz y de hecho se siguen editando libros a diario, con las más novedosas técnicas pedagógicas del momento. En último término, se ha plasmado aquello que a todo estudiante le gustaría tener con unos clics de ratón, a cualquier hora y lugar, siendo cada uno responsable de su propio aprendizaje. Antes de la realización en la práctica clínica habitual de cualquier bloqueo, el anestesiólogo debe familiarizarse con las imágenes ecográficas, debe saber que nervio está buscando y las relaciones anatómicas existentes. Desde este punto de vista, la utilización de esta herramienta puede facilitar la adquisición de estos conocimientos.

La Universidad de Duke, desarrolló un nuevo modelo para el entrenamiento de los residentes en anestesia regional, con el objetivo de mejorar la seguridad de los pacientes, acortar los tiempos muertos quirúrgicos y mejorar la formación de estos. Este modelo se basó en la creación de áreas preoperatorias en las que los residentes realizaran los BNP bajo la supervisión de varios facultativos. Esto incrementó la exposición de los residentes a todas las técnicas de anestesia regional, y especialmente el número de BNP que el residente realizaba (Orebaugh S. et al, 2007). La filmación en video del alumno durante la realización de un bloqueo nervioso es otra metodología de aprendizaje. Así, la filmación en diferentes etapas de la formación, con posterior análisis de las habilidades adquiridas y los errores cometidos durante la práctica del bloqueo, conjuntamente con anestesiólogos experimentados, ha resultado de gran eficacia frente a la enseñanza clásica. Una ventaja de este método es la posibilidad de realizar un aprendizaje de forma posterior sin presencia de pacientes o personal sanitario de apoyo (Bimbach DJ. et al, 2002)

La ultrasonografía, que se ha introducido en los últimos años, ha ganado gran popularidad y está facilitando la realización de los bloqueos (Orebaugh S. et al, 2007; Sites B. et al, 2004). Nuestra aplicación informática cuyo formato es altamente atractivo, creemos fomentará su uso en aquellos que muestren interés por estas técnicas, o al menos atraerá a 
aquellos residentes que empiezan. Incluye todo lo necesario para comenzar sin necesidad de consultar distintas fuentes y probablemente haga que la curva de aprendizaje sea más rápida.

Uno de los grandes retos en cualquier área del saber, dentro de un mundo inmerso en la tecnología, la información y el conocimiento, es la búsqueda de soluciones a problemas que se presentan en la práctica clínica diaria. El uso de las nuevas tecnologías tiene que ser un canal para formar y presentar la información de otra forma (Fairweather PG. et al, 2000). Frente a los tradicionales libros, los nuevos contenidos educativos creados con recursos tecnológicos permiten unas presentaciones más dinámicas (interactividad) más atractivas (presentación simultanea de texto, sonidos e imágenes) y más variados. Estas nuevas prestaciones pueden facilitar el aprendizaje y permitir mejoras cognitivas. Con todas estas premisas se presenta este procedimiento tecnológico para la formación en anestesia regional; se ha creado lo que podría ser un aula o plataforma virtual de ecografía aplicada a la anestesia regional. Es un desarrollo informático de fácil manejo, software sencillo, atractivo diseño y con gran poder pedagógico. Permite al alumno una cosa importante en el aprendizaje de esta técnica, que es el establecimiento de relaciones entre estructuras anatómicas con ecográficas. Aúna en un solo dispositivo anatomía de superficie, imágenes 2D de ecografía y RM con un modelo anatómico 3D, junto con la neurofisiología (neuroestimulación). Como se ha dicho, puede contribuir a elaborar mapas conceptuales o mentales claros, permitiendo, con su uso repetido, la consolidación de los mismos. Cualquiera, sin necesidad de conocimientos tecnológicos amplios puede utilizarlo, lo que no debe ser un obstáculo para aquellos anestesiólogos con menos conocimientos informáticos, para avanzar en la anestesia regional, pudiendo de esta forma aprender nuevas técnicas que complementen o sustituyan aquellas que emplean de forma habitual. Otro aspecto importante es que no necesita grandes equipos ni inversión, tampoco precisa de conexión a Internet con lo que su uso no se ve limitado. No precisa tampoco de mantenimiento del servidor ni autorización.

Consideramos que esta aplicación informática es un proyecto de un alto nivel de innovación y complejidad. Por esto se ha requerido de la colaboración de un equipo multidisciplinar para su realización: anestesiólogos, anatomistas, informáticos y radiólogos. 
No tenemos conocimiento de la existencia de una herramienta similar a nivel mundial, por lo que a través de este procedimiento somos pioneros en esta área de investigación y desarrollo en formación médica. Se trata del primer estudio de esta índole, en este campo de conocimiento, desde la perspectiva docente.

Creemos que con nuestra aportación estamos introduciendo en la enseñanza nuevos elementos que están contribuyendo a una transformación en la práctica educativa. Por otro lado, como todo proceso de autoaprendizaje, el programa requiere de una gran motivación personal.

Con toda la información recopilada y una vez se realizaron las correcciones pertinentes, con la satisfacción de todo el equipo, se procedió a la edición del producto para su posterior distribución. Posteriormente se ha evaluado la calidad y la idoneidad de la información mostrada al realizar la encuesta de satisfacción. Todos los ítems han recibido el valor 4 (de acuerdo) o el máximo valor 5 (totalmente de acuerdo) excepto la cuestión de si todas las imágenes se parecían a lo que veíamos en la práctica real. En dicho ítem, un $20 \%$ de los anestesiólogos encuestados no estaba ni de acuerdo ni en desacuerdo. Una posible explicación sería la variabilidad anatómica que existe en la práctica clínica habitual entre los pacientes, ya que no todas las imágenes expuestas en la aplicación son de lo más representativo, puesto que han sido obtenidas de un solo modelo. Otra explicación, sería que la calidad de la imagen entre los distintos ecógrafos disponibles en los distintos servicios de anestesiología, varía. Nuestros resultados son similares a los obtenidos en otros estudios donde hasta el $80 \%$ de los participantes consideraban que mejoraba la compresión de la teoría y sus habilidades y un porcentaje similar lo recomendarían a sus colegas (Jones I. et al, 2007; Thoren AB. et al, 2007; Juanes JA. et al, 2011). Estos programas interactivos son especialmente útiles cuando existe una gran motivación personal y fuerza de voluntad, si no tienden al fracaso (Carroll C. et al, 2009; Ruf D. et al, 2009)

Entre las limitaciones que presenta el procedimiento tecnológico y que son las que a su vez nos motivan para mejorarlas, cabría comentar:

- El modelo se limita a extremidades y cuello, pudiéndose hacerse extensible a otros territorios en un futuro. 
- No existen videos de la realización de la técnica, ni los posibles abordajes de los distintos bloqueos, con lo cual necesita un complemento de formación práctica. Sin embargo, esta aplicación puede ser el punto de partida de aquellos que se inician en la técnica y ayuda ante la falta de nitidez que se obtiene en algún tipo de paciente por sus características especiales (obeso, zona radiada...). Derivado de este sentido práctico, también se encuentra la limitación de no saber qué presión darle al transductor de ecografía (por ejemplo al colapsar los vasos para distinguir la vena, que se colapsa, de la arteria); así como saber mantener el ángulo adecuado de la punción y la posición de la mano estable durante la inyección.

- Sólo existe de momento la versión para PC, no para MAC.

- No sabemos, por el momento, si una aplicación de simulación interactiva de este tipo tendrá un correlato clínico manifestado por:

o Un mayor número de técnicas de bloqueo regional desde su implantación.

o Un menor número de dosis total de anestésico aplicada.

o Una mayor tasa de éxitos.

o Menor número de complicaciones.

o Una mayor satisfacción por parte del paciente.

El estudio en sí, no evalúa si existe una relación dosis-respuesta entre la cantidad de tiempo dedicado al uso del sistema y los resultados del aprendizaje. Es necesario seguir trabajando para aclarar si el uso de este procedimiento u otras herramientas de aprendizaje electrónico pueden mejorar los resultados del aprendizaje.

Son varios los autores que han validado las prácticas de e-learning, por ejemplo simuladores de reanimación cardiopulmonar (RCP), donde mejoran las capacidades cognitivas y habilidades prácticas (Monsieurs KG. et al, 2004; Jensen ML. et al, 2009; Napier F. et al, 2009; Perkins GD. et al, 2010). El uso de simuladores se ha extendido rápidamente en la formación sanitaria tanto como para la formación pregrado como postgrado en distintas ramas como cirugía (Rogers DA. et al, 1998), medicina interna (Lyon HC. et al, 1991), ORL (Carr MM. et al, 1999). 
En definitiva, esta aplicación informática puede hacer resurgir el interés por este tipo de técnicas y mejorar la confianza de los anestesiólogos. Desde el punto de vista pedagógico permite una gran flexibilidad en la formación médica, adaptándose al ritmo y capacidad de cada usuario. Es un producto novedoso con una gran proyección futura. 



\section{Capitulo 6}

CONCLUSIONES 

Después de haber llevado a cabo un procedimiento informático para la enseñanza y la práctica de bloqueos regionales guiados con ecografía, hemos llegado a las siguientes conclusiones:

1a-- Proporciona una colección iconográfica ecográfica y de RM del aparato locomotor y su correlación con la imagen 3D, lo que aporta un alto valor didáctico.

2a-- El uso de este "atlas ecográfico" constituye una herramienta más para facilitar la compresión e interpretación de la sonografía básica.

3a- La aplicación informática elaborada, permite la práctica en un escenario controlado, seguro y reproducible, recogiendo los principales bloqueos de las extremidades y el cuello.

4a- Nuestro desarrollo informático, ha sido bien aceptado entre los anestesiólogos, con gran satisfacción entre los que la han utilizado; lo han encontrado muy útil y práctico para la formación en anestesia regional.

5a- y última; estamos ante una herramienta novedosa y única a nivel mundial, que con su uso continuado garantiza un mayor conocimiento anatómico y por ende podría aumentar la tasa de éxitos y disminuir el número de complicaciones en la anestesia regional. 



\section{Capitulo 7}

Bibliografía 

Abdallah FW, Chan VW, Brull R. Transversus abdominis plane block: a systematic review. Reg Anesth Pain Med. 2012; 37(2): 193-209.

Abrahams MS, Aziz MF, Fu RF, Horn JL. Ultrasound guidance compared with electrical neurostimulation for peripheral nerve block: a systematic review and meta-analysis of randomized controlled trials. Br J Anaesth. 2009 Mar; 102(3): 408-417.

Abramowicz JS. Technical advances in ultrasound equipment. Clinical Obstetrics and Gynecology 2003; 46: 839-849.

Abramowitz HB, Cohen C. Use of doppler for difficult axillary block. Anesthesiology 1981; 55: 603.

Aldrich JE. Basic physics of ultrasound imaging. Crit Care Med 2007; 35(5): 131-137.

Aliaga L, Catalá E, García Muret A, Masdeu J, Tornero C. Anestesia regional hoy. 3a edición. Barcelona: Publicaciones Permanyer; 2006. pp. 1-111, 263-363 y 375-465.

Alonso P, Hernández F, Mozo G, Muriel C. Atlas de anestesia regional guiada con ecografía. Madrid; Aran ed. 2009. pp. 19-98.

Antonakakis JG, Ting PH, Sites B. Ultrasound-guided regional anesthesia for peripheral nerve blocks: an evidence-based outcome review. Anesthesiol Clin. 2011; 29(2): 179-191.

Auroy Y, Narchi P, Messiah A, Litt L, Rouvier B, Samii K. Serious complications related to regional anesthesia: results of a prospective survey in France. Anesthesiology 1997; 87: 479-486.

Auroy Y, Benhamou D, Bargues L, Ecoffey C, Falissard B. Major complications of regional anesthesia in France. Anesthesiology 2002; 97: 1274-1280.

Ballantyne JC, Carr DB, DeFerranti S. The comparative effects of postoperative analgesic therapies on pulmonary outcome: cumulative meta-analyses of randomized, controlled trials. Anesthesia \& Analgesia 1998; 86: 598-612.

Ban $\mathrm{CH}$, Tsui. Atlas of ultrasound and nerve stimulation-guided regional anesthesia. Alberta, Canada: 2007; pp. 1-18.

Bartussek E, Fatehi S, Motsch J, Grau T. Summary on practice of regional anesthesia in Germany, Austria, and Switzerland. Part I. Quality assurance and training concepts. Anaesthesist 2004; 53(9): 836-846.

Bartussek E, Fatehi S, Motsch J, Grau T. Summary on practice of regional anesthesia in Germany, Austria, and Switzerland. Part II. Use, success rates and techniques. Anaesthesist 2004; 53(9): 847-855. 
Beach ML, Sites BD, Gallagher JD. The use of a nerve stimulator does not improve the efficacy of ultrasound guided supraclavicular nerve blocks. Journal of Clinical Anesthesia 2006; 18: 580-584.

Beattie WS, Badner NH, Choi P. Epidural analgesia reduces postoperative myocardial infarction: a meta-analysis. Anesthesia \& Analgesia 2001; 93: 853-858.

Beux PL, Fieschi M. Virtual biomedical universities and e-learning international journal of medical informatics. Int J Med Inform. 2007; 76(5-6): 331-335.

Bibin L, Lécuyery A, Burkhardtz JM, Delbos A, BonnetM. SAILOR: a 3-D medical simulator of loco-regional anaesthesia based on desktop virtual reality and pseudo-haptic feedback. In: Proceedings of the ACM symposium on virtual reality software and technology, 2008, pp. 97-100.

Biegeleisen PE. Nerve puncture and apparent intraneural injection during ultrasound guided axillary block does not invariably result in neurologic injury. Anesthesiology 2006; 105: 779-783.

Bimbach DJ, Santos AC, Bourlier RA. The effectiveness of video technology as an adjunct to teach and evaluate epidural anesthesia performance skills. Anesthesiology 2002; 96(1): 5-9.

Blanco R, López S, Parras T. Manual de anestesia regional y ecoanatomía avanzada. Abbott Laboratorios. Ene ediciones 2011.

Bolbar I, Catalá E, Cadena R. El dolor en el hospital: de los estándares de prevalencia a los de calidad. Rev Esp Anestesiol Reanim 2005; 52: 131-140.

Bollini CA, Urmey WF, Vascello L, Cacheiro F. Relationship between evoked motor response and sensory paresthesia in interscalene brachial plexus block. Reg Anesth Pain Med. 2003; 28(5): 384-388.

Bollini CA, Cacheiro FJ. Ultrasound, paresthesia, and motor response. Reg Anesth Pain Med. 2007; 32(6): 542-544.

Bonica JJ. The management of pain. Philadelphia: Lea \& Febiger, 1953.

Borgeat A, Ekatodramis G, Kalberer F, Benz C. Acute and nonacute complications associated with interscalene block and shoulder surgery: a prospective study. Anesthesiology 2001; 95: 875-880.

Borrelli A, Ambrosino G, Fasseta G. Blocco del nervo ischiatico per via anteriore. Boloña: Atti Congr Anestesia Ortopedia; 1992: 400-402.

Bosemberg AT, Raw A, Boezaart AP. Surface mapping of peripheral nerves in children with a nerve stimulator. Paedr Anesth 2002; 12(5): 398-403. 
Bröking K, Waurick R. How to teach regional anesthesia. Curr Opin Anaesthesiol 2006; 19(5): 526-530.

Brown PM, Hamilton NM, Denison AR. A novel 3D stereoscopic anatomy tutorial. Clin Teach. 2012; 9(1): 50-53.

Bryson EO, Levine Al. The simulation theatre: a theoretical discussion of concept and constructs that enhance learning. J Cit Care 2008; 23: 185-187.

Bubnov RV, Strokan' AM, Abdullaiev Rla. Comparative study of performance of lower extremities blocks under ultrasonography and nerve stimulator guidance. Lik Sprava. 2011:126-131.

Buist RJ. A survey of the practice of regional anesthesia. Journal of the Royal Society of Medicine 1990; 83: 709-712.

Cabrero FJ, Sánchez JM, Sánchez AB, Borrejo J, Rodríguez Mạ J, Cabrero M, Juanes JA. Simulaciones computacionales en la enseñanza de la Física Médica. Avances tecnológicos digitales en metodologías de innovación docente en el campo de las Ciencias de la Salud en España. Revista Teoría de la Educación: Educación y Cultura en la Sociedad de la Información.2010, Vol. 11, no 2. Universidad de Salamanca, pp. 46-55.

Calatayud J, González A. History of the development and evolution of local anesthesia since the coca leaf. Anesthesiology 2003; 98(6): 1503-1508.

Cannon-Bowers JA. Recent advances in scenario- based training for medical education. Curr Opin Anesthesiol 2008 ;21: 784-789.

Carr MM, Reznick RK, Brown DH. Comparison of computer-assisted instruction and seminar instruction to acquire psychomotor and cognitive knowledge of epistaxis management. Otolaryngol Head Neck Surg 1999; 121: 430-434.

Carroll C, Booth A, Papaioannou D, Sutton A, Wong R. UK health-care professionals' experience of on-line learning techniques: a systematic review of qualitative data. J Contin Educ Health Prof 2009;29: 235-241.

Casati A, Baciarello M, Di Cianni S, Danelli G, De Marco G, Leone S. Effects of ultrasound guidance on the minimum effective anaesthetic volume required to block the femoral nerve. Br J Anaesth 2007; 98(6): 823-827.

Casati A, Danelli G, Baciarello M, Corradi M. Leone S, Di Cianni S. A prospective randomized comparison between ultrasound and nerve stimulation guidance for multiple injection axillary brachial plexus block. Anesthesiology 2007; 106: 992996. 
Chan VW, Peng PW, Kaszas Z. A comparative study of general anesthesia, intravenous regional anesthesia, and axillary block for outpatient hand surgery: clinical outcome and cost analysis. Anesthesia \& Analgesia 2001; 93: 1181-1184.

Chan VW, Perlas A, Rawson R, Odukoya O. Ultrasound-guided supraclavicular brachial plexus block. Anesth Analg 2003;97: 1514-1517.

Chan VW. Applying ultrasound imaging to interscalene brachial plexus block. Reg Anesth.Pain Med 2003;28: 340-343.

Chan VW. Ultrasound evidence of intraneural injection. Anesth Analg. 2005;101(2): 610611.

Chan VW, Nova H, Abbas S. Ultrasound examination and localization of the sciatic nerve: a volunteer study. Anesthesiology 2006; 104: 309-314.

Chan VW, Perlas A, McCartney CJ, Bruli R, Xu D, Abbas S. Ultrasound guidance improves success rate of axillary brachial plexus block. Can J Anaesth 2007; 54(3): 165-170.

Chelly JE, Greger J, Gebhard R, Hagberg C, Al-Samsam T, Khan A. Training of residents in peripheral nerve blocks during anesthesiology residency. J Clin Anesth 2002; 14(8): 584-588.

Chelly JE, David B, Williams BA, Kentor ML. Anesthesia and postoperative analgesia: outcomes following orthopaedic surgery. Orthopedics 2003; 26: 865-871.

Chin KJ, Niazi A, Chan V. Anomalous brachial plexus anatomy in the supraclavicular region detected by ultrasound. Anesth Analg 2008; 107: 729-731.

Chin KJ, Perlas A, Brull R. Needle visualization in ultrasound-guided regional anesthesia: challenges and solutions. Reg Anesth Pain Med 2008; 33(6): 532-544.

Choudhry NK, Fletcher RH, Soumerai SB. Systematic review: the relationship between clinical experience and quality of health care. Ann Intern Med 2005;142: 260-273.

Clark D. Pedagogy and E-Learning. Brighton, UK: Epic; 2006.

Cook DA, Levinson AJ, Garside S, Dupras DM, Erwin PJ, Montori VM. Internet-based learning in the health professions: a meta-analysis. JAMA 2008;300: 1181-1196.

Cumin D, Merry AF. Simulators for use in anaesthesia. Anaesthesia 2007; 62: 151-162.

Cumin D, Merry AF, Weller JM. Standards for simulation. Anaesthesia 2008;63: 12811284.

Curran VR, Fleet L. A review of evaluation outcomes of web-based continuing medical education. Med Educ 2005; 39: 561-567. 
D'Alfonso J, Halvorson CK. E-learning in perioperative education. Surgical Services Management 2002, 8: 20-22.

Danelli G, Fanelli A, Ghisi D, Moschini E, Rossi M, Ortu A. Ultrasound vs nerve stimulation multiple injection technique for posterior popliteal sciatic nerve block. Anaesthesia 2009; 64: 638-642.

Danelli G, Bonarelli S, Tognú A, Ghisi D, Fanelli A, Biondini S, Moschini E, Fanelli G. Prospective randomized comparison of ultrasound-guided and neurostimulation techniques for continuous interscalene brachial plexus block in patients undergoing coracoacromial ligament repair.Br J Anaesth. 2012; 108(6): 1006-1010.

Davis J, Chryssafidou E, Zamora J, Davies D, Khan K, Coomarasamy A. Computer-based teaching is as good as face to face lecture-based teaching of evidence based medicine: a randomised controlled trial. BMC Med Educ 2007; 7: 23.

Davis J, Crabb S, Rogers E, Zamora J, Khan KS. Computer-based teaching is as good as face to face lecture-based teaching of evidence based medicine: a randomized controlled trial. Med Teach 2008; 30: 302-307.

De Andrés J, Sala-Blanch X. Peripheral nerve stimulation in the practice of brachial plexus anesthesia: a review. Reg Anesth Pain Med 2001; 26(5): 478-483.

De Andres J, Sala-Blanch X. Ultrasound in the practice of brachial plexus anesthesia. Reg Anesth Pain Med 2002; 27: 77-89.

De Andrés J. Puesta al día en anestesia regional y tratamiento del dolor. Capitulo: Contribuciones de los médicos españoles a la introducción y desarrollo de la anestesia locorregional. ESRA Menarini España, 2005. Volumen VIII. pp. 15-21.

De Andrés J, Alonso-Iñigo JM, Sala-Blanch X, Reina MA. Nerve stimulation in regional anestesia: theory and practice. Best Pract Res Clin Anesthesiol 2005; 19(2): 153174.

Del Olmo C, López S, Ortigosa E. Anestesia regional y dolor. Madrid Aran; 2010. pp. 19$38,39-88,169-441$.

Del Olmo C, De Diego P, Ortega A. Manual de ecografía básica para anestesia regional. Madrid; Menarini 2010.

Delbos A, Eisenach JC, Albert N, Narchi P. Peripheral nerve blocks on DVD: upper and lower limbs package. Multimedia atlas, 2005.

Denny NM, Harrop-Griffiths W. Editorial: Location, location, location! Ultrasound imaging in regional anaesthesia. Br J Anaesth 2005; 94: 1-3.

Denson JS, Abrahamson S. A computer-controlled patient simulator. J Am Med Assoc 1969; 208: 504-508. 
Díaz N, Garrido RP, Castellano J. Metodología y técnicas. Ecografía: principios físicos, ecógrafos y lenguaje ecográfico. Publicado en Semergen. 2007 ; 33: 362-369.

Diéguez P, Tielens L, García B, López S. Ultrasonografia para bloqueos regionales de adultos en cirugía mayor ambulatoria. Cir May Amb 2007; 12(1): 10-16.

Domingo V, Aguilar JL, Pelaez R. Bloqueos nerviosos periféricos de la extremidad inferior para analgesia postoperatoria y tratamiento del dolor crónico. Rev. Soc. Esp. Dolor 2004; 11: 223-237.

Doyle DJ. Simulation in medical education. Focus in Anesthesiology. Medical Education Online 2002; 7: 1-15.

Dufour E, Quenuesson P, Van Robáis AL, Ledon F, Laloe PA, Liu N. Combined ultrasound and neurostimulation guidance for popliteal sciatic nerve block: a prospective, randomized comparison with neurostimulation alone. Anesth Analg 2008; 106(5): 1553-1558.

Duggan E, El Beheiry $\mathrm{H}$, Perlas A. Minimum effective volume of local anesthetic for ultrasound-guided supraclavicular brachial plexus block. Reg Anesth Pain Med 2009; 34: 215-218.

Eichenberger U, Stockli S, Marhofer P. Minimal local anesthetic volume for peripheral nerve block: a new ultrasoundguided, nerve dimension-based method. Reg Anesth Pain Med 2009; 34: 242-246.

Evans $\mathrm{H}$, Steele SM, Nielsen KC, Tucker MS, Klein SM. Peripheral nerve blocks and continuous catheter techniques. Anesthesiol Clin North Am 2005; 23: 141-162.

Eynon R, Perryer G, Walmsley AD. Dental undergraduate expectations and opinions of web-based courseware to supplement traditional teaching methods. Eur J Dent Educ 2003. 7: 103-110.

Fairweather PG, Gibbons AS. Distributed Learning: Two steps forward, one back? Or one forward, two back? IEEE Concurrency, 2000. 8(2): 8-9.

Färber $M$, Heller J, Handels $H$. Virtual reality simulator for the training of lumbar punctures. In: Proceedings of CURAC, 2006. pp. 126-127.

Federative Committee on Anatomical Terminology (FACT). Terminología anatómica. Thyeme. Stuttgart, 1998.

Finn JE. Learning in resuscitation training - students say they like it, but is there evidence that it works?. Resuscitation 81 (2010) 790-791.

Fordis M, King JE, Ballantyne CM. Comparison of the instructional efficacy of Internetbased CME with live interactive CME workshops: a randomized controlled trial. J Am Med Assoc 2005; 294: 1043-1051. 
Gallardo J. La inervación sensitiva segmentaria dermatomas, miotomas y esclerotomas. Rev. Chil. Anestesia, 2008. 37: 26-38.

Ganesh A, Gurnaney HG. Ultrasound guidance for pediatric peripheral nerve blockade. Anesthesiol Clin. Review 2009; 27(2): 197-212.

Ganesh A. Interscalene brachial plexus block-anatomic considerations. Reg Anesth 2009; 34(5): 525.

Garg AX, Norman G, Spero L. How medical students learn spatial anatomy. Lancet 2001; 357 (9253): 363-364.

Garg AX, Norman GR, Eva KW, Spero L, Sharan S. Is there any real virtue of virtual reality? The minor role of multiple orientations in learning anatomy from computers. Acad Med 2002; 77 (Suppl 10): 97-99.

Gavilán E. Las innovaciones tecnológicas interactivas como herramienta docente: oportunidades y precauciones. Fundación Gaspar Casal para la investigación y desarrollo de la Salud. E-revista NETS num.03, 2010, pp. 29-31.

Gonano C, Kettner SC, Ernstbrunner M, Schebesta K, Chiari A, Marhofer P. Comparison of economical aspects of interscalene brachial plexus blockade and general anaesthesia for arthroscopic shoulder surgery. Br J Anaesth 2009; 103: 428-433.

Good ML, Grevenstein JS. Anesthesia simulators and training devices. Int Anesthesiol Clin 1989; 27: 161-168.

Gouvitos F, Vallet B, Scherpereel P. Les simulateurs d'anesthésie: interest et limites à travers l'experience de plusieurs centres univesitaires européens. Ann Fr Anesth Réanim 1999; 18: 787-795.

Grau T, Leipold RW, Conradi R, Martin E, Motsch J. Efficacy of ultrasound imaging in obstetric epidural anesthesia. Journal of Clinical Anesthesia 2002; 14: 169-175.

Grau T, Bartusseck E, Conradi R, Martin E, Motsch J. Ultrasound imaging improves learning curves in obstetric epidural anesthesia: a preliminary study. Can J Anaesth 2003; 50: 1047-1050.

Grau T, Fatehi S, Motsch J, Bartusseck E. Survey of current practice of regional anaesthesia in Germany, Austria and Switzerland. Use Success rates and techniques, part 2. Anaesthesist 2004; 53: 847-855.

Gray AT. Ultrasound-guided regional anesthesia: current state of the art. Anesthesiology 2006; 104: 368-373.

Greenhalgh T. Computer assisted learning in undergraduate medical education. BMJ 2001; 322: 40-44. 
Greher M, Retzl G, Niel P, Kamholz L, Marhofer P, Kapral S. Ultrasonographic assessment of topographic anatomy in volunteers suggest a modification of the infraclavicular vertical brachial block. British Journal of Anaesthesia 2002; 88: 632-636.

Griffin J, Nicholls B. Ultrasound in regional anaesthesia. Anaesthesia, 2010, 65 (Suppl. 1): $1-12$.

Grigore C, Coiffet P. Virtual Reality Technology (Second Edition) Ed. Wiley-IEEE Press, 2003.

Grottke O, Ntouba A, Ullrich S, Liao W, Fried E, Prescher A. Virtual reality-based simulator for training in regional anaesthesia. British Journal of Anaesthesia 2009. 103 (4): 594-600.

Gunther B. Karl Koller: centennial of the discovery of local analgesia. Rev Med Chil 1984; 112(11): 1181-1185.

Gurusamy K, Aggarwal R, Palanivelu L, Davidson BR. Systematic review of randomized controlled trials on the effectiveness of virtual reality training for laparoscopic surgery. Br J Surg 2008; 95: 1088-1097.

Hadley J , Kulier R , Zamora J , Coppus SF , Weinbrenner S, Meyerrose B. Effectiveness of an e-learning course in evidence-based medicine for foundation (internship) training J R Soc Med 2010: 103: 288-294.

Hadzic A, Blokla JD, Koenigsamen J. Training requirements for peripheral nerves blocks. Curr Opin Anaesthesiol 2002; 15(6): 669-673.

Hadzic A, Arliss J, Kerimoglu B. A comparison of infraclavicular nerve block versus general anesthesia for hand and wrist day-case surgeries. Anesthesiology 2004; 101: 127-132.

Hadzic A, Vloka JD, Claudio RE, Hadzic N, Thys DM, Santos AC. Electrical nerve location. Effects of cutaneous electrode placement and duration of stimulus on motor response. Anethesiology 2004; 100(6): 1526-1530.

Hadzic A, Karaca PE, Hobeika P. Peripheral nerve blocks result in superior recovery profile compared with general anesthesia in outpatient knee arthroscopy. Anesthesia \& Analgesia 2005; 100: 976-981.

Hadzic A, Williams BA, Karaca PE. For outpatient rotator cuff surgery, nerve block anesthesia provides superior same-day recovery over general anesthesia. Anesthesiology 2005; 102: 1001-1007.

Harden RM. Trends and the future of postgraduate medical education. Emerg Med J 2006;23: 798-802. 
Hariri S, Rawn C, Srivastava S, Youngblood P, Ladd A. Evaluation of a surgical simulator for learning clinical anatomy. Med Educ 2004; 38 (8): 896-902.

Hassan ZU, Dorling J, McLamey JT, Sloan PA. The patient simulator for training of anesthesia residents in the management of one lung ventilation. Simul Healthc 2008; 3: 47-52.

Hite BW, McCartney CJ. Pro/Con: teaching residents with ultrasound hinders postgraduate practice of regional anesthesia. ASRA 2007; 6-8.

Holborow J, Hocking G. Regional anaesthesia for bilateral upper limb surgery: a review of challenges and solutions. Anaesth Intensive Care. 2010; 38(2): 250-258.

Horlocker TT, Wedel DJ. Ultrasound-guided regional anesthesia: in search of the holy grail. Anesth Analg 2007; 104(5): 1009-1011.

Hopkins PM. Ultrasound guidance as a gold standard in regional anaesthesia. $\mathrm{Br} \mathrm{J}$ Anaesth 2007; 98(3): 299-301.

Hu J, Lim Y, Tardella N, Chang C, Warren L. Localized virtual patient model for regional anaesthesia simulation training system. Medicine Meets Virtual Reality 2007; 185190.

Hugenholtz NI, De Croon EM, Smits PB, Van Dijk FJ, Nieuwenhuijsen K. Effectiveness of e-learning in continuing medical education for occupational physicians. Occup Med. 2008; 58(5): 370-372.

Issenberg SB, Gordon MS, Gordon DL. Simulation and new learning technologies. Med Teach 2001; 23: 16-23.

Issenberg SB, McHaghie WC, Petrusa ER, Gordon DL, Scalese RJ. Features and uses of high-fidelity medical simulations that lead to effective learning: a BEME systematic review. Med Teach 2005; 27 (1): 10-28.

Issenberg SB, Scalese RJ. Simulation in health care education. Perspect Biol Med. 2008 Winter; 51(1): 31-46.

Jensen ML, Mondrup F, Lippert F, Ringsted C. Using e-learning for maintenance of ALS competence. Resuscitation 2009; 80: 903-908.

Jones I, Handley AJ, Whitfield R, Newcombe R, Chamberlain D. A preliminary feasibility study of a short DVD-based distance-learning package for basic life support. Resuscitation 2007; 75: 350-356.

Juanes JA, Rodríguez MJ, Velasco MA, Prats A, Olmos S, Martinez D, Lagándara ML. Entornos de simulación médica, con animación grafica, para la enseñanzaaprendizaje de forma virtual. CIDUI Barcelona 2010. pp: 1-18. 
Juanes JA, Alvarez $\mathrm{H}$. Sistemas tecnológicos de simulación clínica en educación médica. JID. Ed. De las Heras, Peinado, Pereira y Rodríguez. Universidad de Salamanca. 2011. pp: 241-246.

Juanes JA, Cabrero A, Gómez JJ, Cabrero FJ. Avances tecnológicos en la generación de entornos virtuales de simulación médica. CASEIB.2011. pp: 673-676.

Juanes JA, Ortega F, García B, Rodríguez MJ. Training systems and practical skills acquisition by means of stereoscopic visualization environments. Ed. Publishep by International Association of Technology, Education and Development (IATED). Barcelona, Spain.2011. pp: 4717-4723.

Juanes JA (2011). Nuevos entornos tecnológicos para la simulación en educación médica. Educación Médica. Vol 14 (2) 2011. pp: 18-20.

Juanes JA, Cabrero A, Juanes L, García B, Olmos S, Rodríguez MJ. Computer assisted simulation as a formative strategy for educational innovation. Published by: IATED.2012. pp: 4411-4417.

Kapral S, Krafft P, Eibenberger K, Fitzgerald R, Gosch M, Weinstabl C. Ultrasound-guided supraclavicular approach for regional anesthesia of the brachial plexus. Anesth Analg 1994; 78: 507-513.

Kapral S, Greher M, Huber G. Ultrasonographic guidance improves the success rate of interscalene brachial plexus blockade. Regional Anesthesia and Pain Medicine 2008; 33: 195-198.

Katori N, Tanaka T, Hakamada K. Computer assisted resection of tumors with navigation system. J Craniomaxillofac Surg 2008 . 36(1): 269-270.

Kerr AT. The brachial plexus of nerves in man, the variations in its formation and branches. Am J Anat 1918; 23: 285-395.

Khan ZU, Martín-Montañez E, Baxter MG. Visual perception and memory systems: from cortex to medial temporal lobe. Cell Mol Life Sci. 2011; 68(10): 1737-1754.

Kirvela O, Svedstrom E, Lundbom N. Ultrasonic guidance of lumbar sympathetic and celiac plexus block: a new technique. Reg Anesth. 1992; 17: 43-46.

Konrad C, Schupfer G, Wietlisbach M, Gerber H. Learning manual skills in anesthesiology: is there a recommended number of cases for anesthetic procedures? Anesth Analg 1998; 86(3): 635-639.

Kopacz DJ, Neal JM, Pollock JE. The regional anesthesia "learning curve": what is the minimum number of epidural and spinal blocks to reach consistency?. Reg Anesth 1996; 21(3): 182-190. 
Kopacz DJ, Neal JM. Regional anesthesia and pain medicine: residency training-the year 2000. Reg Anesth Pain Med 2002; 27(1): 9-14.

Koscielniak-Nielsen ZJ, Hesselbjerg L, Fejlberg V. Comparison of transarterial and multiple nerve stimulation techniques for an initial axillary block by $45 \mathrm{~mL}$ of mepivacaine 1\% with adrenaline. Acta Anaesthesiol Scand 1998; 42: 570-575.

Koscielniak-Nielsen ZJ. Ultrasound-guided peripheral nerve blocks: what are the benefits?. Acta Anaesthesiol Scand 2008; 52(6): 727-737.

Koscilelniak-Nielsen ZJ, Rasmussen H, Hesselbjerg L. Long-axis ultrasound imaging of the nerves and advancement of perineural catheters under direct vision: a preliminary report of four cases. Reg Anesth Pam Med 2008; 33: 477-482.

Koscielniak-Nielsen ZJ, Dahl JB. Ultrasound-guided peripheral nerve blockade of the upper extremity. Curr Opin Anaesthesiol. Review. 2012; 25(2): 253-259.

Kulier R, Coppus S, Zamora J. Hadley J, Malick S, Das K. The effectiveness of a clinically integrated e-learning course in evidence-based medicine: A cluster randomised controlled trial. BMC Medical Education 2009; 9: 21.

La Grange P, Foster PA, Pretorius K. Application of the doppler ultrasound blood flow detector in supraclavicular brachial plexus block. Br J Anaesth 1978; 50: 965-967.

Lake CL. Simulation in cardiothoracic and vascular anesthesia education: tool or toy?. Semin Cardiotho- rac Vase Anesth 2005; 9: 265-273.

Latzke D, Marhofer $\mathrm{P}$, Zeitlinger M. Minimal local anaesthetic volumes for sciatic nerve blockade: evaluation of ED99 in volunteers. Br J Anaesth 2010; 104: 239-244.

Lau F, Bates J. A review of e-learning practices for undergraduate medical education, J. Med. Syst. 28 (1). 2004, 71-87.

Leonard M. Carl Koller: mankind's greatest benefactor? The Story of Local Anesthesia. J dent res 1998. 77: 535.

Letterie GS. Medical education as a science: the quality of evidence for computerassisted instruction. Am J Obstet Gynecol 2003; 188: 849-853.

Leung KM, Heng PA, Sun H, Wong TT. A haptic needle manipulation simulator for Chinese acupuncture. In: Proceedings of medicine meets virtual reality. 2003. pp 187-189.

Levine Al, Bryson EO. The use of multimodality simulation in the evaluation of physicians with suspected lapsed competence. J Crit Care 2008; 23: 197-202. 
Levinson AJ, Weaver B, Garside S, McGinn H, Norman GR. Virtual reality and brain anatomy: a randomised trial of e-learning instructional designs. Med Educ. 2007; 41(5): 495-501

Libkind A. Internet y anestesia regional. Rev. Arg. Anest 2004, 62, 6: 518-523.

Lim MW, Burt G. Rutter SV. Use of three-dimensional animation for regional anaesthesia teaching: application to interscalene brachial plexus blockade. $\mathrm{Br} J$ Anaesth 2005; 94(3): 372-377.

Lirk P, Colvin JM, Biebl M. Evaluation of cadaver workshop for education in regional anesthesia. Anaesthesist 2005; 54(4): 327-332.

Liu SS, Zayas VM, Gordon MA. A prospective, randomized, controlled trial comparing ultrasound versus nerve stimulator guidance for interscalene block for ambulatory shoulder surgery for postoperative neurological symptoms. Anesth Analg 2009; 109: $265-271$.

Liu SS, Ngeow JE, Yadeau JT. Ultrasound-guided regional anesthesia and analgesia: a qualitative systematic review. Reg Anesth Pain Med. 2009; 34(1): 47-59.

Liu SS, Ngeow J, John RS. Evidence Basis for Ultrasound-Guided Block Characteristics Onset, Quality, and Duration. Regional Anesthesia and Pain Medicine \& Volume 35, Number 2, Supplement 1, 2010.

López S, García B. Manual del dolor agudo postoperatorio. Madrid: Abbott; 2009: 7-69.

Loubert C, Williams SR, Hélie F, Arcand G. Complication during ultrasound-guided regional block: accidental intravascular injection of local anesthetic. Anesthesiology. 2008; 108(4): 759-760.

Lyon HC Jr, Healy JC, Bell JR, O'Donnell JF, Shultz EK, Wigton RS, Hirai F, Beck JR. Significant efficiency findings while controlling for the frequent confounders of CAI research in the PlanAlyzer project's computer-based, self-paced, case-based programs in anemia and chest pain diagnosis. J Med Syst. 1991; 15(2): 117-32.

Marhofer P, Schrogendorfer K, Koinig H, Kapral S, Weinstabl C, Mayer N. Ultrasonographic guidance improves sensory block and onset time of three-in-one blocks. Anesthesia \& Analgesia 1997; 85: 854-857.

Marhofer P, Schrogendorfer K, Andel H. Combined sciatic nerve 3 in 1 block in high risk patient. Anaesthesiologie, 1998; 33: 399-401.

Marhofer P, Schrogendorfer K, Wallner T, Koinig H, Mayer N, Kapral S. Ultrasonographic guidance reduces the amount of local anesthetic for 3-in-1 blocks. Regional Anesthesia and Pain Medicine 1998; 23: 584-548. 
Marhofer P, Greher M, Sitzwohl C, Kapral S. Ultrasonographic guidance for infraclavicular plexus anaesthesia in children. Anaesthesia 2004; 59: 642-646.

Marhofer P, Greher M, Kapral S. Ultrasound guidande in regional anaesthesia. $\mathrm{Br} \mathrm{J}$ Anaesth 2005; 94: 7-17.

Marhofer P, Willschke H, Greher M, Kapral S. New perspectives in regional anesthesia: the use of ultrasound-past, present, and future. Can J Anesth 2005; 52-56.

Marhofer P, Chan VW. Ultrasound-guided regional anesthesia: current concepts and future trends. Regional Anesthesia 2007; 104(5): 1265-1269.

Marhofer P, Willschke $\mathrm{H}$, Kettner S. Current concepts and future trends in ultrasoundguided regional anesthesia. Curr Opin Anaesthesiol. 2010; 23(5): 632-636.

Marhofer P, Harrop-Griffiths W, Kettner SC, Kirchmair L. Fifteen years of ultrasound guidance in regional anaesthesia: Part 1 British Journal of Anaesthesia 2010: 104(5): 538-546.

Martínez A. Complicaciones de los bloqueos nerviosos periféricos. Rev Esp Anestesiol Reanim 2006; 53: 237-248.

Martín-Laborda R. Las nuevas tecnologías en la educación. Fundación AUNA. Madrid 2005.

Mayfield JB. Diagnosis and management of peripheral nerve block complications. Review. Int Anesthesiol Clin. 2005 ; 43(3): 119-126.

McCann PD, Bindelglass DF. The brachial plexus: clinical anatomy. Orth Rev 1991; 20 : 413-419.

McCartney CJ, Brull R, Chan VW. Early but no longterm benefit of regional compared with general anesthesia for ambulatory hand surgery. Anesthesiology 2004; 101: 461-467.

Medelez E, Burgun A, Le Duff FP. Integration of electronic resources and communication technologies during Clinical Reasoning Learning sessions, Stud. Health Technol. Inform. 2002, 90, 107-111.

Medina J. Bases del Procesamiento de Imágenes Médicas. Web: http://www.ing.ula.ve/ gibula/. 2000.

Miller R, Fleisher L, Johns R, Savarase J, Wiener J, Young W. Anestesia, Cuarta edición. Editorial Harcourt Brace. 1998. Volumen 1, pp. 168-176.

Miller R. Anestesia, Sexta edición, Elsevier, España; 2005. volumen 2, pp. 1685-1719, 2973-2798. 
Minville V, Zetlaoui PJ, Fessenmeyer C, Benhamou D. Ultrasound guidance for difficult lateral popliteal catheter insertion in a patient with peripheral vascular disease. Reg Anesth Pain Med 2004; 29: 368-3670.

Monsieurs KG, Vogels C, Bossaert LL. Learning effect of a novel interactive basic life support CD: the JUST system. Resuscitation 2004; 62: 159-165.

Morgan E, Mikhail MS, Murray M. Anestesiología Clínica 4a edición. México. Ed. Manual Moderno 2007. pp. 1-5, 317-349.

Muller M, Duperret S, Viale JP. E-learning in medicine: appraisal and perspectives. Example of an educational website about echocardiography in anaesthesia, intensive care and emergencies: www.echorea.org. Ann Fr Anesth Reanim. 2008; 27(10): 832-839.

Muñoz M, Mozo G, Ortega A, Alonso P. Anestesia regional con ecografía. Madrid. Ergon 2007, pp. 5-113.

Murray D. Clinical simulation: measuring the efficacy of training. Curr Opin Anaesthesiol 2005; 18: 645-648.

Napier F, Davies RP, Baldock C. Validation for a scoring system of the ALS cardiac arrest simulation test (CASTest). Resuscitation 2009; 80: 1034-1038.

Neal JM, Hebl JR, Gerancher JC, Hogan QH. Brachial plexus anesthesia: essentials of our current understanding. Reg Anesth Pain Med 2002; 27: 402-428.

Neal JM, Brull R, Chan VW, Grant SA, Horn JL, Liu SS, McCartney CJ, Narouze SN, Perlas A, Salinas FV, Sites BD, Tsui BC. The ASRA evidence-based medicine assessment of ultrasound-guided regional anesthesia and pain medicine: Executive summary. Reg Anesth Pain Med. 2010; 35(2): 1-9.

Neal JM. Ultrasound-guided regional anesthesia and patient safety: An evidence-based analysis. Review. Reg Anesth Pain Med. 2010; 35(2): 59-67.

Nielsen KC, Steele SM. Outcome after regional anesthesia in the ambulatory setting-is it really worth it?. Best Practice and Research Clinical Anaesthesiology 2002; 16: 145-157.

O'Donnell BD, Lohom G. An estimation of the minimum effective anesthetic volume of $2 \%$ lidocaine in ultrasound-guided axillary brachial plexus block. Anesthesiology 2009; 111: 25-29.

Okuda Y, Bryson EO, DeMaria S Jr, Jacobson L, Quinones J, Shen B, Levine Al. The utility of simulation in medical education: what is the evidence? Mt Sinai J Med. 2009; 76(4): 330-343. 
Orebaugh S, Williams BA, Kentor ML. Ultrasound guidance with nerve stimulation reduces the time necessary for resident peripheral nerve blockade. Reg Anesth Pain Med 2007; 32(5): 448-454.

Ortega A, De Diego D, Del Olmo C, Maroto E, Rouco R. Ecografía portátil en anestesia regional: bloqueos del plexo braquial. Rev. Esp. Anestesiol. Reanim. 2008; 55: 294303.

Ozuah PO. Undergraduate medical education: Thoughts on future challenges. BMC Med Educ. 2002; 2: 8.

Palés Argullós JL, Gomar C. El uso de las simulaciones en Educación Médica, en Juanes Méndez, JA (Coord.) Avances tecnológicos digitales en metodologías de innovación docente en el campo de las Ciencias de la Salud en España. Revista Teoría de la Educación: Educación y Cultura en la Sociedad de la Información. Universidad de Salamanca, 2010. Vol. 11, no 2. pp. 147-169.

Partridge BL, Benirschke K. Functional anatomy of the brachial plexus sheath: implications for anesthesia. Anesthesiology 1997; 66: 743-747.

Pérez-Cajaraville JD, Ortiz J, Pérez JR. El dolor y su tratamiento a través de la historia Rev. Soc. Esp. Dolor 2005, 12: 373-384.

Perkins GD, Fullerton JN, Davis-Gomez N, Davies RP, Baldock C, Stevens H, Bullock I, Lockey AS. The effect of pre-course e-learning prior to advanced life support training: A randomised controlled trial Resuscitation 2010, 81, 877-881.

Perlas A, Brull R, Chan VW, CMcCartney CJ, Nuica A, Abbas S. Ultrasound guidance improves the success of sciatic nerve block at the popliteal fossa. Regional Anesthesia and Pain Medicine 2008; 33: 259-265.

Peterson MK. Ultrasound-guided nerve blocks. British Journal of Anaesthesia 2002; 88: 621-624.

Plunkett AR, Brown DS, Rogers JM, Buckenmaier CC. Supraclavicular continuous peripheral nerve block in a wounded soldier: when ultrasound is the only option. Br J Anaesth. 2006; 97(5): 715-717.

Pott LM, Santrock D. Teaching without a teacher: developing competence with a Bullard laryngoscope using only a structured self-learning course and practicing on a mannequin. J Clin Anesth 2007; 19: 583-586.

Pouliquen B, Le Duff F, Delamarre D, Cuggia M, Mougin F, Le Beux P. Managing educational resource in medicine: system design and integration, Int. J. Med. Inform. 74 (2-4), 2005; 201-207. 
Prats A, Juanes JA. VIX: una aplicación informática abierta para la visualización y estudio interactivo de la anatomía en 3D. Avances tecnológicos digitales en metodologías de innovación docente en el campo de las Ciencias de la Salud en España. Revista Teoría de la Educación: Educación y Cultura en la Sociedad de la Información. Vol. 11, no 2. 2010. Universidad de Salamanca, pp. 171-193.

Prince NJ, Cass HD, Klaber RE. Accessing e-learning and e-resources. Medical Education 2010; 44: 436-437.

Rabanal JM, Del Moral I, Quesada A., Díaz de Terán JC, Borregán JC, Teja JL, Olalla JJ, Castellanos A, Torio J. Los simuladores médicos en la formación continuada: nuestra experiencia con 553 médicos de urgencia hospitalarios. Emergencias 2003; 15: 333-338.

Retzl G, Kapral S, Greher M, Mauritz W. Ultrasonographic findings of the axillary part of the brachial plexus. Anesthesia \& Analgesia 2001; 92: 1271-1275.

Riazi S, Carmichael N, Awad I, Holt RM, McCartney CJ. Effect of local anaesthetic volume ( $20 \mathrm{vs} 5 \mathrm{ml}$ ) on the efficacy and respiratory consequences of ultrasound-guided interscalene brachial plexus block. British Journal of Anaesthesia 2008; 101: 549556.

Rodgers A, Walker N, Schug S, McKee A, Kehlet H, Van Zundert A. Reduction of postoperative mortality and morbidity with epidural or spinal anaesthesia: results from overview of randomized trials. British Medical Journal 2000; 321: 1493.

Rodríguez MãJ, Juanes JA, García B, Lagángara MạL. Evaluación formativa y entrenamiento con simulación para la adquisición y el refuerzo de habilidades diagnósticas en Ciencias de la Salud. En EVALfor (Ed.), Evaluar para aprender en la universidad: Experiencias innovadoras de evaluación en la era digital Madrid 2010: Bubok Publishing: 132-139.

Roewer N, Thiel H. Atlas de Anestesiologia. Elsevier Masson. 2007. pp. 218-234.

Rogers DA, Regehr G, Yeh KA, Howdieshell TR. Computer-assisted learning versus a lecture and feedback seminar for teaching a basic surgical technical skill. Am J Surg 1998; 175: 508-510.

Roques V, De Andrés J, Hernando J, Hernández FA. Puesta al día en neuroestimulación y respuesta motora. Otros métodos de identificación nerviosa. Mapping o neuroestimulación percutánea (PEG). Algia Hospital 2007; 2(2): 79-87.

Rosenberg M. E-Learning: Strategies for delivering knowledge in the digital age. New York, NY: McGraw-Hill, Inc; 2001.

Rosenblatt MA, Fishkind D. Proficiency in interscalene anesthesia: how many blocks are necessary? J Clin Anesth 2003; 15(4): 285-288. 
Rothe C, Asghar S, Andersen HL, Christensen JK, Lange KH. Ultrasound-guided block of the axillary nerve: a volunteer study of a new method. Acta Anaesthesiol Scand. 2011; 55(5): 565-570.

Rouvière H, Delmas A. Anatomia Humana. 11a EDICION. Ed. Masson 2012. Tomos 1 y 3.

Royse CF, Sha S, Soeding PF, Royse AG. Anatomical study of the brachial plexus using surface ultrasound. Anesth Intensive Care 2006; 34: 203-210.

Ruetsch YA, Boni T, Borgeat A. From cocaine to ropivacaine: the history of local anesthetic drugs. Curr Top Med Chem 2001; 1(3): 175-182.

Ruf D, Kriston L, Berner M, Harter M. General practitioners and online continuing medical education-which factors influence its use? Ger Med Sci 2009; 7-8.

Ruiz JG, Mintzer MJ, Leipzig RM. The impact of e-learning in medical education. Acad Med. 2006; 81: 207-212.

Ruiz JG, Candler CS, Qadri SS, Roos BA. E-Learning as Evidence of Educational Scholarship: A Survey of Chairs of Promotion and Tenure Committees at U.S. Medical Schools Acad Med. 2009; 84: 47-57.

Ruiz MC. Manual de Anestesia Regional. 2a edición. Elseiver España 2010. pp. 1-81, 207303, 533-669.

Sandhu NS, Capan LM. Ultrasound-guided infraclavicular brachial plexus block. British Journal of Anaesthesia 2002; 89: 254-259.

Sandhu NS, Sidhu DS, Capan LM. The cost comparison of infraclavicular brachial plexus block by nerve stimulator and ultrasound guidance. Anesthesia \& Analgesia 2004; 98: 267-268.

Sandhu NS. Ultrasound imaging of brachial plexus. Anesthesiology 2004; 100: 13251326.

Sandhu NS, Bahniwal CS, Capan LM. Feasibility of an infraclavicular block with a reduced volume of lidocaine with sonographic guidance. J Ultrasound Med 2006; 25(1): 5156.

Sandhu NS, Maharlouie B, Patel B, Erkulwater E, Medbalmi P. Simultaneous bilateral infraclavicular brachial plexus blocks with low dose lidocaine using ultrasound guidance. Anesthesiology 2006; 104: 199-201.

Sandhu NS, Manne JS, Medabalmi PK, Capan LM. Sonographically guided infraclavicular brachial plexus block in adults; a retrospective analysis of 1146 cases. Journal of Ultrasound in Medicine 2007; 25: 1555-1561. 
Saranteas T, Karakitsos D, Alevizou A. Limitations and technical considerations of ultrasound-guided peripheral nerve blocks: edema and subcutaneous air. Reg Anesth Pain Med 2008; 33: 353-356.

Scalese RJ, Obeso VT, Issenberg SB. Simulation technology for skills training and competency assessment in medical education. J Gen Intern Med 2008; 23: 46-49.

Schafhalter-Zoppoth I, McCulloch C, Gray A. Ultrasound visibility of needles used for regional nerve block: an in vitro study. Reg Anesth Pain Med 2004; 29(5): 480-488.

Schramm A, Suarez-Cunqueiro MM, Barth EL, Essig H, Bormann KH, Kokemueller H. Computer-assisted navigation in craniomaxillofacial tumors. $2008 \mathrm{~J}$ Craniofac Surg 19(4): 1067-1074.

Schwarz G, Feigl G, Kleinert R, Dorn C, Litscher G, Sandner-Kiesling A. Pneumatic pulse simulation for teaching peripheral plexus blocks in cadavers. Anesth Analg 2002; 95(6): 1822-1823.

Schwid HA, Odonell D. The anesthesia simulator-recorder: a device to train and evaluate anesthesiologists responses to critical incidents. Anesthesiology 1990; 72: 191.

Schwid HA, Rooke GA, Ross BK. Use of compuerized advanced cardiac life support guidelines better than a textbook review. Crit Care Med 1999;27: 821-824.

Selander DE. Peripheral nerve damage and regional anaesthesia. $\mathrm{Br}$ J Anaesth. 1995; 75(1): 116-117.

Selander DE. Combination of intraneural injection and high-injection pressure leads to fasicular injury and neurologic deficits in dogs. Reg Anesth Pain Med. 2005; 30(3): 308-309.

Sheppard DG, Iyer RB, Fenstermacher MJ. Brachial plexus: Demonstration at US. Radiology 1998; 208: 402-406.

Shina A, Chan VW. Ultrasound imaging for popliteal sciatic nerve block. Reg Anesth Pain Med 2004;29: 130-134.

Shung K. Diagnostic ultrasound imaging and blood flow measurements. Taylor \& Francis; 2006.

Silvestri E, Martinoli C, Derchi LE, Bertolotto M, Chiaramondia M. Rosenberg I. Echotexture of peripheral nerves; correlation between ultrasound and histology findings and criteria to differentiate tendons. Radiology 1995; 197: 291-296.

Sinh SK, Abrams JH, Weller RS. Ultrasound-guided interscalene needle placement produces successful anesthesia regardless of motor stimulation above or below 0.5 mA. Anesthesia \& Analgesia 2007; 105: 848-852. 
Sites BD, Gallagher J, Sparks M. Ultrasound guided popliteal block demonstrates an atypical motor response to nerve stimulation in 2 patients with diabeties mellitus. Regional Anesthesia and Pain Medicine 2003; 28: 479-482.

Sites BD, Gallagher JD, Cravero J, Lundberg J, Blike G. The learning curve associated with a simulated ultrasound-guided interventional task by inexperienced anesthesia residents. Reg Anesth Pain Med 2004; 29(6): 444-448.

Sites BD, Gallagher JD, Cravero J, Lundberg J, Blike G. The learning curve associated with a simulated ultrasound-guided interventional task by inexperienced anesthesia residents. Reg Anesth Pain Med. 2004; 29: 544-548.

Sites BD, Gallagher JD, Tomek I, Cheung Y, Beach ML. The use of magnetic resonance imaging to evaluate the accuracy of a handheld ultrasound machine in localizing the sciatic nerve in the popliteal fossa. Reg Anesth Pain Med 2004; 29: 413-416.

Sites BD, Brull R, Chan VWS. Artifacts and pitfall errors associated with ultrasoundguided regional anesthesia. Part I: understanding the basic principles of ultrasound physics and machine operations. Reg Anesth Pain Med. 2007; 32: 412-418.

Sites BD, Brull R, Chan VWS. Artifacts and pitfall errors associated with ultrasoundguided regional anesthesia. Part II: a pictorial approach to understanding and avoidance. Reg Anesth Pain Med. 2007; 32: 419-433.

Sites BD, Spence BC, Gallagher JD, Wiley CW, Bertrand ML, Blike GT. Characterizing novice behavior associated with learning ultrasound-guided peripheral regional anesthesia. Reg Anesth Pain Med 2007; 32: 107-115.

Sites BD, Chan VW, Neal J. The American Society of Regional Anesthesia and Pain Medicine and the European Society of Regional Anaesthesia and Pain Therapy Joint Committee Recommendations for Education and Training in Ultrasound-Guided Regional Anesthesia. Regional Anesthesia and Pain Medicine 2009; 34: 40-46.

Sites BD, Taenzer AH, Herrick MD, Gilloon C, Antonakakis J, Richins J, Beach ML. Incidence of Local Anesthetic Systemic Toxicity and Postoperative Neurologic Symptoms Associated With 12,668 Ultrasound-Guided Nerve Blocks: An Analysis From a Prospective Clinical Registry. Reg Anesth Pain Med. 2012.

Small SD, Wuerz RC, Simon R. Demonstration of high-fidelity simulation team training for emergency medicine. Acad Emerg Med 1999; 6(4): 312-323.

Solis J, Sitges M, Robert A, Hung J. Ecocardiografía tridimensional. Nuevas perspectivas sobre la caracterización de la válvula mitral. Rev Esp Cardiol. 2009; 62: 188-198.

Stolberg VB, Calatayud J, González A. History of the development and evolution of local anesthesia since the coca leaf. Anesthesiology 2003; 98(6): 1503-1508. 
Stolberg VB. El consumo de coca: la prehistoria, la historia y la etnografía. The use of coca: prehistory, history, and ethnography. J Ethn Subst Abuse. 2011; 10(2): 126146.

Tedore TR, YaDeau JT, Maalouf DB. Comparison of the transarterial axillary block and the ultrasound-guided infraclavicular block for upper extremity surgery: a prospective randomized trial. Reg Anesth Pain Med 2009; 34: 361-365.

Thoren $A B$, Axelsson $A B$, Herlitz J. DVD-based or instructor-led CPR education a comparison. Resuscitation 2007; 72: 333-334.

Ting PL, Sivagnanaratnam V. Ultrasonographic study of the spread of local anaesthetic during axillary brachial plexus block. Br J Anaesth 1989; 63: 326-329.

Tobias JD.Brachial plexus anaesthesia in children. Paediatric Anaesthesia 2001; 11 (3): 265-275.

Torres LM. Tratado de Anestesia y Reanimación. Ed. Arán. Madrid 2001. Tomo I, pp. 281-320, 1211-1304.

Tsai TP, Vuckovic I, Dilberovic F. Intensity of the stimulating current may not be a reliable indicator of intraneural needle placement. Reg Anesth Pain Med 2008; 33: 207210.

Tsui B. Ultrasound-guidance and nerve stimulation: implications for the future practice of regional anesthesia. Can J Anaesth 2007; 54(3): 165-170.

Ullrich S, Fischer B, Ntouba A, Valvoda J.T, Prescher A, Kuhlen T, Deserno TM, Rossaint R. Subject-based Regional Anaesthesia Simulator combining Image Processing and Virtual Reality. BVM, 2007; 202-206.

Ullrich S, Valvoda JT, Prescher A, Kuhlen T. Comprehensive Architecture for simulation of the human body based on functional anatomy. Proc BVM 2007; 328-332.

Ullrich S, Mendoza J, Ntouba A, Rossaint R, Kuhlen T. Haptic pulse simulation for virtual palpation. Proc BVM 2008; 187-191.

Ullrich S, Frommen T, Eckert J, Schütz A, Liao W, Deserno TM, Ntouba A, Rossaint R, Kuhlen T. Interactive Modeling and Simulation of Peripheral Nerve Cords in Virtual Environments. SPIE, 2008. pp. 69182-69188.

Urwin SC, Parker MJ, Griffiths R. General versus regional anaesthesia for hip fracture surgery: a metaanalysis of randomized trials. British Journal of Anaesthesia 2000; 84: 450-455.

VadeBoncouer TR, Weinberg GL, Oswald S, Angelov F. Early detection of intravascular injection during ultrasound-guided supraclavicular brachial plexus block. Reg Anesth Pain Med. 2008; 33(3): 278-279. 
Vuchkova J, Maybury TS, Farah CS. Testing the educational potential of 3D visualization software in oral radiographic interpretation. J Dent Educ. 2011; 75(11): 1417-1425.

Walker KJ, McGrattan K, Aas-Eng K, Smith AF. Ultrasound guidance for peripheral nerve blockade. Cochrane Database Syst Rev. 2009.

Wedmid A, Llukani E, Lee DI. Future perspectives in robotic surgery BJU Int. 2011; 108(6 Pt 2): 1028-1036.

Weinger MB. Experience not equal expertise: can simulation be used to tell the difference? Anesthesiology 2007; 107: 691-694.

Weller JM, Merry AF, Robinson BJ, Warman GR, Janssen A. The impact of trained assistance on error rates in anaesthesia: a simulation-based randomised controlled trial. Anaesthesia 2009; 64: 126-130.

Williams SR, Chouinard P, Arcand G, Harris P, Ruel M, Boudreault D. Ultrasoundguidance speeds execution and improves the quality of supraclavicular block. Anesth Analg 2003; 97: 1518-1523.

Willschke $\mathrm{H}$, Marhofer $\mathrm{P}$, Bosenberg A. Ultrasonography for ilioinguinal / iliohypogastric nerve blocks in children. British Journal of Anaesthesia 2005; 95: 226-230.

Willschke H, Bosenberg A, Marhofer P. Ultrasonographicguided ilioinguinal/ iliohypogastric nerve block in pediatric anesthesia: what is the optimal volume? Anesth Analg 2006; 102: 1680-1684.

Winnie AP. Interescalene brachial plexus block. Anesth Analg. 1970. 49 (3): 455.

Winnie AP. Plexus anesthesia perivascular techniques of brachial block. Shultz. Medical Information, Copenhagen. De It Verducci 1984; 215-219.

Wong AK. Full scale computer simulators in anesthesia training and evaluation. Can J Anaesth 2004; 51: 455-464.

Wutoh R, Boren SA, Balas EA. ELearning: a review of Internet-based continuing medical education. J Contin Educ Health Prof 2004; 24: 20-30.

Yacci M. Interactivity demystified: a structural definition for distance education and intelligent computer-based instruction. Educ Technol. 2000; 40: 5-16.

Zapata M. Brecha digital y educación a distancia a través de redes. Funcionalidades y estrategias pedagógicas para el e-learning. Anales de documentacion, $\mathrm{n} 0$ 8, 2005, pp. 247-274. 


\section{PAGINAS WEB}

NYSORA. The New York School of Regional Anesthesia. Available at: www.nysora.com

NGC. National Guideline Clearinghouse en www.guideline.gov

Visible Human set Available from:

http://www.nlm.nih.gov/pubs/factsheets/visible_human.html

http://www.simulationinhealthcare.com

http://www.sosalrspain.es/

http://www.esra-spain.org/

http://www.asra.com/

http://www.nerveblocks.net/ 

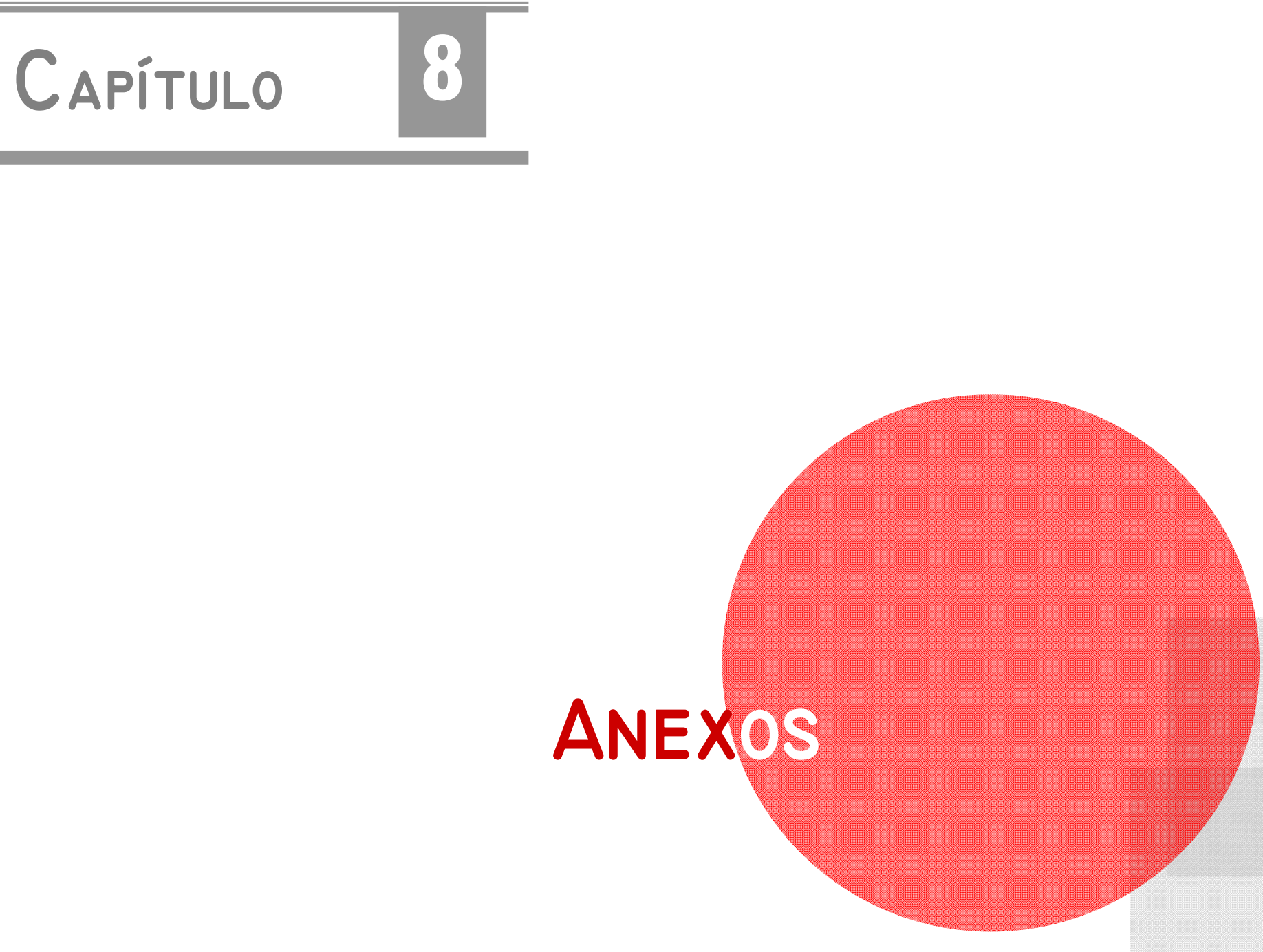



\section{ANEXO 8.1 \\ ENCUESTA DE VALIDACIÓN DEL VISOR ECOGRÁFICO PARA EL APRENDIZAJE DE LOS BLOQUEOS REGIONALES}

POR FAVOR RESPONDA CON SINCERIDAD, SU OPINION ES MUY IMPORTANTE PARA NOSOTROS:

1- ES UN PRODUCTO TOTALMENTE NOVEDOSO

1. Totalmente en desacuerdo

2. En desacuerdo

3. Ni de acuerdo ni en desacuerdo

4. De acuerdo

5. Totalmente de acuerdo

2- RESULTA FACIL DE MANEJAR

1. Totalmente en desacuerdo

2. En desacuerdo

3. Ni de acuerdo ni en desacuerdo

4. De acuerdo

5. Totalmente de acuerdo

3- ES UNA HERRAMIENTA QUE FACILITA EL APRENDIZAJE DE LOS BLOQUEOS REGIONALES GUIADOS POR ECOGRAFIA

1. Totalmente en desacuerdo

2. En desacuerdo

3. Ni de acuerdo ni en desacuerdo

4. De acuerdo

5. Totalmente de acuerdo 
4- ES UTIL PARA NUESTRO TRABAJO DIARIO

1. Totalmente en desacuerdo

2. En desacuerdo

3. Ni de acuerdo ni en desacuerdo

4. De acuerdo

5. Totalmente de acuerdo

5- SU CONTENIDO ES SEMEJANTE A LO QUE VEMOS EN LA PRACTICA CLINICA HABITUAL

1. Totalmente en desacuerdo

2. En desacuerdo

3. Ni de acuerdo ni en desacuerdo

4. De acuerdo

5. Totalmente de acuerdo

6- FACILITA LA COMPRESION DE LA ANATOMIA DE LAS EXTREMIDADES

1. Totalmente en desacuerdo

2. En desacuerdo

3. Ni de acuerdo ni en desacuerdo

4. De acuerdo

5. Totalmente de acuerdo

7- ES UN METODO DE AUTO APRENDIZAJE ADECUADO

1. Totalmente en desacuerdo

2. En desacuerdo

3. Ni de acuerdo ni en desacuerdo

4. De acuerdo

5. Totalmente de acuerdo 
8- LO RECOMENDARIA A OTROS COMPAÑEROS E INCLUSO A ESTUDIANTES DE ANATOMIA Y RADIOLOGIA

1. Totalmente en desacuerdo

2. En desacuerdo

3. Ni de acuerdo ni en desacuerdo

4. De acuerdo

5. Totalmente de acuerdo 



\section{ANEXO 8.2}

\section{CONCEPTOS BÁSICOS DE ECOGRAFIAA APLICADA A LA ANESTESIA REGIONAL}

La ecografía que se utiliza para la realización de bloqueos en anestesiología es una ecografía en escala de grises o modo B. Este tipo de ecografía es plana con dos dimensiones, una horizontal y una vertical.

Según incida el haz de ultrasonidos sobre las estructuras que se quieren visualizar, se pueden hacer infinitos cortes de las mismas.

Pero de forma práctica se eligen dos:

- Un corte transversal denominado "eje corto", en el que el haz de ultrasonidos incide perpendicularmente a las estructuras.

- Un corte longitudinal o "eje largo", donde inciden en la misma dirección.

Para obtener la imagen deseada con el transductor se realizan dos tipos de movimientos:

- Uno de rotación, para buscar un eje corto o largo de la zona explorada.

- Uno de angulación para mejorar la visión de dicha zona. Este movimiento también se denomina coloquialmente de cabeceo y debe ser realizado de forma suave y progresiva hasta que consigamos la mejor imagen posible.

También se puede realizar un movimiento de desplazamiento si se quiere seguir una estructura determinada a lo largo de su recorrido anatómico, en una u otra dirección.

\section{Apariencia de los nervios con ecografía}

La visualización de los nervios va a variar dependiendo de:

- La zona donde se encuentren.

- La resolución del ecógrafo.

- El ángulo de incidencia del ultrasonido. 
- Los tejidos que rodean los nervios.

En un corte en "eje corto", la imagen del nervio es redondeada u ovalada hipoecoica rodeada de un anillo hiperecogénico que corresponde al epineuro.

La imagen transversal del nervio periférico y de los nervios de la pierna tiene aspecto de panal de abeja donde se ven en el interior los fascículos nerviosos hipoecoicos rodeados de tejido conectivo hiperecoico.

En el corte en "eje largo" o longitudinal el nervio periférico es de aspecto fascicular con numerosas líneas paralelas hipo e hiperecogénicas.

Venas y arterias

Las venas y arterias se ven como estructuras redondeadas anecoicas de color negro.

Cuando van juntas, la vena suele ser menos redondeada que la arteria.

Es característico que la vena se colapse con una pequeña presión de la sonda, mientras que la arteria no.

Además, la arteria es pulsátil, lo cual se aprecia fácilmente en modo doppler.

Abordajes para punción

Existen dos formas de punción para la realización de bloqueos nerviosos:

- Dentro de plano (“in plane”).

- Fuera de plano (“out of plane").

\section{Dentro de plano}

La aguja aparecerá en la pantalla del ecógrafo como una imagen lineal hiperecogénica y habitualmente con artefacto de cola de cometa. 
En este abordaje, cuanto más paralela esté la aguja con respecto al haz de ultrasonidos y cuanto más cerca del transductor mejor se verá. Por esto el abordaje en plano es más fácil para estructuras superficiales que profundas.

Se recomienda poner el bisel hacia arriba puesto que eso mejora la visión de la punta de la aguja, o bien utilizar agujas ecogénicas más modernas.

El mayor inconveniente del abordaje en plano es que podemos perder fácilmente la visión de la aguja con pequeños movimientos de la sonda cuando la aguja sale fuera del plano de corte del ultrasonido.

\section{Fuera de plano}

En el abordaje "fuera de plano" la aguja se introduce perpendicular al transductor.

En la pantalla se verá la parte de la aguja que cruce el haz de ultrasonidos y el desplazamiento de tejidos que produce. La aguja aparece como una imagen puntiforme hiperecogénica.

En este abordaje es muy importante que la parte de la aguja que se vea sea siempre la punta, puesto que si lo que estamos viendo es una parte del centro, la punta de la aguja estará situada más distal y puede lesionar diferentes estructuras, lo cual constituye el inconveniente fundamental de este tipo de abordaje.

La principal ventaja del abordaje fuera de plano es que la estructura a bloquear queda más cerca y la punción duele menos.

La forma de abordaje que nosotros recomendamos para la realización de bloqueos nerviosos es en plano y en eje corto; es decir, con un corte transversal del nervio.

Este abordaje nos parece la forma más segura al poderse ver todo el trayecto de la aguja evitando la punción de estructuras que no queremos lesionar, y además nos permite controlar una adecuada difusión del anestésico local alrededor del nervio. 
Habitualmente se colocará la estructura que queremos abordar en el centro de la imagen, y se realizará la punción pegados o cerca de la sonda eligiendo una longitud de aguja suficiente para alcanzar la estructura diana.

Si se pierde la visión de la aguja durante el bloqueo, por movimientos voluntarios o involuntarios del transductor, se debe volver a localizarla mediante pequeñas recolocaciones de la sonda.

También pueden inyectarse pequeñas cantidades de anestésico o suero. Si no se ve la salida de suero tenemos la seguridad de que no estamos viendo la punta de la aguja. Recordad que se debe ver siempre la punta de la aguja.

Combinación de ultrasonidos y neuroestimulación.

Una de las ventajas que aporta la ecografía es que permite el uso conjunto con la neuroestimulación. La utilización combinada de ambas técnicas se recomienda al inicio del aprendizaje de la anestesia regional ecoguiada, y siempre que no obtengamos una imagen de calidad adecuada que permita identificar bien el nervio a bloquear.

Recordar:

La realización de un bloqueo con ecografía sola o combinada con neuroestimulación tiene complicaciones y contraindicaciones.

Contraindicaciones:

- La negativa del paciente.

- La alergia a anestésicos locales.

- La infección en la zona de punción.

- Enfermedades neurológicas (relativa).

- Trastornos de la coagulación (valorar riesgo-beneficio).

Complicaciones generales:

- Infección. 
- Disfunción neurológica.

- Hematoma.

- Toxicidad por anestésico local.

No olvidar:

- Emplear técnica aséptica.

- Valorar sedación-analgesia antes de punción.

- Obtener una buena imagen antes de realizar la punción.

- Fijar la sonda con la mano para que no se mueva durante el bloqueo.

- Aspirar siempre antes de inyectar.

- Ver siempre la punta de la aguja y, si se puede, todo el trayecto.

- Relocalizar la aguja en la imagen si se pierde mediante pequeños movimientos de la sonda.

- Observar salida de anestésico local al inyectar (si no se ve, no estamos en el plano).

\section{CONCEPTOS PRÁCTICOS EN ECOGRAFÍA}

Los equipos de ultrasonidos se pueden considerar como un ordenador que contiene un software especial capaz de interpretar las señales recogidas en un transductor conectado al mismo.

Las características de los diferentes equipos, así como la calidad de los mismos, es muy variada. En la actualidad existen numerosos aparatos de pequeño tamaño comercializados entre otras cosas para su uso en anestesiología y reanimación, cada uno de ellos con sus especificaciones técnicas diferentes, pero todos con una serie de características comunes.

Como se ha indicado en el apartado sobre bases de ecografía, el transductor es una parte muy importante del equipo puesto que emite el haz de ultrasonido y recoge los ecos provenientes de los tejidos, transformándolos en energía eléctrica para formar luego una imagen. 
Una característica fundamental de los transductores es la frecuencia de ultrasonido. Como se ha comentado anteriormente, en ecografía diagnóstica se emplean frecuencias de $2 \mathrm{MHz}$ hasta $15 \mathrm{MHz}$. A mayor frecuencia, mayor resolución de la imagen, pero menor profundidad; por el contrario, con frecuencias menores, la resolución es menor pero se alcanza mayor profundidad en los tejidos.

En anestesiología y para bloqueos nerviosos se suelen emplear rangos entre 5 y 12 $\mathrm{MHz}$.

Para los plexos más superficiales como el interescalénico se utilizan frecuencias de 8$12 \mathrm{MHz}$

Para otros más profundos, como el ciático, se recurre a frecuencias más bajas.

Actualmente las sondas ecográficas en los aparatos portátiles empleados en anestesiología son "multifrecuencia", es decir, que con una única sonda o transductor se pueden seleccionar distintos tipos de frecuencia para las diferentes exploraciones que se realicen.

Los transductores no son estériles y se utilizan de un paciente a otro, por lo que se deben cubrir para la realización de los bloqueos. Existen varias posibilidades para cubrir la sonda:

- Con un apósito transparente de tipo tegaderm.

- Con cubresondas específicos para los transductores.

- Con una funda de cámara de laparoscopia junto con un tegaderm.

\section{Con un apósito transparente de tipo tegaderm}

Se cubre la sonda evitando que quede aire entre el transductor y el apósito. Posteriormente el resto de la sonda se puede tapar con una compresa estéril.

Tener en cuenta que algunas marcas de apósitos transparentes diferentes del tegaderm pueden dejar restos de pegamento en la sonda. 


\section{Con cubresondas específicos para los transductores}

Lo primero que tenemos que hacer es echar gel dentro de la funda para que no quede aire entre el transductor y la funda. Este gel puede ser estéril o normal, ya que va en la parte interna que se pone en contacto con el paciente. Luego se estira la funda para cubrir el cable y posteriormente se fija con las bandas de papel adhesivo que la acompañan.

\section{Con una funda de cámara de laparoscopia junto con un tegaderm}

Para ello tendremos que cortar con tijeras estériles la parte distal para dejar salir parte del transductor y cubrirlo entonces con tegaderm. Finalmente se fija con las cintas de papel adhesivo que trae la funda.

Estas dos últimas opciones son ideales para las vías centrales, donde se necesita más esterilidad, ya que cubren por completo el cable evitando posibles contaminaciones del campo por el mismo.

Para realizar el bloqueo se preparará un campo estéril y se aplicará sobre él gel conductor estéril. Es posible utilizar como gel conductor el Betadine líquido, aunque la calidad de la imagen es algo peor que con un gel específico.

\section{Terminología en ecografía}

En ecografía se utilizan una serie de términos con los que se debe estar familiarizado:

- Hiperecogénico o hiperecoico: hace referencia a la generación de ecos en gran cantidad o intensidad. En este caso, la imagen que se observa en la pantalla del ecógrafo será de color blanco brillante. El hueso es una estructura típicamente hiperecogénica.

- Hipoecogénico o hipoecoico: significa que genera pocos ecos o de baja intensidad. Las estructuras hipoecoicas se verán de color gris oscuro en la imagen (por ejemplo, el músculo normal). 
- Anecogénico o anecoico: son estructuras que no generan ecos y se ven de color negro en la imagen. Las estructuras anecoicas no generan ecos porque no tienen interfases en su interior. Los vasos sanguíneos y los quistes son típicamente anecoicos.

\section{Ajustes habituales}

Los equipos de ultrasonidos tienen una serie de parámetros que se pueden modificar cuando se realicen los diferentes estudios con el fin de optimizar al máximo las imágenes obtenidas. Varias de estas funciones serán específicas del modelo de ecógrafo que se utilice, no obstante existen funciones comunes a todos ellos que son las que habitualmente se ajustan en cada exploración.

- Frecuencia

- Profundidad

- Ganancia

- Foco

\section{Frecuencia}

Está determinada por el transductor que se utilice. Como se indicó anteriormente, a mayor frecuencia de la sonda mayor resolución pero menor profundidad puede alcanzar y viceversa.

\section{Profundidad}

Se ajustará en función del área a explorar. Viene condicionada por la frecuencia de la sonda. No se podrán realizar exploraciones profundas con sondas de alta frecuencia.

\section{Ganancia}

Amplifica o disminuye la señal de retorno (aumenta o disminuye el brillo). Se puede modificar de forma general o solamente en un área específica. 


\section{Foco}

Permite enfocar una zona a una profundidad determinada y modifica un poco el brillo de la franja donde se sitúa.

El Doppler color, aunque no es un ajuste de ecografía propiamente dicho, es de gran utilidad.

Con la función de Doppler obtendremos una imagen con color sobre la propia imagen bidimensional en escala de grises, donde se visualizarán las venas y las arterias de la zona que estamos explorando.

De forma general recomendamos la aplicación de este modo previo a realizar cualquier punción. Así nos aseguramos si en la zona hay venas o arterias que puedan no haberse visualizado bien en modo bidimensional, y evitar así su punción.

\section{Orientación de la sonda y la imagen}

De forma general, cuando se coloque la sonda sobre el paciente lo haremos para que la imagen que se obtenga en la pantalla del ecógrafo sea una correspondencia anatómica del paciente según lo miramos de frente. Así, en la parte izquierda de la pantalla, se deberá ver la parte izquierda del paciente y viceversa.

Para facilitar la orientación, los transductores vienen provistos de una marca, generalmente luminosa, que se traduce luego como una señal en la imagen ecográfica, que nos indica cómo está situada la sonda. Sin necesidad de esta marca, se puede tocar con un dedo el borde del transductor con gel conductor, y orientar ese borde hacia el lado que queramos.

\section{ARTEFACTOS ECOGRÁFICOS}

Los artefactos son errores que se producen durante la exploración ecográfica y que pueden dar lugar a la visualización de estructuras inexistentes u ocultar otras que se deberían ver. 
De forma habitual, en las exploraciones ecográficas que se realizan en anestesia, se observan los siguientes artefactos:

- Sombra acústica posterior.

- Realce o refuerzo posterior.

- Cola de cometa.

- Imagen en espejo.

- Anisotropía.

\section{Sombra acústica posterior}

Son zonas anecoicas que aparecen detrás de una interfase muy ecogénica o altamente reflectante. Cuando el haz de ultrasonidos choca contra esta interfase se refleja completamente, por lo que detrás de dicha interfase se produce una zona libre de ultrasonidos y se verá negra en la imagen. Este artefacto es típico de la visión ecográfica del hueso, material extraño de tipo metálico o cuando hay aire en los tejidos.

\section{Realce o refuerzo posterior}

Ocurre cuando el haz de ultrasonidos atraviesa una estructura sin interfases en su interior o anecoica. Al no tener interfases no absorbe el ultrasonido, el cual llega íntegro al final de la estructura. En la pantalla se verá la estructura sin interfases de color negro y justo detrás de ella una zona hiperecogénica de color blanco. Este efecto ocurre por un ajuste de ganancia que realiza de forma automática el ecógrafo. Como el haz de ultrasonidos se atenúa según atraviesa los tejidos, para que se vea correctamente la imagen el ecógrafo realiza una compensación que depende de la profundidad.

Los ultrasonidos que atraviesan una estructura anecoica no se atenúan pero el ajuste de ganancia se realiza de igual modo, por esto justo detrás de una estructura anecoica se ve una imagen hiperecogénica.

\section{Cola de cometa}

Se produce cuando el haz de ultrasonidos choca con una interfase estrecha y muy ecogénica, apareciendo detrás de esta interfase una serie de ecos lineales. Cuando el haz de 
ultrasonidos choca con una superficie muy reflectante se produce un fenómeno de reverberación, al reflejarse el haz de forma intensa y volver al transductor donde choca y rebota hacia el tejido. Es típico de los cuerpos extraños como por ejemplo una aguja. Este artefacto también se ve en la pleura y pequeñas burbujas de aire dentro de un medio sólido. La periodicidad de las bandas dentro de la cola del cometa depende del grosor del objeto.

\section{Imagen en espejo}

Se produce cuando el haz de ultrasonidos choca contra una interfase muy ecogénica de forma curvilínea, como por ejemplo un hueso como una costilla. Así, parte del haz de ultrasonidos es refractado y continúa en dirección diferente al haz original. Estos ecos, al ir en otra dirección, sufren un retardo con respecto al original y además vuelven al transductor en un ángulo distinto dando imágenes artefactuadas o inexistentes. Por ejemplo, en el espacio supraclavicular se ve la arteria subclavia debajo de la primera costilla en una zona que sería de sombra acústica.

\section{Anisotropía}

Capacidad de una estructura para variar su ecogenicidad dependiendo del ángulo de incidencia del ultrasonido. Es típico de tendones y nervios. Se observa de forma evidente en el ciático en su recorrido por el hueco poplíteo, donde pasa de verse a no verse según la angulación del transductor.

\section{BASES FÍSICAS DE LA ULTRASONOGRAFÍA}

Con este título pretendemos resumir fundamentos de la ultrasonografía, de las bases físicas y fundamentos técnicos de la ecografía.

Los ultrasonidos pueden definirse como ondas mecánicas de frecuencia superior a $20.000 \mathrm{~Hz}, 20 \mathrm{kHz}$.

Al igual que el sonido, se propagan a través de un medio material elástico, no se transmiten en el vacío. 
El dispositivo capaz de producir ultrasonidos es un transductor, una sonda que en el campo del diagnóstico por imagen funciona como emisor y como receptor, emite ultrasonidos durante un tiempo y permanece a la espera de posibles ecos durante otro tiempo.

En medicina se emplean frecuencias de $1 \mathrm{MHz}$ a $3 \mathrm{MHz}$ en terapéutica y entre $2 \mathrm{MHz}$, $12 \mathrm{MHz}$, y $16 \mathrm{MHz}$ en el campo del diagnóstico.

La aplicación de los ultrasonidos en el diagnóstico se basa en la detección y representación de la energía acústica reflejada a partir de diferentes interfases corporales, entendiendo por interfase la superficie de separación de dos medios de distinta impedancia acústica.

El término ecografía hace referencia a la técnica que permite la visualización de imágenes del organismo mediante la utilización del ultrasonido.

Los ultrasonidos presentan las propiedades generales de las sondas. Nos referiremos exclusivamente ahora a su direccionalidad, intensidad y propagación a través del medio.

Los ultrasonidos, por su elevada frecuencia poseen un alto grado de direccionalidad hasta el punto de poder decir que en un medio homogéneo se propagan en línea recta.

Por otra parte, el haz de ultrasonidos porta una determinada energía. Si consideramos esta energía por unidad de tiempo estamos hablando de la potencia del haz.

Pero en las aplicaciones médicas nos interesa sobre todo la intensidad, es decir, potencia por unidad de superficie.

Los ultrasonidos se propagan a través de un medio material elástico, pero en esta propagación pierden intensidad a medida que se transmiten en el organismo. La atenuación se debe, fundamentalmente, a reflexiones porque el medio no es homogéneo y a procesos o fenómenos de absorción de energía y de dispersión que sufre el haz a medida que avanza por los tejidos. 
La velocidad de propagación de los ultrasonidos en el organismo es constante para un mismo tejido.

Las diferencias entre tejidos blandos, hígado, riñón son poco significativas, aproximadamente estos $1540 \mathrm{~m} / \mathrm{seg}$.

Sin embargo con la grasa, $1450 \mathrm{~m} / \mathrm{seg}$. o con el cartílago las diferencias son más acusadas.

En el caso del pulmón o del hueso, la velocidad de transmisión es muy distinta, por lo que, como veremos más adelante, la ecografía tiene limitada utilidad en el estudio de zonas corporales que tengan relación con estas estructuras. El aire y el hueso no se visualizan adecuadamente mediante ultrasonidos.

La impedancia acústica, es $z$, es el producto de la densidad del medio, $\rho$, por c, la velocidad de propagación de la onda en dicho medio.

La impedancia acústica juega, en la ley de Ohm para la acústica, un papel análogo al de la resistencia en la ley de Ohm de la electricidad. Por tanto la impedancia acústica refleja la resistencia que ofrece el medio al paso de la onda sonora.

Si z es pequeña, se favorece la transmisión, sin embargo el aire y el hueso, impiden la visualización por ultrasonido de zonas relacionadas con los mismos, porque el desequilibrio de impedancia acústica entre estas estructuras y los tejidos blandos es tan grande que la mayor parte se refleja, impidiendo la visualización de estructuras situadas más allá de estas interfases.

La atenuación es la pérdida por unidad de longitud que sufre el haz ultrasónico a medida que avanza por los tejidos.

En general, se considera, que la atenuación en las partes blandas del organismo es de $1 \mathrm{~dB}$ por $\mathrm{cm}$ y por $\mathrm{MHz}$, sin embargo, en el hueso, es del orden de $5 \mathrm{a} 10 \mathrm{~dB}$ por $\mathrm{cm}$ y por MHz. El hueso y el pulmón no permiten obtener un estudio correcto. 
Cuanto mayor sea la frecuencia, mayor será la pérdida del haz en profundidad, y, por tanto, si se pretende estudiar órganos profundos es necesario utilizar frecuencias más bajas que en órganos superficiales.

La atenuación se produce sobre todo, como se señaló anteriormente, por reflexiones debidas a inhomogeneidades del medio y por fenómenos de absorción de energía y de dispersión que sufre el haz ultrasónico.

Pues bien, los fenómenos de reflexión constituyen el fundamento para la utilización diagnóstica de los ultrasonidos.

En el fenómeno de reflexión se cumple que el rayo incidente y el rayo reflejado, forman el mismo ángulo con la normal, es decir con la perpendicular a la superficie que separa ambos medios, forma el mismo ángulo. Ángulo de incidencia igual a ángulo de reflexión, es la ley de la reflexión.

Por tanto en ultrasonografía es importante tener en cuenta que, si la incidencia del haz no es perpendicular a la superficie que separa ambos medios, la reflexión seguirá un ángulo idéntico al de incidencia, que puede, y en este caso haría, imposible la detección, porque como hemos dicho las ondas son emisoras receptoras.

Se produce un fenómeno de reflexión de parte del haz que será tanto mayor, cuanto mayor sea la diferencia de impedancia acústica entre ambos medios.

La expresión que tienen es proporcional al valor de coeficiente de reflexión, $R$, o cantidad de energía reflejada por una interfase acústica. Si los medios tienen la misma impedancia acústica, el numerador de la expresión es 0 y no habría reflexión. En realidad estaríamos hablando del mismo medio, todo el ultrasonido se transmite en profundidad.

Es el caso de un medio homogéneo, un medio en el que el haz de ultrasonido no encuentra interfases, un medio anecogénico o quístico.

Sin embargo, cuando la diferencia de impedancia es grande o muy grande, como ocurre por ejemplo en el paso de aire a tejido, el valor del coeficiente de reflexión toma un 
valor de 0.99, aproximadamente es casi de 1, es decir, prácticamente no pasan ultrasonidos al segundo medio, se refleja en su totalidad o prácticamente en su totalidad.

La utilización de un gel que permita un contacto directo entre el transductor y la piel del paciente, logra evitar que exista aire entre la sonda y la piel del paciente, logra evitar gases en los estudios ecográficos y hace posible la transmisión del haz. El haz se transmite en profundidad, es un acoplamiento de impedancias.

Existen aparatos que no proporcionan imágenes, a los que no vamos a hacer referencia, que se basan en el efecto Doppler continuo y que permiten detectar el movimiento de la sangre o del corazón de un feto.

De lo que vamos a hablar es de aquellos equipos que sí proporcionan imágenes basadas en la utilización de un haz de ultrasonido, es decir, los ecógrafos.

Los elementos básicos del ecógrafo, son similares en todos ellos, un transmisor, un transductor, receptor, procesador, distintas modalidades de diagnóstico ultrasonográfico y grabación de la imagen, es decir, almacenamiento de la imagen.

El transmisor o generador, entre otras funciones, proporciona, al transductor la energía para la formación de pulsos de ultrasonidos. Es decir, mediante la aplicación de un voltaje determinado, este transmisor, proporciona al transductor la energía eléctrica necesaria para su conversión en energía mecánica, es decir en un haz de ultrasonidos, y a la inversa, reciben los ecos reflejados, el ultrasonido reflejado en las diferente interfases corporales convirtiendo esta energía mecánica en señales eléctricas.

El receptor capta y amplifica las señales recibidas, y también, entre otras funciones, compensa las diferencias en la intensidad de los ecos procedentes de distintas profundidades.

Las señales proporcionadas por los ultrasonidos pueden representarse de diversas formas, son las distintas modalidades de diagnóstico ultrasonográfico.

El almacenamiento de la imagen puede ser en forma de placas gracias a las actuales impresoras láser o bien en cualquiera de los posibles soportes digitales que existen. 
Las señales proporcionadas por los ultrasonidos pueden representarse de muy diversas formas, en modo $A$, modo $B$, modo $M$, distintas modalidades de ecografía Doppler o ecografía 3D- 4D.

En este resumen nos vamos a referir exclusivamente a aspectos puntuales de la ecografía B y de la ecografía Doppler.

En la pantalla aparecen una serie de puntos luminosos o puntos cuyo brillo es proporcional a la intensidad del eco, es decir, puntos más luminosos cuanto mayor es la reflexión. Al representar la imagen sobre el fondo negro de un osciloscopio las señales de mayor intensidad aparecen blancas. La ausencia de señal se muestra en negro y las señales de tonalidad o intensidad intermedia se corresponden con distintos tonos dentro de una escala de grises.

La representación en modo B modalidad en tiempo real, ofrece la impresión de imagen en movimiento porque genera una serie de imágenes individuales 2D. Son decenas de cortes por segundo que nos proporcionan esta impresión de imagen en movimiento.

La ecografía en modo B genera la imagen a partir de la información sobre la intensidad, sobre la amplitud de la señal reflejada en las diferentes interfases. No obstante estas señales contienen más información, no solo a cerca de la amplitud, sino también de la fase y de la frecuencia.

Pues bien, las variaciones de frecuencia son la base de la ecografía Doppler.

El efecto Doppler es una variación aparente de la frecuencia. En realidad la frecuencia emitida por un foco no varía, es una variación aparente que percibe el observador. Es la variación aparente de la frecuencia que se observa en todo movimiento ondulatorio cuando el foco emisor, el observador o ambos se desplazan uno respecto al otro.

En ecografía, permite calcular la velocidad de una estructura en movimiento a partir de mediciones de la frecuencia Doppler y del ángulo Doppler. 
El cambio de frecuencia es directamente proporcional a la velocidad de la interfase responsable del eco. La relación entre la frecuencia del ultrasonido reflejado y la velocidad de la estructura reflectora se describe mediante la ecuación Doppler.

Donde el cambio de frecuencia doppler o variación total de la frecuencia emitida y percibida por el transductor viene representado por el incremento de $F$, siendo $\mathrm{Ft}$ la frecuencia del ultrasonido emitido por el transductor, $\mathrm{V}$ la velocidad de la estructura móvil y C la velocidad de propagación del ultrasonido en el medio.

En las aplicaciones clínicas, la dirección del haz de ultrasonidos, forma con la estructura en movimiento un ángulo, el ángulo Doppler.

Hay que tener en cuenta que, a medida que este ángulo se aproxima a los 900 el coseno tiende a 0 . Por tanto es aconsejable utilizar ángulos menores de 60ㅡ, alrededor de 45-60으 para el cálculo de la velocidad de la estructura en movimiento. Los aparatos de ultrasonidos Doppler se encargan de la representación de la información referente al flujo.

Existen diferentes tipos de Doppler: Doppler continuo, Doppler pulsado, Doppler dúplex, Doppler color, etc.

Nos referimos exclusivamente a la modalidad Doppler color, es decir, a la forma de ultrasonidos Doppler más comúnmente utilizada en aplicaciones radiológicas.

En el Doppler color, a la derecha de la imagen los datos de amplitud a partir de estructuras fijas proporcionan la base de la imagen en modo B. La fase de la señal ofrece información sobre la dirección del movimiento y los cambios en la frecuencia a cerca de la velocidad de la estructura examinada.

Las señales obtenidas a partir de las células rojas sanguíneas son representadas en distinto color en función del movimiento del flujo hacia el transductor, rojo, o alejándose del transductor, azul. El grado de saturación del color indica la velocidad relativa de las células en movimiento.

Finalmente, la posibilidad de obtener reconstrucciones tridimensionales de imágenes exploradas en los tres planos del espacio hacen aún más sensibles los sistemas utilizados, 
por ejemplo, en medicina perinatal, donde se observa en 3D con una cara color sepia característico de la imagen 3D en ecografía. La ecografía 4D, el concepto 4D, no solo visualiza imágenes en 3D sino imágenes tridimensionales en movimiento, en tiempo real. 


\section{ANEXO 8.3}

TERMINOLOGÍA ANATÓMICA

(NÓMINA ANATÓMICA INTERNACIONAL Y SINÓNIMOS)

- Arteria braquial profunda.

- Arteria braquial.

- Arteria carótida común.

- Arteria cubital.

- Arteria femoral.

- Arteria glútea superior.

- Arteria poplítea.

- Arteria radial.

- Arteria subclavia.

- Arteria vertebral.

- Cabeza corta del músculo bíceps femoral. Porción corta del músculo bíceps femoral.

- Cabeza larga del músculo bíceps femoral. Porción larga del bíceps femoral.

- Fascículo lateral del plexo braquial.

- Fascículo medial del plexo braquial.

- Fascículo posterior del plexo braquial.

- Gran vena safena. Safena magna o mayor. Safena interna. 
- Músculo braquial anterior. Músculo braquial.

- Musculatura paravertebral.

- Músculo cuadrado crural. Músculo cuadrado femoral.

- Músculo abductor largo del pulgar.

- Músculo aductor corto o aproximador menor.

- Músculo aductor grande. Aductor mayor. Aproximador mayor.

- Músculo aductor largo. Aproximador mediano. Aductor mediano.

- Músculo aductor mayor. Aproximador mayor. Aductor grande.

- Músculo ancóneo.

- Músculo aproximador mayor. Aductor mayor.

- Músculo aproximador mediano. Aductor largo. Aductor mediano.

- Músculo aproximador menor. Aductor corto.

- Músculo bíceps braquial.

- Músculo bíceps femoral.

- Músculo braquial anterior.

- Músculo braquiorradial. Músculo supinador largo.

- Músculo coracobraquial.

- Músculo crural. Vasto intermedio.

- Músculo cuadrado femoral. Músculo cuadrado crural.

- Músculo cubital posterior. Músculo extensor carpo cubital. 
- Músculo cutáneo del cuello. Platisma.

- Músculo deltoides.

- Músculo dorsal ancho.

- Músculo elevador de la escápula.

- Músculo escaleno anterior.

- Músculo escaleno medio.

- Músculo escaleno posterior.

- Músculo esternocleidomastoideo.

- Músculo extensor carpo cubital. Músculo cubital posterior.

- Músculo extensor carpo radial corto (segundo radial).

- Músculo extensor carpo radial largo (primer radial).

- Músculo extensor corto pulgar.

- Músculo extensor de los dedos.

- Músculo extensor del índice.

- Músculo extensor largo de los dedos.

- Músculo extensor largo del carpo radial.

- Músculo extensor largo del primer dedo.

- Músculo extensor largo del pulgar.

- Músculo flexor cubital del carpo.

- Músculo flexor del carpo radial. 
- Músculo flexor largo del primer dedo.

- Músculo flexor largo del pulgar.

- Músculo flexor profundo de los dedos.

- Músculo flexor superficial de los dedos.

- Músculo gastrocnemio cabeza lateral o gemelo externo.

- Músculo gastrocnemio cabeza medial o gemelo interno.

- Músculo gemelo externo. Gastrocnemio cabeza lateral.

- Músculo gemelo interno- gastrocnemio cabeza medial.

- Músculo glúteo mayor.

- Músculo glúteo medio.

- Músculo glúteo menor.

- Músculo gracilis. Recto interno del muslo.

- Músculo iliopsoas. Psoasiliaco.

- Músculo intercostal.

- Músculo largo del cuello.

- Músculo obturador externo.

- Músculo obturador interno.

- Músculo omohioideo.

- Músculo palmar largo. Palmar menor.

- Músculo palmar menor. Palmar largo. 
- Músculo pectineo.

- Músculo pectoral mayor.

- Músculo pectoral menor.

- Músculo peroneo lateral corto.

- Músculo plantar.

- Músculo platisma. Cutáneo del cuello

- Músculo primer radial. Extensor carpo radial largo.

- Músculo pronador cuadrado.

- Músculo pronador redondo. Teres pronador.

- Músculo psoasiliaco. Iliopsoas.

- Músculo recto anterior. Recto femoral.

- Músculo recto femoral. Recto anterior.

- Músculo recto interno del muslo. Gracilis.

- Músculo sartorio.

- Músculo segundo radial. Extensor carpo radial corto.

- Músculo semimembranoso.

- Músculo semitendinoso.

- Músculo soleo.

- Músculo subescapular.

- Músculo supinador corto. 
- Músculo supinador largo. Músculo braquiorrial.

- Músculo supraespinoso.

- Músculo tensor de la fascia lata.

- Músculo teres pronador. Pronador redondo.

- Músculo tibial anterior.

- Músculo tibial posterior.

- Músculo trapecio.

- Músculo tríceps braquial.

- Músculo vasto externo. Vasto lateral.

- Músculo vasto intermedio. Crural.

- Músculo vasto interno. Vasto medial.

- Músculo vasto lateral.

- Músculo vasto lateral. Vasto externo.

- Músculo vasto medial. Vasto interno.

- Nervio ciático.

- Nervio ciático poplíteo interno. Tibial común.

- Nervio ciatio poplíteo externo o peroneo común.

- Nervio crural o femoral.

- Nervio cubital. Ulnar.

- Nervio cutáneo antebraquial medial. 
- Nervio femoral o crural.

- Nervio mediano.

- Nervio músculo-cutáneo.

- Nervio obturador.

- Nervio peroneo común o ciatio poplíteo externo.

- Nervio peroneo profundo. Tibial anterior.

- Nervio radial.

- Nervio safeno externo. Sural.

- Nervio safeno.

- Nervio sural. Safeno externo.

- Nervio tibial anterior. Peroneo profundo.

- Nervio tibial común o ciático poplíteo interno.

- Nervio ulnar. Cubital.

- Plexo braquial.

- Rama perforante de la arteria profunda del muslo.

- Rama profunda del nervio obturador.

- Rama superficial del nervio obturador.

- Tendón de Aquiles.

- Tendón del flexor radial del carpo. Palmar mayor.

- Tendón del palmar largo. Palmar menor. 
- Tendón del tríceps sural y de los músculos plantares.

- Tendón tibial posterior y flexor largo de los dedos.

- Tendones extensor carpo radial corto (segundo radial) y largo (primer radial).

- Tronco inferior plexo braquial (c8-t1).

- Tronco medio plexo braquial (c7).

- Tronco superior plexo braquial (c5-c6).

- Vena basílica.

- Vena braquial.

- Vena braquial profunda.

- Vena cefálica.

- Vena ciática.

- Vena cubital.

- Vena femoral superficial.

- Vena femoral.

- Vena gran safena. Safena interna. Safena mayor. Safena magna.

- Vena mediana del antebrazo.

- Vena peronea.

- Vena poplítea.

- Vena radial.

- Vena safena externa. Safena pequeña. Safena menor. 
- Vena safena interna. Safena mayor. Safena magna. Gran safena.

- Vena safena magna o mayor. Safena interna.

- Vena safena mayor. Gran safena. Safena interna. Safena magna.

- Vena safena menor. Safena pequeña. Safena externa. Safena parva.

- Vena safena parva. Pequeña. Safena menor. Safena externa.

- Vena safena pequeña. Safena menor. Safena externa. Safena parva.

- Vena subclavia.

- Vena tibial anterior.

- Vena vertebral.

- Vena yugular externa.

- Vena yugular interna.

- Venas subcutáneas. 



\section{ANEXO 8.4}

\section{SISTEMAS NEUROMUSCULARES DE LA EXTREMIDAD SUPERIOR}

- SNM MUSCULOCUTÁNEO

o Braquial anterior

o Coracobraquial

o Bíceps braquial

- SNM del CUBITAL

o Interóseos dorsales

o Interóseos palmares

o Flexor corto del meñique

o Oponente del meñique

o Separador del meñique

o Palmar cutáneo

o Aproximador del pulgar

o Flexor corto del pulgar

o Lumbricales (tercero y cuarto)

o Cubital anterior

o Flexor profundo de los dedos (cuarto y quinto)

- SNM del MEDIANO

o Flexor profundo de los dedos (segundo y tercero) 
o Lumbricales primero y segundo

o Flexor largo del pulgar

o Flexor corto del pulgar (ramo tenar)

o Oponente del pulgar (ramo tenar)

o Separador corto del pulgar (ramo tenar)

o Flexor superficial de los dedos

o Palmar mayor (flexor radial del carpo)

o Palmar menor (palmar largo)

o Pronador cuadrado

o Pronador redondo

- SNM RAMOS COLATERALES PLEXO BRAQUIAL

- Subescapular (N. subescapular)

o Redondo mayor (N. subescapular)

o Serrato anterior (N. torácico largo)

o Subclavio (N. subclavio)

o Pectoral menor (N. pectoral. Asa de los pectorales)

o Pectoral mayor (N. pectoral. Asa de los pectorales)

- SNM del RADIAL

o Supinador largo o braquiorradial

o Primer radial o extensor radial largo del carpo.

o Segundo radial o extensor radial corto del carpo 
o Separador largo del pulgar

o Extensor corto del pulgar

o Extensor largo del pulgar

o Extensor del índice

o Supinador corto o músculo supinador

o Extensor de los dedos

o Extensor del meñique

o Cubital posterior o extensor cubital del carpo

o Ancóneo

o Tríceps braquial

- SNM del SUPRAESCAPULAR

o Supraespinoso

o Infraespinoso

- SNM del AXILAR o CIRCUNFLEJO

o Redondo menor

o Deltoides 



\section{ANEXO 8.5}

\section{SISTEMAS NEUROMUSCULARES DE LA EXTREMIDAD INFERIOR}

- $\quad$ SNM del PLANTAR EXTERNO

o Interóseos dorsales

o Interóseos plantares

o Flexor corto del quinto dedo

o Oponente del quinto dedo

o Separador del quinto dedo

o Aproximador del primer dedo

o Cuadrado plantar de Silvio

o Lumbricales

- $\quad$ SNM del PLANTAR INTERNO

o Flexor corto del primer dedo

o Separador del primer dedo

o Primer lumbrical

o Flexor corto de los dedos

- $\quad$ SNM del TIBIAL (CIÁTICO POPLÍTEO INTERNO)

o Flexor largo del primer dedo

o Tibial posterior

o Flexor largo de los dedos 
o Poplíteo

o Tríceps sural

o Plantar delgado

- SNM del PERONEO COMÚN (CIÁTICO POPLÍTEO EXTERNO)

o Peroneo lateral corto (N. peronaeus superficialis o musculocutaneus)

o Peroneo lateral largo (N. peronaeus superficialis o musculocutaneus)

o Tibial anterior (N. peronaeus profundus o tibialis anterior)

o Extensor largo del primer dedo (N. peronaeus profundus o tibialis anterior)

o Extensor largo de los dedos (N. peronaeus profundus o tibialis anterior)

o Peroneo anterior (N. peronaeus profundus o tibialis anterior)

o Extensor corto de los dedos o Pedio

- SNM del CIÁTICO MAYOR

o Porción recta del aproximador mayor

o Semimembranoso

o Semitendinoso

o Bíceps femoral

- $\quad$ SNM del PLEXO LUMBO-SACRO (excepto el ciático mayor)

o Cuadrado crural

o Obturador interior

o Géminos 
o Piramidal de la pelvis (piriforme)

o Glúteo menor (N. glutaeus superior)

o Glúteo mediano (N. glutaeus superior)

o Tensor de la fascia lata (N. glutaeus superior)

o Glúteo mayor (N. glutaeus inferior)

- SNM del OBTURADOR

o Porción torcida del aproximador mayor (aductor mayor)

o Aproximador menor

o Aproximador mediano

o Recto interno (Gracilis)

o Obturador externo

o Pectíneo (Ramo anterior del nervio obturador y nervio crural)

- SNM del CRURAL (FEMORAL)

o Psoasilíaco

o Cuádriceps crural

o Subcrural

o Sartorio 



\section{ANEXO 8.6}

\section{DESCRIPCIONES}

\subsection{CUELLO}

\section{Escaleno anterior}

- O: Tubérculos anteriores de las apófisis transversas de las vértebras cervicales tercera, cuarta, quinta y sexta.

- I: Tubérculo del escaleno anterior de la primera costilla.

- F: Cadena cinética abierta: Sobre la columna cervical en contracción bilateral: flexor, produce hiperlordosis; en contracción unilateral: lateralizador y rotador al mismo lado.

- Cadena cinética cerrada: sobre la primera costilla, elevador e inspirador.

- Función estática: estabilizador de la columna cervical inferior sobre la cintura escapular.

\section{Escaleno medio}

- O: Tubérculos posteriores de las apófisis transversas de las seis últimas vértebras cervicales.

- I: En la primera costilla, por fuera del escaleno anterior. A veces también en la segunda costilla.

- F: Cadena cinética abierta: sobre la columna cervical, en contracción bilateral: flexor, produce hiperlordosis; en contracción unilateral: lateralizador y rotador al mismo lado.

- Cadena cinética cerrada: sobre la primera costilla, elevador e inspirador.

- Función estática: estabilizador de la columna cervical inferior sobre la cintura escapular.

\section{Escaleno posterior}

- O: Tubérculos posteriores de las apófisis transversas de las vértebras cervicales cuarta, quinta y sexta. 
- I: Borde superior de la primera y segunda costillas.

- F: Cadena cinética abierta: Sobre la columna cervical en contracción bilateral: flexor, produce hiperlordosis; en contracción unilateral: lateralizador y rotador al mismo lado

- Cadena cinética cerrada: sobre la primera costilla, elevador e inspirador.

- Función estática: estabilizador de la columna cervical inferior sobre la cintura escapular.

\section{Largo del cuello}

- Porción longitudinal o interna

o O: Cuerpo de las tres primeras vértebras dorsales y de las tres últimas cervicales.

0 I: Cuerpo del axis y arco anterior del atlas.

- Porción oblicua superior o superoexterna

o O: Tubérculos anteriores de las apófisis transversas de las vértebras cervicales tercera a sexta.

0 I: Tubérculo anterior del atlas.

- Porción oblicua inferior o inferoexterna

O O: Cuerpo de las tres primeras vértebras dorsales.

o I: Tubérculos anteriores de las apófisis transversas de las vértebras cervicales cuarta, quinta y sexta.

- F (de todas las porciones): Cadena cinética abierta: sobre la columna cervical, flexor y lateralizador del mismo lado.

- Cadena cinética cerrada: sobre la columna cervical en contracción bilateral: rectifican la lordosis cervical.

- Función estática: fija la columna cervical.

\section{Recto anterior mayor de la cabeza}

- O: Tubérculos anteriores de las apófisis transversas de las vértebras cervicales tercera a sexta.

- I: En la lámina basilar, por delante del agujero occipital. 
- F: Cadena cinética abierta: sobre la columna cervical, flexor y lateralizador del mismo lado. Sobre la cabeza, flexor y lateralizador del mismo lado.

- Cadena cinética cerrada: sobre la columna cervical, en contracción bilateral, rectifican la lordosis cervical.

\section{Recto anterior menor de la cabeza}

- O: Parte anterior de la apófisis transversa del atlas, cerca de las masas laterales.

- I: En la lámina basilar, por detrás de la inserción del recto anterior mayor.

- F: Cadena cinética abierta: sobre la cabeza, flexor, lateralizador y rotador hacia el mismo lado.

\section{Recto lateral de la cabeza}

- O: Apófisis transversa del atlas.

- I: Apófisis yugular del occipital.

- F: Cadena cinética abierta: sobre la cabeza, flexor y lateralizador al mismo lado.

\section{Intertransversos anteriores cervicales}

- O: Tubérculos anteriores de las apófisis transversas de las vértebras cervicales.

- I: Tubérculos anteriores de las apófisis transversas de las vértebras cervicales.

- F: Cadena cinética abierta: sobre la columna cervical, lateralizador al mismo lado.

\section{Esternocleidomastoideo}

- O: Manubrio esternal y clavícula.

- I: Apófisis mastoides y línea curva occipital superior.

- F: Cadena cinética abierta: sobre la columna cervical y cabeza, en contracción bilateral, flexor y extensor de la cabeza y el cuello, según la posición previa. En contracción unilateral, lateralizador hacia el mismo lado y rotador hacia el contrario.

- Cadena cinética cerrada: sobre la columna cervical y la cabeza, en contracción bilateral y sin contracción sinérgica del músculo largo del cuello produce hiperlordosis. Sobre el tórax, inspirador. 
- Función estática: sobre la columna cervical y la cabeza, la fijan en contracción bilateral.

\section{Esternotiroideo}

- O: Manubrio esternal y primera costilla.

- I: Línea oblicua del cartílago tiroides.

- F: Cadena cinética abierta: sobre la laringe, la desciende, modula la voz, participa en la emisión de tonos graves y vocales "o", "u". Sobre la columna cervical y la cabeza, flexor (con sinergismo fijador de los músculos milohioideo, digástrico, masetero y temporal).

- Cadena cinética cerrada: sobre la columna cervical y cabeza, rectificador de la lordosis.

\section{Tirohioideo}

- O: Línea oblicua del cartílago tiroides.

- I: Cuerpo y asta mayor del tiroides.

- F: Cadena cinética abierta: sobre la laringe, elevador, modula la voz, participa en la emisión de tonos agudos y vocales "a", "e", "i". Sobre el hioides, lo desciende. Sobre la columna cervical y la cabeza, flexor (con sinergismo fijador de los músculos milohioideo, digástrico, masetero y temporal).

- Cadena cinética cerrada: sobre la columna cervical y cabeza, rectificador de la lordosis.

\section{Esternocleidohioideo}

- O: Manubrio esternal y clavícula.

- I: Cuerpo del hioides.

- F: Cadena cinética abierta: sobre el hioides, lo desciende. Sobre la columna cervical y la cabeza, flexor (con sinergismo fijador de los músculos milohioideo, digástrico, masetero y temporal).

- Cadena cinética cerrada: sobre la columna cervical y cabeza, rectificador de la lordosis. 


\section{Omohiodeo}

- O: Borde superior de la escápula medial a la escotadura coracoidea.

- $\quad$ I: Cuerpo del hioides.

- F: Cadena cinética abierta: sobre el hioides, lo desciende. Sobre la aponeurosis cervical media, tensor. Sobre la columna cervical y la cabeza, flexor (con sinergismo fijador de los músculos milohioideo, digástrico, masetero y temporal).

- Cadena cinética cerrada: sobre la columna cervical y cabeza, rectificador de la lordosis.

\subsubsection{EXTREMIDAD SUPERIOR}

\section{Braquial anterior}

- O: En los dos tercios inferiores de la cara anterior del húmero.

- I: Apófisis coronoides del cúbito.

- F: Cadena cinética abierta: sobre el codo, flexor (motor anterior).

- Función estática: en sinergismo con el tríceps braquial es coaptador del cúbito en flexión del codo de 90‥

\section{Coracobraquial}

- O. Apófisis coracoides de la escápula.

- I: Porción media de la cara anterointerna del húmero.

- F: Cadena cinética abierta: sobre la articulación escapulohumeral, flexor (motor principal), rotador interno y aproximador del brazo.

- Función estática: en sinergismo con la porción larga del tríceps y la porción corta del bíceps, impide la luxación inferior de la cabeza del húmero que podría ocasionar el mantenimiento de las cargas o la contracción del latísimo.

\section{Bíceps braquial}

- O: Porción corta, apófisis coracoides de la escápula. Porción larga, tubérculo supraglenoideo de la escápula. 
- I: Tuberosidad biccipital del radio. Por medio de la expansión aponeurótica bicipital, en la aponeurosis del antebrazo que cubre los músculos epitrocleares.

- F: Cadena cinética abierta: sobre la articulación radiocubital, supinador (motor principal, máxima eficacia en flexión de codo de 90ㅇ). Sobre el codo, flexor (motor principal, máxima eficacia en flexión de 80). Sobre la articulación escapulohumeral, flexor; la porción larga es también separadora del brazo y la porción corta es aproximadora.

- Función estática: porción corta, en sinergismo con la porción larga del bíceps, coaptador de la articulación escapulohumeral en separación intermedia. Porción larga, coaptador de la articulación escapulohumeral en rotación externa.

\section{Interóseos dorsales}

- O: En los dos metacarpianos del correspondiente espacio interóseo. El tercer dedo tiene un interóseo dorsal externo y otro interno. El segundo dedo, uno externo. El cuarto dedo, uno interno.

- I: Falange proximal, en los tubérculos laterales interno y externo del tercer dedo, lateral externo del segundo y lateral interno del cuarto, y en la aponeurosis dorsal, respectivamente, de los dedos segundo, tercero (dos interóseos) y cuarto.

- F: Cadena cinética abierta: sobre los dedos, flexores de la falange proximal y extensores de las otras dos (motor principal). Separadores de los dedos respecto al eje de la mano (tercer dedo) (motor principal).

- Cadena cinética cerrada: sobre el primer metacarpiano, el primer interóseo es aproximador.

- Función estática: favorece la acción sobre las articulaciones de la muñeca e interfalángicas, del extensor de los dedos, evitando así los dedos en garra, y de los flexores profundo y superficial de los dedos.

\section{Interóseos palmares}

- O: Cara interna del segundo metacarpiano y cara externa del cuarto y quinto metacarpianos. 
- I: Falange proximal, en los tubérculos lateral interno del segundo dedo y lateral externo del cuarto y quinto, y en la aponeurosis dorsal, respectivamente, de los dedos segundo, cuarto y quinto.

- F: Cadena cinética abierta: sobre los dedos, flexores de la falange proximal y extensores de las otras dos (motor principal). Aproximadores de los dedos respecto al eje de la mano (motor principal).

- Función estática: favorece la acción, sobre las articulaciones de la muñeca e interfalángicas, del extensor de los dedos, evitando así los dedos en garra, y de los flexores profundo y superficial de los dedos.

\section{Flexor corto del meñique}

- O: Apófisis unciforme del hueso ganchoso y ligamento transverso del carpo.

- I: Tubérculo lateral interno de la falange proximal del quinto dedo.

- F: Cadena cinética abierta: sobre el quinto dedo, flexor de la falange proximal (motor principal) y separador respecto al eje de la mano.

\section{Oponente del meñique}

- O: Apófisis unciforme del hueso ganchoso y ligamento transverso del carpo.

- I: En la cabeza y la diáfisis del quinto metacarpiano.

- F: Cadena cinética abierta: sobre el quinto metacarpiano, lo opone (motor principal, es antepulsor, aproximador y rotador externo).

\section{Separador del meñique}

- O: Hueso pisiforme y ligamento transverso del carpo.

- I: Tubérculo lateral interno de la falange proximal del quinto dedo y aponeurosis dorsal del quinto dedo.

- F: Cadena cinética abierta: sobre el quinto dedo, separador respecto al eje de la mano (motor principal), flexor de la falange proximal y extensor de las otras dos.

\section{Palmar cutáneo}

- O: Borde interno de la aponeurosis palmar. 
- I: Piel de la eminencia hipotenar.

- F: Cadena cinética abierta: sobre la piel de la eminencia hipotenar, la arruga.

\section{Aproximador del pulgar}

- O: Cuerpo del tercer metacarpiano.

- I: Sesamoideo interno y tubérculo lateral interno de la falange proximal del primer dedo.

- F: Cadena cinética abierta: sobre el primer metacarpiano, aproximador (motor principal); realiza la oposición subterminolateral u oposición en rotación externa (antepulsor, aproximador y rotador externo) y la oposición frente al quinto dedo. Sobre la falange proximal del quinto dedo, flexor con aproximación.

- Función estática: estabilizador de la columna osteoarticular del primer dedo.

\section{Flexor corto del pulgar}

- O: Huesos grande y trapezoide.

- I: Sesamoideo externo y tubérculo lateral externo de la falange proximal del primer dedo.

- F: Cadena cinética abierta: sobre la falange proximal del primer dedo, flexor (motor principal) y aproximador. Sobre el primer metacarpiano, ayuda a oponer frente al cuarto y quinto dedos en rotación interna (antepulsor, aproximador y rotador interno).

- Función estática: estabilizador de la columna osteoarticular del primer dedo.

\section{Lumbricales (tercero y cuarto)}

- O: Tendones del músculo flexor profundo de los dedos cuarto y quinto.

- I: Cara posterior de la falange proximal y tendones extensores de los correspondientes dedos.

- F: Cadena cinética abierta: sobre los dedos, flexores de la falange proximal y extensores de las otras dos (motor principal).

- Función estática: ajustan los movimientos de flexoextensión de los dedos. También realiza la misma función que los interóseos dorsales. 


\section{Cubital anterior}

- O: En la epitróclea y el olecranon.

- I: Hueso pisiforme. Algunas expansiones alcanzan al hueso ganchoso y a la base del cuarto y quinto metacarpianos.

- F: Cadena cinética abierta: sobre el carpo, flexor (motor principal) y aproximador (motor principal).

- Función estática: Estabilizador en aproximación de la muñeca, en sinergismo con el músculo cubital posterior.

\section{Flexor profundo de los dedos (cuarto y quinto)}

- O: Cara anterior del cúbito.

- I: Falanges distales de los dedos cuarto y quinto.

- F: Cadena cinética abierta: sobre el cuarto y quinto dedos, flexor de la falange distal (motor principal, alcanzando su máxima eficacia en extensión de carpo e interfalángica proximal). Flexor de las falanges intermedia y proximal. Sobre el carpo, alcanzando su máxima eficacia en extensión de dedos.

\section{Flexor profundo de los dedos (segundo y tercero)}

- O: Cara anterior del cúbito y membrana interósea.

- I: Falanges distales de los dedos segundo y tercero.

- F: Cadena cinética abierta: sobre el segundo y tercer dedos, flexor de la falange distal (motor principal, máxima eficacia en extensión del carpo e interfalángica proximal), participa en la realización de la pinza terminal. Flexor de las falanges intermedia y proximal. Sobre el carpo, flexor (máxima eficacia en extensión de los dedos).

\section{Lumbricales primero y segundo}

- O: Tendones del flexor profundo de los dedos segundo y tercero.

- I: Cara dorsal de la falange proximal y tendones extensores de los dedos correspondientes. 
- F: Cadena cinética abierta: sobre el segundo y tercer dedos, flexor de la falange proximal y extensor de las otras dos (motor principal).

- Función estática: ajusta los movimientos de flexoextensión de los dedos. Favorecen la acción de los músculos flexores profundo y superficial y del extensor de los dedos sobre las articulaciones de la muñeca e interfalángicas, evitando los dedos en garra.

\section{Flexor largo del pulgar}

- O: Tercio medio de la cara anterior del radio y de la membrana interósea.

- I: Falange distal del pulgar.

- F: Cadena cinética abierta: sobre el primer dedo, flexor de la falange distal (motor principal), participa en la pinza terminal por oposición. Sobre el carpo, flexor.

\section{Flexor corto del pulgar}

- O: Hueso trapezoide y ligamento transverso del carpo.

- I: Sesamoideo externo y tubérculo lateral externo de la falange proximal del primer dedo.

- F: Cadena cinética abierta: Sobre la falange proximal del primer dedo, flexor (motor principal) y aproximador. Sobre el primer metacarpiano, contribuye a oponerlo con el cuarto y quinto dedos en rotación interna. Participa en la pinza por oposición subterminal.

- Función estática: Estabilizador de la columna osteoarticular del primer dedo.

\section{Oponente del pulgar}

- O: Hueso trapezoide y ligamento transverso del carpo.

- I: Borde externo del primer metacarpiano.

- F: Cadena cinética abierta: sobre el primer metacarpiano, lo opone (motor principal, es antepulsor, aproximador y rotador interno).

- Función estática: estabilizador de la columna osteoarticular del primer dedo en la separación. 


\section{Separador corto del pulgar}

- O: Hueso trapezoide y ligamento transverso del carpo.

- I: Borde externo del primer metacarpiano.

- F: Cadena cinética abierta: sobre el primer metacarpiano, contribuye a oponerlo frente al segundo y tercer dedos (es antepulsor, aproximador y rotador interno). Participa en la pinza por oposición subterminal. Sobre la falange proximal del primer dedo, separador (motor principal), flexor y rotador interno. Sobre la falange distal del primer dedo, extensor.

- Función estática: estabilizador de la columna osteoarticular del primer dedo. Sinergismo con el separador largo en la oposición.

\section{Flexor superficial de los dedos}

- O: Epitróclea, apófisis coronoides del cúbito y cara anterior del radio.

- I: Falanges intermedias de los cuatro últimos dedos.

- F: Cadena cinética abierta: sobre los dedos, flexor de las falanges intermedias de los dedos correspondientes (motor principal, máxima eficacia en extensión del carpo y metacarpofalángica), participa en la pinza subterminal. Sobre el carpo, flexor (máxima eficacia con los dedos extendidos.

\section{Palmar mayor (flexor radial del carpo)}

- O: Epitróclea.

- I: Base del segundo metacarpiano.

- F: Cadena cinética abierta: sobre el carpo, flexor (motor principal) y separador (motor principal). Sobre las articulaciones radiocubitales, pronador. Sobre el codo, flexor.

- Función estática: en sinergismo con el músculo primer radial, estabiliza externamente la muñeca en separación.

\section{Palmar menor (palmar largo)}

- O: Epitróclea. 
- I: Aponeurosis palmar.

- F: Cadena cinética abierta: sobre la mano, tensa la aponeurosis palmar flexionando la mano. Sobre el carpo, flexor. Sobre el codo, flexor.

\section{Pronador cuadrado}

- O: Porción distal del borde anterior del cúbito.

- $\quad$ I: Porción distal de la cara anterior del radio.

- F: Cadena cinética abierta: sobre las articulaciones radiocubitales, pronador (motor principal).

\section{Pronador redondo}

- O: Epitróclea y apófisis coronoides del cúbito.

- I: Parte media de la cara anteroexterna del radio.

- F: Cadena cinética abierta: sobre las articulaciones radiocubitales, pronador (motor principal; máxima eficacia en flexión de codo de 90ํ). Sobre el codo, flexor.

\section{Subescapular}

- O: Fosa subescapular.

- I: Tubérculo menor o troquín del húmero.

- F: Cadena cinética abierta: sobre la articulación escapulohumeral, rotador interno (motor principal) y aproximador del brazo.

- Función estática: Coaptador de la articulación escapulohumeral. Durante la separación, participa en el sinergismo estabilizador de la cabeza humeral neutralizando el empuje vertical del deltoides.

\section{Redondo mayor}

- O: Ángulo inferior de la escápula.

- I: Cresta subtroquiniana del húmero.

- F: Cadena cinética abierta: sobre la articulación escapulohumeral, rotador interno (motor principal), aproximador y extensor del brazo (motor principal). 
- Cadena cinética cerrada: sobre la escápula, rotador, desplaza su ángulo inferior hacia fuera.

- Función estática: en la aproximación necesita del sinergismo fijador del músculo romboides.

\section{Serrato anterior}

- O: Porción superior, en las cuatro primeras costillas mediante digitaciones. Porción inferior, en la quinta a novena costillas.

- I: Porción superior, en el borde espinal de la escápula, desde el ángulo superior. Porción inferior, en el ángulo inferior de la escápula.

- F: Cadena cinética abierta: porción superior, sobre la escápula (motor principal, lleva la escápula hacia delante y afuera). Porción inferior, sobre la escápula, rotador (desplaza el ángulo inferior hacia delante y afuera y el ángulo externo hacia arriba); participa en la elevación del brazo.

- Cadena cinética cerrada: ambas porciones, inspiradores sobre el tórax.

- Función estática: mantiene pegado el borde espinal de la escápula al tórax. Participa en el sinergismo fijador de la escápula con el romboides.

\section{Subclavio}

- O: Primera costilla y primer cartílago costal.

- I: Cara inferior de la clavícula, en su mitad externa.

- F: Sobre la articulación esternoclavicular, descensor y antepulsor.

- Función estática: coaptador de la articulación esternoclavicular. Protege a los vasos y nervioso que pasan desde el cuello a la axila.

\section{Pectoral menor}

- O: En la tercera, cuarta y quinta costillas, por medio de digitaciones.

- I: Apófisis coracoides de la escápula.

- F: Cadena cinética abierta: sobre la escápula, propulsor del hombro hacia delante y abajo. Participa en la rotación interna del hombro. 
- Cadena cinética cerrada: sobre el tórax, respirador.

\section{Pectoral mayor}

- O: Porción clavicular, mitad interna de la clavícula. Porción esternocostal, esternón y los seis primeros cartílagos costales. Porción abdominal, vaina del músculo recto del abdomen.

- I: En la cresta subtroquiteriana del húmero. Sus fibras se disponen formando una " $U$ ", ya que se insertan en dos planos.

- F: Cadena cinética abierta: porción clavicular, sobre la articulación escapulohumeral, flexor, rotador interno (motor principal) y aproximador horizontal (motor principal). Porción esternocostal, sobre la articulación escapulohumeral, aproximador oblicuo, rotador interno (motor principal). Porción abdominal, sobre la escápula, propulsor del hombro hacia delante y abajo. Participa en la rotación interna del hombro.

- Cadena cinética cerrada: sobre el tórax, respirador. Sobre el tronco, en contracción bilateral, elevador (acción que realiza, por ejemplo, en la marcha con muletas).

\section{Supinador largo o braquiorradial}

- O: Borde externo del húmero, por encima del epicóndilo. Tabique aponeurótico intermuscular del brazo.

- $\quad$ I: Apófisis estiloides del radio.

- F: Cadena cinética abierta: sobre el codo, flexor (motor principal, máxima eficacia en flexión de 110ㅇ․ Sobre la articulación radiocubital, la conduce a la posición neutra, al ser pronador en supinación y supinador en pronación.

\section{Primer radial o extensor radial largo del carpo}

- O: Por encima del epicóndilo. Tabique aponeurótico intermuscular del brazo.

- I: Cara dorsal de la base del segundo metacarpiano.

- F: Cadena cinética abierta: sobre el codo, flexor. Sobre el carpo, extensor (motor principal) y separador. 
- Función estática: estabilizador externo en separación de la muñeca en sinergismo con el palmar mayor.

\section{Segundo radial o extensor radial corto del carpo}

- O: Epicóndilo.

- I: Cara dorsal de la base del tercer metacarpiano.

- F: Cadena cinética abierta: sobre el codo, flexor (poca eficacia). Sobre el carpo, extensor (motor principal) y separador (poca eficacia).

\section{Separador largo del pulgar}

- O: Cara posterior del cúbito, membrana interósea y radio.

- I: Base del primer metacarpiano.

- F: Cadena cinética abierta: sobre la articulación radiocubital, supinador. Sobre el carpo, separador (motor principal) y flexor. Sobre el primer metacarpiano, separador (motor principal) y antepulsor.

- Función estática: sinergismo con el separador corto en la oposición.

\section{Extensor corto del pulgar}

- O: Cara posterior del radio y membrana interósea.

- I: Falange proximal del pulgar.

- F: Cadena cinética abierta: sobre el carpo, extensor y separador (motor principal). Sobre el primer metacarpiano, separador y retropulsor. Sobre el primer dedo, extensor (motor principal) y separador.

- Función estática: antagonista de la oposición.

\section{Extensor largo del pulgar}

- O: Cara posterior del cúbito y membrana interósea.

- I: Falange distal del pulgar. 
- F: Cadena cinética abierta: sobre el carpo, extensor. Sobre el primer dedo, extensor (motor principal). Sobre el primer metacarpiano, aproximador y retropulsor.

- Función estática: antagonista de la oposición.

\section{Extensor del índice}

- O: Cara posterior del cúbito y membrana interósea.

- I: Falange distal del pulgar.

- F: Cadena cinética abierta: sobre el carpo, extensor (máxima eficacia con el segundo dedo flexionado). Sobre el segundo dedo, extensor (motor principal, máxima eficacia en flexión de muñeca).

- Función estática: abre la pinza terminal.

\section{Supinador corto o músculo supinador}

- O: Epicóndilo, cresta del supinador del cúbito, ligamento lateral externo del codo y ligamento anular del radio.

- I: Rodea al radio al atarse en la cara anterior, borde externo y cara posterior del mismo.

- F: Cadena cinética abierta: sobre la articulación radiocubital, supinador (motor principal).

\section{Extensor de los dedos}

- O: Epicóndilo y aponeurosis del antebrazo.

- I: Aponeurosis dorsal y falanges distales de los cuatro últimos dedos.

- F: Cadena cinética abierta: sobre el codo, extensor. Sobre el carpo, extensor (máxima eficacia con los dedos flexionados). Sobre los dedos, extensor (motor principal, máxima eficacia en flexión de la muñeca).

\section{Extensor del meñique}

- O: Epicóndilo y aponeurosis del antebrazo.

- I: Aponeurosis dorsal y falange distal del quinto dedo. 
- F: Cadena cinética abierta: sobre el codo, extensor. Sobre el carpo, extensor (máxima eficacia con el quinto dedo flexionado). Sobre el quinto dedo, extensor (motor principal) y separador (máxima eficacia en flexión de la muñeca).

\section{Cubital posterior o extensor cubital del carpo}

- O: Epicóndilo y cara posterior del cúbito.

- I: Base del quinto metacarpiano. Su tendón pasa entre el radio y la apófisis estiloides del cúbito.

- F: Cadena cinética abierta: sobre el codo, extensor. Sobre el carpo, extensor (motor principal) y aproximador.

- Función estática: estabiliza internamente la muñeca en aproximación, en sinergismo con el cubital anterior.

\section{Ancóneo}

- O: Epicóndilo.

- $\quad$ I: Olecranon y cara posterior del cúbito.

- F: Cadena cinética abierta: sobre el codo, extensor.

- Función estática: estabilizador del cúbito durante la pronosupinación.

\section{Tríceps braquial}

- O: Vasto interno, medial y distalmente al canal de torsión del húmero y tabique intermuscular aponeurótico del brazo. Vasto externo, lateral y proximalmente al canal de torsión del húmero y tabique intermuscular aponeurótico del brazo. Porción larga, tubérculo infraglenoideo de la escápula.

- I: Olecranon.

- F: Cadena cinética abierta: sobre la articulación escapulohumeral, la porción larga, aproximadora. Sobre el codo, extensor (motor principal, máxima eficacia en flexión de 23으). 
- Función estática: Coaptador del cúbito en flexión de codo de 90으, en sinergismo con el braquial anterior. La porción larga, en sinergismo con el coracobraquial y la porción corta del bíceps, impide la luxación inferior de la cabeza del húmero ocasionada por el mantenimiento de cargas o por la contracción del latísimo.

\section{Supraespinoso}

- O: Fosa supraespinosa de la escápula.

- I: Faceta superior del troquíter.

- F: Cadena cinética abierta: sobre la articulación escapulohumeral, separador (motor principal en los primeros 10ㅇ) y rotador externo (poca eficacia).

- Función estática: limita la luxación superior de la cabeza del húmero, acolcha la bóveda acromiocoracoidea, y neutraliza el empuje vertical del deltoides, de la porción larga del tríceps, del coracobraquial y de la porción corta del bíceps.

\section{Infraespinoso}

- O: Fosa infraespinosa de la escápula.

- I: Faceta media del troquíter.

- F: Cadena cinética abierta: sobre la articulación escapulohumeral, separador (poca eficacia) y rotador externo (motor principal).

- Función estática: coaptador de la articulación escapulohumeral. Durante la separación participa en el sinergismo estabilizador de la cabeza humeral y neutraliza el empuje vertical del deltoides.

\section{Redondo menor}

- O: Fosa infraespinosa y borde axilar de la escápula.

- I: Faceta inferior del troquíter.

- F: Cadena cinética abierta: sobre la articulación escapulohumeral: rotador externo (motor principal) y aproximador. 
- Función estática: coaptador de la articulación escapulohumeral. Durante la separación participa en el sinergismo estabilizador de la cabeza humeral y neutraliza el empuje vertical del deltoides.

\section{Deltoides}

- O. Porción clavicular, tercio externo de la escápula. Porción acromial, acromion. Porción espinal: espina de la escápula.

- I: Impresión o "V" deltoidea del húmero.

- F: Cadena cinética abierta: Porción clavicular, sobre la articulación escapulohumeral, rotador interno y flexor (motor principal). Aproximador (en posición neutra) y separador (en separación de más de 30ํy y flexión de 30으). Porción acromial, sobre la articulación escapulohumeral, separador hasta la horizontal (motor principal). Porción espinal, sobre la articulación escapulohumeral, rotador externo, extensor (motor principal) y separador horizontal (motor principal). Aproximador (en posición neutra) y separador (en separación de más de 30ㅇ).

- Función estática: porciones clavicular y espinal, estabilizadoras de la articulación escapulohumeral durante la separación.

\subsubsection{EXTREMIDAD INFERIOR}

\section{Interóseos dorsales}

- O: En los dos metatarsianos del espacio interóseo correspondiente. El segundo dedo tiene uno externo y otro interno; los de tercer y cuarto dedos son externos.

- I: Falanges proximales del segundo (primer y segundo interóseos) y del tercer y cuarto dedos. También en la aponeurosis dorsal de los dedos.

- F: Cadena cinética abierta: sobre los dedos, flexores de la primera falange y extensores de las otras dos. Separadores de los dedos del eje del pie, que pasa por el segundo dedo.

- Función estática: matizan la base de sustentación y el apoyo. 


\section{Interóseos plantares}

- O: En la cara interna del metatarsiano correspondiente a su dedo.

- I: Falanges proximales del tercer, cuarto y quinto dedos. Aponeurosis dorsal de los dedos.

- F: Cadena cinética abierta: sobre los dedos, flexores de la primera falange y extensores de las otras dos. Aproximadores de los dedos al eje del pie.

- Función estática: Favorecen la acción sobre las articulaciones interfalángica y talocrural del extensor de los dedos, evitando la garra de los dedos.

\section{Flexor corto del quinto dedo}

- O: Ligamento plantar largo y base del quinto metatarsiano.

- I: Falange proximal del quinto dedo.

- F: Cadena cinética abierta: sobre el quinto dedo, flexor de la falange proximal y separador.

\section{Oponente del quinto dedo}

- O: Ligamento plantar largo.

- I: Borde externo del quinto metatarsiano.

- F: Cadena cinética abierta: sobre el quinto dedo, lo opone.

- Función estática: Acentúa la bóveda plantar y en particular el arco plantar transversal.

\section{Separador del quinto dedo}

- O: Tuberosidad externa del calcáneo y aponeurosis plantar.

- I: Falange proximal del quinto dedo.

- F: Cadena cinética abierta: sobre el quinto dedo, flexor de la falange proximal y separador.

- Función estática: Ligamento activo del arco plantar longitudinal externo. 


\section{Aproximador del primer dedo}

- O: Fascículo oblicuo, cuboides, tercera cuña y ligamento plantar largo. Fascículo transverso, cápsulas articulares de la tercera, cuarta y quinta articulaciones metatarsofalángicas.

- I: Hueso sesamoideo externo y falange proximal del primer dedo.

- F: Cadena cinética abierta: fascículo oblicuo, sobre el primer dedo, aproximador de este dedo al eje del pie.

- Función estática: Fascículo transverso, ligamento activo del arco plantar transversal anterior.

\section{Cuadrado plantar de Silvio}

- O: Calcáneo.

- I: Tendón del músculo flexor largo de los dedos.

- F: Cadena cinética abierta: corrige la dirección de dicho tendón y le ayuda en su acción flexora.

\section{Lumbricales}

- O: Tendones para el tercer, cuarto y quinto dedos del músculo flexor largo de los dedos.

- I: Dorso de las falanges proximales de tercer, cuarto y quinto dedos y tendones para esos dedos del músculo extensor largo de los dedos.

- F: Cadena cinética abierta: sobre los dedos, flexores de la primera falange y extensores de la segunda y tercera de su dedo correspondiente.

- Función estática: como los músculos interóseos.

\section{Flexor corto del primer dedo}

- O: Ligamento plantar largo y primera cuña.

- I: En ambos sesamoideos y en la falange proximal del primer dedo.

- F: Cadena cinética abierta: sobre el primer dedo, flexor de la falange proximal. 


\section{Separador del primer dedo}

- O: Tuberosidad interna del calcáneo, aponeurosis plantar y retináculo flexor.

- I: Sesamoideo interno y en la falange proximal del primer dedo.

- F: Cadena cinética abierta: sobre el primer dedo, separador del primer dedo del eje del pie.

- Función estática: Ligamento activo del arco plantar longitudinal interno.

\section{Primer lumbrical}

- O: Tendón para el segundo dedo del músculo flexor largo de los dedos.

- I: Dorso de la falange proximal del segundo dedo y tendón para ese dedo del músculo extensor largo de los dedos.

- F: Cadena cinética abierta: sobre el segundo dedo, flexor de la falange proximal y extensor de la media y la distal.

- Función estática: como los músculos interóseos.

\section{Flexor corto de los dedos}

- O: Tuberosidad interna del calcáneo y aponeurosis plantar media.

- I: Falanges medias de los cuatro últimos dedos (tendón perforado).

- F: Cadena cinética abierta: sobre los dedos, flexor de las falanges medias de los cuatro últimos dedos.

- Función estática: Ligamento activo de los arcos plantares longitudinales.

\section{Flexor largo del primer dedo}

- O: Cara y borde posteriores del peroné y membrana interósea.

- I: Falange distal del primer dedo.

- F: Cadena cinética abierta: sobre el primer dedo, flexor. Sobre la articulación subtalar, inversor. Sobre la articulación talocrural, flexor plantar (motor principal). 
- Cadena cinética cerrada: sobre la articulación talocrural, pone de puntillas e interviene en la marcha, carrera y salto elevando el talón. Retroversor de la pierna.

- Función estática: Estabiliza al astrágalo y calcáneo. Ligamento activo del arco plantar interno. Cuerda subtotal del arco plantar longitudinal interno, con descenso del antepié.

\section{Tibial posterior}

- O: Membrana interósea, tibia y peroné.

- I: Escafoides y primera cuña. También, mediante expansiones tendinosas, en la segunda y tercera cuñas y base de segundo, tercer y cuatro metatarsianos.

- F: Cadena cinética abierta: sobre la articulación subtalar, inversor (motor principal). Sobre la articulación talocrural, flexor plantar.

- Cadena cinética cerrada: sobre la articulación talocrural, pone de puntillas e interviene en la marcha, carrera y salto elevando el talón. Retroversor de la pierna.

- Función estática: cierra la pinza tibioperonea. Mantiene el arco plantar transversal (escafocuboideo). Mantiene el vértice de la bóveda plantar. Cuerda parcial de los arcos plantares longitudinales, con descenso del antepié.

\section{Flexor largo de los dedos}

- O: Cara posterior de la tibia.

- I: Falanges distales de los cuatro últimos dedos.

- F: Cadena cinética abierta: sobre el segundo, tercer, cuarto y quinto dedos, flexor. Sobre la articulación subtalar, inversor. Sobre la articulación talocrural, flexor plantar.

- Cadena cinética cerrada: sobre la articulación talocrural, pone de puntillas e interviene en la marcha, carrera y salto elevando el talón. Retroversor de la pierna. 
- Función estática: Cuerda subtotal de los arcos plantares longitudinales, con descenso del antepié. Se cruza con el flexor largo del primer dedo en el vértice de la bóveda plantar, fijándolo.

\section{Poplíteo}

- O: Cara posteroexterna del cóndilo externo del fémur. Su tendón se hace intraarticular, y algunas de sus fibras llegan hasta el menisco externo de la rodilla

- I: Cara posterior de la tibia, por encima de la línea oblicua.

- F: Cadena cinética abierta: sobre la rodilla, flexor y rotador interno.

- Cadena cinética cerrada: sobre la rodilla, rotador externo del fémur. Extensor, por insertar distal al eje. Sinergismo extensor con los gemelos, el cuádriceps y los isquiotibiales.

- Función estática: limita la hiperextensión de la rodilla. Estabilizador rotacional de la rodilla. Estabilizador anteroposterior de la rodilla. Tracciona el menisco externo hacia atrás.

\section{Tríceps sural}

- O: Sóleo, cara posterior, borde externo y cabeza del peroné. Línea oblicua de la tibia. Gemelo medial, cara posterointerna del cóndilo interno del fémur y casquete condíleo medial. Gemelo lateral, cara posteroexterna del cóndilo externo del fémur y casquete condíleo lateral.

- I: Por medio del tendón calcáneo o de Aquiles, en el borde posteroinferior de la tuberosidad posterior del calcáneo.

- F: Cadena cinética abierta: sobre la articulación subtalar, inversor en eversión. Eversor en inversión. Sobre la articulación talcrural, flexor plantar (motor principal); máxima potencia con la rodilla extendida (gemelos) y en flexión dorsal del tobillo. Sobre la rodilla (gemelos): flexor.

- Cadena cinética cerrada: sobre la articulación talocrural, pone de puntillas e interviene en la marcha, carrera y salto elevando el talón. Retroversor de la 
pierna. Sobre la rodilla (gemelos): sinergismo extensor con el cuádriceps, los isquiotibiales y el poplíteo.

- Funciones estáticas: sóleo, estabiliza el deslizamiento anterior de la tibia sobre el astrágalo. Gemelos, en contracción excéntrica frena la flexión dorsal de la articulación talocrural durante la fase de "apoyo medio". Aplana la bóveda plantar, elevando el retropié.

\section{Plantar delgado}

- O: Cara externa del cóndilo externo del fémur.

- I: En el tendón de Aquiles, o directamente en el calcáneo o la aponeurosis plantar.

- F: Cadena cinética abierta: sobre la rodilla, flexor.

- Función estática: protege el paquete vasculonervioso de la región poplítea en la flexión interna de la rodilla.

\section{Peroneo lateral corto}

- O: Tercio medio de la cara externa y borde anterior del peroné.

- I: Base del quinto metatarsiano.

- F: Cadena cinética abierta: sobre la articulación talocrural, flexor plantar. Sobre la articulación subtalar, eversor (motor principal).

- Función estática: estabilizador lateral del tobillo. Cuerda parcial del arco plantar longitudinal externo.

\section{Peroneo lateral largo}

- O: Dos tercios superiores de la cara externa del peroné llegando hasta su cabeza.

- I: Base del primer metatarsiano y primera cuña.

- F: Cadena cinética abierta: sobre la articulación talocrural, flexor plantar. Sobre la articulación subtalar, eversor (motor principal).

- Cadena cinética cerrada: sobre la articulación talocrural, levanta el talón. Retroversor de la pierna. 
- Función estática: estabilizador lateral del tobillo. Ligamento activo de los arcos plantares transversal medio y longitudinales externo e interno.

\section{Tibial anterior}

- O: Cara externa de la tibia y membrana interósea.

- I: Primera cuña y primer metatarsiano.

- F: Cadena cinética abierta: sobre la articulación talocrural, flexor dorsal (motor principal). Sobre la articulación subtalar, inversor (motor principal).

- Cadena cinética cerrada: sobre la articulación talocrural, levanta el talón. Retroversor de la pierna.

- Función estática: estabilizador lateral del tobillo. Ligamento activo de los arcos plantares transversal medio y longitudinales externo e interno.

\section{Extensor largo del primer dedo}

- O: Membrana interósea y peroné.

- I: Superficie dorsal del primer dedo llegando hasta la falange distal.

- F: Cadena cinética abierta: sobre la articulación talocrural, flexor dorsal. Sobre el primer dedo, extensor.

- Función estática: aplanta el arco plantar longitudinal interno.

\section{Extensor largo de los dedos}

- O: Tuberosidad externa de la tibia, membrana interósea y peroné.

- I: Fascia dorsal de los cuatro últimos dedos.

- F: Cadena cinética abierta: sobre la articulación talocrural, flexor dorsal. Sobre la articulación subtalar, eversor. Sobre los dedos, extensor.

- Función estática: aplana el arco plantar longitudinal externo.

\section{Peroneo anterior}

- O: Tercio inferior del peroné y membrana interósea.

- I: Base del quinto metatarsiano. 
- F: Cadena cinética abierta: sobre la articulación talocrural, flexor dorsal. Sobre la articulación subtalar, eversor.

- Función estática: aplana el arco plantar longitudinal externo.

\section{Extensor corto de los dedos o pedio}

- O: Cara dorsal y externa del calcáneo.

- I: Fascia dorsal del pie y tendones del extensor largo para los cuatro primeros dedos.

- F: Cadena cinética abierta: sobre los dedos, extensor de los cuatro primeros dedos.

\section{Porción recta del aproximador mayor}

- O: Tuberosidad isquiática.

- I: Cóndilo interno del fémur (tubérculo del gran aproximador).

- F: Cadena cinética abierta: sobre la cadera, aproximador del muslo hasta la línea media y extensor.

- Cadena cinética cerrada: sobre la cadera, retroversor de la pelvis.

- Función estática: coaptador de la cadera en separación. Estabilizador anteroposterior de la pelvis.

\section{Semimembranoso}

- O: Tuberosidad isquiática.

- I: Mediante tres tendones: directo, en la tuberosidad interna de la tibia; reflejo, en la tuberosidad anterointerna de la tibia y en el menisco interno; oblicuo (ligamento poplíteo oblicuo), en la cápsula articular.

- F: Cadena cinética abierta: sobre la cadera, aproximador, extensor (motor principal), rotador externo en rotación interna y rotador interno en rotación externa. Sobre la rodilla, flexor (motor principal) y rotador interno de la pierna.

- Cadena cinética cerrada: sobre la cadera, retroversor de la pelvis. Sobre la rodilla, sinergismo extensor con el cuádriceps y los gemelos. 
- Función estática: coaptador de la cadera en separación. Estabilizador anteroposterior de la pelvis. Estabilizador lateral interno de la rodilla en hiperextensión. Tracciona el menisco interno hacia atrás.

\section{Semitendinoso}

- O: Tuberosidad isquiática.

- $\quad$ I: Cara superointerna de la tibia (forma parte de la pata de ganso).

- F: Cadena cinética abierta: sobre la cadera, aproximador, extensor (motor principal), rotador externo en rotación interna y rotador interno en rotación externa. Sobre la rodilla, flexor (motor principal) y rotador interno de la pierna.

- Cadena cinética cerrada: sobre la cadera, retroversor de la pelvis. Sobre la rodilla, sinergismo extensor con el cuádriceps y los gemelos.

- Función estática: coaptador de la cadera en separación. Estabilizador anteroposterior de la pelvis. Estabilizador lateral interno de la rodilla en flexión de 10 .

\section{Bíceps femoral}

- O: Porción larga, tuberosidad isquiática. Porción corta, labio externo de la línea áspera del fémur.

- I: Cabeza del peroné.

- F: Cadena cinética abierta: porción larga, sobre la cadera, aproximador, extensor (motor principal) y rotador externo. Sobre la rodilla, flexor (motor principal) y rotador externo de la pierna. Porción corta, sobre la rodilla, flexor (motor principal) y rotador externo de la pierna.

- Cadena cinética cerrada: porción larga, sobre la cadera, retroversor de la pelvis. Sobre la rodilla, sinergismo extensor con el cuádriceps y los gemelos. Porción corta, sobre la rodilla, sinergismo extensor con el cuádriceps y los gemelos. 
- Función estática: porción larga, coaptador de la cadera en separación. Estabilizador anteroposterior de la pelvis. Estabilizador lateral externo de la rodilla. Porción corta, estabilizador lateral externo de la rodilla.

\section{Cuadrado crural}

- O: Tuberosidad isquiática.

- I: Cresta intertrocantérea posterior.

- F: Cadena cinética abierta: sobre la cadera, aproximador y rotador externo (motor principal), flexor en extensión y extensor en flexión.

\section{Obturador interno}

- O: Contorno del agujero obturado por su cara pelviana y en la membrana obturatriz.

- I: Fosa trocantérea o digital del fémur.

- F: Cadena cinética abierta: sobre la cadera, separador (coxa vara), aproximador (coxa valga) y rotador externo (motor principal).

- Función estática: músculo pelvitrocantéreo coaptador de la cadera.

\section{Géminos}

- O: Superior, espina ciática. Inferior, tuberosidad isquiática.

- I: Tendón del músculo obturador interno.

- F: Cadena cinética abierta: sobre la cadera, separador (coxa vara), aproximador (coxa valga) y rotador externo.

\section{Piramidal de la pelvis (piriforme)}

- O: Cara pelviana del sacro.

- I: Vértice del trocánter mayor.

- F: Cadena cinética abierta: sobre la cadera, rotador externo (motor principal) e interno y separador. En flexión acentuada es rotador interno, extensor y separador.

- Función estática: músculo pelvitrocantéreo coaptador de la cadera. 


\section{Glúteo menor}

- O: Fosa ilíaca externa, entre las líneas glútea anterior e inferior.

- I: Vértice y cara anterior del trocánter mayor.

- F: Cadena cinética abierta: sobre la cadera, separador (motor principal), flexor y rotador interno (motor principal).

- Función estática: coaptador de la cadera. Estabilizador transversal de la pelvis.

\section{Glúteo mediano}

- O: Fosa ilíaca externa, entre las líneas glúteas anterior y posterior.

- I: Cara externa del trocánter mayor.

- F: Cadena cinética abierta: sobre la cadera, separador (menos fuerza con el trocánter alto, más fuerza con el trocánter bajo) (motor principal), flexor y rotador interno (fibras anteriores) y externo (fibras posteriores).

- Función estática: coaptador de la cadera. Máximo estabilizador transversal de la pelvis.

\section{Tensor de la fascia lata}

- O: Espina ilíaca anterosuperior.

- I: En la cintilla isquiotibial la cual, como un largo tendón plano, llega a la tuberosidad externa de la tibia.

- F: Cadena cinética abierta: sobre la cadera, flexor (máxima amplitud, 120)), separador y rotador interno (motor principal). Sobre la rodilla, flexor, extensor y rotador externo.

- Función estática: estabilizador transversal de la pelvis. Estabilizador lateral externo de la rodilla. Fija la rodilla en extensión.

\section{Glúteo mayor}

- O: Espinas ilíacas posterosuperior y posteroinferior. Cara posterior del sacro, cóccix y ligamento sacrociático mayor. 
- I: Fibras superiores, trocánter mayor. Fibras inferiores, fascia lata y rama de trifurcación externa de la línea áspera del fémur (cresta glútea).

- F: Cadena cinética abierta: sobre la cadera, extensor (motor principal), rotador externo (motor principal), separador (fibras superiores) y aproximador (fibras inferiores).

- Cadena cinética cerrada: sobre la cadera, retroversor de la pelvis. Juega un importante papel en la posición erecta del tronco.

- Función estática: estabilizador anteroposterior de la pelvis.

\section{Porción torcida del aproximador mayor (aductor mayor)}

- O: Tuberosidad isquiática (fibras más inferiores) y rama isquiopubiana (fibras más superiores).

- I: Labio interno de la línea áspera del fémur.

- F: Cadena cinética abierta: sobre la cadera, aproximador (motor principal), flexor y rotador externo.

- Cadena cinética cerrada: sobre la cadera, anteversor de la pelvis. Inclinador lateral, conduce a un apoyo asimétrico.

- Función estática: coaptador de la cadera en separación.

\section{Aproximador menor}

- O: Pubis (próximo al agujero obturador).

- I: Tercio superior del labio interno de la línea áspera del fémur.

- F: Cadena cinética abierta: sobre la cadera, aproximador (motor principal), flexor (hasta 50을 y rotador externo (si está aproximado).

- Cadena cinética cerrada: sobre la cadera, anteversor de la pelvis. Inclinador lateral, conduce a un apoyo asimétrico.

\section{Aproximador mediano}

- O: Espina del pubis.

- I: Tercio medio del labio interno de la línea áspera del fémur. 
- F: Cadena cinética abierta: sobre la cadera, aproximador (motor principal), flexor (hasta 50을 y rotador externo (si está aproximado).

- Cadena cinética cerrada: sobre la cadera, anteversor de la pelvis. Inclinador lateral, conduce a un apoyo asimétrico.

\section{Recto interno (Gracilis)}

- O: Junto a la sínfisis del pubis.

- I: Cara superointerna de la tibia (forma parte de la pata de ganso).

- F: Cadena cinética abierta: sobre la cadera, aproximador (motor principal) y flexor (hasta 40 ). Sobre la rodilla, flexor y rotador interno.

- Cadena cinética cerrada: sobre la cadera, anteversor de la pelvis. Inclinador lateral, conduce a un apoyo asimétrico.

- Función estática: estabilizador lateral de la rodilla en flexión de 10․․

\section{Obturador externo}

- O: Contorno del agujero obturado por su cara externa. Membrana obturatriz.

- I: Fosa trocantérea (fosita digital) del fémur.

- F: Cadena cinética abierta: sobre la cadera, aproximador y rotador externo (motor principal).

\section{Pectíneo}

- O: Cresta pectínea del pubis.

- I: Línea de trifurcación media de la línea áspera.

- F: Cadena cinética abierta: sobre la cadera, aproximador (motor principal), flexor y rotador externo.

- Cadena cinética cerrada: sobre la cadera, anteversor de la pelvis. Inclinador lateral, conduce a un apoyo asimétrico.

\section{Psoasilíaco}

- O: Psoas mayor, cuerpo de las vértebras $12^{\text {a }}$ torácica, primera a cuarta lumbares. Apófisis costiformes de las vértebras lumbares y discos 
intervertebrales. Ilíaco, fosa ilíaca interna. Psoas menor, cuerpo de la $12^{a}$ vértebra torácica, y disco vertebral entre la 12a $\mathrm{T}$ y la primera lumbar.

- I: Psoas mayor e ilíaco, trocánter menor. Psoas menor, eminencia iliopectínea.

- F: Cadena cinética abierta: psoas mayor e ilíaco, sobre la cadera, flexor (amplitud máxima 120으, motor principal) y rotador externo. Psoas menor, sobre la pelvis, retroversor.

- Cadena cinética cerrada: psoas mayor e ilíaco, sobre la columna lumbar, flexor (en contracción simétrica), lateralizador y rotador hacia el lado contrario. Sobre la pelvis, anteversor. Psoas menor, sobre la columna lumbar, flexor y lateralizador.

- Función estática: psoas mayor e ilíaco, acentúa la lordosis lumbar.

\section{Cuádriceps crural}

- O: Crural, cara anterior del fémur. Vasto interno, labio interno de la línea áspera del fémur, incluida la rama interna de trifurcación de la misma. Vasto externo, labio externo de la línea áspera del fémur llegando al trocánter mayor. Recto anterior, espina ilíaca anteroinferior; borde superior de la ceja cotiloidea.

- I: El tendón del cuádriceps se inserta en la rótula y desde aquí, por medio del tendón rotulinano, en la tuberosidad anterior de la tibia. Los vastos, mediante expansiones aponeuróticas directas y cruzadas, en la meseta tibial.

- F: Cadena cinética abierta: sobre la cadera, el recto anterior es flexor. Sobre la rodilla, los cuatro vientres son extensores (motor principal).

- Cadena cinética cerrada: el recto anterior, sobre la pelvis, anteversor.

- Función estática: convierte el miembro inferior en una columna rígida. Estabilizador lateral externo e interno y anteroposterior de la rodilla en extensión y flexión de 10․ Tracciona de la meseta tibial hacia delante. El vasto interior es estabilizador de la rótula. Tracciona hacia delante de ambos meniscos en extensión, del menisco interno en rotación interna y del menisco externo en rotación externa. El recto anterior, estabilizador anteroposterior de la pelvis. 


\section{Subcrural}

- O: Cara anterior del fémur.

- I: Cápsula articular de la rodilla.

- F: Cadena cinética abierta: tracciona de la cápsula y sinovial de la rodilla.

\section{Sartorio}

- O: Espina ilíaca anterosuperior.

- I: Cara superointerna de la tibia (forma parte de la pata de ganso).

- F: Cadena cinética abierta: sobre la cadera, flexor (amplitud máxima), separador y rotador externo. Sobre la rodilla, flexor y rotador interno.

- Cadena cinética cerrada: sobre la pelvis, anteversor.

- Función estática: estabilizador lateral interno de la rodilla en flexión de 10․ Estabilizador anteroposterior de la pelvis. 


\section{ANEXO 8.7}

\section{NERVIOS}

\section{Plexo cervical}

Conjunto de cordones nerviosos que forman, antes de su distribución periférica, las ramas anteriores de los cuatro primeros nervios cervicales. Se sitúa por detrás del esternocleidomastoideo, entre los músculos prevertebrales y las inserciones del esplenio y el angular. Sus ramas se dividen en ramas cutáneas y ramas profundas.

\section{Nervio accesorio}

Se separa del tronco secundario anterointerno del plexo braquial algo por encima del braquial cutáneo interno. Sus fibras proceden de la primera raíz dorsal. En su origen se sitúa interno a la arteria axilar. Se dirige hacia abajo y adentro. Atraviesa la aponeurosis braquial en la parte superior del brazo y desciende superficialmente por la cara interna del brazo hasta la epitróclea.

\section{Nervio musculocutáneo}

Se desprende del tronco secundario superior. Sus fibras proceden del quinto y sexto pares cervicales. Se origina en la axila, bastante arriba, y se dirige oblicuamente hacia abajo y afuera. Atraviesa diagonalmente la cara anterior del brazo hasta el pliegue del codo, donde perfora la aponeurosis para hacerse subcutáneo y se ramifica por la mitad externa de la piel del antebrazo.

\section{Nervio cubital}

Se desprende de la raíz interna del mediano, tronco secundario anterointerno. Sus fibras provienen del octavo nervio cervical y del primer dorsal. Es un nervio grande que se extiende, como el mediano, desde la región de la axila hasta la punta de los dedos. Nace en la axila y sigue un trayecto vertical descendente por la parte interna del brazo, en un plano algo posterior al mediano. Llegado al codo, rodea la epitróclea para situarse en la cara 
anterointerna del antebrazo y desciende hasta la muñeca, en donde termina bifurcándose a la altura del hueso pisiforme.

\section{Nervio mediano}

Nace de la porción axilar del plexo braquial por dos raíces: una externa y otra interna. La raíz externa procede del tronco superior, y la interna del tronco anterointerno. En la axila, ya como nervio mediano, desciende por el lado interno del brazo y llega a la cara anterior de la epitróclea. Allí, se inclina hacia fuera, aproximándose al eje del miembro; se hace mediano y, de nuevo en posición vertical, atraviesa la cara anterior del antebrazo y el conducto carpiano, ramificándose hasta la punta de los dedos.

\section{Nervio radial}

Es continuación del tronco secundario posterior del plexo braquial. Sus fibras proceden de la sexta, séptima y octava raíces cervicales y de la primera dorsal. Nace en la axila de la parte posterior del plexo braquial, atraviesa la cavidad axilar, llega al húmero, al que cruza oblicuamente hacia abajo y afuera. Atraviesa el tabique intermuscular externo y desemboca en la cara anterior del brazo, a unos diez centímetros por encima del epicóndilo. Se dirige entonces hacia la interlínea articular del codo, donde se divide en dos ramas terminales, unas veces por encima y otras por debajo del epicóndilo.

\section{Nervio axilar}

Nace del tronco secundario posterior, bastante alto en el hueco de la axila. Atraviesa el agujero cuadrado de Velpeau junto con la arteria axilar, y llega a la cara posterior del hombro. Rodea el cuello del húmero de atrás adelante y se agota en sus ramas terminales.

\section{Nervio plantar externo}

Es la rama externa de bifurcación del nervio tibial posterior. A su salida del canal calcáneo se dirige hacia delante y afuera hasta el extremo posterior del cuarto espacio interóseo, donde termina. 


\section{Nervio plantar interno}

Más voluminoso que el plantar externo, se dirige hacia delante desde el canal calcáneo por la cara interna del hueso calcáneo, hasta llegar a la planta del pie. A partir de allí camina de atrás adelante por debajo de los tendones flexores de los dedos hasta la base de los metatarsianos, donde se divide en sus ramas terminales.

\section{Nervio tibial}

Rama de bifurcación interna del ciático mayor. Es más voluminoso que el nervio peroneo. Nace en el hueco poplíteo, sigue un trayecto vertical y penetra por debajo de los gastrocnemios hasta atravesar el anillo del sóleo. En ese punto cambia de nombre, pasando a denominarse tibial posterior. Camina por la cara posterior de la pierna en un trayecto oblicuo hacia el maléolo interno. Termina en el conducto calcáneo bifurcándose en nervio plantar interno y nervio plantar externo.

\section{Nervio peroneo}

Es la rama externa de bifurcación del ciático mayor. Nace en el hueco poplíteo, y de allí se dirige hacia el compartimiento externo de la pierna. Aplicado al cuello del peroné, camina entre las inserciones superiores del peroneo lateral largo en un conducto musculofibroso, en el interior del cual se divide en sus ramas terminales.

\section{Nervio ciático mayor}

El plexo sacro suministra una única rama terminal, el nervio ciático mayor, destinado a los músculos posteriores del muslo y a la piel y músculos de pierna y pie. Discurre verticalmente a lo largo de la cara posterior del muslo hasta el rombo poplíteo. Al llegar a este punto se divide en dos ramas: poplíteo interno y poplíteo externo.

\section{Plexo lumbosacro}

Está formado por las ramas anteriores de los nervios lumbares y sacros. Las ramas lumbares primera a tercera forman el plexo lumbar; el plexo sacro está formado por la rama 
lumbar quinta y las sacras primera a cuarta. La cuarta rama anterior lumbar participa de ambos plexos.

\section{Nervio obturador}

Nace del plexo lumbar por tres raíces procedentes de los pares lumbares segundo, tercero y cuarto. Estas raíces convergen entre sí, forman el nervio, que cruza la articulación sacroilíaca y sigue por la cara interna de la pelvis hasta el agujero obturador, en el cual se introduce, dividiéndose entonces en sus ramas terminales, dentro del conducto y en su salida.

\section{Nervio femoral (crural)}

Es la mayor de las ramas del plexo lumbar. Inerva los músculos de la cara anterior del muslo y la piel de la cara anterointerna del miembro inferior.

Nace los pares lumbares segundo, tercero y cuarto por tres raíces, que convergen entre sí y se reúnen en el espesor del psoas. Ya como nervio femoral sale del psoas por su parte externa, recorre el canal entre psoas e ilíaco en toda su extensión hasta llegar al arco femoral, donde termina en cierto número de ramas. 
